Beyond Print:

Journeying Beyond the Page to Uncover the Social Influences on the Meaning of Pre-

Kindergarten Children's Writing

A Dissertation

Presented to

The Faculty of the Curry School of Education

University of Virginia

In Partial Fulfillment

of the Requirements for the Degree

Doctor of Philosophy

by

Brian T. Kissel, B.S., M.Ed., Ph.D.

May 2006 
(C) Copyright by

Brian T. Kissel

All Rights Reserved

May 2006 


\begin{abstract}
To understand pre-kindergarten children's writing, and the social conditions that influence its meaning, I conducted a qualitative study to address the following questions:

1. What are the settings in which social interactions occur in one prekindergarten classroom during writing instruction?

2. In what ways, if any, do these social interactions influence the children's writing processes?

3. In what ways, if any, are these social influences manifested in the written products of the pre-kindergarten children?
\end{abstract}

This study builds on research that addresses writing from a socio-cultural perspective, wherein writing is situated within a community of students.

To collect my data, I made 34 visits to one pre-kindergarten classroom over a four month period of time to observe the children before, during, and after the daily block of time during which they wrote. My intent was to understand the social interactions that influenced them as writers and that influenced their written products. I interviewed students on every observation day to ascertain the meanings of their writings. On three occasions, I formally interviewed the teacher. To answer the above questions, I analyzed the children's written documents, my field notes of my observations, and my interview transcripts.

According to my results, the settings in which social interactions occurred in the classroom were: The read-aloud experiences, the teacher's writing demonstrations, and the tables at which the children wrote. Social interactions in these three settings influenced the decisions the children made when writing. Through these social settings 
the children gleaned writing ideas, learned how to create specific symbols in writing, developed knowledge of letters and their corresponding sounds, and enhanced their notions of genre structure. 


\author{
APPROVALS \\ Elementary Education \\ Curriculum, Instruction, and Special Education \\ Curry School of Education \\ University of Virginia \\ Charlottesville, Virginia
}

APPROVAL OF THE DISSERTATION

This dissertation, "Beyond Print: Journeying Beyond the Page to Uncover the Social Influences on the Meaning of Pre-Kindergarten Children's Writing" has been approved by the Graduate Faculty of the Curry School of Education in partial fulfillment of the requirements for the degree of Doctor of Philosophy.
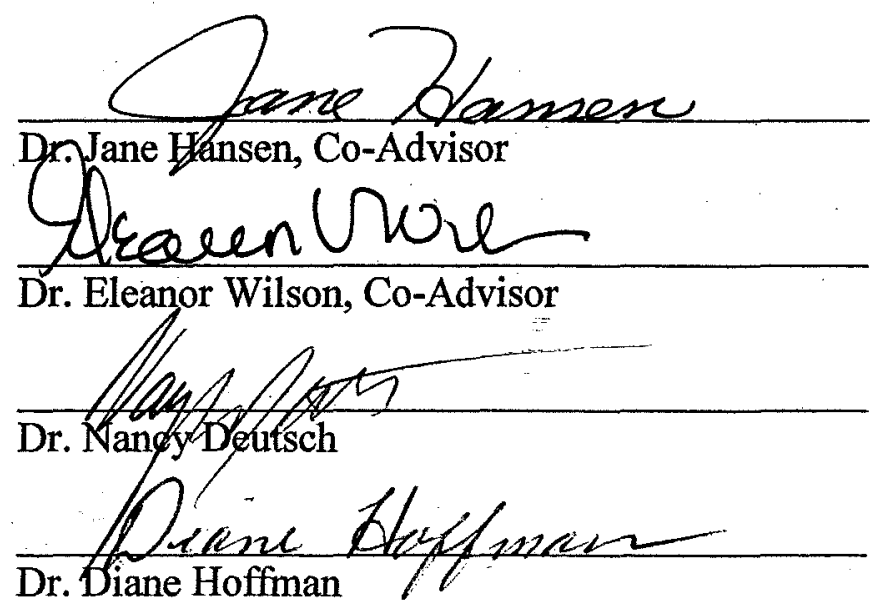

$$
\text { - 3/21/06 Date }
$$




\section{DEDICATION PAGE}

To my wife, Hattie. Beyond these pages, you provided us with the love and support to make this dissertation possible. Whenever I feel like I can't, you always remind me that I can. Thank you for your faith in me. For better or for worse, but never for granted. 


\section{ACKNOWLEDGEMENTS}

I would like to acknowledge and thank the members of my dissertation

committee. Dr. Diane Hoffman introduced me to the world of ethnography and showed me the importance of giving voice to cultures that are not often heard in research. You made it possible for me to bring the voices of a group of pre-kindergarten children to these pages. Dr. Nancy Deutsch taught me how to be a researcher. Your availability and willingness to talk about your life as a researcher and professor has made a profound impression on me. I am so grateful that our paths merged while I was at the University of Virginia. Dr. Ellie Wilson inspired me with her humor, enthusiasm, and sage advice. For many of us, you are the heart and soul of the Curry School. Thank you for your smile and caring interest in my life and work.

This dissertation would not be possible without Dr. Jane Hansen, my advisor, mentor, teacher, and friend. Through this doctoral process I learned from you the value of patience, perseverance, and ethics. I especially want to thank you for your tireless dedication to me as a student and your deep reservoir of knowledge about teaching and learning. I came to the University of Virginia to study under your tutelage in the hopes of learning more about reading and writing with young children. I leave UVA knowing much more than I ever imagined about teaching, learning, and life. 
Jody Kahn Lawrence, fellow doctoral student, officemate, and friend made this doctoral experience bearable. Thank you for making me laugh all those times I felt like crying. And thank you for being a great friend during this whole process.

I wish to thank my family. You allowed Hattie and me to leave Florida guilt-free and supported us along the way. Thank you for maintaining your residences in Florida so we could have sunny places to visit when we needed long breaks.

I wish to acknowledge Ronda who allowed me to be part of her classroom culture for two years. Each visit guaranteed a hearty laugh. I have told you before, but will say it again, those children are so lucky to have you as a teacher. Your love and kindness for those children are something they desperately need.

Finally, I wish to acknowledge the children in Ronda's class. Without their willingness to share the meanings of their writing with me, I would not know them as unique individuals. Thank you for helping me to understand that I had to go beyond your pages to truly know you. 


\section{TABLE OF CONTENTS}

$\begin{array}{ll}\text { ABSTRACT } & \text { ii }\end{array}$

APPROVALS iv

DEDICATION V v v v v

ACKNOWLEDGEMENTS vi

TABLE OF CONTENTS IX

LIST OF TABLES Xii

LIST OF FIGURES $\quad$ XV

CHAPTER ONE: Introduction to the Study $\quad 1$

The Need for this Study 5

Research Questions $\quad 9$

$\begin{array}{ll}\text { Potential Significance } & 11\end{array}$

Limitations $\quad 13$

$\begin{array}{ll}\text { CHAPTER TWO: Review of the Literature } & 15\end{array}$

Definition of Writing as it Pertains to Young Children 16

Written Products and Oral Language $\quad 18$

The Influence of Read-Aloud Experiences $\quad 25$

Research Concerning the Writing Processes of Young Children $\quad 28$

Research Concerning the Socio-Cultural Influences on the Written Products 33 and Writing Processes of Young Children

The Influence of the Home on Young Writers 38

The Influence of the Teacher on Young Writers 44

The Influence of Peers on Young Writers 48

The Need for Investigation $\quad 59$

$\begin{array}{ll}\text { CHAPTER THREE: Methodology } & 61\end{array}$

$\begin{array}{ll}\text { Overall Approach and Rationale } & 61\end{array}$

Site and Population Selection $\quad 64$

Definition of Terms $\quad 66$

$\begin{array}{ll}\text { Data Gathering Methods } & 67\end{array}$

Data Analysis $\quad 73$

Trustworthiness of Research Design $\quad 78$ 
Ethical Considerations

Personal Interest in Study $\quad 83$

CHAPTER FOUR: Results $\quad 86$

First Finding: The Read-Aloud Experience Influenced the Child Writers $\quad 87$

The Birth of Read-Alouds $\quad 91$

An Overview of the Read-Aloud Experience $\quad 94$

Frequency of Read-Aloud Experiences $\quad 95$

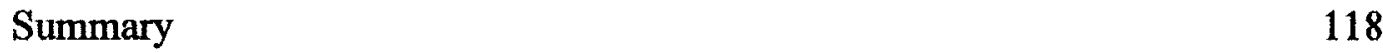

Second Finding: The Teacher's Writing Demonstrations Influenced the 120 Child Writers

Overview of the Teacher's Writing Demonstration 124

The Three Major Elements of the Writing Demonstrations 128

Children Use the Teacher's Writing Demonstration for Initial Ideas in their 143 Own Writing

The Teacher's Writing Demonstration Led Children to Explore Uses of Print 149

The Teacher's Writing Demonstration Encouraged Children to Explore $\quad 159$ Various Genres

Summary

173

Third Finding: Interactions among the Children as they Wrote Influenced them 176 as Writers

Three General Types of Interactions Influenced These Young Writers

Students' Interactions about Popular Culture Influenced their Writing 201

Student Interactions as Teacher/Researcher Influenced Their Writing 206

Students Help Their Peers with their Writing 210

Students' Non-Verbal Interactions Influenced their Writing 214

Student Talk Not Related to Written Products 216

Summary

CHAPTER FIVE: Discussion of Findings $\quad 222$

First Finding $\quad 225$

$\begin{array}{ll}\text { Second Finding } & 227\end{array}$

$\begin{array}{ll}\text { Third Finding } & 229\end{array}$ 
Implications for Practice and Policy 232

Suggestions for Future Study 236

Summary 237

$\begin{array}{lr}\text { AFTERWORD } & 239\end{array}$

REFERENCES 241

APPENDICES 252 


\section{LIST OF TABLES}

\section{TABLE}

2.1. Uninterrupted Writing and Drawing Samples (Terry, Age 3).

2.2 Terry's Process in Creating Writing and Drawing

3.1 Profile of the Children who Participated in the Study

3.2 Timeline of Study

3.3 Time Commitment of the Various Participants

3.4 Example of Part of a File of Data

3.5 Example of Analytic Memo

3.6 Example Data Sheet of Student Writing

3.7 Partial Example Data Sheet of Categories and Themes

$3.8 \quad$ Example of Reflective Journal Entry $\quad 80$

3.9 Example of One-Page Analytic Memo 82

$\begin{array}{lll}4.1 & \text { Findings from Data Analysis } & 87\end{array}$

4.2 The Gathering Experience within the Writer's Workshop 92

4.3 Routine of the Read-Aloud Experience 94

4.4 Frequency of Read-Aloud Texts during the Gathering Experience 95

4.5 Elements of the Read-Aloud Incorporated into Student's Writing 97

4.6 Illustrations from Read-Aloud Texts Included in Student's Writing 98

4.7 Student Writing that Reflected Symbols from the Read-Aloud Text 102

4.8 Spiders in the Children's Texts, Influenced by Read-Aloud 106

4.9 Students Incorporate Genres of the Read-Aloud into their Writing 118

4.10 The Teacher's Writing Demonstration within the Writer's Workshop 125 
4.11 Dissected Teacher Talk during the Writing Demonstration

4.12 The Three Main Components of the Teacher's Writing

Demonstration

4.13 The Teacher's Writing Demonstration and its Influence on Student

Products

4.14 Symbols of the Teacher's Writing Demonstration Incorporated by

Students in their Own Writing

4.15 Frequency of Students' Name Addition to Text

4.16 Talisha's Name Progression

4.17 Name Progression of Jibir, Lisa, and Cathie

4.18 Students Match Letters and Sounds in their Writing

4.19 The Genre Structures Used in the Teacher's Writing Demonstration

4.20 Students who Used Personal Recounts as a Genre Structure

4.21 Kallen's Stories

4.22 Students who Created Informational Texts as a Genre Structure in Their Writing

4.23 Talisha and Lisa as Researchers

4.24 Students who Used Research Writing as a Genre Structure

4.25 Students Confer while in the Process of Writing

4.26 Student Writing as a Result of their Table Conversation

4.27 Student Writing as a Result of their Conversations

4.28 Lisa's Writing Idea is Incorporated by Peers into their Own Writing

4.29 Frank's Writing Idea is Incorporated into the Writing of his Peers

4.30 Jibir's Writing Idea is Incorporated into the Writing of his Peers 
4.32 Talisha's Original Idea is Modified in the Writing of Ta-Loni and Pierson

4.33 Student Writing as a Result of No Interaction

4.34 The Influence of Popular Culture in the Writing of Cathie, Frank, and Roderick

4.35 Popular Culture and its Influence on the Writing of Pre-kindergarten Students as a Result of Student Interaction.

4.36 Talisha and Lisa Write Down the Responses of their Peers

4.37 Students Ask for Assistance in Symbol-Making

4.38 Students Ask for Assistance in Name Writing

4.39 Non-Verbal Interactions of Students and Incorporation of Symbols, Letters, and Names into the Writing 


\section{LIST OF FIGURES}

FIGURE

1.1 Jibir's writing, 9/12/05 2

$\begin{array}{lll}3.1 & \text { The classroom } & 64\end{array}$

$\begin{array}{llr}4.1 & \text { Pierson's writing, 10/07/05 } & 90\end{array}$

4.2 Malcolm's writing, 10/07/05 90

4.3 Jibir's writing, 10/07/05 91

4.4 Josephina's writing, 9/06/05 96

$\begin{array}{lll}\text { 4.5 Josephina's writing, 10/11/05 } & 107\end{array}$

$\begin{array}{lll}\text { 4.6 Lisa's writing, 10/31/05 } & 109\end{array}$

$\begin{array}{ll}4.7 & 109\end{array}$

$\begin{array}{lll}\text { 4.8 Malcolm's writing, 11/09/05 } & 109\end{array}$

$\begin{array}{lll}4.9 & \text { Chars's writing, 11/09/05 } & 109\end{array}$

4.10 Jibir's writing, 10/07/05 111

4.11 Josephine's writing, 10/11/05 111

4.12 Kallen's writing, 10/31/05 112

4.13 Lisa's writing, 11/16/05 113

$\begin{array}{lll}4.14 \text { Cathie's writing, 10/11/05 } & 114\end{array}$

$\begin{array}{ll}4.15 \text { Chars's writing, 11/09/05 } & 115\end{array}$

4.16 Ronda's writing demonstration, 9/30/05 122

4.1 Talisha's writing, 9/30/05 123

4.18 Josephina's writing, 9/30/05 123

4.19 Cathie's writing, 9/30/05 123 
4.20 Lisa's writing, 9/30/05

4.21 Ronda's writing demonstration, 9/06/05

4.22 Talisha's writing, 9/06/05

4.23 Pierson's writing, 9/06/05

4.24 Kallen's writing, 9/06/05

4.25 Ronda's writing demonstration, 9/16/05

4.26 Kallen's writing, 9/16/05

4.27 Ronda's writing demonstration, 10/10/05

4.28 Pierson's writing, 10/10/05

4.29 Ronda's writing demonstration, 11/02/05

4.30 Talisha's writing, 11/02/05

4.31 Ronda's writing demonstration, 11/22/05

4.32 Roderick's writing, 11/22/05

4.33 Ronda's letter to Lisa, 10/11/05

4.34 Talisha's birthday card to her mom, 9/23/05

4.35 Talisha's letter, 10/11/05

4.36 Chars's writing, 9/23/05

4.37 Travion's writing, 9/23/05

4.38 Malcolm's writing, 9/23/05

4.39 Jibir's writing, 9/12/05

4.40 Lisa's writing, 11/21/05 
One written word is worth a thousand pieces of gold

(Ancient Chinese Proverb) 


\section{CHAPTER ONE \\ INTRODUCTION TO THE STUDY}

I begin this dissertation with a piece of writing by Jibir (Figure 1.1). At initial glance, his writing is unconventional-a collection of lines, circular forms, and letters. Jibir had meaningful intent when he created this piece of writing. As the reader, the meaning was uncovered to me when I witnessed the social interactions that occurred as Jibir composed among peers and verbally explained the meaning of his writing during a subsequent interview. Suddenly, the lines, forms, and letters made sense. I began to understand that the form in the middle of the page was a horse. The circular line around the middle form was a confining line to keep the horse onto the page- - a purposeful inclusion to reassure his friend Frank, an audience member who was scared of his writing. The line at the top of his page was water. This was an element he added so dolphins, sharks, and whales could be included in his writing. Jibir wrote a J and I on the top of the page. These are the first two letters of his name. Similar to the writing demonstrations of his teacher, who always wrote her name on the her writing, Jibir wanted to show ownership of his work. 


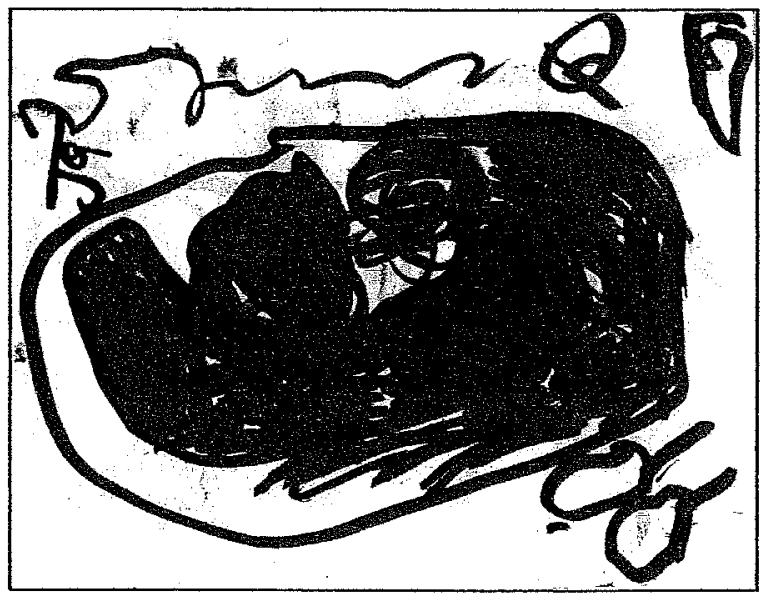

Figure 1.1. Jibir's writing. 9/12/05

Before the children began to write, Jibir explained to the teacher and his peers that he wanted to write about horses. Frank, Jibir's friend, thought his idea was interesting, and walked over to Jibir, who was sitting on the carpet. They engaged in a conversation about horses, and then walked over to a table to begin writing. As the boys wrote, they talked to one another.

Jibir: [writing] This is a big, big, big horse.

Frank: [stops writing] You make a horse. I'm scared of the horse.

Jibir: He's not mad at you. 'Cause he a good boy. See, he won't get you. He can't get out. [Jibir draws a circle around his horse.] See. He can't get out.

Frank: What?

Jibir: My big horse. He can't get out. I'm making a big circle so he can't get out. [The conversation ends and Jibir continues writing without talking.]

[Transcript 9/12/05]

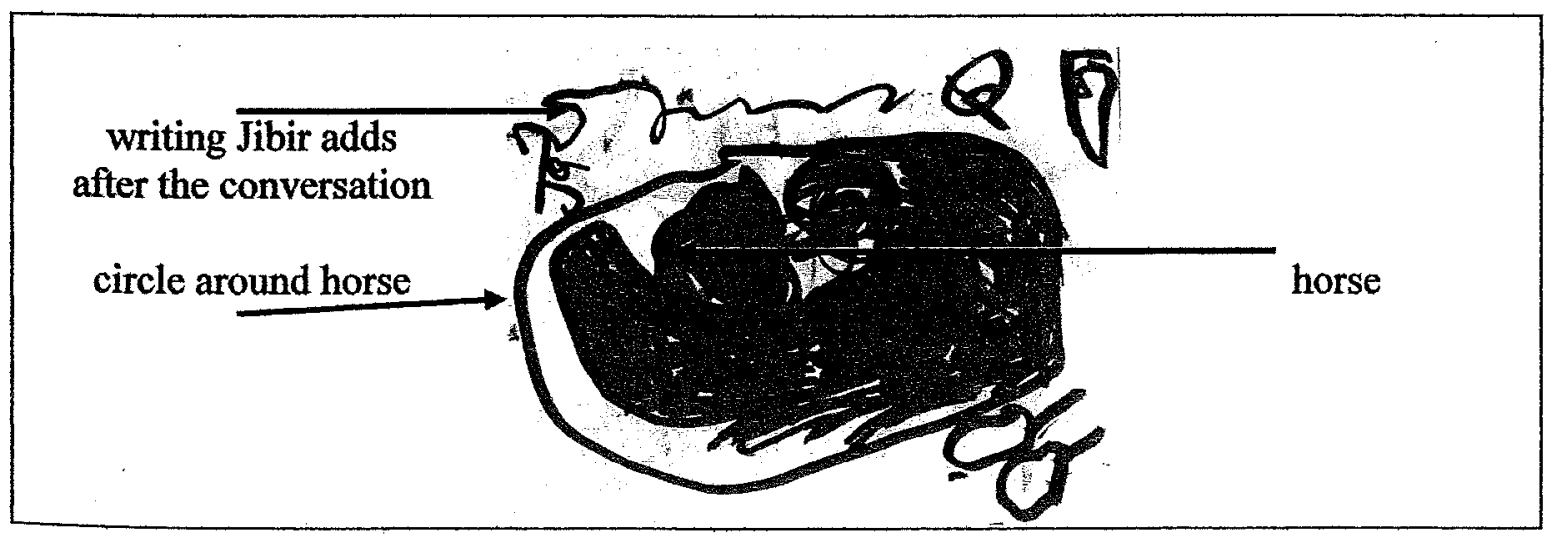


The lines Jibir included made sense when I heard the conversation he had with Frank.

When he finished writing, I asked him if he would tell me about his writing. He proudly sat down next to me and we began.

Brian: Jibir, tell me about your writing today.

Jibir: This is a big horse. And the pig is not in there [not in the circle]. I made a letter here. It's down. And this way and that way. [Jibir does not know the name of the letter so he just explains to me how he made it.]

Talisha: [interrupting] It's a T. [She was incorrect. It was a J for Jabir.]

Jibir: This is water. So dolphins. So people can get on the dolphins. There's a bad shark on there following a whale. He's playing with his brother but he does not have big teeth. [Pointing to the $J$ and I] This is my name.

[Transcript 9/12/05]

The conversation that occurred between Jibir and Frank and the explanation he gave me in his description share commonalities and differences. In conversation with Frank, he wrote about a horse. He confined the horse with a barricade as a response to Frank's reaction to his writing. Later, when I asked him about his writing, this portion of his writing remained consistent. He continued his explanation by commenting about the elements of the text that he did not describe when he conferred with Frank. These comments to me uncovered the meaning of what he wrote when he fell silent. He described the pig that was not in the circle, the letters that formed his name, and the water he wrote for the dolphin and shark. The inclusion of these elements made better sense when I remembered that Jibir continuously read books about ocean life during independent times. He also watched carefully as the teacher wrote her name on her own writing to show ownership. 


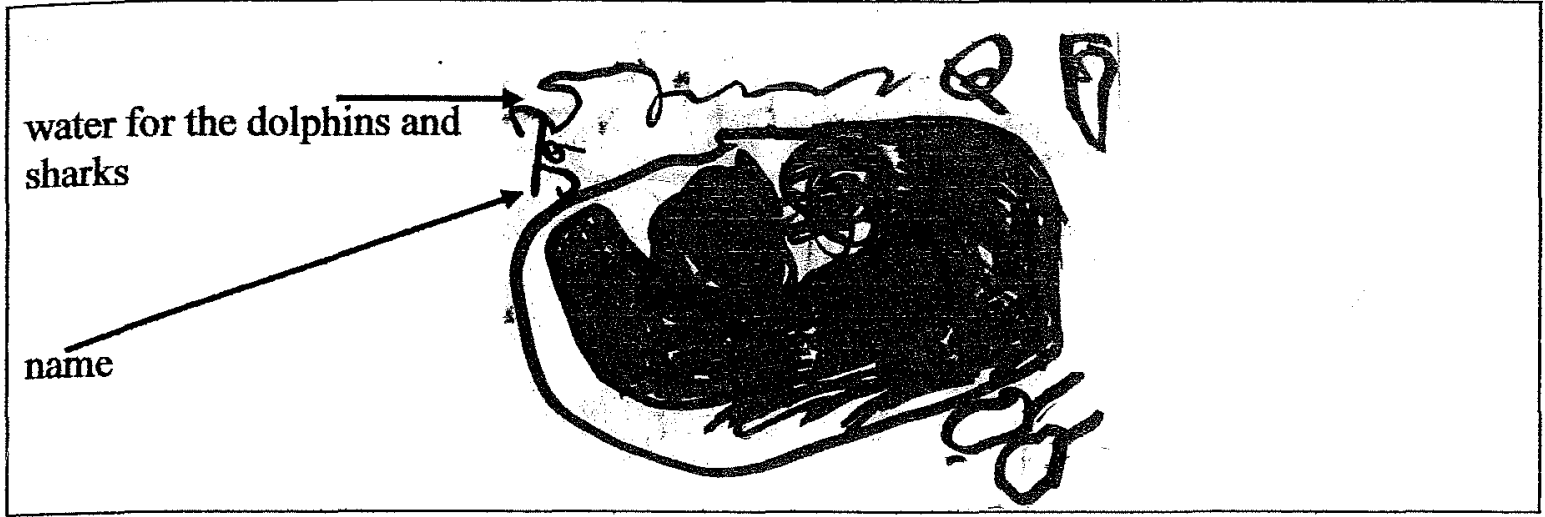

When I look back on Jibir's writing, I see that the lines and forms are not random. They have purposes and meaning. These meanings became clear when I witnessed his writing in action, listened to his conversations with Frank, asked about the meaning of his writing, considered his interests when he chose independent reading material, and understood how the teacher's writing demonstrations may have influenced Jibir's inclusion of his name. Without knowing the classroom events that occurred before and during Jibir's writing, the meaning of his text is difficult to ascertain. In this way, the social context in which writing occurs must be a consideration when deciphering the meaning of young children's writing.

In this study, I observed children as they engaged in daily writing. The teacher respected the unconventional lines, forms, and letters they created on the page. She talked to children daily about their writing and its meaning, and conducted classroom experiences that provided them with ideas for meaningful writing. Ronda (the teacher) carefully scaffolded instruction so the children witnessed the process involved in crafting detailed pictures, with some print, using specific genre structures. She encouraged the children to freely talk to peers as they constructed their writing, which allowed a plethora of ideas to influence their writing. She knew that writing instruction for pre-kindergarten 
children went far beyond handwriting instruction and letter formation.

Pre-kindergarten children are often seen as scribblers, rather than writers (Harste, Woodward, \& Burke, 1984). Their writing is assessed based on the final written products without a consideration for the process that was used to create them. When child writing is assessed based solely on the orthographic qualities of their final products, the meaning embedded within their printed pictures is unrealized (Newkirk, 1989). Additionally, the social situations and interactions that occurred before and during writing are often not considered when the meaning of children's texts is studied (Dyson, 1993). The absence of this awareness may lead to non-interpretations or misinterpretations of their meanings.

\section{The Need for this Study}

The emergence of pre-kindergarten education throughout the country has initiated new interest in the literacy development of four-year children. Small children, with writing instruments in hand, have announced themselves through their written productions, but their efforts have been largely ignored. Teachers who choose to listen carefully to the messages children attach to their writing can learn an immense amount of information about the students they teach. At the same time, when children are given the opportunity to explain what they have written, their explanations can provide a lens into the multiple worlds that influence their written efforts (Dyson, 1989, 1993).

For many years, the written products of pre-kindergarten children have been chiefly disregarded as "scribbles" or "drawings" (Harste, Woodward, \& Burke, 1984). Unfortunately, such descriptions of young children's writing suggest that their constructions of text are meaningless. Where these perceptions prevail, educators believe 
that when young children write, they do not assign a message to their creations.

Supposedly, according to that belief system, children simply explore the page by making playful marks divorced of meaning.

Whereas this can be true of very young children when they initially explore markers, my purpose in this dissertation is to show that four-year-old children, in a prekindergarten class, do write with meaningful intention. They have something to say. This research will show the various social influences (the multiple worlds) that affect children when they are in the process of writing, and how these influences are manifested in their final written products. The written product and the processes children use when creating them will be shown within the context of the children's social settings in their classroom. Studying children's writing from a socio-cultural perspective (Vygotsky, 1978) yields insights regarding the sources and purposes of their writing choices, the routes of their writing processes, and the meanings of their final products. Policy makers, researchers, and classroom teachers will benefit from this knowledge because they will be more aware of what pre-kindergarten children do as they write.

Research on the teaching of writing to young children is a relatively new endeavor in educational research. For well over one hundred years, research explorations in early literacy focused on reading, and writing was overlooked. It has only been in the last thirty years that writing has received increased research attention.

In the few initial studies involving early writing development and pre-kindergarten children, a focus on the written products dominated the research agenda and led to increased attention to children's orthographic and spelling development. Clay (1975), Gentry (1982), Henderson and Beers (1980), Read (1971), Richgels (2002), and 
Schickedanz (1990) have reported important insights regarding the orthographic and spelling development of young learners. Their findings regarding the written products of young children have led to a wealth of knowledge regarding how children develop their understandings of letter formations and spelling development.

Some researchers (Gentry, 1982; Schickedanz, 1999) have formulated continua to explain that written language develops through various developmental stages (drawing, scribbling, letter-like forms, random letters, letter strings, conventional writing). These continua highlight how many children develop orthographic knowledge, but do not address the meanings young children assign to their written work.

Others (Graves, 1982; Newkirk, 1989) have looked beyond the orthographic forms young children print on a page to determine the meanings children assign to their written products. These researchers determined that children may share similar orthographic characteristics as they grow in awareness of written language, but children approach writing in ways that cannot be easily captured in developmental continua. When young writers focus on developing meaning within their written products, their writing does not necessarily develop in a specific orthographic order.

Early statements about literacy by the National Association for the Education of Young Children (NAEYC) fought against the traditional scope and sequence approach to curriculum that placed an emphasis on teaching letters and sounds in a particular order via isolated drill and practice (Bredekamp, 1987). They underscored the importance of a focus on the meaning the child was trying to convey.

To bring complexity into the picture, another strain of research noted that a prereader's letter knowledge is one of the best predictors of first-year reading success 
(Adams, 2001; Bond \& Dykstra, 1967; Chall, 1967; Ehri \& Sweet, 1991). Using this research as support, many early childhood educators returned to a focus on the orthographic features young children use when writing. They conduct instruction that focuses on isolated skills to learn letter names, sounds, and formations. The National Reading Panel report (2000) recommended that instructional programs focusing on these tasks should be used as the way to introduce children to reading. What the children did with these skills as writers fell by the wayside.

An updated statement by the National Association for the Education of Young Children (Bredekamp \& Copple, 1997) reveals a change in their position. They now advocate an emphasis on phonics-based instruction. A position statement by the International Reading Association (1998) also emphasized phonics instruction. Together, these statements influence current early childhood settings. Based on the studies revealing the importance of phonological awareness and letter knowledge in predicting future reading success (Adams, 2001; Wagner \& Torgesen, 1987; Whitehurst \& Lonigan, 1998), these statements are powerful declarations that are often heeded by influential decision makers in the field of early childhood education.

An instructional focus on letter formations in reading instruction poses a significant problem, however, for young child writers and their pre-kindergarten teachers. If early educators base their instructional emphasis on letter formations during writing instruction, then the children's desire to assign meaning to their products loses importance. Additionally, if letter formulation becomes the only skill that is evaluated, then teachers may miss the important processes and social interactions that occur in the classroom as children write messages influenced by their relationships with their peers. 
When children make meaning of their texts through various modalities (speaking, listening, and writing) and practitioners assess a child's meaning based exclusively on the surface features of the final, written product, then critical information about the child as a writer is lost. Most alarming, if the teacher does not view his/her students' written compositions as messages containing meaning, then how can pre-kindergarten children possibly see the worth, value, and purpose of creating a written text? Plus, how will children come to believe that any text-including those they are learning to read-carry meaning?

While learning letters and their subsequent sounds are essential components of literacy success, this trend fails to acknowledge a child's desire and ability to create meaning within a text before they have the ability to create conventional letters on the page.

\section{Research Questions}

The overall questions that guided the research inquiry were:

1. What are the settings in which social interactions occur in one prekindergarten classroom during writing instruction?

2. In what ways, if any, do these social interactions influence the children's writing processes?

3. In what ways, if any, are these social influences manifested in the written products of the pre-kindergarten children?

The general approach to this research study was to use a naturalistic, qualitative approach of inquiry to answer these questions. Through an interpretive, ethnographic paradigm, I studied one pre-kindergarten classroom of writers as they engaged in writing. 
The research design consisted of four months of data collection during which I observed the children on 34 occasions. During each observation, I asked the children about the meanings of their texts, and collected their texts.

There were three purposes for the proposed study:

1.) To describe the social settings in which social interactions occur in one prekindergarten classroom during writing instruction,

2.) To describe how these social interactions influence the children's writing processes, and

3.) To examine how these influences are manifested in the meaning the children attach to their written products.

In pursing the above questions, I studied the children as they wrote and the meaning they assigned to their writing. I collected this data within the complex social environment of the pre-kindergarten classroom, and analyzed the social acts that influenced the children and their writing. The students engaged frequently with their teacher and peers, and these social encounters influenced the decisions the young children made when assigning meaning to their writing. To capture these interactions, I recorded detailed renderings of the teacher-led read-aloud sessions, the writing demonstrations of the teacher, and interactions among students as they composed.

To determine how the three main social interactions mentioned above influenced the children as they wrote, I created a detailed system of coding. My findings show: 1) the read-aloud experiences influenced the children's topic choice; 2) the teacher's writing demonstrations influeced the children's topic choices, orthographic notions of print, and 
genre selections; and 3) the student-to-student interactions during writing influenced the children's topic choices and symbol and print production.

The meanings the children assigned to their written texts were often the result of the various social interactions described above. At other times, however, the meaning was a product of factors that occurred outside my understandings. Regardless, I analyzed the meanings of the final texts beyond the various features the children included on their papers. The social acts that occurred in the classroom and the interviews I conducted with the individual children enabled me to gain the most complete meaning possible for the final texts of the students.

\section{Potential Significance}

Currently, a gap exists in the research on pre-kindergarten children as writers. Because little is known about their composing acts within the classroom context, this study provides additional information for the growing field of writing research in early childhood education. Policy makers, researchers, pre-kindergarten teachers, and prekindergarten students all have the potential to benefit from this study.

For policy makers, this study illustrates that the writing products of children represent more than their knowledge of orthographic ability. A repertoire of social interactions occurs while children write and influences writing decisions in ways that are not fully realized. When producing policy regarding writing instruction in early childhood classrooms, decisions may be considered that will honor social interactions such as speaking, listening, gesturing, and play in the early learning curriculum.

For researchers, this study provides an alternative view of early writing research. Rather than focusing on the orthographic development of students' writing, this study 
investigates the importance of the messages the children are creating. Additionally, this research describes the social acts that occurred during the composing time of prekindergarten writers. Currently, there are a few studies that have focused on the sociocultural aspect of young children's writing (Dyson, 1993; Kantor, Miller, \& Fernie, 1992; Matthews \& Kesner, 2003). These studies have been influential contributors to the research base but they do not specifically address pre-kindergarten learners. This dissertation study specifically addresses pre-kindergarten learners through a comprehensive, naturalistic investigation of their learning environment. Results of the study contribute to the research base concerning theory, knowledge, and practice.

For pre-kindergarten teachers, this study illustrates the instructional strategies of one pre-kindergarten teacher as she teaches writing. By reading about the lessons she conducts and the subsequent conversations of children as they compose, educators will notice that children make explicit decisions when they are given choice during writing, and that classroom social factors often contribute to the decisions they make. Teachers will also benefit from seeing the written products of a group of pre-kindergarten children. While the study will not be generalizable to the entire population of pre-kindergarten learners, educators will have some basis to transfer this knowledge and use it to compare the social acts that occur in the study site with the social acts of their own classrooms.

Pre-kindergarten students have been marginalized in past research studies concerning writing acquisition. Due to their developing ability to explain their written work, it is difficult for four-year-old children to fully express the meaning of their writing. As a result, the meanings children assign to their written work have been relatively ignored in previous research studies. Their voices have been silenced in 
intense investigations of their final products where researchers infer the meanings of the children's pieces of writing without asking children to explain the true intentions of their text.

In this study, child voices are acknowledged by highlighting classroom conversations and analyses that consider the meanings children ascribe to their writing. In this study, children explain the meaning of their writing. Then, their explanations are compared to what I witnessed in the interactions that occurred before and during the act of writing. Through this comparison, I uncovered that the explanations children use to describe their writing are insufficient. In other words, I saw almost nothing when I solely studied their final products. I realized more when they explained their writing to me, but I learned a lot when I listened to them talk and considered the social interactions that occurred before and during their acts of writing.

\section{Limitations}

There are limitations to studying the writing of one classroom of pre-kindergarten writers. Access to participants, the inability to capture every social occurrence, the difficulty of identifying all the social dynamics of the classroom, and the bias of investigating only one pre-kindergarten site are all contributing limitations to the proposed study.

Another limitation was my status as a Caucasian, upper-middle class, postgraduate man which was in obvious contrast to those I studied who were mostly AfricanAmerican, poor, 4-year old children. Our worlds collided when I spent 3-4 hours, three times a week in their classroom. Then we shifted back to our respective environments. 
When attempting to understand the meaning of the writing created by these 4-year old children, I was restricted by the descriptions they provided me during interviews and my interpretations of the social influences that occurred in the classroom during the times in which I observed. Their meanings were restricted by what they were willing to share with me and their limited ability to vocalize the total intentions of their writing.

Finally, I was limited in my ability to observe every social event that occurred in the classroom. I couldn't engage in all of their conversations, nor listen to all of their ever-occurring talk. Limited access to their background experiences, inner-thoughts, and implicit feelings complicated my ability to fully understand every symbol placed on the page.

Despite these limitations, I attempt to display full descriptions of the three major settings of the social interactions that occurred in the classroom, many written products of the children, and transcripts of the meanings they attribute to them. In this way, readers can draw their own conclusions about the significance of these interactions to the writing of the children presented within these pages. 


\section{CHAPTER TWO}

\section{REVIEW OF THE LITERATURE}

This literature review will examine the research that has been conducted concerning young children's written products, their writing processes, and the social interactions that influence them and their work. Almost all of the studies in the review focus on young children from ages two through grade three. Particular attention was given to studies that were conducted with children ages four and five and who were involved in formalized school settings such as preschool or pre-kindergarten classrooms.

This review begins with definitions of writing. Various researchers define writing as it pertains to young children who do not yet write conventionally. In the next section I present what researchers found when they focused on the written products of children. Connections between oral and spoken language will be provided to show how children initially use their knowledge of spoken language to assist them in their understanding of written language. The following section will focus on research that describes the writing processes of young children as they compose. The findings show what young children do to create their final products. Then, a rationale is presented to argue for the need to study children's writing acquisition using a socio-cultural perspective. Several key theorists and their views will provide a theoretical perspective that shows social influences. Within this context, I explore how children are influenced by their teachers, peers, and families as they acquire written language. Finally, I review the research on the influences 
of read-alouds on young children as writers. The prose of professional children's literature can impact the decisions of pre-kindergarten writers.

\section{Definitions of Writing as they Pertain to Young Children}

Early childhood research offers many alternative terms to describe the written productions of young learners. Because young children create written forms that do not follow conventional orthography, or use no orthographic features at all, there is much debate regarding a definition of writing that fits their work.

Conventional definition of writing. Some believe that print must be conventional in order for a product to be considered actual writing (Bissex, 1980; Read, 1971). That is, the writing must contain words that a reader can understand without the presence of the writer to explain it.

Writing expands beyond conventional forms to include communicative marks.

Others expand beyond the conventional notion of print to describe writing as letters and letter-like forms (Temple, Nathan, Temple, \& Burris, 1993). In this way, writing is a way of making marks that call to mind the ideas children have when they write.

Writing is a composing process. Writing, by others, is considered to be a composing process in which the writer expresses ideas through letters, words, or drawings (Dahl \& Farnan, 1998a). This definition is expansive enough to consider the drawings created by young children as written products (Dyson, 1986, Graves, 2003; Kendrick \& McKay, 2004; Kress, 1997). Because drawings often contain the meaning and message of a child's text, they are considered a legitimate forum for expressing thought. 
Newkirk (1989), however, fears that this latter definition does not receive enough consideration. He describes the prevailing school culture as being "word centered." That is, educators are often only willing to accept conventional forms of writing rather than acknowledge the value of drawing. Since young learners primarily attend to the pictures when reading a text, they often assume that the message is carried through the illustrations. Also, they know how to draw before they know letters and sounds. Consequently, when children compose their own meaning-filled texts, much effort will be focused on the drawing aspects of writing. The meaning of the text is also influenced by forces beyond the paper. The integration of talking, drawing, and producing print have been described as "symbol weaving" since children are constantly shifting among these processes when creating text (Dyson, 1986).

Writing includes a consideration for the audience. An additional component to consider is the role an audience plays. When a child has composed a text that can be read or understood by others, regardless of the presence of print, it is assumed to be a written product. Talk and discussion while in the process of composing leads to important understandings of a text's meaning. Discussion of the written product adds additional dimensions as a child shares it with others (Donald Graves \& Hansen, 1983; Nystrand, 1989; Sperling, 1996). Thus, these researchers suggest that writing must be defined beyond the forms that are created on the page.

Writing is a communicative act. Most researchers would agree that writing should be defined as a form of communication. Whether it is between the individual writer and readers or between the writer and him/herself, it is a communicative act. Perhaps most encompassing is Goodman's (Goodman, 1986) definition of writing as 
being a human interaction in which the reader and writer make sense of language. It is this definition that I will incorporate when talking about writing throughout this review of literature.

\section{Written Products and Oral Language}

A child's ability to make distinctions between oral language and written language is important for early reading and writing experiences (Gunn, Simmons, \& Kameenui, 1998). Young children in the midst of figuring out how to create meaning with marks on paper, often rely on their oral spoken language to bridge the gap between the two processes (Egan, 1987).

Just as speech acts require humans to collaboratively interact with others through socially mediated conversations, writing acts require a similar process of co-constructed meaning between the reader and the writer. Rosenblatt's (1978) transactional theory attests to this similarity. She noted that when people engage in conversations with others, they receive verbal and physical cues from the listener. These cues influence the content of the conversation, thus shaping the meaning that becomes co-constructed between the speaker and the listener. Likewise, as writers compose text, they typically do so with an audience in mind (Flower \& Hayes, 1984). In this sense, writers anticipate the reactions of the readers and consider the personal, social, and cultural environment in which the product will be read. In these general ways, oral language and written language share commonalities. More specifically, young children use their knowledge of oral language when they attempt to inventively create written products.

Young children's inventive spellings reflect oral language. Spoken and written language are closely linked when children attend to speech sounds to inventively spell 
words (Bissex, 1980; Read, 1971, 1975; Schickedanz, 1990). Attention to sound patterns when writing allows children to make important connections between the phonemes used in spoken words and graphemes used in written language (Henderson, 1981).

Charles Read (1971) was the first to reveal how children use their knowledge of phonemes when spelling words. He examined the writing of thirty children between the ages of four and eight who were able to identify the letters of the alphabet and relate the letter names to the sounds of the letters in words. Through his investigation of how children formulate words, he determined that their writing attempts were neither random nor confused attempts at spelling words. Rather, he found that children were able to attend to the phonemes when creating words and their early spellings were both systematic and rule-governed. This extremely important discovery legitimized the early spelling efforts of preschool children.

Inventive spelling development with an increased focus on meaning was studied in research conducted by Glenda Bissex (1980). Bissex learned that the written products employed by her son Paul included both drawings and scribbles and represented phonetic and nonphonetic word forms. In her longitudinal case study that explored Paul's writing acquisition from age two through early elementary school, Bissex noted Paul's various spelling choices in his written products. At home, Paul wrote with abandon using his own understandings of written language in order to convey his message. When he was faced with assignments in school a year later, his inventive spellings were not understood, so Paul's written products became less sophisticated. He could only use words he knew how to spell. Bissex's study was an important contribution to research in child writing because it mapped the spelling development of one child and highlighted 
his various purposes for writing, from creating signs to writing stories. It showed the acivanced concepts of young children's written products represent when their inventive spellings are encouraged.

Schickedanz (1990) conducted a similar study of writing development with a case study of her son Adam as his writing progressed from age two through elementary school. Using Adam's written products, Schickedanz noted the various forms and functions Adam used when constructing text. Initially, Adam's writing demonstrated awareness that words and pictures are different. Beginning towards the end of his second year of life, Adam drew a picture of himself and wrote three vertical lines underneath the drawing to represent his age. One month later, when he created a similar pictorial image of himself, he printed the letters $\mathrm{A}$ and $\mathrm{O}$ to represent his age; he had learned that those forms were in the print that often appears under pictures. This was the first time he represented himself with letters and began his entrance into orthographic understanding. By age three, Adam began to think about how words sounded by attending to the phonemes in them. Schickedanz termed this period of his writing life as, "his honeymoon with writing, the time when he thought it was easy" (p. 31).

For Adam, problems emerged when he discovered that not all words were written as they were sounded. When he made the discovery that there was a difference between spoken phonemes and written graphemes, he became distressed and writing became a dreaded activity. His desire for every single word to be correct became an impediment to his writing fluency. He felt betrayed by the writing system.

Similar to Bissex's study, Schickedanz's study is limited because of her position as the child's mother and an expert in early childhood education. These factors may have 
influenced their sons' early writing discoveries. Despite the limitations, their findings are important because they show how children's initial considerations of spoken language aid their entry into written language. As children are continuously exposed to print in home and classroom settings, however, they eventually recognize that there are differences between oral and written language.

Efforts to show patterns of growth in children's written products. The changes in children's written products as they rely less on oral language have been represented as a continuum of development (Ferreiro \& Teberosky, 1983), a progression of steps (Sulzby, 1985), a set of principles (Clay, 1975), and as developmental stages (Gentry, 1982).

Using the research collected by Bissex (1980), Gentry (1982) created developmental stages based on Paul's written products. He assigned categories to describe the various features of Paul's writing and created labels for the written marks Paul created on the page. His stages included the precommunicative stage, the semiphonetic stage, the phonetic stage, the transitional stage, and the correct stage. As Paul acquired more knowledge about how print is formed, letter-like forms, random letters, and letter strings ultimately became part of his understanding of print. Gentry found that Paul eventually developed enough competence that his writing evolved into a conventional form easily understandable by all readers and writers. In his stages, Gentry does not focus on the meanings in the young children's products. He only considers the match between the phonemes and letters. In other words, he chose to critically analyze one aspect of Paul's development as a writer, and from this first analysis of this type, we learn a great deal about children's development of written language. In Gentry's study, 
written products are viewed as a valuable component of understanding children as developing writers.

In her research on young writers, Sulzby (1985) conducted a two-year longitudinal study of five- and six-year-old kindergarten children. Her work, using nine children as case studies, has become a classic in the field of emergent literacy. She observed students within their natural classroom environment and used prompts to encourage the children to write. Sulzby collected their writing samples and organized them from least to most sophisticated using a continuum of development. She found six broad steps and used them to describe the writing of young children. She asserted that children first enter writing via drawing. Eventually, the drawings evolve into scribbles that differentiate drawing and print. Through immersion in written language, scribbles turn into letter-like forms. Next, letters that are well-learned by the student (typically letters from their own names) become recurring letter strings. This leads children to write via invented spellings. As children inventively spell, they create their own spellings of words. Eventually, over time, the child learns how to spell conventionally and their writing begins to mirror those of adult writers. Given Sulzby's focus on the children's written products, without conferring with the children as they wrote or asking them to interpret their work, we do not know about the meaning they ascribed to their drawings and scribbles. Her work, however, acknowledged and welcomed the drawings and scribbles of young children as legitimate forms of expressing communicative thought.

Marie Clay (1975), another early icon in the study of young children's literacy, did not map a specific continuum of development in her observations of young writers. 
Rather, Clay found that children used various techniques when writing as they tried to understand the idiosyncrasies of written language. By collecting several writing samples and examining their forms, Clay noted several characteristics of writing created by young children. In her analysis she created these principles: the recurring principle, the directional principle, the generating principle, the inventory principle, the contrastive principle, and the abbreviation principle. Rather than describe her findings in stages or steps, Clay notes that these principles may occur simultaneously as children attempt to understand the written language. In brief, she found that children repeat forms, learn to write from left to right, burst forth with large amounts of texts, create lists, compare and contrast letter forms, and abbreviate word forms. Importantly, they do not do these things in a specific order. Clay studied each product for what it showed of a child's knowledge, as different from where it fit into a developmental continuum.

Other researchers, in addition to Clay, have negated the belief that young writers develop in specific stages (Graves, 2003; Newkirk, 1989). Graves conducted a two-year longitudinal study of writers in first through fourth grade. The original design of the study attempted to capture a sequential set of stages that children progress through when writing. Using observations and case study methodology, his findings reflected some of the same principles that were noted in the studies by Clay and Bissex. Graves concluded that children pave their own paths towards writing acquisition as their individual differences dominated the research data. That is, while some qualities of writing development are exhibited in most children (such as from scribbles to letter forms to letters), there is not a particular sequence that all children proceed through when developing their knowledge of written language. 
Newkirk (1989) made a similar assertion in his studies of kindergarten writers. Using observations of students as they composed and analyzed the writing samples they produced, Newkirk confirmed that the drawings created by young children are much more sophisticated than originally perceived. More specifically, he identified, within the realm of drawing, the various ways children show action, such as with midaction pictures (drawings that suggest ongoing action), postaction pictures (representing the conclusion of a story), and multiple frames (action that is shown in more than one picture). Newkirk did not find specific stages in the written representations of the kindergarten children. Rather, they used drawings in their own ways to create the meaning of their compositions.

In summary, whereas all children somehow move from drawings to the use of letters in order to create meaning, their development as writers appears to be nonlinear. At some stage in their life, however, all children reach a critical point: they develop a concept of word (Morris, 1980). When students learn the strategies to hear the beginning and ending sounds of words and can represent them in print, with spaces to designate the next word, they have crossed the cognitive bridge between oral and written language (Henderson, 1990). Oral language has no spaces between words. Further, as children become aware of spelling patterns and meanings that are not represented by spoken phonemes, the differences between oral and written language becomes especially important to them (Henderson \& Templeton, 1986).

Written products differ from oral language. While oral language and written language share common traits, writing and speech actually differ greatly (Adams, 2001; Chafe \& Tannen, 1987; Horowitz \& Samuels, 1987; Sperling, 1995). Almost all humans are 
innately equipped to engage in speech acts to communicate (Chomsky, 1986). Because of this biological disposition, humans who are immersed in talking societies often acquire speech without much explicit instruction. On the other hand, writing (like reading) is not naturally acquired and requires explicit instruction. Gee (2002) provides the following explanation to highlight this point:

While core grammar is acquired with biological help, no form of literacy is. Oral language has been around long enough in human history to be 'wired' into our genes. But literacy has not been around long enough to be so wired (it is at best 10,000 years old). Thus, however forms of literacy are acquired, this process must, in some important respects, be different from how the core grammar of a language is acquired (p. 32).

The prevailing myth that writing is simply "speech written down" negates the complexity of written language and its syntactic uniqueness when compared to oral language acts (Sperling, 1995). There are distinct differences in the language one uses to speak versus the language used to compose written texts (Danielewicz \& Chafe, 1985).

\section{The Influence of Read-Aloud Experiences on Young Writers}

Research suggests that young children have a developing awareness of print and they have the ability to differentiate between the language used in read-aloud texts and oral language (Ferreiro \& Teberosky, 1982; Sulzby, 1985). Sulzby (1985) conducted a study of the emergent reading of three- to six-year-old children as they "read" storybooks aloud. Using books that had been repeatedly read to them throughout the year, the children were asked to produce their own renderings of the text as they pretended to reread the stories aloud. Sulzby found that the speech children used during reading sounded like written language rather than oral discourse. Sulzby's study was limited, 
however, in two ways. First, the task involved students using the language of narrative text to differentiate between spoken and written language. Sulzby did not consider what would happen to their language if the children read from expository texts. Also, the children had multiple exposures to the language of the book through previous readings. As a result, the children may have simply memorized key lines of the story. This memorized recall may have skewed the results so that it appeared that children consciously used storybook language, when in actuality, they simply reproduced familiar lines from the story.

In an effort to overcome this limitation, Vicki Purcell-Gates (1988) randomly selected kindergarten children to participate in two different language tasks. In one task, the researcher asked children to orally tell a story about a birthday party that happened in the child's life. The task was designed so that children would produce the natural linguistic registers they used during speech. The other task required children to "read" a story using an unknown wordless storybook. Children were asked to use what they knew about story language to make their speech sound like written discourse, rather than conversational speech. In the first task, the researcher's goal was to elicit oral narratives in an attempt to understand the style of speech used by the student to tell a story. In the second task, the researcher's goal was to elicit a written narrative to determine how it differs from the spoken story.

Purcell-Gates (1988) found that children did differentiate between oral and written language. Students used different linguistic registers when they orally told a story than when they orally "read" a story aloud. This ability to distinctly use varied forms of speech showed that children employ different vocabulary and syntax depending on the 
language act they are asked to perform. This study did overcome the limitations of Sulzby's study; Purcell-Gates did not use a book the children had previously heard. The study is limited, however, in that the wordless picture book was narrative in nature. Results may be different if expository text were used.

In an effort to determine how children could differentiate spoken and written language using expository texts, Duke and Kays (1998) conducted a study that encouraged kindergarten children to participate in pretend readings of nonfiction books. The researchers studied 23 predominately low-income kindergarten children representing diversity in race, as they "read" wordless nonfiction and fiction texts. First, Duke and Kays gathered preliminary data by encouraging the students to initially "read" the books in September. Between September and December, the researchers asked the teacher to read both informational texts and fictional texts three to four times a week. In December, the researchers retested the children by asking them to "read" the same texts again. The researchers found that when the children "read" the books in December, their readings contained many more usages of features consistent with nonfiction texts including: timeless verbs, generic noun constructions, repetition of the nonfiction theme, informational book beginnings, classificatory structures, and comparative/contrastive structures.

The study (Duke \& Kays, 1998) appears to find that young children hear differences between expository and narrative texts. Moreover, it can be argued that children may have less trouble with reading and writing in later years, if they have frequent exposure to nonfiction and fiction texts in younger grades. 


\section{Research Concerning the Writing Processes of Young Children}

As the above researchers collected data regarding children's knowledge of written language by focusing on written products, other researchers began to notice the processes young writers used when creating written texts (Calkins, 1983; Graves, 1983/2003; Hansen, 1987/2001; Harste, Woodward, \& Burke, 1984). Their processes allow children to explore and develop a growing awareness of written language.

The processes writers use were first examined in Emig's (1971) groundbreaking research (her dissertation from Harvard) when she examined the writing processes of twelfth grade students. By focusing on processes, rather than completed texts, she found that the writers problem-solved during writing and considered the audience while composing. These were important findings because they showed the importance of studying writing beyond the final products, and, more specifically, she determined that the processes writers use vary, depending on the difficulties they resolve and for whom they are writing.

Harste, Woodward, and Burke (1984) studied the writing processes that three-s four-, five-, and six-year-old children used within their classrooms. In their fieldnotes, they recorded what the children were doing as they composed. The researchers gained a wealth of information regarding the children's purposes for writing. To show the dangers of only attending to the written products of young child writing, the researchers provided the example of Terry (p.16), a three-year-old child in the act of composing. First, the researchers asked the child to compose a piece of writing that was of interest to the child. Then they asked Terry to create a drawing. The researchers displayed Terry's writing 
and drawing attempts side-by-side to show how the two look similar even though the child had different intentions for each endeavor (Figure 2.1).

Table 2.1. Uninterrupted Writing and Drawing Samples (Terry, Age 3).

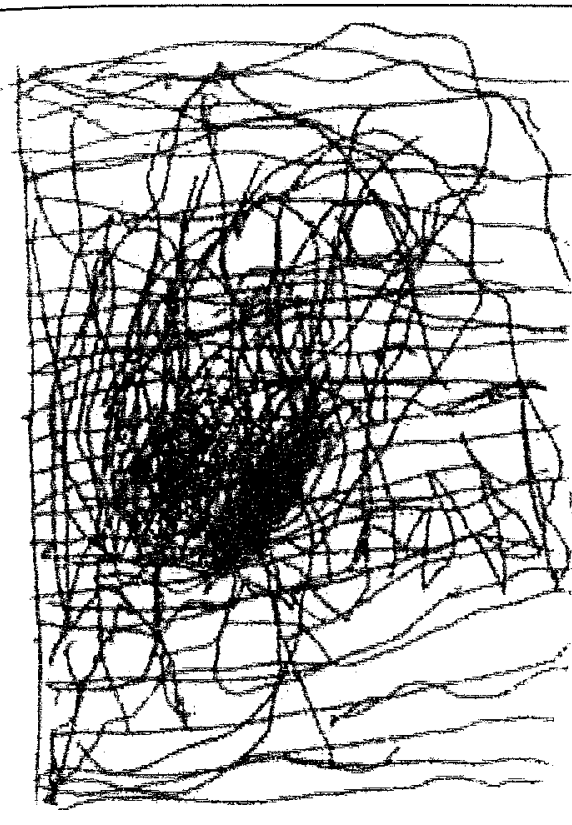

Uninterrupted Writing

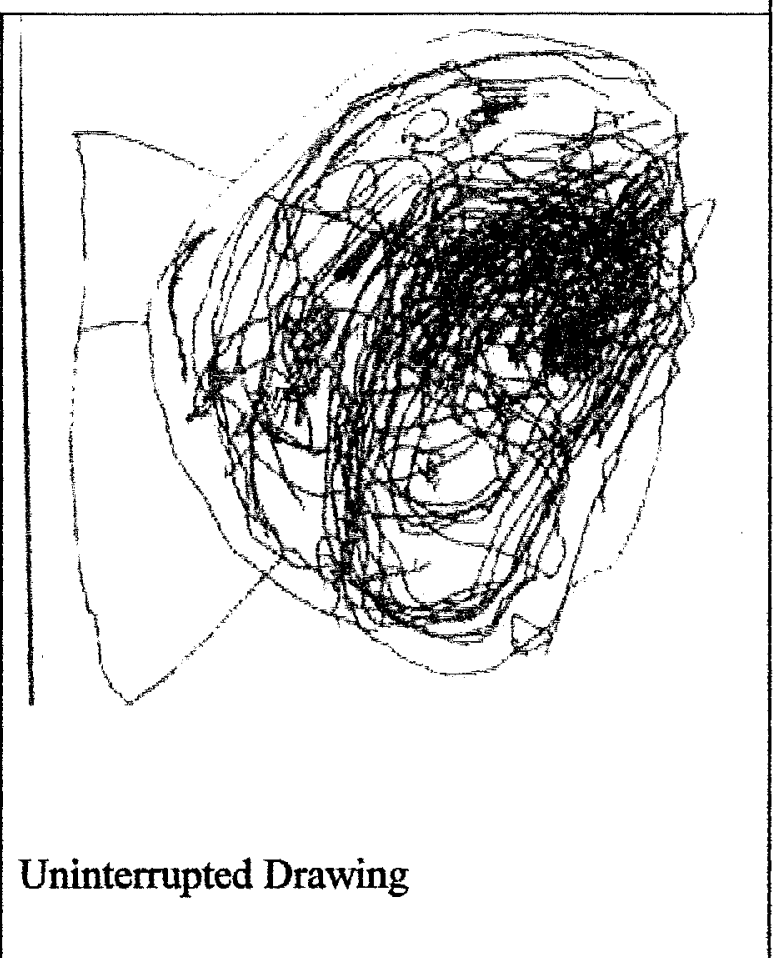

Initially, readers would typically note little difference between the two. They both resemble "scribble-like" forms with few distinguishing marks that differentiate one from the other. Next, the researchers provide the same samples while capturing the process Terry used as he created the two (Table 2.1). 


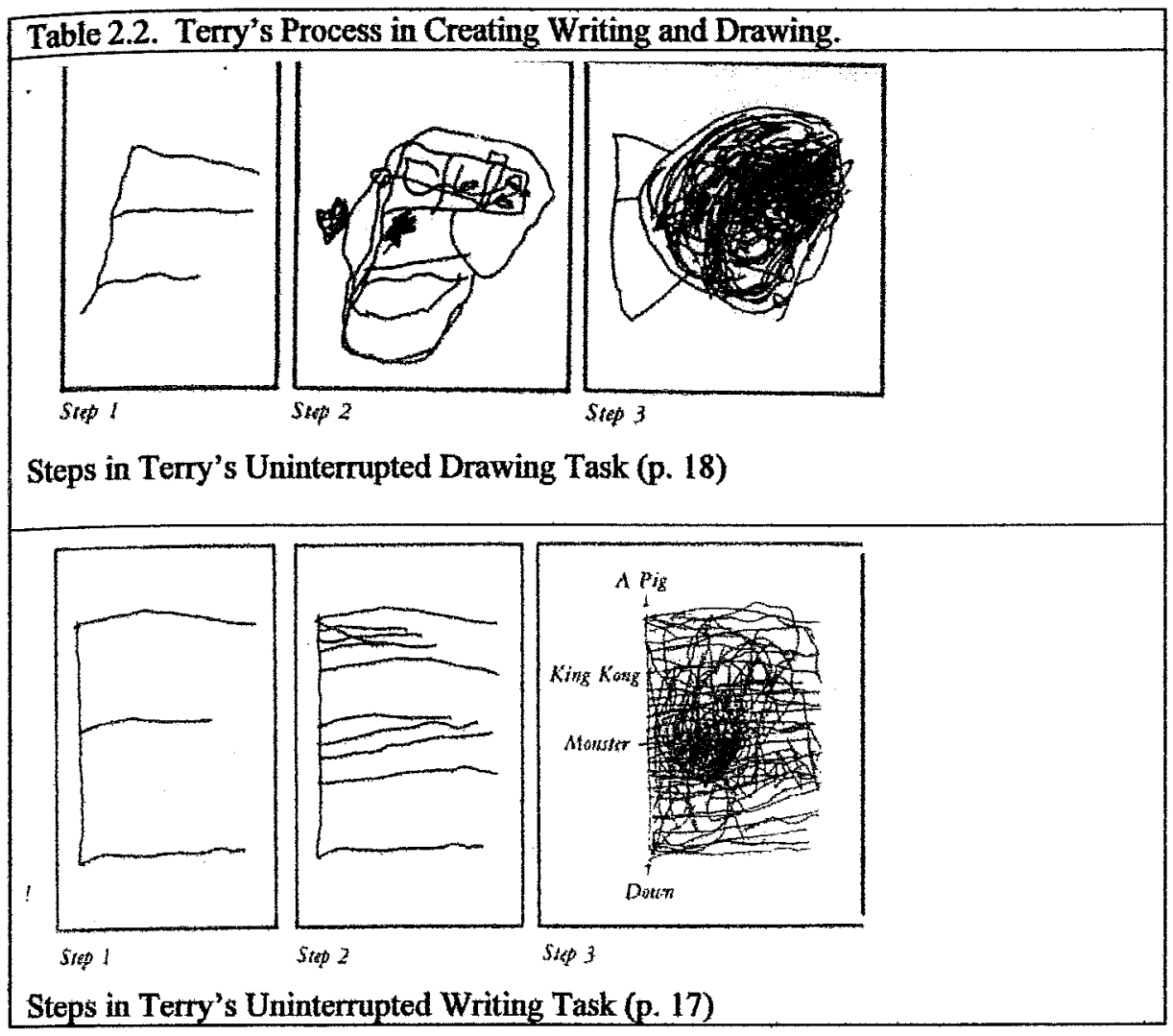

In Terry's uninterrupted writing and drawing samples, both works began with the letter $E$; a letter Terry knows is in his name. For the first example, he continues to make marks and eventually covers his entire work with scribble-like forms, much like the work he did in his uninterrupted drawing. For the second example, the marks he continues to make are linear. He calls this "writing." The researchers concluded that by the age of three, all children in their study had developed a marking system to symbolize their names. In Terry's case, the E represented his name and he used his name as a starting point to further compose his drawing and writing. The researchers learned this by observing Terry write. This is information they would not have known had they only studied his written product. 
Other early 1980 s research also explicated the processes children use when they write for specific purposes (Calkins, 1983; Graves, 1983/2003; Hansen, 1987/2001). The researchers collected their data in classrooms where the teachers assisted children in developing their awareness of the processes they used when they wrote. The teachers conferred with the children while they were in the process of writing, asking them to talk about what they were doing and why. The birth of a research-based instructional approach to the teaching of writing emerged and was examined fully in texts written by groundbreaking writing researchers (Calkins, 1983; Emig, 1971; Flower \& Hayes, 1984; Graves, 1983/2003). Teachers began to teach writers to talk about the processes they used to create their intended meaning.

Donald Graves (1983/2003) conducted the seminal research that showed children composing in a variety of ways including drawing, talking, gesturing, and acting. They used these actions as part of their writing processes. Classrooms that encouraged these acts to occur while children were in the process of writing typically contained students who were interested in writing and felt comfortable sharing their work with others. When students learn about variations in writing processes via scaffolding and motivational support from within their community of writers, they can skillfully craft a final product.

As a member of Graves' research team, Lucy Calkins (1983) studied writing in elementary classrooms. She conducted a two-year case study which examined the writing growth of Susie as she progressed through second and third grade. The research presented several descriptions of the processes Susie used to create written text, including revision techniques. Calkins goes further in her text (her dissertation from Teachers 
College) to explain the lessons the teachers employed to help Susie progress as a writer, including the mini-lessons they taught, the writing demonstrations they provided, and the frequent conferences they held. Her explanations of the teachers' instructional techniques influenced writing instruction across the country.

Jane Hansen (1987/2001), a co-researcher with Graves, was another influential voice in the study of child's writing processes. She conducted extensive research in a variety of classrooms that encouraged a process approach to reading and writing instruction. Using children's writing and processes as documentation, she explicitly described various actions children engaged in when they connected their writing and reading experiences. She found that the children listened to their own voices, noticed the decisions peers made in their writing, read texts written by professionals and noticed their writing techniques, sought and accepted evaluative response from others, and maintained self-discipline when composing texts.

Observing children while they write and conferring with them about their writing processes brought increased attention to the meaning-making processes children use when constructing texts. While these researchers concurred that written products are significant, their findings showed that the products should be viewed from the perspective of the processes the children used when they composed. That is, conventional formulations of letters, words, and sentences should not be used as the sole assessment of writing ability in emergent learners. Rather, an awareness of what they did to create an intended message should be of paramount importance. 
Research Concerning the Socio-Cultural Influences on the Written Products and Writing

\section{Processes of Young Children}

In an effort to distinguish between oral and written language, James Gee (2002)

claimed that the distinction between the two processes is ambiguous. Gee recognizes that humans are born with a core grammar, which is the basic biological design we genetically acquire at birth. This core grammar comes with a set of grammatical properties and is the guiding force that provides humans with the ability to learn language. Humans, however, are cultural beings who are immersed within communities that influence speech decisions. Social influences result in a modification of the core grammar thus impacting the speaking and (ultimately) writing choices one makes when communicating. Within languages are genres that routinely combine words (oral and written) in ways to represent patterns resulting in cultural models (everyday, or folk, theories about the world). The cultural models become representative of particular groups of people and establish the "typical" or "normal" aspects of language acquisition within the community. Gee concluded that making distinctions between oral and written language is not adequate. He explained:

What is important is not the distinction between written and oral language but specific socio-cultural practices, social languages, and genres. Within these there is a complex interplay of written language, oral language, and interaction. In turn, the issue for early literacy is not 'learning to read' but how the child-at home, in the community, and at school - does or does not acquire specific social practices, social languages, and genres that involve 'ways with printed words,' along with much else (p. 35).

Gee implies that language acquisition (both oral and written) is influenced by accepted cultural norms of speaking and writing. As a result, research in writing acquisition must 
go beyond the initial study of written products and processes. When studying young writers, a substantive effort must be made to consider the cultural background of the child and his/her social practices, languages, and influences. Past studies have noted the cultural influences of children acquiring language within inner-city contexts (Taylor \& Dorsey-Gaines, 1988) and rural communities (Heath, 1983). In these studies, the home and community environments were explored to explain social and cultural influences on the literacy lives of children.

Researchers have started to show the significance of various social factors on the writing processes of children in primary classrooms (Dyson, 1993; Gundlach, McLane, Scott, \& McNamee, 1985). Their knowledge of writing is typically embedded in social interactions that occur within their homes and classrooms. To understand children's written meanings and agendas, we must go beyond information about the processes they use to an appreciation of the ways their multiple worlds influence them as writers (Dyson, 1989, 1993; Geneshi, Stires, \& Yung-Chan, 2001).

An exploration of the social realms of writing cannot be possible without acknowledging several key theorists who have contributed to the collective understanding of how humans create knowledge. A combination of these theorists provides the framework for studying child writing as a process involving the social interactions of children within a socio-cultural learning environment.

According to Piaget (1959), children between the ages of two and seven function within a preoperational stage of development. During this stage, a child is able to represent objects and events mentally through symbolic thought. Within this world view, children consider their past experiences as they learn new concepts. Their ability to 
represent symbolic thought is a critical aspect of their language development. A child's oral and written language reflects a recollection of past events and present understandings as they encode meaning within their writing.

Through his socio-cultural theory, Lev Vygotsky (1978) reasoned that children coconstruct knowledge while interacting with their environment. Rather than learning individually, Vygotsky believed that children learn when they are able to socially interact with others more skilled within a zone of proximal development. Vygotsky's view of language development (both oral and written) involves a person's ability to obtain 'inner speech" through the internalization of various social interactions. In his seminal work, Mind in Society, Vygotsky notes:

Every function in the child's cultural development appears twice: first, on the social level, and later, on the individual level; first, between people (interpsychological) and then inside the child (intrapsychological). This applies equally to voluntary attention, to logical memory, and to the formation of concepts. All the higher functions originate as actual relationships between individuals (p. 57).

Vygotsky's insights highlight the importance of learning amongst others and are echoed in the social learning theory of Bandura (1977). Bandura explains human behavior as a synchrony of interactions among cognitive, behavioral, and environmental influences. People rely on others to help provide information about what to do within a social context. Teacher demonstrations of what they do when they write and social interactions among children while they write have great impact on how a child learns the processes of writing. Bandura writes:

Learning would be exceedingly laborious, not to mention hazardous, if people had to rely solely on the effects of their own actions to inform them what to do. Fortunately, most human behavior is learned observationally through modeling: from observing others one forms an 
idea of how new behaviors are performed, and on later occasions this coded information serves as a guide for action (p. 22).

The constructivist theory of Bruner (1986) provides additional support for the importance of the social influences on young writers. Bruner asserts that learning is an active process involving a person's ability to construct new ideas or concepts based upon previously accumulated knowledge. Young writers, therefore, construct new knowledge about print when they are exposed to it by others through socially enabled classroom settings. In his work, Actual Minds, Possible Worlds, Bruner explains his constructivist philosophy within the social context:

I have come increasingly to recognize that most learning in most settings is a communal activity, a sharing of the culture. It is not just that the child must make his knowledge his own, but that he must make it his own in a community of those who share his sense of belonging to a culture. It is this that leads me to emphasize not only discovery and invention but the importance of negotiating and shating (p. 127).

Urie Bronfenbrenner $(1979,1989)$ provides a compatible interpretation of child development through his ecological systems theory. From his perspective, children develop through various relationships situated within complex concentric realms of the child's world. The microsystem represents the individual child and his/her immediate world. Mesosystems (classroom, immediate family, neighborhood) influence their immediate worlds by creating links and connections between experiences in the microsystem. Enveloping the microsystem is the exosystem (friends/neighbors, extended family, community services, school), and macrosystem (laws, values, and customs) which also provides additional layers to the life experience of the child. The complex and integrated connections and interactions among the child and others have great 
influence on the social, emotional, and cognitive development of the child. This notion impacts the writing acquisition of young children. As children write, the experiences they bring to the page are not necessarily confined to the classroom environment. Rather, writing may begin with lived experiences long before a pencil or marker is used by the individual child. It also continues long after the pencil and marker have been pushed aside.

Lindfors (1989) suggests that language acquisition is embedded in a child's ability to formulate and maintain social relationships when constructing knowledge.

I believe that whatever the community within which a child develops language, he will use it throughout life to carry out three fundamental, compelling human urges: to connect with others, to understand his world, and to reveal himself within it. Because we inquire of others in order to further our understanding, inquiry is as much a social act as it is an intellectual one (p. 2).

Lindfors asserts that social interactions and inquiries that occur within the social realm of the child influence a child's ability to acquire language.

Finally, this dissertation study is framed within a theory of situated learning (Lave \& Wenger, 1991). This theory asserts that acquisition of knowledge occurs within the context of social relationships, or what Lave and Wenger call "communities of practice." According to this theory, learners move from the periphery of communities to the center as they assume a role as apprentice. They become active and engaged with learning through social interaction with the teacher and peers. The experts (teacher and peer) provide scaffolding to support a child's developing capabilities within a context (Rogoff \& Lave, 1984). As learners gain more confidence in their abilities, they assume the role of expert and teach others within their community. This theory has implications for classrooms where pre-kindergarten children write. As children engage in apprenticeships 
with the teacher (through her writing demonstrations) and their peers (through social interactions during writing), they gain a gradual acquisition of knowledge as they learn from others within the social contexts of the writing classroom.

In naturalistic studies of writing acquisition, researchers have described the sociocultural aspects of the home and classroom that influence children's knowledge of language and literacy (Atwell, 1994; Bissex, 1980; Calkins, 1986; Dyson, 1993; 1999; Gallas, 1994; Graves, 1975; 1983/2004; Gundlach, McLane, Scott, McNamee, 1985; Hansen, 1987/2001; Heath, 1983; Paley, 2004; Wiseman, 2003). Research concerning influences on student writing is provided in the following section. Influences on the part of the teacher, peer influences, and home influences will be described in separate subsections to provide examples of some of the social influences that may affect a child's ability to acquire written language.

The Influence of the Home on Young Writers

Literacy learning begins at birth as children are initially influenced by the experiences provided to them by their parents and guardians. This section will examine the influence of the home environment on the literacy learning of preschool children. General descriptions of parental involvement influences will be highlighted to explain their impact on the educational outcomes of young children. Socioeconomic factors will also be noted to describe how children from low-income families develop language and literacy abilities as compared to their counterparts from other income levels.

Parental involvement impacts educational outcomes for young children. In the last ten years, the national policy agenda has focused on the importance of promoting parental involvement in the overall growth of students (National Education Goals Panel, 
1997a). The National Goals Panel established eight educational goals for the year 2000.

The eighth goal stated that schools should promote parent involvement to support children's social, emotional, and academic growth. It is widely believed that children must begin formalized schooling with a readiness to develop academic success (Goldenberg, 2002). Much learning happens in the home before children enter the school environment (Morrow, 2001). Schools play a critical role in helping parents develop teaching strategies that extend beyond the classroom and into the home environment (Baker, Kessler-Sklar, Piotrkowski, \& Parker, 1999).

In a study examining parent-school involvement and its association with positive educational outcomes, Zellman and Waterman (1998) examined the relationship between children and their mothers in an attempt to confirm how the relationship affects student academic outcomes. The researchers sought to determine the relationship between the mother's involvement and student success, the demographic and family background characteristics that are associated with the mother's involvement, and the importance of her involvement in predicting child outcomes. To accomplish this, the researchers examined 193 second and fifth grade students and their mothers from five public elementary schools and one private elementary school that represented a racially diverse population. Families were identified for the study and interviewed at the local school. Initially, mothers and children were interviewed separately, then they were joined together to participate in a 10-minute conflict resolution task. The interviews and observations were videotaped and coded based on four scales involving the mother's parenting style. These codes included clarity (engagement, problem resolution, and statement of expectations), negativity (demandingness, intrusiveness, and antagonism), 
emotionality (feeling expression and feeling acknowledgement), and warmth. The researchers found that the interactions between the mothers and their children were important in predicting child academic outcomes. When mothers set clear expectations for their children, interacted positively when resolving conflicts, and warmly revealed expressions and feelings to their child, the child was more likely to be academically successful in the classroom. This study is limited, however, because volunteers were used to conduct the observations and interviews. Those parents who did volunteer were more likely to be successful parents since they responded to the flyer sent out by the researchers.

In summary, when parents interact with their children in relation to educationrelated literacy tasks, studies suggest that children are more likely to succeed in school (Baker, Kessler-Sklar, Piotrkowski, \& Parker, 1999; Baker \& Soden, 1998; Zellman \& Waterman, 1998). The learning that takes place at home can be just as vital as the learning that takes place within formalized school settings (Henderson \& Berla, 1994). The home environment is an influential setting (Dickinson \& Tabors, 1991), but some home environments are more influential than others when fostering literacy knowledge, as socioeconomic status plays a role in language development.

The socioeconomic status of the family often influences young writers. The relationship between parents and children who represent different socio-economic situations, and the verbal interactions that occur between them, provided the basis of a landmark, longitudinal study conducted by Hart and Risley (1995). The researchers investigated the effects of home experiences on the development of children from 42 different families reflecting three distinct socio-economic backgrounds: professional 
families, working families, and families on welfare support. The researchers were particularly interested in the verbal interactions that occurred between families and their children. During the course of almost three years, the researchers collected monthly samples of parent-child interactions through one-hour tape recordings. The researchers found that there were major differences in the vocabulary development of various children. For instance, by the time children reached the age of three, the vocabulary acquisition of the children varied greatly depending upon the socio-economic status of the family. Children in professional families learned and used approximately 1,100 words in their speech compared to 750 for working class families, and 500 for welfare families. Additionally, the number of words spoken between caregiver and child varied greatly depending upon the child's background. Children from professional backgrounds heard an average of 2,153 words per hour. This is in stark contrast to their working class (1,251 words per hour) and welfare peers (616 words per hour) who heard significantly fewer words per hour. The Hart and Risley study resulted in a growing awareness of the amount of language that occurs in various households.

This discrepancy in language leads to what Keith Stanovich (1986) termed the "Matthew Effect." The term refers to the notion that a child's background experience before schooling influences the rate of potential literacy growth as they proceed through schooling. Children who enter a formalized school setting with rich home experiences in literacy exposure and learning, continue to grow steadily throughout their experiences at school. However, those students who enter school with less exposure to literacy experiences (books, vocabulary, and oral language) are already at a disadvantage by preschool age. As a result, the rich get richer while the poor get poorer because frustrated 
students who are low-achieving in literacy skills begin to dislike reading and writing. Eventually, this lack of motivation leads students to abandon reading and writing tasks altogether, thus perpetuating the vicious cycle of illiteracy.

Poorer families are not always in a financial position to provide what may be seen as necessary literacy materials at home, nor are some of the parents necessarily able to read aloud to their children, offer phonological awareness activities, or engage their children in requisite preliteracy experiences (Vernon-Feagans, Hammer, Miccio, \& Manlove, 2002). This lack of literacy experience in the home may result in later reading and writing difficulties in the classroom (Raz \& Bryant, 1990). As a result, children from low-income families are more dependent on school experiences for their academic literacy development than their middle-class peers (Alexander \& Entwisle, 1988).

To fully understand how children acquire writing ability in the preschool classroom, it is important to explore how writing is fostered within the home environment. By the time children enter school, they already have some pre-established notions of writing and language developed within their home environment (Morrow, 2001). The earliest experiences children have with literacy revolve around real-life experiences with their families (Bissex, 1980; Gundlach, McLane, Scott, \& McNamee, 1985). Such experiences may include writing notes, composing lists, creating holiday greetings, and writing directions (Morrow, 2001).

Gundlach, McLane, Scott, and McNamee (1985) conducted a case study of a middle-class child in the process of writing within his home environment. They observed the interactions that occurred between Jeremy, a four year-old child, and his parents during composing. The researchers were interested in studying how the parents 
facilitated writing development, the interactions that occurred during writing, and the support and scaffolding the parents provided to help Jeremy compose. Data were collected through observational notes of the parents, observations of interactions, and collection of writing samples. The researchers noted four different categories concerning Jeremy's writing activity. First, they noted that Jeremy spent a great deal of time engaged in pretend play in his home environment. Next, they found that Jeremy liked to make up songs and words as he composed and enjoyed performing these songs to his mother. In this way, his reading and writing experiences were similar to theatrical performances as his family played the role of responsive audience. The researchers also found that Jeremy was concerned with correctness and mastering the skills of writing. He was aware that there was a correct way to write and he carefully composed knowing that there was an order to writing that he attempted to understand. Finally, Jeremy often copied words listed in a book and often asked his mother for assistance with the mechanics of writing. These scaffolding experiences were important elements of Jeremy's writing development. The researchers found that writing was very much a part of Jeremy's daily life and he used the process of composing to gain the attention, approval, and interest of his parents. Furthermore, his parents were influential instructors in his language acquisition. They provided a powerful scaffold for Jeremy as he continued to explore the multi-faceted nature of writing.

The home environment in which children compose can help foster or hinder the experiences of children learning to write (Dorsey-Gaines, 1988; Heath, 1983). If writing is a common occurrence in the home and parents provide appropriate models for their children, then writing is a positive experience for the child. However, in homes where 
children have less exposure to writing purposes and are provided less opportunity to compose, then they are at a disadvantage (Purcell-Gates, 1996).

To summarize, the home environment plays an important role in the language development of young children. Children who come from supportive environments and caring families have more successful educational outcomes in formalized classroom settings (Zellman \& Waterman, 1998). Children from low socio-economic backgrounds are at a particular disadvantage because they typically receive less opportunity to engage in meaningful interactions with their families (Hart \& Risley, 1995). Family interactions during writing do provide important scaffolds for children as they learn how to write at home (Gundlach, McLane, Scott, and McNamee, 1985). The described studies note the importance of family interactions in the language learning of young children. However, there remains a dearth of research describing how preschool children incorporate various family experiences into their classroom written compositions.

\section{The Influence of the Teacher on Young Writers}

The teacher has a significant role when teaching writing to young children. By becoming a writer him/herself in the classroom, the teacher learns to recognize the struggles children may have when constructing their own texts (Reif, 1994; Atwell, 1998; Calkins, 1994). When teachers provide writing demonstrations for their students, many students may use the teacher's idea for their own writing choices. Mainly, the students see "writer" as part of their teacher's identity. The writing teacher who writes has credibility with the students. 
Middle school teacher-researcher Linda Reif (1994) acknowledges that teachers of writing must be writers themselves. When teachers experience their own struggles with writing, they are better informed about the complicated process, and become knowledgeable informants about how writing works.
All teachers should be readers and writers, but language arts teachers must be writers and readers. We must be what we teach in order to: recognize and understand the challenges, the frustrations, and the achievements experienced by our students; understand the complexity of the processes in which we ask children to participate; show our students that we value what we ask them to do by doing it ourselves (p. 92).

By being writers themselves teachers are able demonstrate to children the struggles a writer may face when choosing topics and drafting ideas. When teachers write, they provide themselves with a context in which they can more readily help student writers.

Nanci Atwell (1987/1998), another middle school teacher-researcher, provides additional insights into the notion of the teacher as writer. She focused on the importance of composing texts in front of her students. When writing before one group of students, she asked children to notice techniques she used when composing her text. The children noticed Atwell's inclusion of many lessons that she had already taught the class. In addition, they noticed many acts that she was unaware of as a teacher. The acts included Atwell's tendency to: close her eyes to visualize a setting, give hints to predict events in the story, use humor to break the tension, and her willingness to continually stop writing to review what she had already written. She notes:

One of the benefits of demonstrating writing is the element of surprise. I wasn't aware I did these things when I write, and my kids weren't aware these were things a writer could do. The demonstrations made them explicit and gave us new ways of 
talking about what writers do-and about what students might do as writers (p. 334).

Although the children Atwell describes are middle school students, the writing demonstration provides similar important strategies for pre-kindergarten children. When teachers demonstrate their writing in front of the class, young writers are given the opportunity to see that writing ideas can come from many places.

Lucy Calkins (1994) maintains that the teacher's role in the writing classroom is influential because he/she sets the stage for writing to occur throughout the day. When teachers create opportunities for writing in meaningful contexts throughout the classroom, children are encouraged to write using a variety of contexts and purposes. When the teacher and other students respond in a supportive manner to these various kinds of writing, the message is sent to the writer that their writing is valued.

Sometimes people ask me what I think is the most important message I could convey to teachers of young children. My answer is simple: I want teachers to delight in what youngsters do and to respond in real ways about what they are trying to do. I want teachers to have a wonderful time watching and admiring and working with young writers (p. 70).

When the teacher and other students offer authentic responses to the texts created, the social context of the classroom enables children to witness the value their writing has for others.

The intricate relationships between teachers and students provide an additional social influence in the writing of young children. Often, the roles of power negotiated between teachers and students can influence children as they compose. Corsaro and Nelson (2003) found that teachers and peers engage in power roles within their early childhood classroom settings. They gathered over a 30-year period in ethnographic 
studies of preschool and early elementary school children in the United States and Italy in seven early education settings, and their goal was to capture the culture of early childhood classrooms by examining student participation during literacy events. Using a sociocultural and interpretivist paradigm, the researchers sought to understand children's intentions when they wrote. They found that when teachers set rules for assignments the children often ignored them and crafted their own agendas as they interacted with peers during classroom literacy events. In one case, a first grade teacher began to focus on teaching specific letters during formal lessons. Rather than allowing children to draw pictures to represent their stories, the teacher began to require children to print letters and words instead. The colored markers, which had been readily available for children in the past, were taken away by the teacher. In response, Carolina (a young Italian girl) secretly used a marker to draw a picture on a Kleenex as a way to resist the teacher's rule and maintain her status within the peer culture of the classroom. Young children have a strong desire to use their writing to create a place for themselves among their peers and are often determined to fulfill those literacy agendas.

To summarize, the teacher plays an important role in preschool classrooms. Certainly, many of the interactions that occur between teachers and students are greatly beneficial to the literacy learning of the child. When children have teachers who are writers, they witness writing demonstrations and elicit important understandings about what it means to be a writer (Reif, 1994). As teachers compose in front of students, young children receive the benefit of writing demonstrations that show how writing is done (Atwell, 1987/1998). These demonstrations provide students with insights into the writing process and the struggles many writers face when composing. 
Teachers are also influential when they construct classroom environments that are conducive for writing (Calkins, 1994). When students have opportunities to write everyday in supportive environments, their writing typically flourishes as the teacher nurtures their desire to construct meaningful texts. Along with the important interaction with the teacher, close relationships among peers foster the cognitive and linguistic development essential for future reading and writing success (Pellegrini, 2002).

\section{The Influence of Peers on Young Writers}

Peer relationships have been defined as friendships that are built between or among individuals who view themselves as equals within a social situation (Jones, 2002). When peers engage with one another in classrooms, particularly preschool pretend play areas, their interactions influence the development of their literate language (Jones and Pellegrini, 1996). Purcell-Gates (1988) notes that literate language is composed of word choice, syntax, topic, and discourse community style which distinguishes between oral and written language in the number of participles, attributive adjectives, literary words and phrases, direct quotes, and formulaic openings. Additionally, word choice, syntax, topic, and discourse community style are differentiated when the composer of a text writes for various purposes. Children's language learning is enhanced when they are given opportunities to engage in lessons concerning print concepts, narrative competence, receptive vocabulary, writing concepts, knowledge of letter names, and awareness of phonemes (Purcell-Gates, 1996). The development of this language among peers has been determined to be an important aspect of early reading and writing acquisition and a great predictor of future reading and writing success (Pellegrini \& Galda, 1991). 
A number of researchers have examined the interactions of young children as they engage in pretend play and other less teacher-directed activities in the classroom (CraigUnkefer, Kaiser, 2003; Dickinson, 2001; Jones, 2002; Kantor, Miller, \& Fernie, 1992; Lindsey, 2002; Matthews \& Kessner, 2003; Neuman and Roskos, 1997; Nixon \& Topping, 2001; Salyer, 1994). These studies provide insights into the types of interactions that occur among children and the importance of these interactions in developing literacy skills.

Peers influence literacy learning through play. Kantor, Miller, and Fernie (1992) examined the literacy experiences of children as they interacted with peers and the teacher in preschool classrooms. The researchers used videotapes and fieldnotes for data collection to study the social dynamics in a 3-and 4-year-old preschool classroom. They studied the children in four classroom contexts. In two of the contexts (3- and 4-year-old teacher led groups), the teacher determined the literacy experiences of the children. In the other two contexts (block and art areas), the students determined their literacy activities with peers.

The researchers found that the interactions initiated among the children enabled them to learn uses of literacy that went beyond those taught by the teacher. For example, a group of boys in the block area used this social context to establish friendships by building structures for one another. After creating structures, several of the boys composed printed signs to warn other students to "keep out" of the buildings they constructed. In this context, apart from formalized instruction of the teacher, the children were free to practice, explore, and create on their own written products amongst peers and the assistance of the teacher was not needed or requested. In the art context, several 
of the children in the classroom were interested in drawing and painting familiar superheroes. Through interactions with peers, children discovered that particular print was assigned to the costumes of specific superheroes. Consequently, children spontaneously created and demonstrated print use and knowledge when they created superhero capes inscribed with logos or names. Within the free-play contexts of the classroom, children took diverse paths to literacy as they ventured beyond the teacher and towards their peers for additional insight. Literacy became a method children employed to interact within their social worlds.

The importance of peer influences on literacy learning was further substantiated in the research endeavors of Neuman and Roskos (1997). The researchers observed 30 preschoolers as they engaged in free play activities in the classroom involving a post office, a doctor's office, and a restaurant. They employed qualitative methods and analyzed the results based on a constant-comparative approach. The study was limited to the specific classroom areas that were studied, but the findings suggest that children obtain considerable knowledge about literacy when they are given opportunities to learn in peer-centered contexts. Because children engaged with peers during pretend play, their oral language and vocabulary development was enhanced, their knowledge about classroom routines and rituals established by the teacher was strengthened, and strategic knowledge like metacognition was explored. When teachers provided students with free choice play settings, the researchers found that the children's literacy development was enhanced because they had additional opportunities to learn from peers.

Paley (2004) conducted research over many years in her own classrooms. Her research shows that play provides the foundation for children to learn literacy skills. In 
the studies conducted in her classroom, Paley documents several instances of children engaging in writing acts as they assume various roles in play areas around her classroom. These interactions were essential components to children who were new to realm of writing. In a non-threatening environment where children were encouraged to interact with one another, Paley showed that children often rely on each other to help increase their understanding of written language. Paley's work staunchly defends the practice of incorporating play into the early childhood curriculum. To children, writing is part of their play.

The teacher supports young children's interactions during writing. Wiseman (2003) observed kindergarten students as they engaged in writing lessons with the teacher. The role of the teacher was dialogic as students' interactive responses to story books and talk among themselves about their writing were prominent among the classroom practices. After engaging in the read aloud with the teacher, the students wrote and conferred together in less formal settings. Through observations, Wiseman noticed that children influenced each other during writing by constructing stories together, assisting one another with spelling mastery, initiating writing ideas, and enforcing the rules of the teacher during composing time. Wiseman found that the teacher provided the initial support for the children in the classroom during writing time by reading aloud a text, demonstrating writing, and developing the routines which included encouraging the children to interact as they wrote. As they composed together, peers increasingly influenced each other as writers. Wiseman noted that peers are important mediators in literacy learning and her findings demonstrate how important it is for teachers to encourage interaction among young writers. 
Young writers are influenced through structured peer interactions. Some researchers (Campbell, 1998; Jones, 2002; Nixon and Topping, 2001; Steward, 1995) have studied how structured peer interactions may enhance the literacy experiences of preschool children. Nixon and Topping (2001) evaluated the effects of one preschool instructional procedure that encouraged children to write with more competent peers throughout the week. Training was provided for the teacher and the intervention was implemented over a 6-week period. The teacher provided resources such as writing instruments and paper, enhanced her modeling strategies, and engaged the students in experiences that increased their desire to write. Then, they wrote, in pairs, with peers who were more skilled as writers. The gains of the students who were originally the weaker writers were judged in three different areas of writing competence: understanding that writing conveys meaning, understanding of how to construct the message, and elaboration of text. Using a point scale, the children's writing was evaluated using a preand post-score and the researchers found that there was a significant improvement in the writing scores. The paired children showed a positive change in attitude, were more willing to write in the classroom than they were when they worked individually, and were more eager to share their writing with others than they had been when they did not work with others.

Young writers are influenced by their interactions with same-gendered peers. A growing field of inquiry concerns gender influences in establishing peer relationships among young children in early childhood classrooms (Fabes, Martin, \& Hanish, 2004; Leaper, 1994; Maccoby, 2002; Maccoby \& Jacklin, 1987). Notably, in many cases, young children prefer to engage in interactions with members of their own sex rather than 
cross gender lines. These relationships are important to explore because they have ramifications for students as they engage with peers in literacy learning.

As children enter formalized preschool settings, their preference to socially engage with same-sex peers has already been well established (Martin \& Fabes, 2001). By the age of two, girls already show a preference for interacting with other girls (Serbin, Moller, Gulko, Powlishta, \& Colbourne, 1994). Boys soon follow with their preference for interacting with other boys (Powlista, Servin, \& Moller, 1993). By the time children reach preschool age, they are three times less likely to engage with peers of the opposite sex when given the opportunity to select peers for various classroom activities (Maccoby \& Jacklin, 1987). Because same-sex play preferences become more pronounced by the time children reach the age of three, these interactions influence the learning that occurs in preschool settings.

Martin and Fabes (2001) conducted a study to determine how same-sex partners influence a child's behavior during free-choice experiences in the classroom. The goal of the researchers was two-fold. First, the researchers wanted to observe young students throughout the course of one school year to investigate the stability of children's playpartner choices. Once stability was established, the researchers sought to determine the consequences same-sex partner choices might pose for students learning in a socially mediated classroom. Child participants from three classrooms (both preschool and kindergarten) were observed at a university day-care facility, limiting the study to mostly Caucasian students from upper-middle class environments. 19,382 observations were collected over the course of 6.5 months, coded, and rated by nine observers with high levels of inter-rater reliability. Regarding the stability issue, the researchers found 
significant instances of stability within same-sex interactions in the classrooms. Over $90 \%$ of the girls in the study played with girls more than with boys, and about $45 \%$ of the girls played exclusively with other girls. For boys, $82 \%$ played more with other boys than with girls, and about $35 \%$ played exclusively with other boys. This finding concludes that stability occurred in both genders with higher levels displayed in female interactions.

When they analyzed the consequences of sex segregation, the researchers determined that play within same-sex peer groups was related to subsequent behaviors of the children. These behaviors were consistent with the pervasive stereotypes of boys and girls that regard boys as being more active and girls as being calmer in their interactions. Additionally, as children spent more time interacting with their same-sex counterparts, they experienced more opportunity and greater pressure to conform to gender-related behaviors. Although not noted in the research study, these findings may have consequences for preschool children as they engage in literacy activities in the classroom. If children naturally seek same-sex play partners, gender may play a role in the types of activities and the quality of interactions that occur when children write. In addition, if one gender shows more competence in literacy-type behaviors (reading, writing, and speaking), some children may be at a disadvantage because they do not socially interact with more competent members of the opposite sex.

In a study examining the role of young children's same-sex peer interactions on competence and effortful control, 98 preschool children were observed in four preschool classrooms (Fabes, Martin, Hanish, Anders, \& Derdich, 2003). The researchers defined school competence as a child's ability to show appropriate age-level skill in social, 
academic, and perceptual-motor tasks. Effortful control was defined as an individual's ability to maintain self control within social group processes. The purpose of the study was to examine how same-sex interactions affected early school competence and to observe how effortful control modulated competence levels. 2,787 recorded observations were systematically collected and coded into five different codes (effortful control, school competence, academic competence, social competence, perceptual-motor competence). Each observation was scored by two observers, who were determined to have high inter-rater reliability. Results of the study concluded that same-sex play among boys at high levels of effortful control was positively related to social, academic, and perceptual-motor competence. In settings where boys exhibited a low level of effortful control, there was an inverse link to social competence, but not to academic competence. For girls, no moderating effects of effortful control were found in social competence. However, in academic and perceptual-motor competencies, there were positive relationships between competence and higher levels of effortful control.

The researchers concluded that children spend large amounts of time in same-sex groups, which makes an impact on their development. When young children exhibit high levels of effortful control within their classroom experiences, social, academic, and perceptual-motor competencies are enhanced. Therefore, same-sex play partners have the potential to affect school-related competencies. However, there are limitations to the study. Children were observed in environments where peer interactions were selfselected by the students. An argument can be made that it was the relationship dynamics between the same-sex students that enhanced competence rather than their status of being the same sex. That is, there may have been different results if children of the same sex 
were selected to work together who did not have a positive relationship. Additionally, the study was conducted at a university preschool that did not represent vast diversity amongst its students. The majority of the students were Caucasian who came from homes of highly educated parents. Race and socioeconomic factors were not a consideration in the peer interactions that occurred within the setting.

To summarize, same-sex peer interactions are influential for young children (Bussey \& Bandura, 1999). The interactions that occur among same-sex children provide the primary peer socialization context for young children as they develop roles in the classroom (Fabes, Martin, \& Hanish, 2004). There is evidence to suggest that students segregate themselves into same-sex partnerships during play. This sexual segregation has learning ramifications for children in early childhood classrooms (Leaper, 1994; Maccoby, 1990). Because there have been few studies that have explored the effects of same-sex interaction during literacy events in preschool classrooms, it is difficult to ascertain what effects same-sex relationships may have on the writing and reading development of preschool children. Thus, further investigation is warranted to explore the role gender plays in the writing development of preschool children.

Peers influence each other as writers. When studying the influence of peers, it is necessary to understand the social dynamics of the entire classroom. Jones (2002) conducted an experimental study of first grade students to determine how peers interacted with one another during specific literacy tasks. Using a rating scale, Jones first conducted interviews with 36 children to determine who they considered friends in the classroom. Using photographs of peers, the students were instructed to determine who they considered friends in the classroom using a five-point scale. Next, they were asked 
to explicitly note their best friend in the classroom. Based on the ratings, Jones used different pairings of students to conduct her experiment. Students were grouped with others according to peer relationships (friends and non-friends) and gender. During the computer activity, children were shown pictures of story events, and the partners were instructed to co-create a story based on the pictures. The talk that occurred between the two students the peers was labeled and coded based on the particular function of the student talk. As a result, 10 specific categories were developed to describe the interactions that occurred amongst peers. These categories included: negotiation, directing, conflicts, conflict resolution, agreements, literate language, metacognitive language, reading text, social regulation, and emotion terms.

Jones found that the talk that occurred among children was different depending upon various combinations of students. Students who were friends were more willing to negotiate, collaborate, generate more emotional language, and engage in more literate language when completing the computer-based task. Students who did not regard one another as friends did not engage in similar conversations. This study was limited as it did not identify specific interactions that occurred between students of the same gender, but it did demonstrate evidence that not all peer groupings were equally constructive when encouraging literacy learning within the classroom. It becomes clear that students learn more from others when they engage in certain kinds of interactions.

Matthews and Kesner (2003) found similar results when they investigated the writing and reading experiences of children in a first-grade classroom. They found that peers can have a direct influence on the learning of an individual child. When children in the study were called together to participate in group literacy experiences, a particular 
social dynamic influenced the collaborative nature of participation. Those who were more knowledgeable about a particular subject or topic often ostracized those who were unaware. Their findings suggest that peer influences are not always positive within the social realm of literacy learning. The researchers concluded, however, that children eventually were more successful in reading and writing acts when they are given the opportunity to socially interact with their peers during literacy learning.

A preschool child's ability to collaboratively interact with peers is also important. Many teachers view this as a step towards preschool success (Lindsey, 2002; Paley, 2004). When children are able to engage with at least one mutual friend, they are better liked by peers. Likewise, when children are given opportunities to communicate with other peers in non-literacy classroom settings, they are more likely to engage with others on various literacy tasks (Craig-Unkefer \& Kaiser, 2003).

To summarize, peers play an important role in the social development of children within a preschool classroom. When preschool and primary classrooms are structured so that children have opportunities to socially confer with peers in various pretend play and other less formal classroom settings, the interactions that occur may have positive or negative effects on the student. Consequently, when teachers construct classroom settings that are supposedly cooperative in nature and encourage peer interaction, it becomes vital for the teacher to understand the social dynamics of the classroom and the combinations of students that may provide the best learning experiences for the children learning to read and write. 


\section{The Need for Investigation}

Throughout this review of literature, I have highlighted various studies to show that young children are influenced by various interactions at home, with the teacher, and among peers. Several studies of early writing acquisition have focused on the written products of young children as they move from oral to an understanding of written language (Bissex, 1980, Clay, 1975; Henderson \& Bears, 1980; Read, 1971;

Schickedanz, 1990). Through examination of their written products, these studies have shown how children gradually develop their awareness of written language. Other studies have focused on the processes children use to create their written products (Calkins, 1983; Graves, 1983/2003; Harste, Woodward, \& Burke, 1984). These studies highlight how children implement their awareness of written language as their write. Other studies focus on how the home and community are influential contributors for children acquiring written language.

Additional knowledge about written language acquisition can be obtained when pre-kindergarten children are studied holistically within the classroom environment. A study is needed to determine how the pre-kindergarten classroom environment directly influences the writing acquisition of young children. By studying instructional techniques of the educator and the written processes and products of children, we may begin to notice how children conceptualize new information and bring it onto the page. By recording and transcribing the voices of children as they interact with others, the social interplay among them can yield additional insights into their writing purposes. By asking students questions through conferring, researchers can begin to more completely understand the multiple meanings encoded within their writing. 
To understand young student writers, researchers and educators must know their friends, understand their interests, be cognizant of their home environments, observe the lessons of the class, and listen to their conversations. To understand the pre-conventional writing that young children compose, researchers and educators must know students beyond the written page. 


\section{CHAPTER THREE}

\section{METHODOLOGY}

\section{Overall Approach and Rationale}

The purpose for this study was to identify the various settings in which social interactions occurred in a pre-kindergarten classroom during writing instruction, and to describe how these interactions influenced the decisions the children make when constructing texts. Currently, there remains a gap in research; the influences of various social acts that occur in pre-kindergarten classrooms during writing instruction is not known. While many studies are beginning to address the socio-cultural aspect of writing, little research addresses this notion in relation to the writing decisions of young children; these children are an underrepresented population in research conducted about writing acquisition.

To study these social interactions, I collected data in one classroom, and employed a qualitative, naturalistic, ethnographic approach (Marshall and Rossman, 1999). Qualitative methodology was used because it allowed me to delve deeply into the complexities and processes of the classroom of writers. This methodology also allowed the research to "unfold, cascade, roll, and emerge" throughout the course of the study (Lincoln and Guba, 1985). Observations and interviews of the teacher and students throughout the study provided complex data about the writing of the children. 
I employed an interpretivist approach to study the culture of the pre-kindergarten classroom (Erickson, 1986). In this approach to qualitative inquiry, my intent was to acknowledge the multiple truths that existed in the culture of the classroom. When using this paradigm in a particular setting, it is necessary to explicitly note the ontological, epistemological, and methodological beliefs of interpretivism.

The ontological beliefs of reality for interpretivists reflect the idea that there are multiple realities within the research setting. These realities are locally and specifically constructed and can only be understood, in my research, by studying the multiple realities of the children in the pre-kindergarten classroom. As an interpretivist, I believe every child assigns their own specific meaning to the writing they create. In my role as the researcher, I attempted to ascertain each child's true meaning of each piece of their written work. Because it was impossible to fully know the precise meanings of every piece of writing constructed by every student, I show their written documents and transcripts of their interactions before and during writing. I follow this with my interpretations of their work. Readers of this dissertation can draw alternative explanations of their written meanings through this access to the data.

Epistemologically, interpretivists do not believe their findings are cemented; that is, there could be additional meanings assigned to the findings that have not been realized by the researcher. My goal as a researcher was to seek, define, and describe the "invisibility" of the textual meanings that occurred in the writings of the pre-kindergarten children. To uncover the textual meanings, I conducted observations and interviews, documented local meanings in specific settings, and attempted to understand the differences that occurred among various students. Collection of the data was one small 
step in the process. Interpretation of the data through analysis provided the critical link between the known and unknown. It was during the process of analysis that I was able to construct some meanings that represent the influences on the written work that the young children produced.

In terms of methodology, I considered myself a symbolic interactionist. That is, my goal in collecting data was to explicitly describe how particular individuals exist within a group. Since I was embedded in the natural surroundings of the classroom environment, my relationships with those I studied influenced the research findings.

I began this study with the assumption that there are social and cultural influences that affect the writing outcomes of young children. That is, I have established in my literature review that the home environment, children's literature, the teacher, and peers influence students' writing acquisition. However, I wanted to determine with greater specificity the various factors that influenced the writing of these pre-kindergarten children, since this has not been carefully researched in past studies. Because I was uncertain about what the social influences were going to be, the dissertation design was emerging and it reflected my belief that if I study the myriad of cultural influences that occurred when students composed, I may better understand those influences.

To show the social interactions of the child writers, I provided thick description of the classroom acts and the participants (Geertz, 1978). I attempted to capture the culture of the classroom by exposing its normalcy and showing particularities. The goal of the description was to make clear the events that occurred. Throughout the course of the study, descriptions of events in the classroom were collected as fieldnotes, and then systematically studied to find emerging patterns or themes that occurred within the data. 
Access to the participants was crucial to my understanding of the events that occurred in the classroom and the meanings the children assigned to their writing (Hammersley and Atkinson, 1983). I was present in the classroom, close to the children; I needed to be psychologically able to understand the multiple meanings of their work.

\section{Site and Population Selection}

A pre-kindergarten classroom in a small, Southeastern college town in the United States was chosen as the site for this study. The classroom was situated within an elementary school. Its layout is displayed in Figure 3.1. The classroom was chosen because the teacher conducted writing instruction on a daily basis.

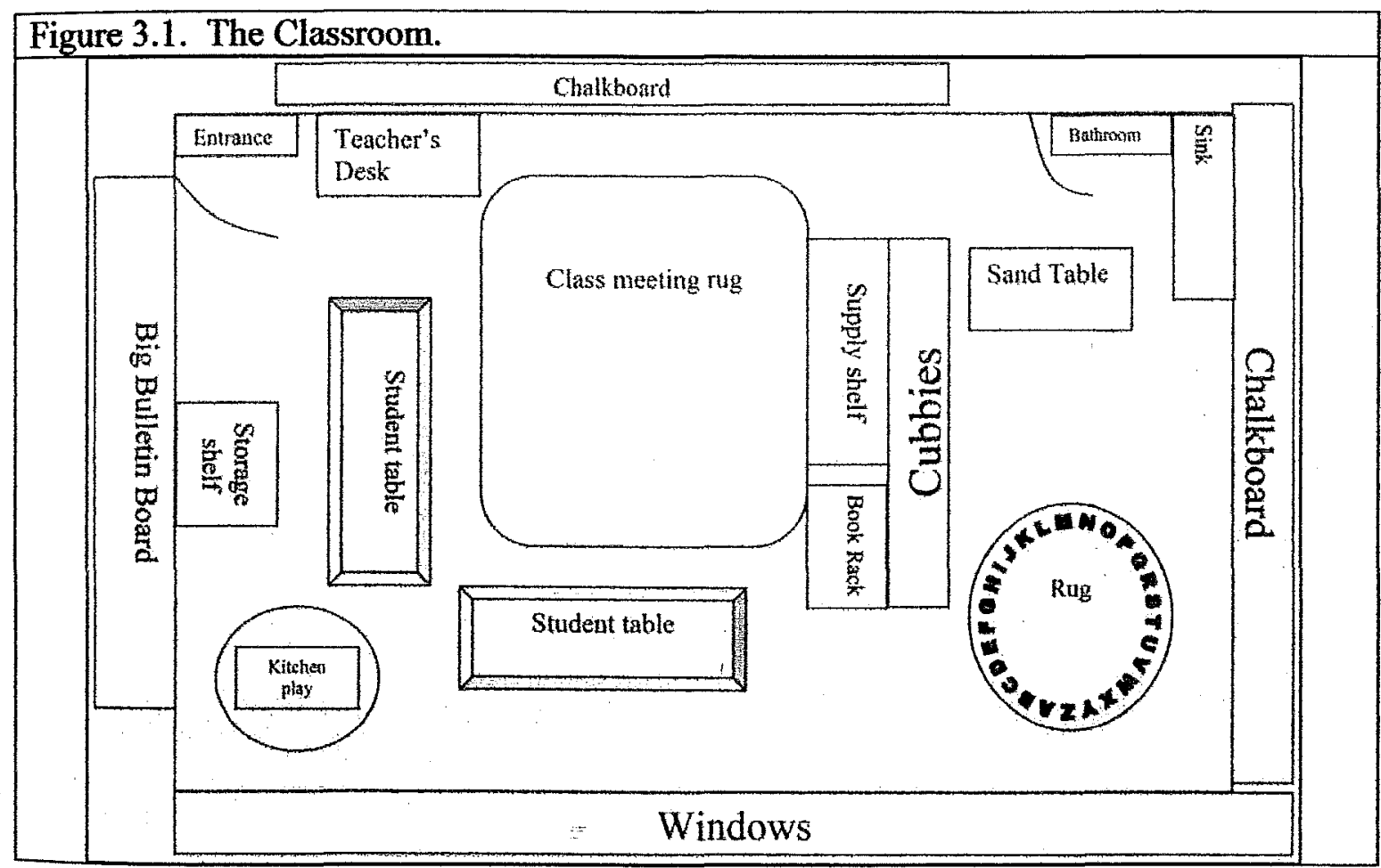

The teacher, Ronda, has been an early childhood educator for eight years. She teaches writing to her students by creating a writers workshop (Fletcher and Portalupi, 2000). She creates a classroom experience that begins daily when she gathers her 
students and reads a book to them in an interactive discussion format. Then, she presents a writing demonstration for the students. This demonstration is interactive; the children discuss the teacher's writing as she is in the process of composing. Following the writing demonstration, the students are encouraged to share their own writing ideas with peer partners or the entire class. Next, the teacher asks the children to move to tables where they write. During this time they interact with each other while they are in the process of composing. Finally, children are asked to more formally share their writing with the class by describing their written productions. Because the teacher encouraged social interaction to occur in the classroom during writing instruction, I chose this site for the study. I was able to observe, record, and identify the social interactions that occurred within this group of pre-kindergarten writers and learn about the influences of their interactions on their writing.

There were sixteen students involved in the research study. The grant associated with the classroom required that the children be members of families with financial, emotional, or learning needs in order to participate in the pre-kindergarten program. Nine students were male, seven female. Of the 16 students, 11 were African-American, two were Caucasian, and two were Latina (Table 3.1). 


\begin{tabular}{|l|l|l|}
\hline \multicolumn{3}{|l|}{ Table 3.1. Profile of the Children who Participated in the Study } \\
\hline Name (Pseudonyms) & Sex & Ethnicity \\
\hline Arianna & Female & African-American \\
\hline Cathie & Female & African-American \\
\hline Chars & Male & African-American \\
\hline Frank & Male & African-American \\
\hline Jibir & Male & African-American \\
\hline Josephina & Female & Latina \\
\hline Kallen & Male & Caucasian \\
\hline Katalina & Female & Latina \\
\hline Kendrick & Male & African-American \\
\hline Lisa & Female & African-American \\
\hline Malcolm & Male & African-American \\
\hline Pierson & Male & Caucasian \\
\hline Roderick & Male & African-American \\
\hline Talisha & Female & African-American \\
\hline Te-Loni & Female & African-American \\
\hline Travion & Male & African-American \\
\hline & & \\
\hline
\end{tabular}

\section{Definition of Terms}

The following definitions of terms are provided in an effort to delineate the meaning of words used throughout the dissertation.

Gathering experience: A period of time in the classroom when the teacher gathers the children together on a circular carpet. During this time, the teacher typically reads a story and engages children in conversations about its content.

Teacher writing demonstrations: A period of time in which the teacher writes in front of her children. During this time, the teacher constructs a piece of text with the assistance of her students. Students typically interact with the teacher as she writes. The teacher also explicitly notes strategies she uses as a writer with the intention that children will integrate similar strategies into their own writing. 
Read-aloud: A classroom experience in which the teacher reads a child aloud to a group of children. During this time, students respond to the read-aloud by asking questions or making comments.

Student interactions: A verbal or non-verbal exchange among students as they are engaged in the process of writing. Typically, these interactions occur when students make comments or offer suggestions to peers during writing. Oftentimes, these interactions are non-verbal as students watch the writing efforts of their peers and mirror their symbols or ideas into their own writing.

Personal recount: A piece of writing that tells the reader something that happened in the life of a writer.

Imaginary story: A fictional piece of writing in which the writer tells a fantasy story or a story that did not happen in real life.

Informational text: A non-fiction piece of writing in which the writer states facts and main ideas about a particular subject.

Letters writing: A piece of writing in which a writer corresponds to another person via a postal letter.

Research writing: A piece of writing in which the writer queries another writer about his/her writing and records the response.

\section{Data Gathering Methods}

Observations of the class, interviews with the students and teacher, and written documents of the students were the primary sources of data collection. Between August and November, I collected data in the classroom three times a week for three hours each visit (Table 3.2). I observed the students as they engaged in all the writing experiences 
listed previously, and wrote fieldnotes while I observed. I audio-recorded and transcribed the conversations that took place among the children while writing and in their lessons with the teacher. At the end of each research day, I elaborated on my field notes, and wrote an analytic memo describing the themes that emerged from the collected data (Miles \& Huberman, 1984). These field notes were filed with the transcribed interactions of the class and the scanned copies of the children's writing.

\begin{tabular}{|c|c|c|c|c|c|c|c|c|}
\hline \multicolumn{9}{|c|}{ Table 3.2. Timeline of Study } \\
\hline Project Activities & $8 / 05$ & $9 / 05$ & $10 / 05$ & $11 / 05$ & $12 / 05$ & $1 / 06$ & $2 / 06$ & $3 / 06$ \\
\hline Establish Procedures & $\mathrm{X}$ & & & & & & & \\
\hline $\begin{array}{l}\text { Teacher and Student } \\
\text { Informed Consent }\end{array}$ & $\mathrm{X}$ & & & & & & & \\
\hline $\begin{array}{l}\text { Data Collection: } \\
\text { Observations, } \\
\text { Interviews, Document } \\
\text { Collection }\end{array}$ & $\mathrm{X}$ & $\mathrm{X}$ & $\mathrm{X}$ & $\mathrm{X}$ & $\mathrm{X}$ & & & \\
\hline Data Analysis & $\mathrm{X}$ & $\mathrm{X}$ & $\mathrm{X}$ & $\mathrm{X}$ & $\mathrm{X}$ & $\mathrm{X}$ & & \\
\hline $\begin{array}{l}\text { Writing about } \\
\text { Findings }\end{array}$ & & & $\mathrm{X}$ & $\mathrm{x}$ & $\mathrm{x}$ & $\mathrm{X}$ & $\mathrm{x}$ & $\mathrm{X}$ \\
\hline $\begin{array}{l}\text { Discussion of } \\
\text { Findings at } \\
\text { Conferences and } \\
\text { Presentations }\end{array}$ & & $=$ & & $\mathrm{X}$ & & $\mathrm{X}$ & $\mathrm{X}$ & \\
\hline
\end{tabular}




\section{Observations}

During each research day, I systematically recorded the events of the prekindergarten classroom as I observed their interactions. I arrived at the classroom as the school day began and observed the children as they conferred during breakfast. Following breakfast, the teacher typically gathered the children together and conducted a classroom experience. These experiences were comprised of a scripted language program, read-alouds with conversations, and teacher demonstrations of writing. For the latter, the teacher discussed writing ideas with the class, and then wrote on a chart tablet or bulletin board in front of the students. They talked with her as she composed.

Following the demonstration, the children shared their writing ideas with the class before composing at tables. As they composed, the children often shared ideas and engaged in conversations with peers. After composing, the children shared their work with others.

I observed these interactions each time I was in the research site, and noted high and low inferences when I analyzing my detailed field notes. Verbal and non-verbal acts of the students and teacher were included to provide a full picture of the events that happened.

\section{Audio-recording}

With an audio-tape recorder I recorded the discussions among the children that occurred during the read-alouds, the teacher's demonstration lessons, and among them at the tables. I transcribed and included them in the field notes written at the end of each research day.

During read-alouds and teacher demonstrations, I sat on the carpet with the children as they engaged in the lessons, and recorded the talk. As the students talked, I 
noted their names and topic of discussion in my field note journal to use as a reference during transcription. I then added these transcribed exchanges to the field notes.

During the teacher's lessons, I sat to the side of the teacher so I could see the faces of the students. I placed the audio-recorder by the teacher so her words would be clear. As students engaged in classroom conversations during the lesson, I noted the names of the children who talked and wrote some simple notes about the themes of their talk. I used this notation as a reference during transcription. The transcribed recordings were added to the field notes written at the end of each research day and used as a means to develop themes during data analysis.

After the teacher's lesson, as children wrote with their peers at tables, I situated myself in the middle of the students and listened to their conversations. When I noticed particular children engaging in a conversation, I moved closer to the students to capture their talk on the audio-recorder. I transcribed all interactions and added to my field notes at the end of each research day. The themes that emerged from all the interactions I observed are the basis of my findings.

The data is not comprehensive; it was impossible to capture all the talk that occurred in the classroom. There were groups and pairs that talked simultaneously. During these instances, I devised a system that required me to consider all the students in the classroom. On each research visit, I limited my observations to one table of students as they talked to each other. On subsequent days, I guided my attention towards other groups of children. By the end of each research week, I maintained a tally of the children I observed during their social interactions with peers. To ensure that I observed all the 
children, I made conscious decisions to observe any students I had missed during the previous week.

\section{Interviews}

After students finished their compositions, I conducted a short 2-3 minute interview with each child in which they explained the meaning of their writing. Because their oral language proficiency is developing, I had difficulty understanding the full meanings of their writing, but made every attempt to understand their meaning by asking follow-up probes. I recorded and transcribed these short interviews. During my fieldnote write-up, I transcribed the interviews and combined them with scanned copies of the students' writing. I used these determine themes that emerged during analysis.

I conducted three formal interviews with the teacher, each for approximately 30 45 minutes, during the months of August, October, and December, using an ethnographic interview model (Spradley, 1979). I asked Ronda several open-ended questions to explore the complexities of her thoughts regarding the class and her background experiences, and I asked several follow-up probes to gain deeper understandings of her answers. I recorded, transcribed, and analyzed these interviews.

I also engaged in several informal conversations with the teacher during each visit. These were conversational in tone and were used to collect information about her current thoughts, feelings, and moods. These exchanges were not recorded but they were noted in the write-up of field notes and used during data analysis.

\section{Document Collection}

I collected writing samples produced by the children, scanned them, and uploaded the pictures into my field notes written at the end of each research day. For each child in 
the classroom, I created a file folder where I kept copies of the children's writing, the date, and the child's transcribed explanation of it. Plus, I noted themes that occurred in their writing. Additionally, I included a brief summary of the social interaction that occurred during the production of that text. A small note with these four things were stapled to the back of the work and assigned a document number to use during my recurring analysis. This documentation proved helpful when further analyzing and writing the findings. The time I spent collecting documentation with the various participants are documented in Table 3.3.

\begin{tabular}{|c|c|c|c|}
\hline $\begin{array}{l}\text { Project } \\
\text { Activities }\end{array}$ & Brian Kissel & Classroom Teacher & Students \\
\hline $\begin{array}{l}\text { Establish } \\
\text { Procedures }\end{array}$ & $\begin{array}{l}40 \\
\text { (Preparing and writing the } \\
\text { Research Proposal) }\end{array}$ & & \\
\hline $\begin{array}{l}\text { Teacher and } \\
\text { Student Informed } \\
\text { Consent }\end{array}$ & $\begin{array}{l}\text { (Preparing forms and } \\
\text { distributing them to the } \\
\text { participants) }\end{array}$ & $\begin{array}{l}10 \text { minutes } \\
\text { (Reading and consenting to } \\
\text { study) }\end{array}$ & $\begin{array}{l}15 \text { minutes } \\
\text { (Parents will read consent } \\
\text { form and decide to } \\
\text { consent or not consent) }\end{array}$ \\
\hline Data Collection: & $\begin{array}{l}96 \\
(9 \text { times a week for } 2 \text { hours over } \\
\text { four nonths) }\end{array}$ & $\begin{array}{c}3 \\
\begin{array}{c}\text { (Three one-hour formal } \\
\text { interviews) }\end{array}\end{array}$ & $\begin{array}{l}\text { Approx } 5 \text { hours per } \\
\text { student } \\
\text { (Students will be asked } \\
\text { about their written } \\
\text { productions for } 23\end{array}$ \\
\hline Data Analysis & $\begin{array}{l}\text { (8 hours a week over seven } \\
\text { nonths) }\end{array}$ & $\begin{array}{c}8 \\
\text { (2 hours a month over four } \\
\text { months for member } \\
\text { checking) }\end{array}$ & \\
\hline $\begin{array}{c}\text { Write } \\
\text { Dissertation }\end{array}$ & $\begin{array}{l}560 \\
(20 \text { hours a week for seven } \\
\text { nonths) }\end{array}$ & & \\
\hline $\begin{array}{l}\text { Submit Proposals } \\
\text { for conferences }\end{array}$ & $\begin{array}{c}30 \\
\text { (3 hours a day for two months) }\end{array}$ & & \\
\hline Total Hours & 951 hours & $\begin{array}{l}11 \text { hours } \\
10 \text { minutes }\end{array}$ & $\begin{array}{l}5 \text { hours } \\
15 \text { minutes per student }\end{array}$ \\
\hline
\end{tabular}




\section{Data Analysis}

Using the interpretivist paradigm, I determined the events that appeared to influence the pre-kindergarten writers. I attempted to understand the multiple events of the classroom. Through constant analysis, I began to see how these events made an impact on the writers. I created an account of the interactions that surrounded the production of each piece of writing, which established the warrant for the particular products (Erickson, 1986). I used content analysis to analyze the data; I identified, coded, and categorized the influences (Patton, 2002). These influences are systemically analyzed and reported in the findings.

\section{Organizing Data}

Throughout the study I collected observations, interviews, and written documents. I created a file containing all the collected data: the field notes, transcriptions of interactions, transcriptions of interviews, scanned writing documents, and analytic memos (Table 3.4). 
Table 3.4. Example of File Containing the Collected Data

November 28, 2005: 1

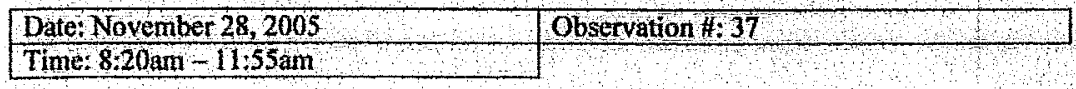

Part I. What are the Social Interactions that Occur in the Classroom?

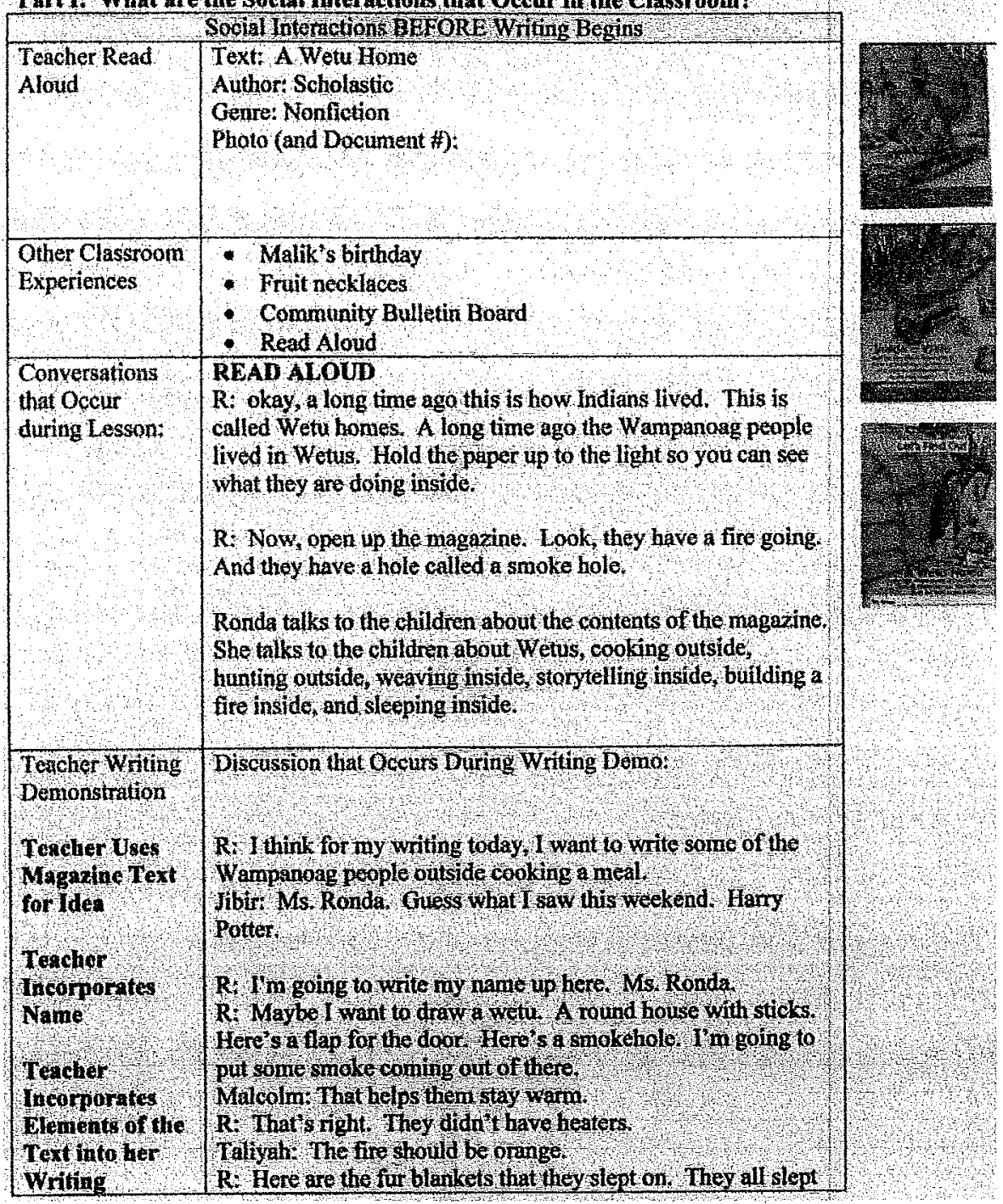

The field note document had three columns to organize the data. The middle

column included the events that happened during the day. These included transcribed

conversations and observations and high and low level inferences. In the left column, 
codes were used to denote categories and themes of the data collected. The third column included scanned copies of the read-aloud texts, the writing demonstration of the teacher, and student writing.

Throughout the data analysis process, I wrote analytical memos as a method of consolidating my thoughts and finding emerging themes that emerged. At the end of each day, I wrote an analytic memo to help clarify my understanding of the meaning students assigned to their writing (Table 3.5).

Table 3.5. Example of an Analytic Memo.

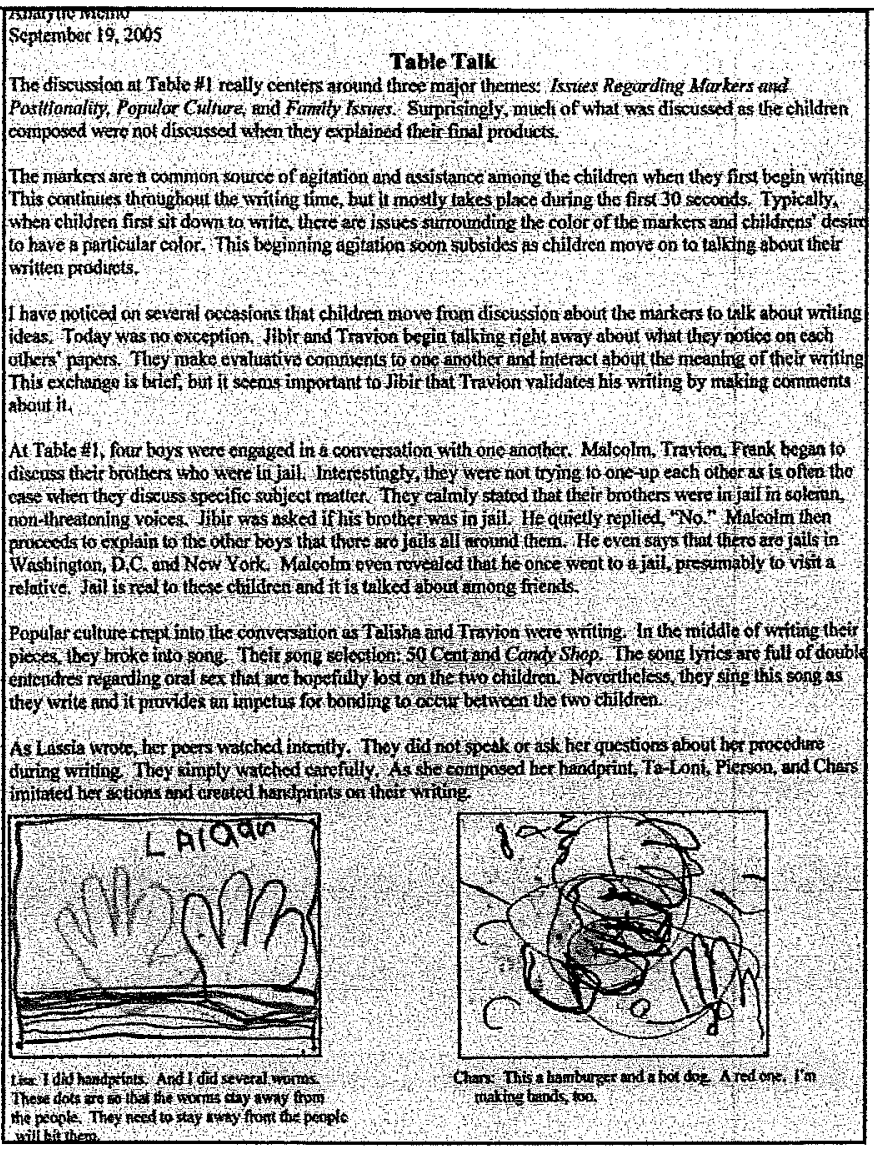

For each child, I created a separate data sheet to analyze their writing (Table 3.6).

I included the child's name, date of writing, document number, themes that emerged from 
the product and process, the child's description of its meaning, possible influences, and analytical notes.

TABLE 3.6. Example Data Sheet of Student Writing

October $3,2005 * 16$
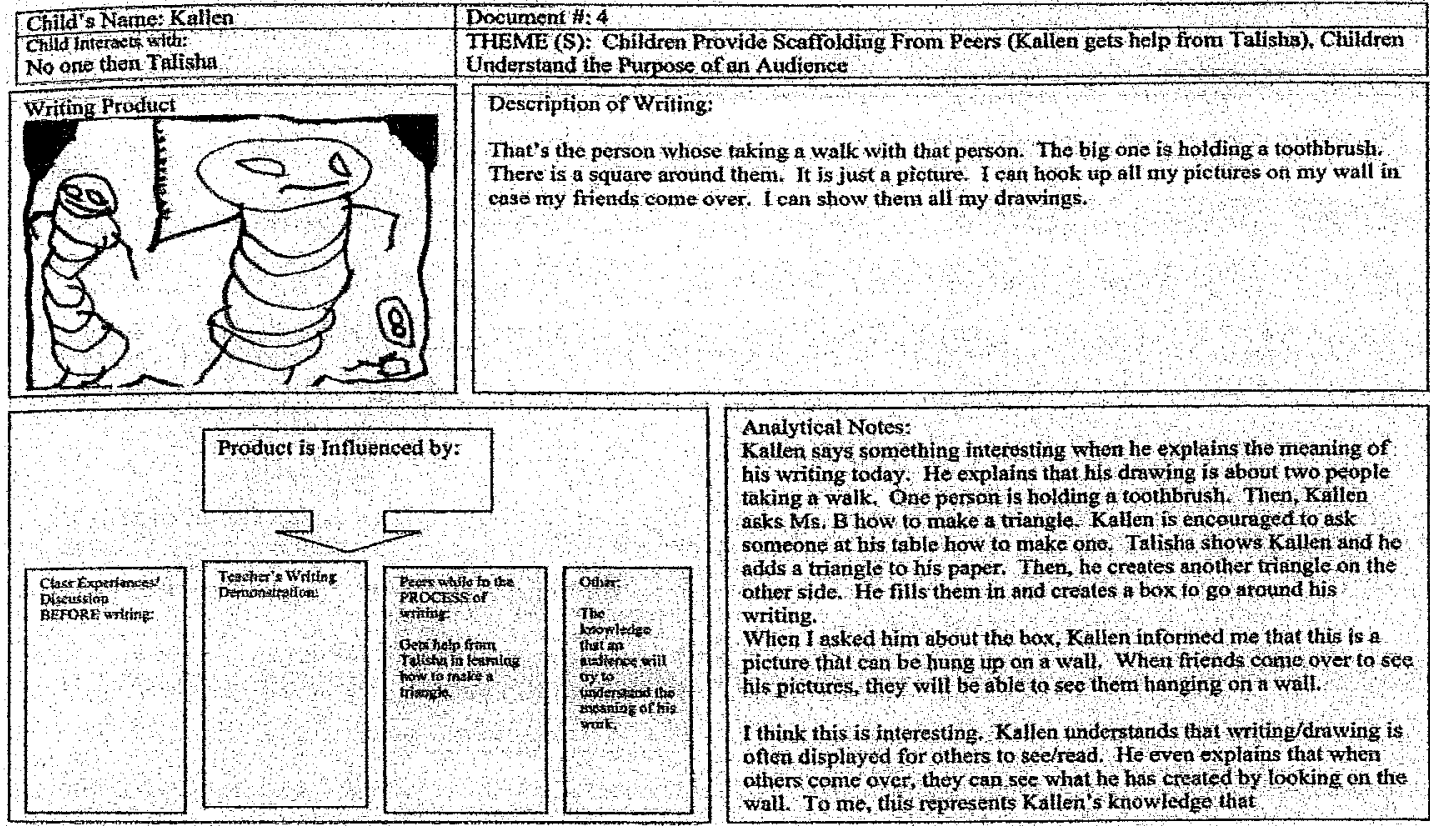

Aralytical Notes:

Kallen says something fateresting whon he explatns the meaning of his writing today. He explains that his drawing is about two people taking a walk, One person is holding a toothbrush Tien Kallen akks $\mathrm{ks}$, a to to moke triand katlen is enceuraged to ask

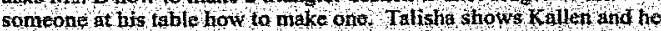
ahts a tiangle to his paper. Then, he creates another tringle on the other side. He fills them in and creates a box 10 go around his writing.

When I asked him about the box Kollen informed me that thit is a picture that can be huag to on a wall, whien frends domio over to see his pictures, they will be able to see the minging on a wall

Ithin this is interesting, Kallen understands that writhg/dnawing is ofter displayed for others to seefread. He even explains that when others come over they cap see what he has created by looking on the wall To me, this represents Kallen's know tedgo that

\section{Generating Categories and Themes}

Data analysis was ongoing and recursive. Each day, I looked through the data and noted emerging categories and themes that arose from the observations, interviews, and documents. I coded these categories and themes into a data sheet (Table 3.7). As subsequent data were collected, I assigned the data an additional code or incorporated the data into pre-existing codes. This data record allowed me to reduced my data into a manageable chart and allowed me to quickly reference what I observed on a given day. 
TABLE 3.7. Example Data Sheet of Student Writing

27

DATA RECORD:

Date, September 19,2005 Observation \#: 12

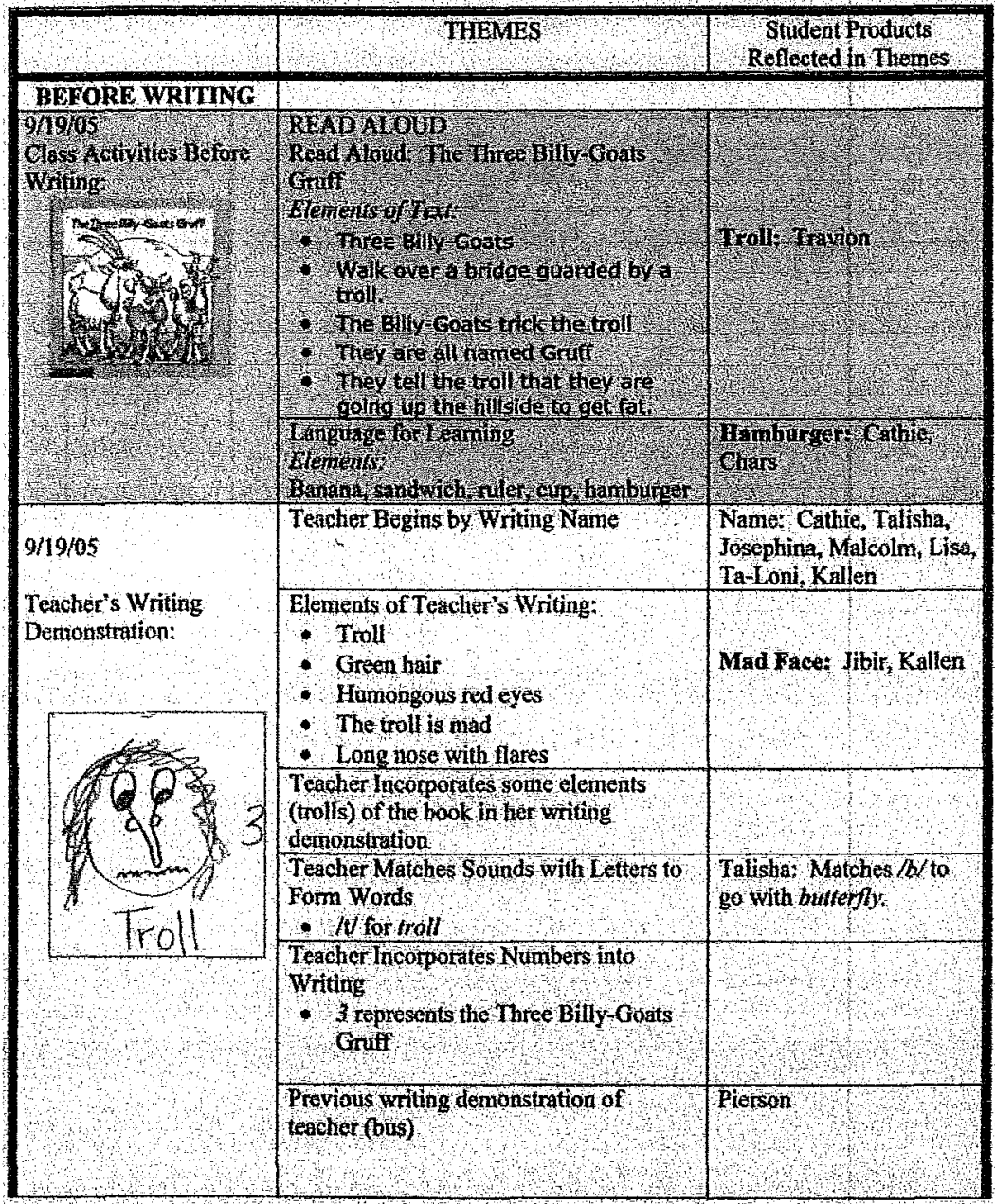

\section{Testing Emergent Understandings}

As the categories and themes emerged, I negotiated back and forth throughout the data to find confirming and disconfirming instances of social influences and how these influences affected the students' writing. I continued to find alternative explanations as I pored through the data. Since the pre-kindergarten children do not typically have a fully functioning verbal register to explain their written products, it was challenging to 
ascertain the full meanings of their written work. Because of this, I put forth, in my findings, examples of student writing that clearly shows the connections between a particular social interaction and a child's writing product.

\section{Trustworthiness of Research Design}

There is an ongoing debate regarding the criteria that should be used to judge qualitative research. For the purpose of this study, I have chosen to use the trustworthiness approach established by Lincoln and Guba (1984). According to them, trustworthiness is a hallmark of qualitative research and is achieved by using four criteria to ensure rigor: credibility, dependability, transferability, and confirmability. The following components will be examined to describe how I plan to ensure trustworthiness in my proposed study.

\section{Credibility}

To obtain credibility, I describe the participants, provide explanations of their writing, and explain the context in which their writing was created. In so doing, the descriptions and interpretations would be recognized by those sharing the experiences of the group being studied (Krefting, 1999).

Also, I attempted to ensure credibility by spending four months in the field, three days a week for three hours each visit. These prolonged engagements in the field exposed patterns that may not have emerged with a shorter data collection period. Triangulation of data sources was used so that I could have a convergence of multiple perspectives. Observations, interviews, and document collection provide cross-check data needed during the interpretation. Member checks occurred through three different sources. The teacher provided one means of member checking. She received my written 
field notes containing the writing of the children and provided, for me, her interpretations of the data. A second source of member checking was the students. After they told me about their written texts, I recited back what they had said. This ensured that I properly understood the meanings they chose to tell me. Finally, a research team studying writing provided an additional member check. I met weekly with that group of writing researchers to discuss my findings.

\section{Transferability}

In qualitative research, generalization is not necessarily applicable. Each site and the participants within the site are unique. Measures, however, were taken so the data were sufficiently presented to allow comparison with other sites. This was done by providing thick description of the research site and participants (Geertz, 1973). Throughout the findings section of my dissertation, I provide extensive examples of field notes, transcripts from interviews, and examples of documents collected. These examples provide the readers with the necessary information to establish their own independent conclusions.

\section{Dependability}

According to Lincoln and Guba (1985), it is impossible to achieve credibility without dependability. For dependability, I provided dense description of my research methods so that other researchers may be able to repeat the path I took to understand prekindergarten writing. These descriptions of the research methods provide information to the reader regarding the uniqueness of the situation.

Within my field notes, I make note of research decisions I made that influenced the data (Table 3.8). For this study, I maintained a reflexive journal in which I 
specifically noted decisions I made as a researcher and my interpretations of the data collected. I wove these journal entries within my fieldnotes. In addition, I include methodological challenges or decisions I made as challenges arose within the site.

Table 3.8. Example of Reflective Journal Entry

October 5,2005

Reflective Journal Entry

Today was a tough day. Language for Learning lasted 20 minutes and the children seemed off-task. Kendrick was particularly agitated this morning. He was distracted and was a distraction throughout the Language to Learning time.

N., the preschool evaluator, was in Ronda's classroom today. She made notes throughout the lesson.

After Ronda's lesson I talked to her about Language for Learning. We discussed the pros and cons of this curriculum. As a researcher, l think I infringed my opinions of the program. I told Ronda that I noticed that the children were off-task. I also told Ronda that it seemed to go very long. Then, I wondered aloud if reading a book would be a better way to transition into writing. It scems the children are stagnant in their writing ideas and a read aloud book may be helpful in giving children altemative ideas for writing.

As soon as I said all this to Ronda, I regretted it. I should not have spoken to her about this. It is her classroom. I am Just an observer. I fear that I embarrassed Ronda. Now I worty that 1 will lose access to Ronda because of this blunder.

I apologized to Ronda profusely about this exchange. I told her that I didn't know if I stould say anything. She told me that everything 1 said aloud were things that she has been thinking about. She also said that she appreciates when I say something because it is constructive.

I don't think Ronda was particularly offended by my statements. However, as a researcher, I feel that I may have crossed the line. I also think the research will be changed now that she is going to do a read aloud in front of the class rather than Language for Learning. Hopefully this will be a positive change. 


\section{Confirmability}

Confirmability allows the researcher to bring his/her own unique perspective to the study (Lincoln and Guba, 1985). I established confirmability in this study as I explicitly detailed my stance as a researcher, acknowledged my influence on the research, revealed my personal interest in the study, and sought confirmation from other researchers.

Additionally, I sought confirmability from a number of sources. I conducted member checks with the participating teacher to ascertain her understandings of the data. Next, I consulted with my advisor who served as a cross-check of what I found in the field. Results of my findings were discussed at conferences and research talks where researchers asked questions regarding my findings and provided alternative explanations.

The results of my data were corroborated by others through my involvement in a research team studying child writers. Jane Hansen led the research team that studied the writing of children from pre-kindergarten through high school. The research team met weekly to discuss data collected in the field and to provide an explanation of their findings. These explanations, which were read aloud to the group, were written in onepage analytic memos to accompany a piece of student writing (Table 3.9). The other research members provided feedback to the researcher concerning other possible interpretations or meanings of the data. 


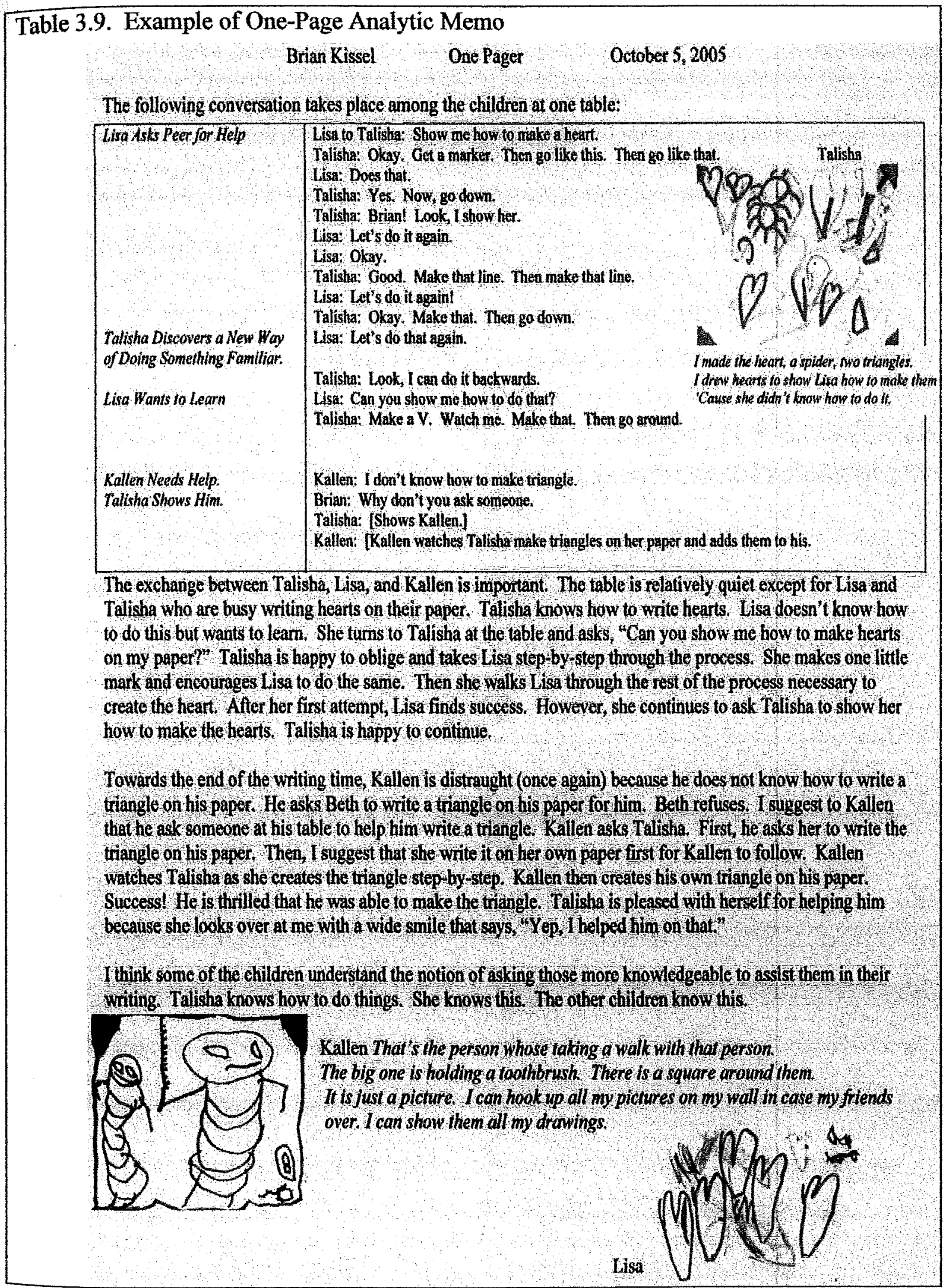




\section{Ethical Considerations}

I considered several ethical issues as I planned, conducted, and concluded this dissertation study. Confidentiality of the participants, an exit strategy for myself, anticipation of sensitive topics, and member checking with the teacher were four areas that merit consideration.

To protect the participants in the study, all real names were assigned pseudonyms. Audiotapes were transcribed each day and recorded in the field notes using pseudonyms. After each tape was transcribed, it was destroyed. All research documents were kept in locked file cabinet in my home and no one else had access to them. It was impossible to conceal the identity of all the participants because of the nature of their writing. In many cases, the writing was altered slightly to conceal the names of the participants. I did not, however, change any of the symbols, images, print, ideas, or meanings of the other aspects of their writing.

Because young children frequently become attached to the people they see often in their lives, I prepared them for my exit from the field. I reminded students throughout the study that I would leave their classroom at the end of December. At least one month before exiting the site, I reminded students during each visit that I would be leaving soon.

\section{Personal Interest in Study}

I began my career as a second grade teacher. I taught third grade when I moved with a class of students to a new grade level. During the year that I taught third grade, I was asked to participate in a comprehensive literacy training seminar. Designed and implemented by the National Center of Education and the Economy, I received 
specialized training in reading and writing practices. I was responsible for implementing the reading and writing models in my classroom, and other teachers and administrators in Jacksonville, Florida, observed my teaching practices. Essentially, my classroom was used as a testing ground to monitor the success of the literacy models, and teachers received weekly professional development through observations of my teaching lessons.

The following year, I was asked by the principal to leave my classroom and provide professional development throughout the school. She was especially interested in my willingness to assist teachers in developing writing workshops in their own classrooms. I was responsible for working with third, fourth, and fifth grade teachers as we developed classrooms that were conducive to writing. I spent approximately six weeks with each teacher and I taught them specific strategies that they could use in the classroom to support writing instruction. While resisting initially, the teachers at the school eventually acknowledged the benefit of implementing writers' workshops and their efforts did not go unnoticed. At the end of the 2000-2001 school year, the school received the highest writing grades in a district of approximately 100 elementary schools. This was a remarkable feat for a school considered "poor and low-achieving."

The following year, I left the school to work at the Florida Institute of Education (FIE) at the University of North Florida. In 1997, FIE created an Early Learning and Literacy Model (ELLM) that was implemented in several preschools throughout the Jacksonville area. When I joined the organization in 2001, the model was expanding to over 200 preschools in the poverty-stricken areas of the city. I served as a literacy consultant and worked with several teachers throughout the area to help them design experiences that promoted literacy in their early childhood classrooms. 
In my role as a literacy consultant assisting preschool teachers, I expected to find some of them teaching writing to their young students. Unfortunately, I noticed very few writing events occurring in the classrooms. Often, paper was not provided for students to write, writing instruments were not readily available, and teacher demonstrations of writing were nonexistent. Most times, when children were encouraged to "write," the teacher distributed lined paper with letters on it for the children to copy and trace. This handwriting instruction was hardly the message-making productions encouraged in the recent research literature. I was disturbed by this discovery and began to think of different ways to improve writing instruction in early childhood classrooms.

I noticed a dire need for increased attention in the area of writing instruction. As part of my job, I was responsible for finding research articles focusing on writing in preschool classrooms. I was constantly frustrated with the lack of research done in this area and the lack of knowledge preschool teachers had regarding this instructional practice. With much chagrin and a supportive push from my colleagues at the Florida Institute of Education, I decided to leave my position in 2003 to pursue a graduate degree that would allow me to conduct further investigation into early childhood writing.

As a doctoral student at the University of Virginia I have thoughtfully studied the literacy endeavors of pre-kindergarten children. During the 2004-2005, one year before my data collection for my dissertation, I spent a transformative year studying the writing acquisition of the pre-kindergarten classroom I would later use as my dissertation site. My experiences in this classroom monumentally changed the way I view young writers and led to my interest in the following study. 


\section{CHAPTER FOUR}

\section{RESULTS}

In this study I researched influences of social interactions on the writers in one prekindergarten classroom during the first four months of their school year. Specifically, I: a) identified the social settings in which interactions occurred that influenced the young writers; b) explored how those social interactions influenced the meaning-making of the children as they wrote, and c) determined the meanings of the children's written products. These questions guided my inquiry:

1. What are the settings in which social interactions occur in one prekindergarten classroom during writing instruction?

2. In what ways, if any, do these social interactions influence the children's writing processes?

3. In what ways, if any, are these social influences manifested in the written products of the pre-kindergarten children?

Analysis of the data revealed three main findings (Table 4.1). These findings illustrate the importance of the teacher's read-aloud, demonstrations, and student interactions while writing. Specifically, these findings show how children were influenced by the read-aloud, demonstration, and interaction with peers when they made decisions in their writing. 


\begin{tabular}{|l|l|}
\hline \multicolumn{2}{|l|}{ Table 4.1 } \\
\hline Findings from Data Analysis \\
\hline Second Finding & $\begin{array}{l}\text { The read-aloud experiences influenced the child writers. } \\
\text { The teacher's writing demonstrations that occurred before } \\
\text { children wrote influenced the child writers. }\end{array}$ \\
\hline Third Finding & $\begin{array}{l}\text { The peer interactions that occurred among the children while } \\
\text { they were in the process of writing influenced them as writers. }\end{array}$ \\
\hline
\end{tabular}

\section{First Finding}

The read-aloud experience influenced the child writers.

\section{Vignette 4.1}

Ronda gathers the children together on the circular carpet inscribed with alphabet letters. Each child finds a suitable letter of the alphabet and sits "criss-cross applesauce." As they wait for Ronda's direction, they take advantage of the opportunity to talk with friends, argue, jockey for position on the carpet, and hum. Silently, Ronda sits on her padded rocking chair, looks at the children, and pauses. Several students notice that she is ready to begin and the murmurs begin to dissipate. Holding a stack of magazines daintily in her lap, she looks into the eyes of each child as they take note of her body language. The class is quiet. It is time to read.

Ronda begins. "Okay, I have new Scholastic magazines for everyone to read today. I would like for you to take one and pass the rest along to your friends. The magazine is about pumpkins today."

Noticeable smiles cross the faces of the children and their tiny legs begin to bounce up and down in anticipation. Slowly, copies of the magazine are passed from student to student. Students at the latter end of the circle grow impatient as they yearn 
for their own individual copy of the magazine. Ronda asks the children to quickly pass the magazines around so that everyone can have their own copies.

When all the magazines are distributed, Ronda gives the children a couple minutes to look at the contents. They notice a man planting seeds in one photograph and rows of plants in the next. On the third picture, a yellow flower blooms near a green pumpkin. Malcolm shouts, "Oh! A flower!" The fourth and fifth pictures of the magazine show an orange pumpkin followed by rows of already-picked pumpkins. The children, magazines in hand, turn to one another and talk, pointing at the pictures and announcing what they see. They interact with one another as they interact with the text.

The lesson begins.

Ronda: Let's look at the cover of this magazine. Everyone turn to the cover. Children: [Flip their magazines to the front and notice a young girl on the cover holding a pumpkin that is as big as her head.]

Ronda: What is the little girl holding?

Children: A pumpkin!

Ronda: Does it look like it weighs a little bit or a lot?

Children: [loudly] A lot!!!

Ronda: Why do you think it looks like it weighs a lot?

Talisha: 'Cause it big and it look heavy.

Ronda: And look how she's standing. She's standing back like she is having trouble standing up. Right?

Children: [audibly] Uh huh.

Ronda: How do you think she feels?

Malcolm: She happy. She can eat it!

Ronda: How do you know she's happy?

Lisa: 'Cause her mouth is going up.

[Transcript 10-07-05]

After allowing children some more time to talk about the picture, Ronda asks the children to notice the print on the cover. Holding her magazine in front of them, Ronda sweeps her finger under the words of the title and says, "Lumpy, Bumpy Pumpkins." Again, she instructs. 
Ronda: This has a little bit of a rhyme on it. Lumpy, bumpy. That rhymes doesn't it? What do you think they are talking about when they say lumpy, bumpy? What do you think is on this picture that would be lumpy and bumpy? Talisha: The pumpkin!

Ronda: That's right, Talisha!

Jibir: Green, orange, orange.

Ronda: It says, 'Watch a pumpkin grow. The pumpkin gets bigger and it turns orange. It's pumpkin-picking time! Which lumpy, bumpy pumpkin would you pick? Let's see some are tall and skinny. Some are short. Put your finger on the one that you would pick.'

Talisha: I would pick the small one.

Ronda: Why would you pick the small one, Talisha?

Talisha: 'Cause I would want the one that's really small.

Pierson: "I love pumpkins."

[Transcript 10-07-05]

After the read-aloud, when the children all go to the table to write, Pierson creates the following piece of writing (Figure 4.1). In a photograph from the text, pumpkins are lined up in rows. Pierson's writing mirrors this element of the read-aloud text. On his paper, he writes ten pumpkins. Seven of the pumpkins are green, one is pink, one is purple, and one is black. Pierson describes his writing. "That's a pumpkin. Ten pumpkins. They are different colors because they are for different people. The pink one is for Talisha. The purple one for Jibir. The black one for Max (his brother)." As he describes his writing, Pierson looks at his friends who are sitting across the table from him. He is proud and a slow smirk emerges on his face. Talisha and Jibir smile back, seemingly happy to be featured players in his writing. Initially, the read-aloud text influences his decision to write about pumpkins on this day. The friends sitting near him precipitated his desire to assign his written pumpkins to individual classroom peers. 


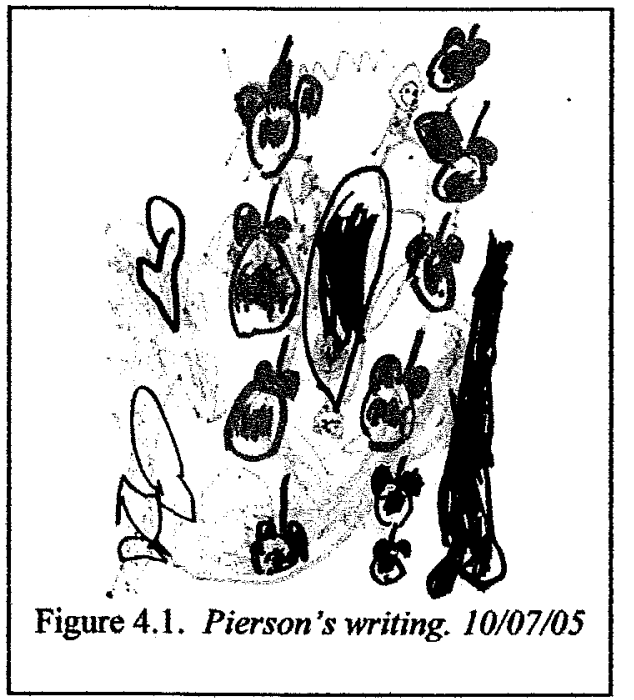

To return to the class when they studied the magazine, we see a photograph of a flower as it emerges from a green, unripe pumpkin still attached to a long, winding vine.

Malcolm is interested in this flower during Ronda's read-aloud. He becomes so excited that he shouts, "Oh, flower!" when he first sees it in the text. When Malcolm writes, he incorporates several of the features of the photograph into his writing (Figure 4.2). He draws vines and green pumpkins emerging from them. When asked about his text, he replies, "Pumpkins. Flower. This is a flower right here." The read-aloud text provides Malcolm with initial interest. Then, he continues to explore this interest when he writes flowers in his own text.

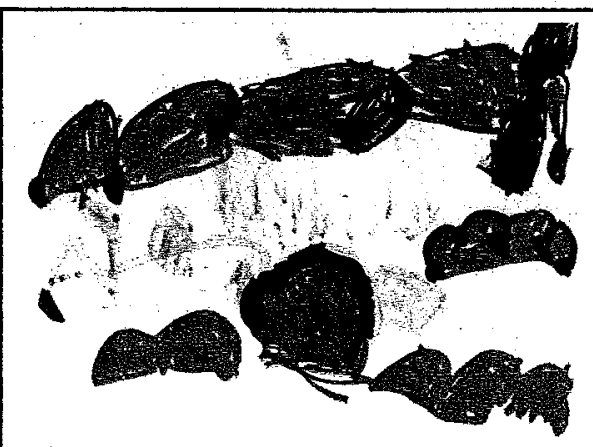

Figure 4.2. Malcolm's writing. 10/07/05 
Jibir was not as confident in his ability to write the symbols he wanted on his page (Figure 4.3). As he wrote, he became frustrated. When he began, he wrote two orange pumpkins on the bottom right of his paper, but was not satisfied.

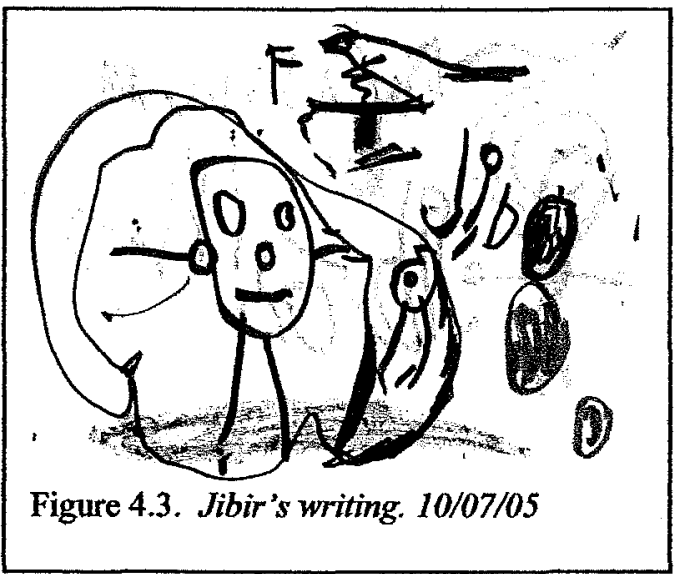

Jibir: I can't make a pumpkin!

Ronda: Your pumpkins look fine. Use the magazine if you need some extra help. Jibir: [Walks over to the small carpet. He grabs a copy of the magazine, opens it to the page that shows a man planting seeds. He continues to write.] Jibir: [Pointing to the figure of the person] That's not me. That's a man. I don't know him. [Using his blue marker, Jibir attempts to make one more pumpkin. This time with a small stem on top.]

Jibir: Look, Ms. Ronda! I made a pumpkin!

[Transcript 10-07-05]

Jibir's frustration leads him to seek support from other sources. At first, he attempts to seek out the teacher for scaffolded support. She directs him back to the read-aloud text. Jibir uses the text to help him convey his meaning.

\section{The Birth of Read-alouds}

Ronda began writing instruction with a gathering experience she used to bring the children together as a community (Table 4.2). The majority (60\%) of these experiences were conducted using a read-aloud text. On these occasions, the teacher gathered the 
children together on the carpet, read to them, and they interacted with her by asking questions and making comments.

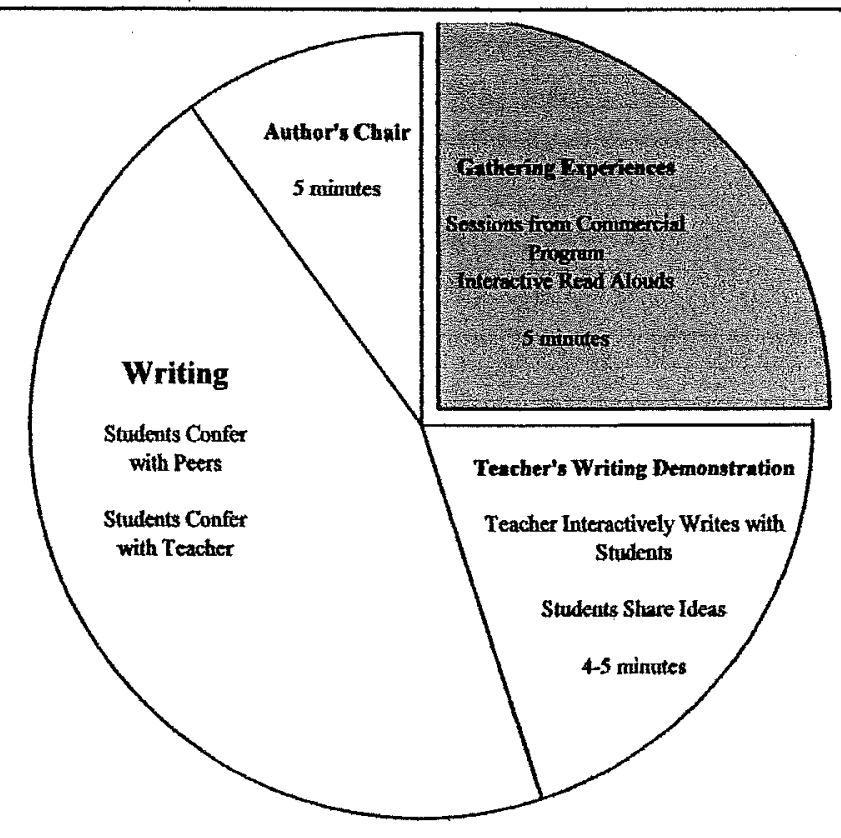

Table 4.2. The Gathering Experience within the Writer's Workshop.

Toward the beginning of the school year, however, Ronda did not read to the class at this time. She conducted the gathering experience by using a scripted language program titled, Language for Learning (Open Court Reading, 2005). During this lesson, the teacher held up pictures of objects in a book and named them. Then, using a signal system, the children repeated the language of the teacher as she pointed to the various pictures. The teacher recited a line, clapped her hands to her legs as a signal, and the children repeated the lines that she said. The lessons lasted approximately 10 minutes and were repetitive exercises designed to help children learn new words. During the first one-and-a-half months of my data collection, the teacher used this program in place of a read-aloud text 13 of 18 times to begin the writing lesson. 
The following excerpt from field notes reveal an epiphany Ronda had in October

after conducting a Language for Learning lesson with her students.

The Language for Learning lesson went much longer than Ronda expected. It dragged on for 20 minutes and the children seemed off-task. Kendrick is particularly agitated this morning. He is distracted and is a distraction throughout the entire Language for Learning time. The other children are antsy as they squirm in their seats and robotically name the objects in the pictures of the book Ronda holds up. The lesson is painfully long and laborious. The children and Ronda seem bored with the lesson. Ronda holds up a picture of a dog. She tells the class to wait for the signal. Then, they all say in unison, "This is a dog." After the children say the line Cathie continues. "I have a dog at home," she says. "He likes to play outside." Ronda interrupts her in the middle of the story. "I'm sorry, Cathie," Ronda says. "We can't tell stories during this time." Then, Ronda pauses, looks at me as I record these field notes, and laughs. Sarcastically, she continues. "This is Language for Learning time. You're not allowed to use your own language."

Recognizing the absurdness of this claim, she starts laughing even louder. She places her Language for Learning script down on the chair and begins writing in front of the children. After the lesson, Ronda talks to me about her concerns with the program. Ronda discusses the pros and cons of the program. She tells me that she is giving it a year to see if it really works.

Ronda asks me, "Do you think reading books would be a better way to begin their writing instruction than Language for Learning?" Immediately, I respond with, "Yes. From my observations I think they get more language from books than this program." Finally, she looks back over the field notes I have given her to use as a member check. She looks carefully at the children's writing. "I don't know if they are really advancing," she says. "I mean, they are writing the same things over and over again." It does seem as though the children are stagnant. They seem to continuously write the same symbols. The Language for Literacy program seems to stunt their writing growth because they are not getting any real ideas for their writing.

[Analytic Memo 10-05-05]

After this day, Ronda never used the Language for Learning program again to begin her writing lessons. Instead, she used read-alouds, conversations, and outdoor experiences as the initial gathering experiences for the writing lessons, with read-alouds as her main method of bringing together her community of writers. 


\section{An Overview of the Read-Aloud Experience}

When Ronda read to the students, she followed a routine (Table 4.3). Instruction began when she held the text upright for all the children to see the cover. In some cases, such as the one described above, all the children had access to their own text. In most cases, there was one copy held by the teacher.

The initial introduction of the text was accompanied by students who made comments about the cover followed by questions about the content. In many instances, the comments and questions children made had nothing to do with the text or its contents. Rather, children used this opportunity to inform the class and teacher about particular aspects of their lives. Ronda allowed for some of the children to share these experiences. Eventually, she quieted the children and began to read the text.

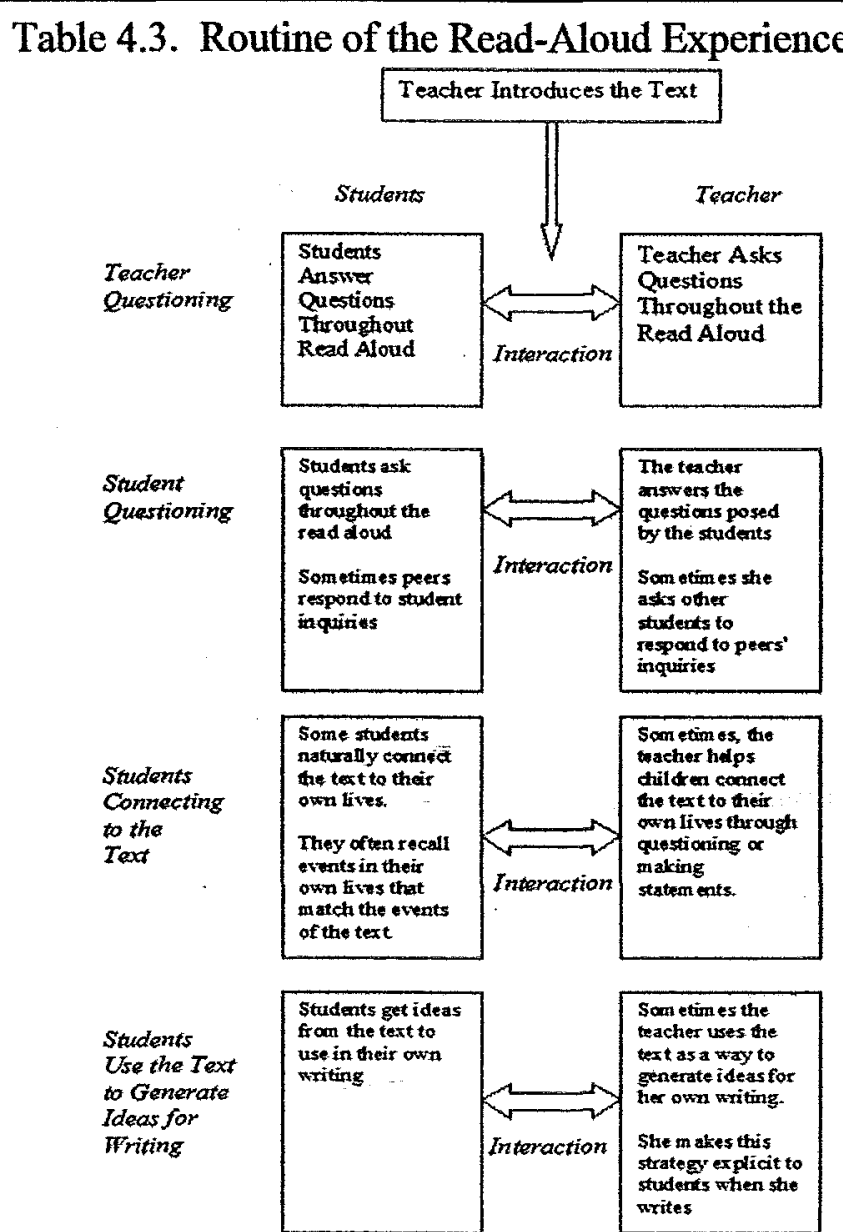


The read-alouds in Ronda's classroom were interactive. The children and the teacher were embedded in a continuous flow of comments and questions. Questions were asked by both parties as the children and teacher participated in a read-aloud tango: a linguistic dance sometimes led by the teacher but oftentimes led by the student. The teacher maintained the pace of the interaction, but the children often dictated its direction. By the end of the read-aloud, the teacher informed children that they could (if they wanted to) use elements of the text as the basis of their own writing. As children wrote, and asked for support to create various symbols to include on their page, the teacher directed them to the book to look for the pictures or words they wanted. In this way, they used authentic texts to glean ideas and information. They also used the read-aloud texts as a support for symbol creation and letter formation. This was done when they asked the teacher for help to create a symbol from the text. She directed them towards the text and encouraged them to use it as a support for the symbol or letter they tried to create.

\section{Frequency of Read-aloud Experiences}

As the year progressed Ronda used read-alouds more frequently and children began to incorporate elements of the those texts into their own writing (Table 4.4).

\begin{tabular}{|l|l|l|l|}
\hline \multicolumn{3}{|l|}{ Table 4.4. Frequency of Read-Aloud Texts During the Gathering Experience. } \\
\hline Month & $\begin{array}{l}\text { Number of } \\
\text { Observations }\end{array}$ & $\begin{array}{l}\text { Number of } \\
\text { writing } \\
\text { experiences } \\
\text { started with } \\
\text { read-aloud }\end{array}$ & $\begin{array}{l}\text { Percentage of } \\
\text { times the teacher } \\
\text { began writing } \\
\text { instruction with } \\
\text { a read-aloud }\end{array}$ \\
\hline August & 4 & 0 & $0 \%$ \\
\hline September & 12 & 6 & $50 \%$ \\
\hline October & 11 & 8 & $73 \%$ \\
\hline November & 10 & 9 & $82 \%$ \\
\hline
\end{tabular}


When Ronda started read-alouds she used fictional texts. As she read she held the texts so children could see the illustrations, and often used them as the catalyst for her own writing idea when she wrote. The children, however, did not do this at the beginning of the year. On only one occasion did a child incorporate forms similar to those in the texts into her own writing.

Josephina, a young Latina girl who spoke little English, listened to Ronda carefully when Ronda read the story Rosie's Walk to the class. In it, a rooster named Rosie walks around town looking for her home. Along the way, a sinister fox follows her in the hopes of eating her for a delicious snack. The story ends when Rosie finds her home and makes it safely inside.

Josephina watched Ronda as she read the text and studied the illustrations intently. On her sheet of paper, she wrote an orange chicken with a worried frown. Then she colored in the chicken using a pink marker. She added feathers all around the chicken to make it look similar to the rooster in the read-aloud text. When asked about her writing, Josephina responded in her quiet, broken English, "Dis the chicken."

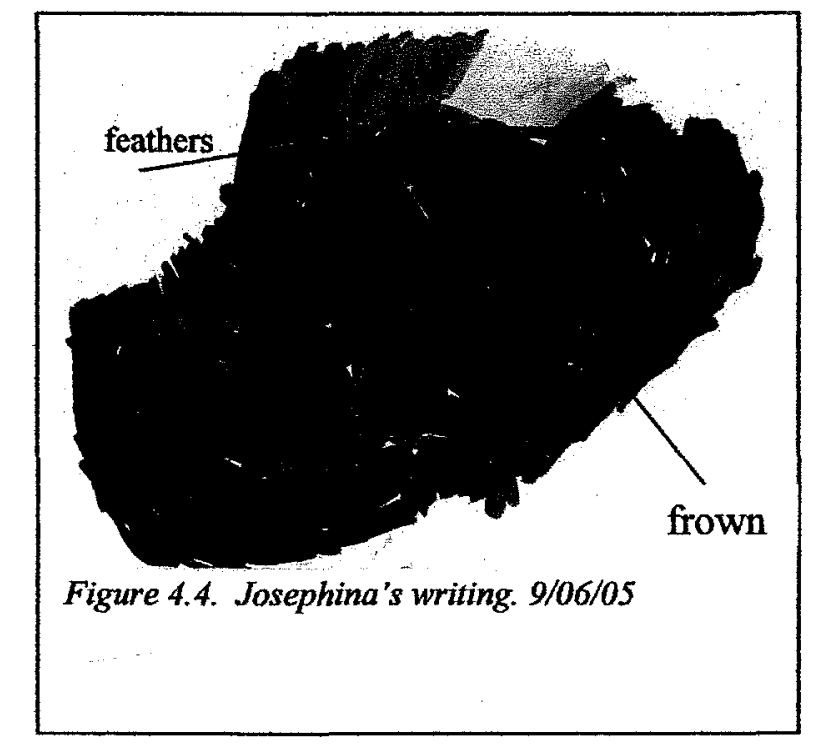


During the first six weeks of school, the children appeared to have their own agendas for writing, and their agendas did not include incorporating elements of the readaloud text.

The read-alouds texts Ronda chose during the early weeks of school were mostly simple, patterned texts and fairytales that focused on characters, settings, problems, and solutions. As the year progressed, Ronda began to read more informational texts during that gathering experience. With this increase in the number of informational texts readaloud, there was a noticeable increase in the number of students who incorporated elements of the read-aloud into their own writing (Table 4.5).

\begin{tabular}{|l|l|c|c|l|}
\hline $\begin{array}{l}\text { Table 4.5. Elements of the Read-Aloud incorporated into the } \\
\text { Student's Writing. }\end{array}$ & & October & November & $\begin{array}{l}\text { Number of } \\
\text { Students } \\
\text { Who } \\
\text { Incorporated } \\
\text { Elements of } \\
\text { Text into } \\
\text { their Writing }\end{array}$ \\
\hline Read-aloud Text & September & the & 2 & 2 \\
\hline Fiction & 3 & 2 & 2 & 0 \\
\hline Folktale/Fairytale & 1 & 1 & 0 & 33 \\
\hline $\begin{array}{l}\text { Informational } \\
\text { Text }\end{array}$ & 2 & 5 & 7 & \\
\hline
\end{tabular}

An analysis of the elements in the read-aloud texts and in the student writing revealed that students were influenced by the read-aloud in two different ways. The readaloud texts influenced students to: a) create symbolic forms in their writing that were similar to the illustrations in the texts and b) incorporate print into their writing that matched the print in the texts. In the next two sections I will show these two influences. 
Children use the read-aloud texts to incorporate symbols of the text into their

writing. In several cases, children used the read-aloud text as a support for specific symbols they wanted to create in their own writing. Table 4.6 displays the read-aloud texts used by the teacher, the text genre, symbols in the text, and the children's symbols included in their texts on that day. The title, author, illustrator, text genre, symbols of the text, and symbols included in student texts display the influence of the read-aloud in the children's writing.

\begin{tabular}{|c|c|c|c|c|}
\hline $\begin{array}{c}\text { Date of } \\
\text { Observation }\end{array}$ & $\begin{array}{c}\text { Title of Text } \\
\text { Author/Illustrator }\end{array}$ & Text Genre & $\begin{array}{l}\text { Symbols in of Text } \\
\text { Illustrations }\end{array}$ & $\begin{array}{c}\text { Symbols } \\
\text { Included } \\
\text { in } \\
\text { Student } \\
\text { Texts }\end{array}$ \\
\hline $8 / 24 / 05$ & $\begin{array}{l}\text { No Read-aloud Text } \\
\text { Before Writing }\end{array}$ & & & \\
\hline $8 / 26 / 05$ & $\begin{array}{l}\text { No Read-aloud Text } \\
\text { Before Writing }\end{array}$ & & & \\
\hline $8 / 29 / 05$ & $\begin{array}{l}\text { No Read-aloud Text } \\
\text { Before Writing }\end{array}$ & & & \\
\hline $8 / 31 / 05$ & $\begin{array}{l}\text { No Read-aloud Text } \\
\text { Before Writing }\end{array}$ & & & \\
\hline 9/02/05 & $\begin{array}{l}\text { No Read-aloud Text } \\
\text { Before Writing } \\
\end{array}$ & & & \\
\hline $9 / 06 / 05$ & $\begin{array}{l}\text { Rosie's Walk } \\
\text { Pat Hutchins }\end{array}$ & Fiction & $\begin{array}{l}\text { Rooster walks around } \\
\text { town. } \\
\text { A fox follows the } \\
\text { rooster } \\
\text { The rooster makes is } \\
\text { safely back to the } \\
\text { henhouse }\end{array}$ & $\begin{array}{l}\text { Chicken: } \\
\text { Josephina }\end{array}$ \\
\hline $9 / 07 / 05$ & $\begin{array}{l}\text { No Read-aloud Text } \\
\text { Before Writing } \\
\end{array}$ & & & \\
\hline $9 / 09 / 05$ & $\begin{array}{l}\text { Mr. Whisper } \\
\text { Author: Joy Cowley } \\
\text { Illustrator: Eric Kincaid }\end{array}$ & Fiction & $\begin{array}{l}\text { A man wants } \\
\text { porridge.. } \\
\text { Mr. Whisper tries to } \\
\text { find a blue cup to } \\
\text { drink soup. }\end{array}$ & None \\
\hline $9 / 12 / 05$ & $\begin{array}{l}\text { No Read-aloud Text } \\
\text { Before Writing }\end{array}$ & & & \\
\hline 9/14/05 & $\begin{array}{l}\text { Cookie's Week } \\
\text { Author: Cindy Ward } \\
\text { Illustrator: Tomie } \\
\text { dePaola }\end{array}$ & Fiction & $\begin{array}{l}\text { A cat lives in a } \\
\text { house and } \\
\text { everywhere he goes } \\
\text { in the house, he gets } \\
\text { in trouble }\end{array}$ & None \\
\hline
\end{tabular}




\begin{tabular}{|c|c|c|c|c|}
\hline \multicolumn{5}{|c|}{ Table 4.6 continued } \\
\hline $9 / 16 / 05$ & \begin{tabular}{|l|} 
No Read-aloud Text \\
Before Writing \\
\end{tabular} & & & \\
\hline $9 / 19 / 05$ & $\begin{array}{l}\text { The Three Billy-Goats } \\
\text { Gruff } \\
\text { Author and Illustrator: } \\
\text { Ellen Appleby }\end{array}$ & Folktale & $\begin{array}{l}\text { There are three } \\
\text { Billy-Goats that } \\
\text { trick a troll }\end{array}$ & None \\
\hline $9 / 21 / 05$ & $\begin{array}{l}\text { No Read-aloud Text } \\
\text { Before Writing }\end{array}$ & & & \\
\hline $9 / 23 / 05$ & $\begin{array}{l}\text { What Do You Know } \\
\text { About Apples? } \\
\text { Author and Illustrator: } \\
\text { Scholastic magazine }\end{array}$ & Informational text & $\begin{array}{l}\text { Apples grow on } \\
\text { trees } \\
\text { Apples come in } \\
\text { different colors }\end{array}$ & None \\
\hline $9 / 28 / 05$ & $\begin{array}{l}\text { I See a Spider } \\
\text { Author and Illustrator: } \\
\text { Scholastic magazine }\end{array}$ & Informational text & $\begin{array}{l}\text { Spider on a flower } \\
\text { Spider on rocks } \\
\text { Spider on a web } \\
\text { Spider on a leaf } \\
\text { Spider has } 8 \text { legs }\end{array}$ & $\begin{array}{l}\text { Spider: } \\
\text { Lisa, Chars, } \\
\text { Ta-Loni, } \\
\text { Roderick }\end{array}$ \\
\hline $9 / 30 / 05$ & $\begin{array}{l}\text { No Read-aloud Text } \\
\text { Before Writing }\end{array}$ & & & \\
\hline $10 / 03 / 05$ & $\begin{array}{l}\text { No Read-aloud Text } \\
\text { Before Writing }\end{array}$ & & & \\
\hline $10 / 05 / 05$ & $\begin{array}{l}\text { No Read-aloud Text } \\
\text { Before Writing }\end{array}$ & & & \\
\hline $10 / 07 / 05$ & $\begin{array}{l}\text { Lumpy, Bumpy, } \\
\text { Pumpkins! } \\
\text { Author and Illustrator: } \\
\text { Scholastic magazine }\end{array}$ & Informational text & $\begin{array}{l}\text { A farmer plants } \\
\text { pumpkin seeds. } \\
\text { The seeds sprout. } \\
\text { Water and sunlight } \\
\text { help the plants } \\
\text { grow. } \\
\text { A small green } \\
\text { pumpkin grows on a } \\
\text { vine. } \\
\text { The pumpkin gets } \\
\text { bigger and turns } \\
\text { orange. It's } \\
\text { pumpkin-picking } \\
\text { time. }\end{array}$ & $\begin{array}{l}\text { Man } \\
\text { Planting } \\
\text { Seeds: } \\
\text { Talisha, } \\
\text { Jibir } \\
\text { Flowers: } \\
\text { Lisa, } \\
\text { Malcolm } \\
\text { Pumpkins: } \\
\text { Pierson, } \\
\text { Arianina, } \\
\text { Cathie }\end{array}$ \\
\hline $10 / 10 / 05$ & $\begin{array}{l}\text { Pumpkin, Pumpkin } \\
\text { Author and Illustator: } \\
\text { Jeanne Titherington }\end{array}$ & Informational text & $\begin{array}{l}\text { The life cycle of a } \\
\text { pumpkin } \\
\text { A boy watches a } \\
\text { pumpkin grow } \\
\text { The boy picks a } \\
\text { pumpkin off the } \\
\text { vine }\end{array}$ & $\begin{array}{l}\text { Pumpkins: } \\
\text { Pierson }\end{array}$ \\
\hline $10 / 11 / 05$ & $\begin{array}{l}\text { Apples and Pumpkins } \\
\text { Author: Ann Rockwell } \\
\text { Illustrator: Lizzy } \\
\text { Rockwell }\end{array}$ & Informational text & $\begin{array}{l}\text { How apples grow } \\
\text { How pumpkins } \\
\text { grow } \\
\text { Compares apples } \\
\text { and pumpkins }\end{array}$ & $\begin{array}{l}\text { Pumpkins: } \\
\text { Chars, } \\
\text { Josephina } \\
\text { Apples: } \\
\text { Jibir, Cathie, } \\
\text { Chars } \\
\end{array}$ \\
\hline
\end{tabular}




\begin{tabular}{|c|c|c|c|c|}
\hline $10 / 12 / 05$ & $\begin{array}{l}\text { Lumpy, Bumpy, } \\
\text { Pumpkins! } \\
\text { Author and Illustrator: } \\
\text { Scholastic magazine }\end{array}$ & Informational text & $\begin{array}{l}\text { The life cycle of a } \\
\text { pumpkin }\end{array}$ & None \\
\hline $10 / 17 / 05$ & $\begin{array}{l}\text { My Crayons Talk } \\
\text { Author: Patricia } \\
\text { Hubbard } \\
\text { Illustrator: G. Brian } \\
\text { Haras }\end{array}$ & Fiction & $\begin{array}{l}\text { There are crayons } \\
\text { that talk. } \\
\text { A little girl in the } \\
\text { story uses crayons } \\
\text { to make different } \\
\text { scenes in the story. }\end{array}$ & None \\
\hline $10 / 18 / 05$ & $\begin{array}{l}\text { The Three Little Pigs } \\
\text { Author and Illustrator: } \\
\text { James Marshall }\end{array}$ & Fairytale & $\begin{array}{l}\text { Three pigs avoid } \\
\text { being eaten by a } \\
\text { wolf. }\end{array}$ & None \\
\hline $10 / 19 / 05$ & $\begin{array}{l}\text { Is Your Mama a } \\
\text { Llama? } \\
\text { Author: Deborah } \\
\text { Guarino } \\
\text { Illustrator: Steven } \\
\text { Kellogg }\end{array}$ & Fiction & $\begin{array}{l}\text { A baby llama asks } \\
\text { each of his animal } \\
\text { friends if their } \\
\text { mama is a llama. } \\
\text { Each animal } \\
\text { response with a } \\
\text { rhyming description } \\
\text { of their mother. } \\
\text { The book highlights } \\
\text { several different } \\
\text { animals. }\end{array}$ & None \\
\hline $10 / 27 / 05$ & $\begin{array}{l}\text { No Read-aloud Text } \\
\text { Before Writing }\end{array}$ & & & \\
\hline $10 / 31 / 05$ & $\begin{array}{l}\text { It's Pumpkin Time } \\
\text { Author: Zoe Hall } \\
\text { Illustrator: Shari } \\
\text { Halpern }\end{array}$ & Informational text & $\begin{array}{l}\text { The text describes } \\
\text { the life cycle of a } \\
\text { pumpkin. } \\
\text { The pumpkin is cut } \\
\text { off a vine. } \\
\text { The pumpkin is } \\
\text { carved into a Jack- } \\
\text { O-Lantern }\end{array}$ & $\begin{array}{l}\text { Growing } \\
\text { Pumpkins: } \\
\text { Kallen, Lisa, } \\
\text { Josephina }\end{array}$ \\
\hline $11 / 02 / 05$ & $\begin{array}{l}\text { No Read-aloud Text } \\
\text { Before Writing }\end{array}$ & & & \\
\hline $11 / 03 / 05$ & $\begin{array}{l}\text { IKnow' It's Autumn } \\
\text { Author: Eileen Spinelli } \\
\text { Illustrator: Nancy } \\
\text { Hayashi }\end{array}$ & Fiction & $\begin{array}{l}\text { A little girl awaits } \\
\text { the beginning of the } \\
\text { fall. } \\
\text { She goes on } \\
\text { hayrides, picks } \\
\text { apples, and listens } \\
\text { to stories around a } \\
\text { campfire. }\end{array}$ & None \\
\hline $11 / 09 / 05$ & $\begin{array}{l}\text { Are You Ready for } \\
\text { Winter, Chipmunk? } \\
\text { Author and Illustrator: } \\
\text { Scholastic, Inc. }\end{array}$ & Informational Text & $\begin{array}{l}\text { The text shows how } \\
\text { a chipmunk gets } \\
\text { ready for the winter. }\end{array}$ & None \\
\hline $11 / 10 / 05$ & $\begin{array}{l}\text { Sharks } \\
\text { Authors and } \\
\text { Illustrators: Mevin and } \\
\text { Gilda Berger }\end{array}$ & Informational text & $\begin{array}{l}\text { The text includes } \\
\text { information about } \\
\text { sharks. }\end{array}$ & $\begin{array}{l}\text { Sharks: } \\
\text { Chars }\end{array}$ \\
\hline
\end{tabular}




\begin{tabular}{|c|c|c|c|c|}
\hline $11 / 11 / 05$ & $\begin{array}{l}\text { Dolphins } \\
\text { Authors and } \\
\text { Illustrators: Mevin and } \\
\text { Gilda Berger }\end{array}$ & Informational text & $\begin{array}{l}\text { The text includes } \\
\text { information about } \\
\text { dolphins. }\end{array}$ & $\begin{array}{l}\text { Dolphins: } \\
\text { Chars, } \\
\text { Travion }\end{array}$ \\
\hline $11 / 15 / 05$ & $\begin{array}{l}\text { From Robin to Egg } \\
\text { Authors: Susan } \\
\text { Canizares and Betsey } \\
\text { Chessen }\end{array}$ & Informational text & $\begin{array}{l}\text { The text includes } \\
\text { information the life } \\
\text { cycle of a robin }\end{array}$ & $\begin{array}{l}\text { Eggs: } \\
\text { Roderick }\end{array}$ \\
\hline $11 / 16 / 05$ & $\begin{array}{l}\text { Thanksgiving Day } \\
\text { Author and Illustrator: } \\
\text { Scholastic, Inc. }\end{array}$ & Informational text & $\begin{array}{l}\text { The } 5 \text { Senses } \\
\text { Family } \\
\text { Cooking } \\
\text { Parades } \\
\text { Football } \\
\text { Thanksgiving Foods }\end{array}$ & $\begin{array}{l}\text { Five Senses: } \\
\text { Lisa } \\
\text { Thanks- } \\
\text { giving } \\
\text { foods: Lisa } \\
\text { and Talisha } \\
\text { Turkey: } \\
\text { Travion }\end{array}$ \\
\hline $11 / 21 / 05$ & $\begin{array}{l}\text { Feast for } 10 \\
\text { Author and Illustrator: } \\
\text { Catheryn Falwell }\end{array}$ & $\begin{array}{l}\text { Fiction } \\
\text { Numbers Book }\end{array}$ & $\begin{array}{l}\text { A family goes to the } \\
\text { store to collect } \\
\text { items for a family } \\
\text { feast. } \\
\text { This is a number } \\
\text { book because each } \\
\text { page begins with a } \\
\text { number. }\end{array}$ & $\begin{array}{l}\text { Numbers: } \\
\text { Arianna }\end{array}$ \\
\hline $11 / 22 / 05$ & $\begin{array}{l}\text { The Very First } \\
\text { Thanksgiving } \\
\text { Author: Ronda Galler } \\
\text { Greene } \\
\text { Illustrator: Susan } \\
\text { Garber }\end{array}$ & Informational text & $\begin{array}{l}\text { Describes the events } \\
\text { of the First } \\
\text { Thanksgiving } \\
\text { Children ask } \\
\text { questions about the } \\
\text { bathrooms } \\
\text { The book describes } \\
\text { the passage of the } \\
\text { Pilgrims on the } \\
\text { Mayflower } \\
\text { Part of the } \\
\text { discussion focused } \\
\text { on sharks that } \\
\text { followed the } \\
\text { Mayflower. }\end{array}$ & $\begin{array}{l}\text { Mayflower } \\
\text { Malcolm, } \\
\text { Roderick } \\
\text { Sharks: } \\
\text { Jibir }\end{array}$ \\
\hline $11 / 28 / 05$ & $\begin{array}{l}\text { A Wetu House } \\
\text { Author and Illustrator: } \\
\text { Scholastic, Inc. }\end{array}$ & Informational text & $\begin{array}{l}\text { Wetus } \\
\text { cooking outside } \\
\text { hunting outside }\end{array}$ & $\begin{array}{l}\text { Bed: } \\
\text { Talisha, Lisa }\end{array}$ \\
\hline
\end{tabular}


Table 4.7 shows the children's symbols that were only listed in Table 4.6. The children often used the read-aloud text as a support for specific symbols they wanted to create in their own writing.

Table 4.7. Student writing that reflected symbols from the read-aloud text.

\begin{tabular}{|c|c|c|c|}
\hline \multirow{2}{*}{$\begin{array}{l}\begin{array}{c}\text { Date of } \\
\text { Read-aloud }\end{array} \\
9 / 28 / 05 \\
\text { Read-aloud } \\
\text { Text: } \\
\text { I See a } \\
\text { Spider }\end{array}$} & \multicolumn{2}{|c|}{ Student Writing } & \multirow{2}{*}{\begin{tabular}{l}
\multicolumn{1}{c}{$\begin{array}{c}\text { Symbols } \\
\text { Included in } \\
\text { Student Text }\end{array}$} \\
Spiders \\
Legs
\end{tabular}} \\
\hline & $\frac{11}{\text { Lisa's writing }}$ & $\begin{array}{l}\text { Lisa: "This is the big spider. } \\
\text { Him going in the drain. And } \\
\text { Ms. Spider are taking him legs } \\
\text { off and bugs. And he's takin" } \\
\text { him. And the Sun came up and } \\
\text { blew him away. And I put this } \\
\text { box here. I need it. Because we } \\
\text { need to be able to keep our } \\
\text { spiders in so they don't bite." }\end{array}$ & \\
\hline \multirow[t]{2}{*}{$\begin{array}{l}\text { Elements of } \\
\text { Text: } \\
\text { Spiders, } \\
\text { webs, } 8 \text { legs }\end{array}$} & 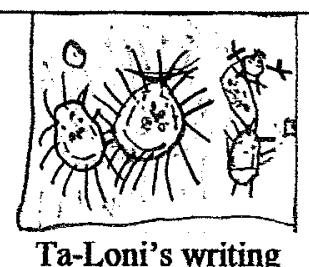 & $\begin{array}{l}\text { Ta-Loni: "I made a spider. That } \\
\text { box 'cause they crying 'cause } \\
\text { they can't find their momma." }\end{array}$ & $\begin{array}{l}\text { Spiders } \\
\text { Legs }\end{array}$ \\
\hline & & $\begin{array}{l}\text { Chars: "I made me a spider. } \\
\text { There the legs. This the hair. } \\
\text { This the mouth." }\end{array}$ & $\begin{array}{l}\text { Spiders } \\
\text { Legs }\end{array}$ \\
\hline \multirow[t]{3}{*}{$\begin{array}{l}10 / 07 / 05 \\
\text { Read-aloud } \\
\text { Text: } \\
\text { Lumpy, } \\
\text { Bumpy, } \\
\text { Pumpkins! }\end{array}$} & Talisha's writing & $\begin{array}{l}\text { Talisha: "This is a man. He } \\
\text { about to eat an apple. He makin" } \\
\text { a pumpkin. The man planting a } \\
\text { garden. That's a pumpkin. That } \\
\text { rainbow." }\end{array}$ & $\begin{array}{l}\text { Pumpkins } \\
\text { Man planting } \\
\text { seeds }\end{array}$ \\
\hline & $\begin{array}{l}(00) \\
\text { Jibir's writing }\end{array}$ & $\begin{array}{l}\text { Jibir: "I can't make a pumpkin." } \\
\text { [Then Jibir opens a magazine, } \\
\text { opens to the page with a man } \\
\text { planting seeds and adds him to } \\
\text { the paper.] "That's not me. } \\
\text { That's a man. I don't know } \\
\text { him." }\end{array}$ & $\begin{array}{l}\text { Pumpkins } \\
\text { Man planting } \\
\text { seeds }\end{array}$ \\
\hline & Lisa's writing & $\begin{array}{l}\text { Lisa: "I did circles so water can } \\
\text { go to the flowers. The raindrops } \\
\text { are on season. Because they are } \\
\text { going to grow the flowers." }\end{array}$ & Flower \\
\hline
\end{tabular}




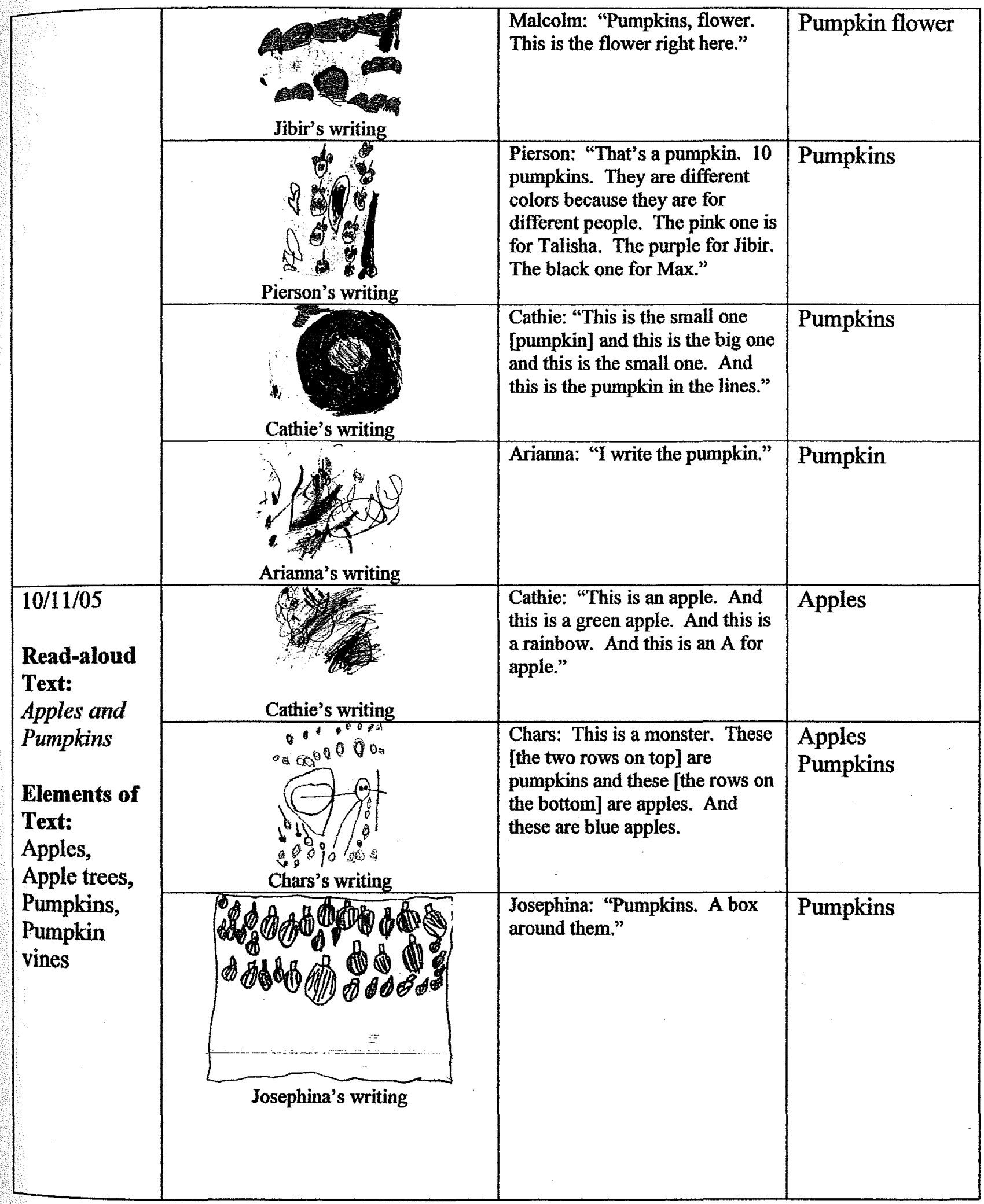




\begin{tabular}{|c|c|c|c|}
\hline $\begin{array}{l}\text { 10/31/05 } \\
\text { Read-aloud } \\
\text { Text: } \\
\text { It's Pumpkin } \\
\text { Time }\end{array}$ & 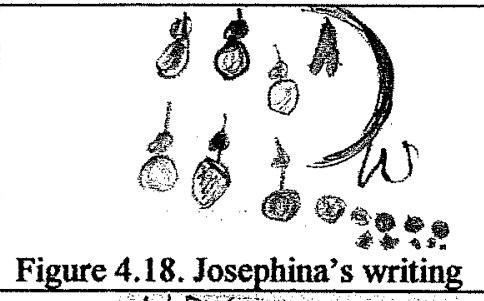 & $\begin{array}{l}\text { Josephina: "Pumpkins. A } \\
\text { rainbow." }\end{array}$ & Pumpkins \\
\hline $\begin{array}{l}\text { Elements of } \\
\text { Text: } \\
\text { Life cycle of } \\
\text { a pumpkin, } \\
\text { Pumpkins, } \\
\text { Jack-O- } \\
\text { Lanterns, }\end{array}$ & $\begin{array}{l}\text { Kola b } \\
\text { pa , }\end{array}$ & $\begin{array}{l}\text { Kallen: "I made people } \\
\text { guarding a pumpkin. } \\
\text { There is a yellow screen } \\
\text { around them. The people } \\
\text { that are guarding the } \\
\text { pumpkin is green. The } \\
\text { pumpkin has a green stem } \\
\text { and my name is orange." }\end{array}$ & Pumpkin \\
\hline Halloween & & $\begin{array}{l}\text { Lisa: "This is the grass. } \\
\text { Then raindrops come } \\
\text { down. I write stems. } \\
\text { Then they turn into green. } \\
\text { Then they turn into } \\
\text { pumpkins. These are the } \\
\text { raindrops that help to grow } \\
\text { the pumpkin. Then I } \\
\text { wrote my name." }\end{array}$ & $\begin{array}{l}\text { The Life Cycle } \\
\text { of a Pumpkin }\end{array}$ \\
\hline $\begin{array}{l}11 / 09 / 05 \\
\text { Read-aloud } \\
\text { Text: } \\
\text { Get Ready } \\
\text { for Winter, } \\
\text { Chipmunk! }\end{array}$ & 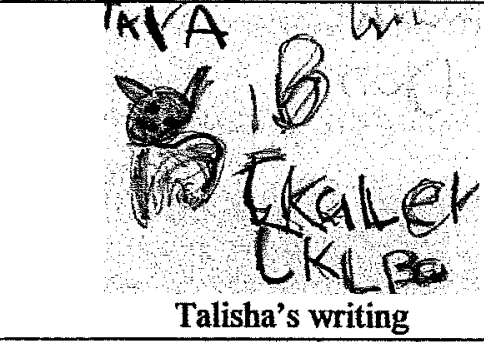 & $\begin{array}{l}\text { Talisha: "It's a chipmunk. } \\
\text { Then I start to write } \\
\text { something about, 'I love } \\
\text { my mommy.' That's a B } \\
\text { for Ms. B. That's a w. } \\
\text { That is is for a 1. That's } \\
\text { my name." }\end{array}$ & Chipmunk \\
\hline $\begin{array}{l}\text { Elements of } \\
\text { Text: } \\
\text { Chipmunks, } \\
\text { Gathering } \\
\text { food for } \\
\text { winter }\end{array}$ & $\begin{array}{l}\int^{1} \\
\sigma\end{array}$ & $\begin{array}{l}\text { Malcolm: "A chipmunk. } \\
\text { He walking to his house. } \\
\text { The pink box is his food." }\end{array}$ & Chipmunk \\
\hline & 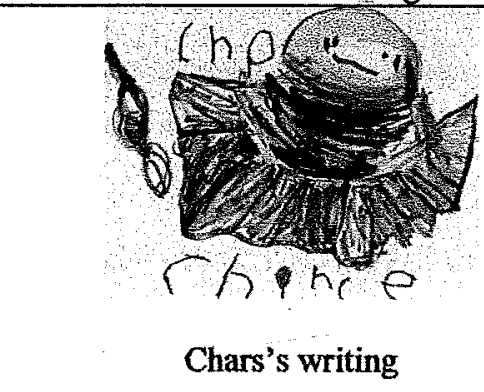 & $\begin{array}{l}\text { Chars: "A chipmunk. It's } \\
\text { a different chipmunk. He } \\
\text { has a green face. No, he } \\
\text { have a... no he have a...I } \\
\text { don't know how to put it. } \\
\text { He have two tails." }\end{array}$ & Chipmunk \\
\hline
\end{tabular}




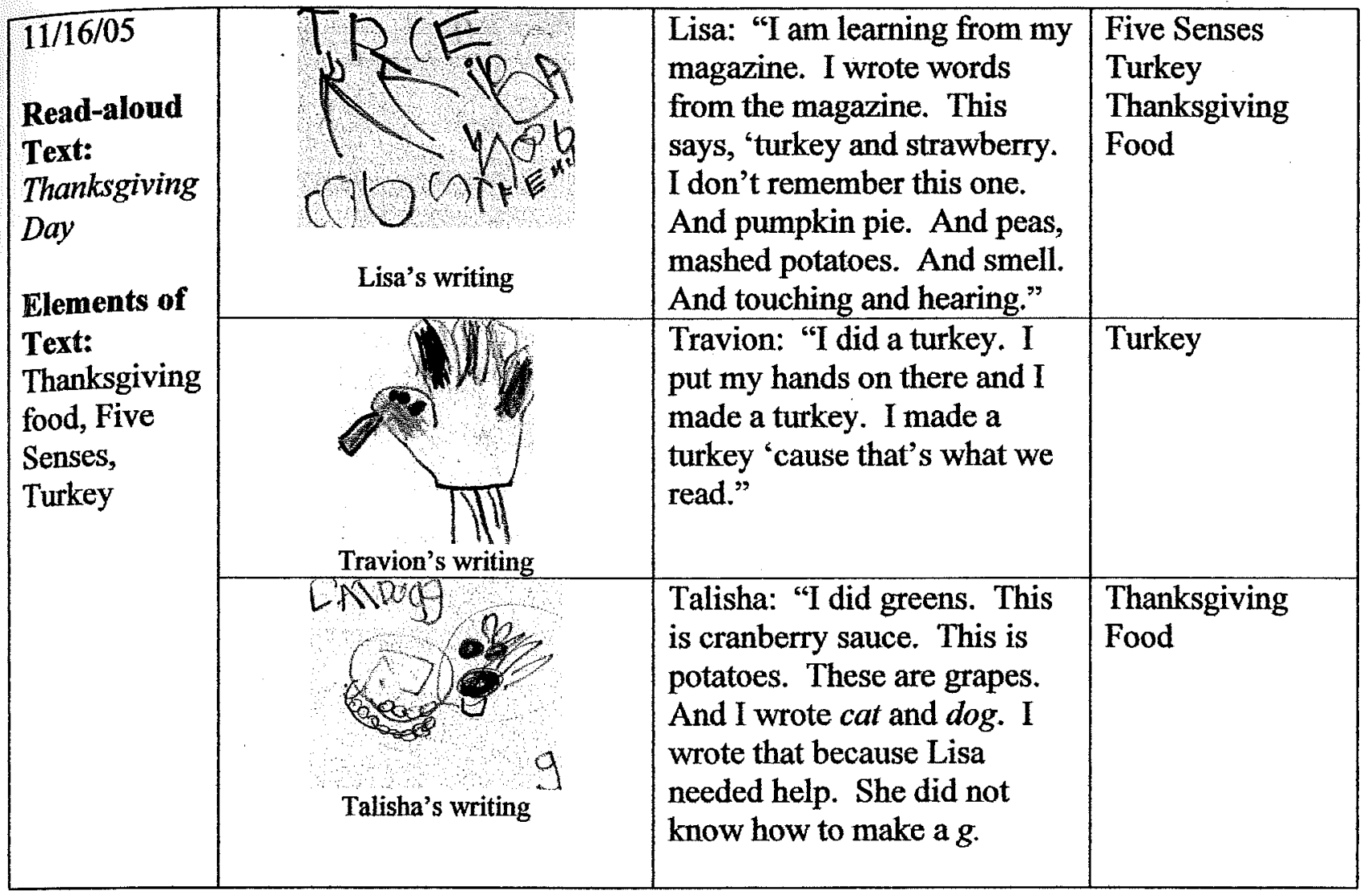

To elaborate on some of the examples in the above Table, I will begin with the writing that occurred on September 28, 2005. Ronda read an informational magazine about spiders, and several children talked about the fact that spiders had eight legs. Later, three children decided to incorporate spiders and spider legs into their writing (Table 4.8). For each child, however, the spider had a different meaning and purpose for being on the paper. 


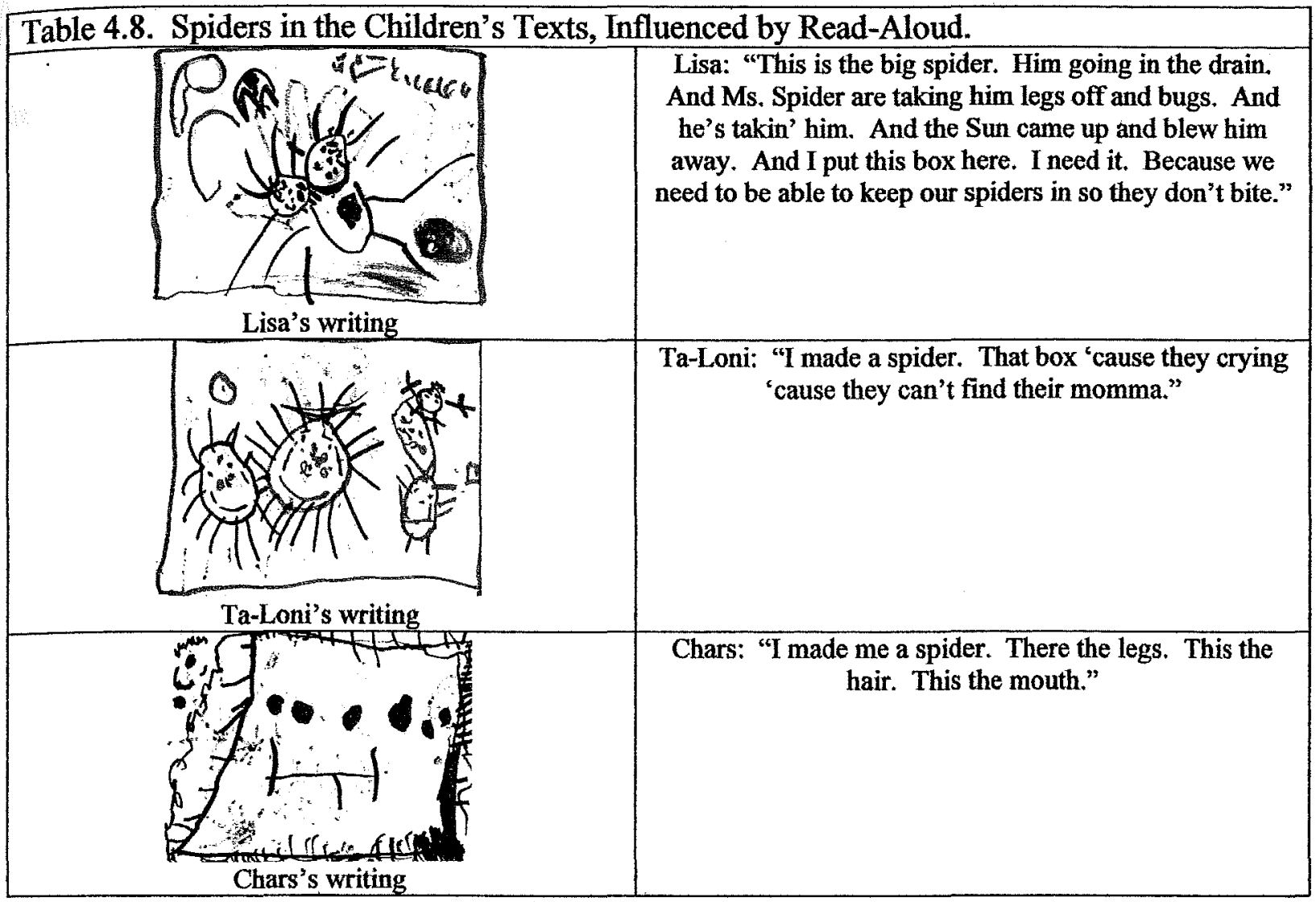

Lisa's spider was in peril as he fell down a drain and was blown away by the

wind. Her explanation bears similarities to the popular children's song, The Itsy, Bitsy

Spider, which Ronda had taught the children.

Ta-Loni drew four spiders that were trapped in a box and were crying because they missed their momma. The clear photographs in the magazine helped show Ta-Loni how to create the symbols on her page.

Finally, Chars covered his entire page with his symbolic rendition of the spider. His explanation of his writing was similar to the language in the read-aloud text. He gave facts about his spider and explained, "There the legs. This the hair. This the mouth." Like the magazine, his illustration is big and encompasses the page. Chars verbally labeled the illustration when he pointed to the symbols on the page and named them. 
During a different read-aloud experience, Ronda read a text about pumpkins titled, Apples and Pumpkins. The text contained several illustrations of pumpkins at various stages of development. Josephina studied these pumpkins and included them in her own writing (Figure 4.5), repeating them over and over again and enclosing them with a box - a symbol introduced by Lisa the day she created her spiders.

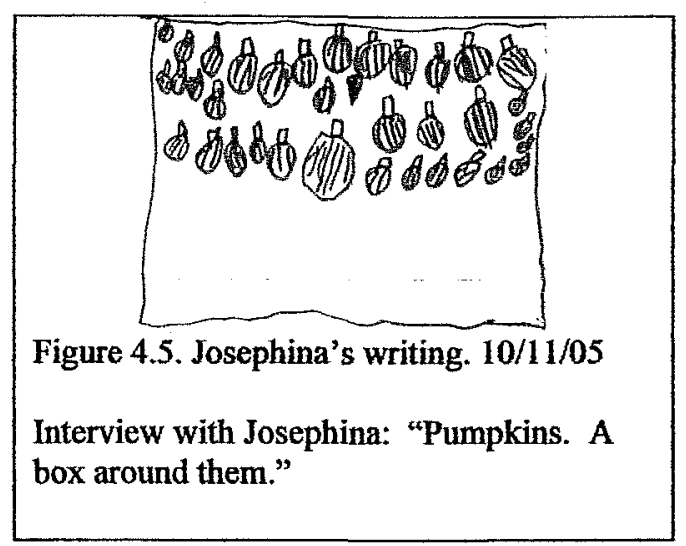

On October 31, 2005, Ronda read-aloud a text titled It's Pumpkin Time. It describes the life cycle of a pumpkin from its genesis as a seed until the time it is ripe and ready to be picked. Throughout the read aloud experience, the children talked about the book and life cycles of pumpkins. Lisa asked questions about how pumpkins grew from flowers. After Ronda explained this to her, she decided to mirror the read-aloud text in her own writing (Figure 4.6). She explained, "This is the grass. Then raindrops come down. I write stems. Then they turn into green. Then they turn into pumpkins. These are the raindrops that help to grow the pumpkin. Then I wrote my name."

From the text, Lisa was inundated with information about pumpkins, vines, and stems. Her knowledge of the life cycle of the pumpkin is encoded on the page with the text serving as a support for information and symbol creation. 
When Ronda read a text about chipmunks to the class, several students were interested in creating chipmunks in their writing. The following conversation occurred as Ronda read the text aloud to the children:

Ronda: Look at that chipmunk's cheeks. He stores food in there. We can't do that. We would choke. A chipmunk can store up to 8-9 acorns at once. Chipmunks only wake up to have snack.

Trajon: Oh, I like to eat snacks. Chipmunks live in trees.

Chance: They in a tree.

Jibron: Ms. Ronda, why his cheeks like that?

Ronda: Because he has acorns in his cheeks.

Malcolm: That chipmunk hungry?

Talisha: Oh, I'm going to write about that chipmunk.

Chance: Me too!

As Talisha wrote (Figure 4.7), she drew a chipmunk on her paper, and then quickly added print: specifically, a message to her mother. She also included letters known to her. This is a complex piece of writing in which the Talisha displays much of what she knows.

Malcolm's chipmunk (Figure 4.8) was the focus of his text. Like the chipmunk in the informational text, his chipmunk was hungry. His chipmunk differed, however, in that it did not have to forage for nuts. The chipmunk in Malcolm's writing ate food that was provided in a pretty, pink box within a home.

Finally, Chars's chipmunk is reminiscent of the spider he created several weeks before (Figure 4.9). The chipmunk was written on the entire page and was accompanied by Chars's explanation. "A chipmunk," he muttered. "It's a different chipmunk [from the one in the text]. He has a green face. No, he have a...no, he have a...I don't know how to put it. He have two tails." Chars studied the photograph of the chipmunk and tried to include similar details in his symbolic representation. 


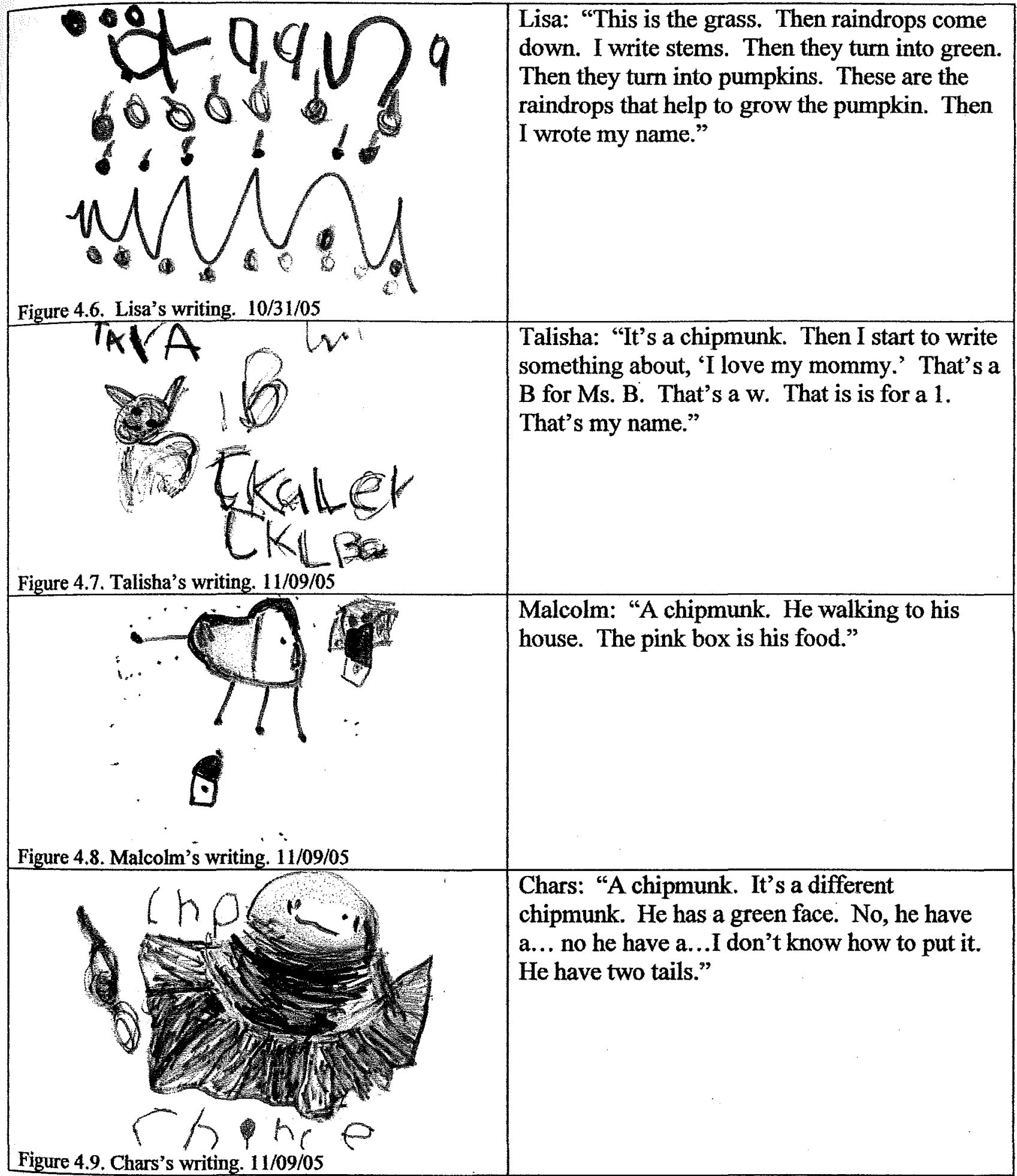

On a different day, after distributing copies of an informational magazine about pumpkins to each child, Ronda read the text aloud as the children followed using their 
own copies. Following the demonstration, the children shared their own ideas for writing. The following conversation took place.

Roderick: I'm going to write a dinosaur again.

Ronda: Roderick's going to write a dinosaur again. You know what? If you decide to write about pumpkins - which you do not have to do-you can take this [the magazine] over there to look at it.

Kallen: I'm going to write superheroes, too.

Talisha: I'm going to write me and my house and my mommy and my uncle.

Malcolm: A pumpkin

Cathie: Me too, a pumpkin

[Field Notes Excerpt: 10/07/05]

Several of the students took the magazines to the tables and placed them in front of them as they wrote. Talisha and Jibir talked about a man in a photograph who was planting seeds, and when they wrote, they included this man in their writing. Lisa and Malcolm referred to the magazine to draw flowers on their paper to represent what a pumpkin does during an early stage of its development. Pierson, Arianna, and Cathie used the text to create pumpkins. Every child who considered the magazine's information wrote with a copy of the magazine in front of them. The ability to take the magazine to their tables appeared to influence their talk and writing.

Children in this pre-kindergarten class used the illustrations from the read-aloud text for ideas in their writing. The symbols they encountered when they were exposed to the illustrations and photographs in the texts made impressions on them. They studied the symbols when they listened to the text and integrated them into their own writing. For some children, this was a frustrating task. Jibir (Figure 4.10) began his writing by drawing pumpkins, but was not satisfied with his initial renditions. When Ronda encouraged him to use the magazine for support, he complied. Then he went further and 
included the man from the text who was planting seeds. The text was essential for Jibir. It gave him support.

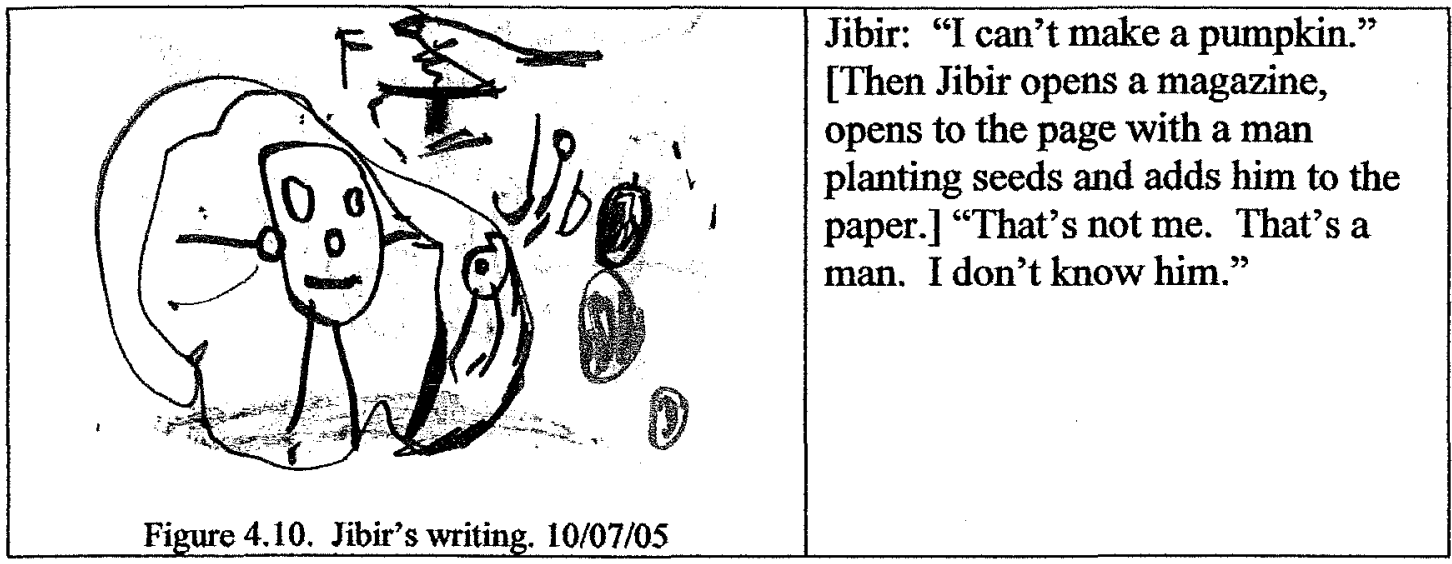

In summary, the illustration appeared to influence the children in three ways. In some cases, the children repeated the symbols in the writing without assigning any other meaning to their texts. Josephina's repetitive pumpkins are an example of this (Figure 4.11).

\begin{tabular}{|l|l|}
\hline & Josephina: "Pumpkins. A box around \\
them." & \\
\hline
\end{tabular}

In other cases, children created a symbol, and then moved on to other important subjects in their writing; Talisha's cursory inclusion of a chipmunk is followed by notes to her mother and letters to represent the names of people she knew (Figure 4.7). 
Third, some children embedded the symbols within more complex informational and story structures. The illustrations from the texts provided these children with an initial idea for writing, and their texts then diverged into other meanings. After learning about pumpkins from a read-aloud text, Kallen made the pumpkin a centerpiece of his writing (Figure 4.12). Then a story unfolded around it. His imagination led him to incorporate guards to protect his pumpkin.

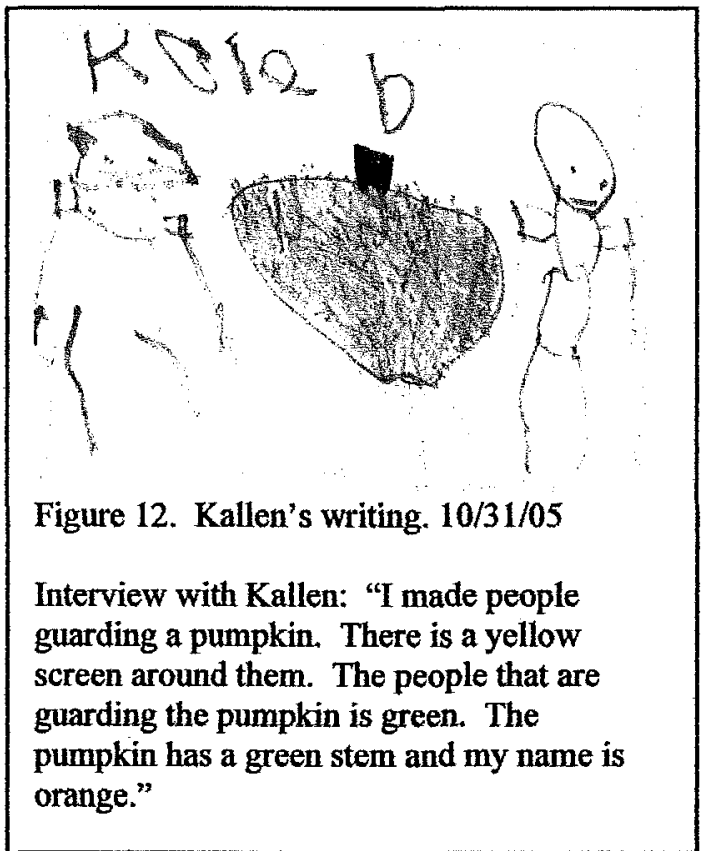

Overall, in this pre-kindergarten classroom, the read-alouds influenced the children's initial ideas and the subsequent meanings they assigned to their writing. In particular, the illustrations influenced the students as they incorporated similar symbols into their own texts.

The read-aloud text influenced children's incorporation of print into their writing. When Ronda read books aloud to the children, she would occasionally run her finger 
underneath the print to show children that she was reading the words written on the page.

In one of our interviews I asked Ronda about this practice.

Brian: Walk me through what you do during a read-aloud.

Ronda: Well, usually I try to pick different books or magazines. Books that really represent different genres. I think that it is important that they hear both fiction and informational texts. Then, I bring all the students together on the floor to listen to the read-aloud. I ask them lots of questions. They ask me questions. And usually tell me lots of stories! Ha.

Brian: I notice when you read that you sometimes sweep your finger underneath the words. Tell me more about this.

Ronda: I read the books out loud and hold them up so they can see the illustrations. I think this is so important. To them, those illustrations hold the meaning. But, I want them to learn that there is print on that page and it says something. So, usually I sweep my finger underneath the print so that they see that I'm reading those words. I think some kids get it. I think others still don't notice. I think the kids who get it are the ones adding print to their writing.

[Interview with Ronda: 10/18/05]

On one occasion, Ronda read information from a magazine to the students about Thanksgiving. The text featured a photograph of a Thanksgiving feast labeled with corresponding words. After the read-aloud, Ronda drew and used print when she wrote about a plate of food in her demonstration. Then, the children dispersed to a table of their choice and wrote. Lisa took her copy of the magazine with her, placed it to her left, and started writing (Figure 4.13). Her head swung back to forth, from her page to the text. She did not talk to peers. She silently composed. One finger remained on the text underneath a word she thought corresponded to a particular feature: In her hand, she held a marker and busily wrote letters on her paper. After several minutes, she was done and brought her paper to me.

\begin{tabular}{|l|l|}
\hline Figure 4.13. Lisa's writing. 11/16/05 & $\begin{array}{l}\text { Lisa: "I am learning from my magazine. I } \\
\text { wrote words from the magazine. This says, } \\
\text { turkey and strawberry. I don't remember } \\
\text { this one. And pumpkin pie. And peas, } \\
\text { mashed potatoes. And smell. And } \\
\text { touching and hearing." }\end{array}$ \\
\hline
\end{tabular}


Brian: "Lisa, tell me about your writing today."

Lisa: "I am learning from my magazine. I wrote words from the magazine. This says, 'turkey and strawberry. I don't remember this one. And pumpkin pie. And peas, mashed potatoes. And smell. And touching and hearing."

Brian: "This looks different than other writings you have done."

Lisa: "Yep. I used the magazine. I wrote some words today. See. Turkey."

Like Lisa, other children incorporated print in their writing after reading about a particular subject. Each month, the children in Ronda's classroom were given free books as part of a pre-kindergarten grant aimed at promoting literacy at home. One book the children received was an informational text titled, Apples and Pumpkins. Ronda was sending the books home with the children on October 11,2005, and wanted to read the book aloud with the children before they took it home. After the read-aloud, children wrote as usual. Cathie decided to bring her book back to the table with her as she wrote (Figure 4.14).

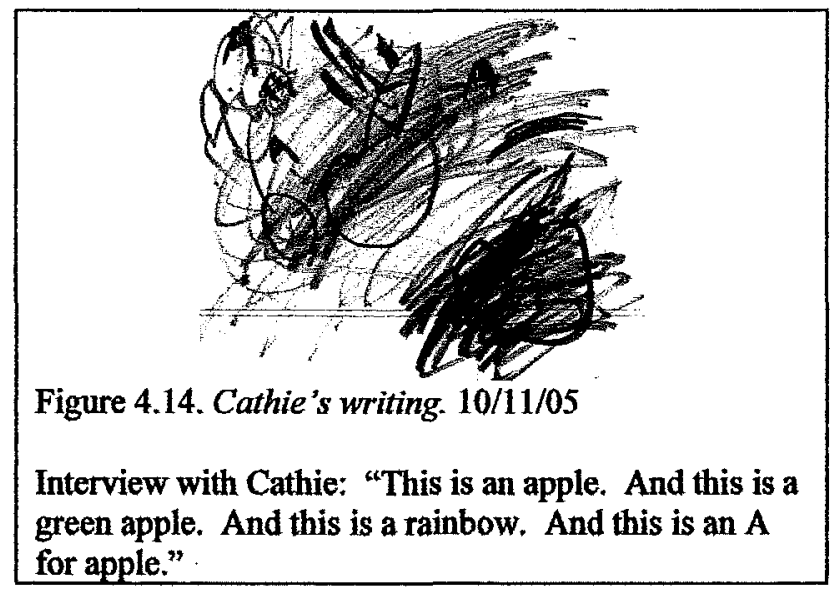

Initially, Cathie looked at the book and wrote different-colored apples. Then she wrote $A$ s next to them. When I asked about her writing, Cathie responded, "And this is an $A$ for apple." Cathie understands the difference between print and drawing. She begins to distinguish between the two in this written piece. 
In November, Chars makes a breakthrough in his writing (Figure 4.15). For the first time, he incorporates print that is distinctive from his name. After reading an informational text about chipmunks, Ronda talks with the class about chipmunks. Chars participated in the conversation and informed the class that he was going to write about a chipmunk. He drew a chipmunk, wrote his name underneath the drawing, and labeled it with the word chipmunk using clear letter-sound correspondence.

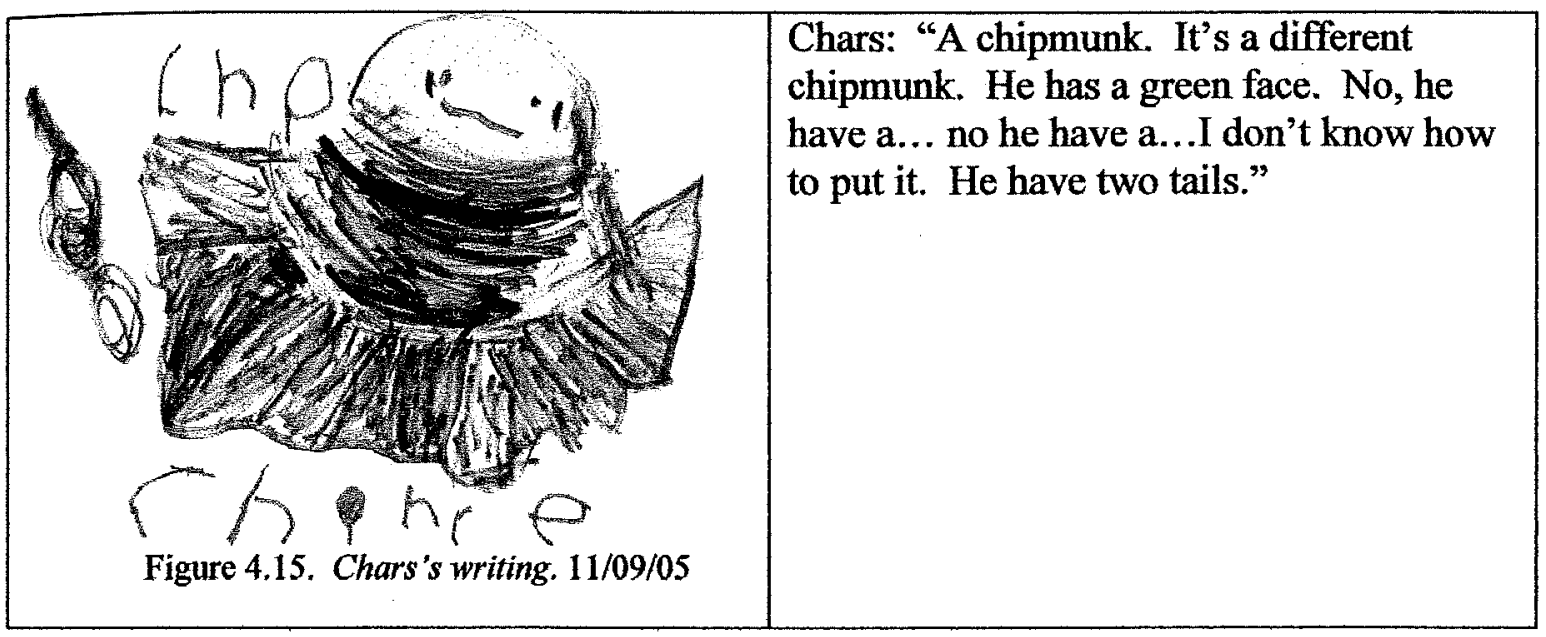

He did this with the support of the text, which rested next to him as he wrote, and he had seen Ronda do the same thing in her writing demonstration. The first two letters in his name matched the first two letters of the text, which may have given him the confidence to try writing a word on his paper.

In summary, there were several occasions when the children used the read-aloud experience as their entry into learning about print. It served as a scaffold, giving children support as they took this large, first step to include print into their own writing. Ronda said, "Usually I sweep my finger underneath the print so they see that I'm reading those words. I think some kids get it." Lisa, Talisha, and Chars appear to be the first children who "get it." 
In the picture books around the classroom, Lisa, Talisha, and Chars started to notice the lettering that accompanied the pictures. And as Ronda read-aloud, sweeping her finger underneath the written text, they began to notice that the print being highlighted by her meant something. In understanding this, they began to incorporate print into their own writing. The read-aloud experience and the teacher's procedure for reading them appear to precipitate this awareness.

\section{The Read-aloud Experience Bears Little to No Influence on Several Days}

During my 22 observations the students incorporated an element of the read-aloud into their writing on 10 days. A total of 13 children were influenced as writers because of the read-aloud experience. Three children incorporated elements of the text once, four children incorporated elements twice, four students included elements three times, one child incorporated elements four times, and one child incorporated elements five times. During the other 12 days, the read-aloud experience did not bear an observable influence on the writing of the children.

Fictional texts were especially inconsequential as idea starters for the children. On seven different occasions, the teacher began writing instruction by reading a fictional text, but only one student incorporated elements of the fictional texts in her writing. When fairytales and folktales were used as the read-aloud, no children incorporated elements of the texts into their writing. These occasions, however, were mostly at the beginning of the year; the children were writing every day, but they may not have been as engaged as they became after they settled into the pre-kindergarten classroom. 
Especially influential were informational texts read-aloud by the teacher. Ronda read informational texts to the children on 14 different occasions. On these days, students incorporated elements of the text into 33 different pieces of writing. Most of the elements incorporated within the writing were symbols from the illustrations of the particular subject that was focused on in the text. Often, children used the symbols as central figures in a story and others using the symbols to explain something new that they had learned.

For Chars and Lisa, the read-aloud texts were influential in several pieces of their writing. These two children were especially talkative during the read-aloud, making comments and asking questions throughout the experience. They also took advantage of having their own copies of several of the texts. On the occasions when they had their own individual texts, both students often brought the texts back to their table to study and incorporate into their own writing.

For Frank, Katalina, and Kendrick, the texts appeared to have no influence. Both Frank and Kendrick were a behavior challenge for Ronda in the classroom. Often, they misbehaved and interrupted throughout the day. This disruption prevented both children from actively participating with the class during the read-aloud time. Thus, when it was time for the two children to write, they may not have had the knowledge from the readaloud text to use in their writing. Katalina, an English Language Learner, spoke little to no English in the classroom for the three months. Often, when asked about her writing, she did not respond. Even when asked in Spanish, Katalina responded with simple Spanish words that appeared to have no connection with the read-aloud text. 
In conclusion, the read-aloud text was influential to some students as they incorporated symbols of the text into their own writing. Students who actively engaged in the read-aloud experience were more influenced by the texts than their peers who were less engaged. Especially influential were informational texts; the majority of students who incorporated elements of the read-aloud text into their writing did so on these days (Table 4.9).

\begin{tabular}{|l|l|l|l|l|}
\hline Table 4.9. Students Incorporate Genres of the Read-Aloud into their Writing. \\
\hline Student & Fiction & Fairytale & $\begin{array}{l}\text { Informational } \\
\text { Text }\end{array}$ & Total \\
\hline Arianna & 1 & 0 & 1 & 2 \\
\hline Cathie & 0 & 0 & 2 & 2 \\
\hline Chars & 0 & 0 & 4 & 4 \\
\hline Frank & 0 & 0 & 0 & 0 \\
\hline Jibir & 0 & 0 & 3 & 3 \\
\hline Josephina & 1 & 0 & 2 & 3 \\
\hline Kallen & 0 & 0 & 1 & 1 \\
\hline Katalina & 0 & 0 & 0 & 0 \\
\hline Kendrick & 0 & 0 & 0 & 0 \\
\hline Malcolm & 0 & 0 & 2 & 2 \\
\hline Lisa & 0 & 0 & 5 & 5 \\
\hline Pierson & 0 & 0 & 2 & 2 \\
\hline Roderick & 0 & 0 & 2 & 2 \\
\hline Talisha & 0 & 0 & 3 & 3 \\
\hline Ta-Loni & 0 & 0 & 1 & 1 \\
\hline Travion & 0 & 0 & 3 & 3 \\
\hline
\end{tabular}

\section{Summary}

The read-aloud gathering experience that occurred before students engaged in writing was influential to the ideas, symbols, print, and genres children included in their writing. At the beginning of the school year, the teacher began the gathering experience with a scripted language program. When she recognized that the scripted program limited their awareness of written language, she conducted the program at another time of the day and replaced it with more authentic experiences such as read-alouds. 
In place of the scripted program, she began to read authentic texts, and the children used the read-aloud texts as catalysts for their talk and writing ideas. Along with the teacher's writing demonstrations, the students used the illustrations of the texts for support in creating symbols. As children became more familiar with the print attached to the illustrations of the texts and Ronda's demonstrations, they began to talk about the print and use it in their own writing. Additionally, because the texts were written using different genre structures, the children used their growing awareness of genre structure to create similar pieces of writing.

These data show that the read-aloud texts provided a considerable influence on the writing of the pre-kindergarten children. Books and magazines, and the talk that surrounded them, helped the children create symbols, letters, and words in their writing. Additionally, exposure to the multiple genres of text encouraged children to consider writing their own texts in multiple ways. Children's interactions with texts, through the read-aloud experiences and their own tacit handling of the texts, provided a scaffold for the children who used them to incorporate new elements into their writing. 


\section{Second Finding}

The teacher's writing demonstrations influenced the child writers.

\section{Vignette 4.2}

Squished together, side-by-side, the children participate in a guidance lesson about feelings. The guidance counselor has her typical accoutrements with her to engage the children. A friendly stuffed dog, an instigating cat, and several large photographs of expressive children make up a repertoire of props to ensure that children understand their feelings and how to successfully manage them. Talisha and Jibir volunteer to roleplay scenes of this emotion.

Talisha, a short, squat African American girl with braided hair stands on one end of the classroom with her left hand positioned on her hip. In class she is the "star of the show." Her gifts of attracting attention are well-served in her role in this performance as the scorned child. This is almost a role she was born to play. Jibir, a vociferous African American boy, is her antagonist: fitting and reflective of his status in the classroom.

The guidance counselor provides the set-up. One child (Talisha) will play blocks quietly by herself. The other child (Jibir) will run over and knock them down. The builder will become very upset and start crying. The demolisher will then be responsible to help her rebuild and apologize for his carelessness. It is a scene played out in prekindergarten classrooms across the country and a familiar scenario in Ronda's room.

The class gathers in a semi-circle on the large carpet and laughs. Talisha and Jibir prepare for their roles. Talisha sets up the blocks while humming a quiet tune. Jibir waits impatiently kicking his foot up and down preparing for the climatic moment 
when he will knock down the blocks. When Talisha builds a tower high enough, Jibir sprints towards the structure and flattens it with a swift kick. In response, Talisha pretends to cry. She rubs her eyes and whimpers. Jibir laughs at her misery. When the guidance counselor re-enters the scene, Jibir apologizes to Talisha, assists in block pickup, and finally promises not to do mean things to her again.

When the lesson ends, the children applaud. The performance was successful as it accurately conveys the true events that occur in the active, play-centered classroom. The children are equipped with strategies to use when people do mean things. Instead of physically fighting, they can apologize and talk about their feelings.

When the guidance counselor leaves the classroom the students are ready to watch Ronda write. Ronda speaks and writes simultaneously [Figure 4.16].

Ronda: Remember yesterday? I made an enormous spider. Then I put a heart on it. I got that idea from Cathie. When I am the writer, I get to choose whether I'm going to do what other people tell me to do, or whether I'll do it the way I want to do it. I can get ideas or I can just make up my own ideas. I'm going to put my name up here: Ms. Ronda. I always want to put my name on my paper. [Ronda notices an angry look on Roderick's face.] Whoops, did you get hurt Roderick?

Roderick: [Answers with clinched teeth] Yep.

Ronda: Do you remember what [the guidance counselor] said about getting hurt? Instead of making a mean face, you can just say, "You hurt me. Can you be a little more careful, please?"

Roderick to Malcolm: [Angrily] You hurt me. Could you be a little more careful?

Ronda: Malcolm, you may want to say that you are sorry.

Malcolm: [rolling his eyes] I'm sorry.

Ronda: I got an idea from [the guidance counselor] today.

Jibir: Where you get that idea from?

Ronda: Well, I remember that she had a picture of child who was having a rainy day: [Ronda starts writing and talks as she does this.] I'm going to make a rainy day picture [Figure 4.16]. It's going to have rain coming down all over. I'm going to put a window pane on here. It's going to be a rectangle. I'm going to put a sad face here. This is a little girl and she wants to go out to play. But it is raining outside. Her mom says, "No, you can't go outside and play in the rain today. It's too cold. It's too rainy." She is very sad in this picture. 
Cathie: Oh, why is she sad?

Lisa: 'Cause it raining!

Ronda: [continues] But then! In my story, the rain stops and her mom let her put on her rain boots and her raincoat and let her go and jump in the puddles. And then, she had a happy face when she was out in the rain -after the rain. And she is wearing a rain poncho. She got to jump and splish and splash. That made her so much happier. Okay, that's my picture for today and I'm going to write the word rain.

Ronda: [sounding out the individual letters in the words] /r/.

Talisha: $R$ !

Ronda: R! Like Roderick and Ronda.

Ronda: $/ r / . . . / a /$...../al

Lisa: A! [Ronda includes the a]

Ronda: rain [Ronda inserts an $n$.]

Ronda: I also want to include the word day. Lisa, what does day start with?

Lisa: $D$

Ronda: $/ a / / a / / a /$

Lisa: $A$

Ronda: Rain day.

Roderick: $R$ starts with me.

Ronda: You do start with R. We share that together. Okay, now put your thinking caps on. Think about what you are going to write about today.

[Transcript 9-30-05]

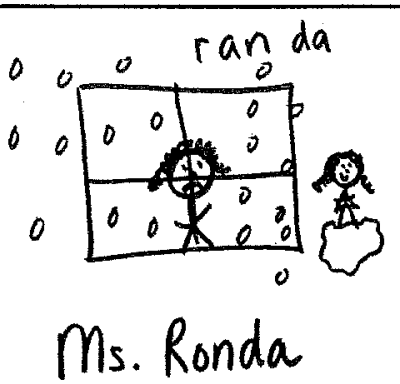

Figure 4.16. Ronda's writing demonstration. 9/30/05

When the demonstration is completed, the children walk over to the tables, choose peers to sit next to, and write.

The following writing samples were composed by four of the students at the completion of the lesson. Their explanations accompany their texts. 


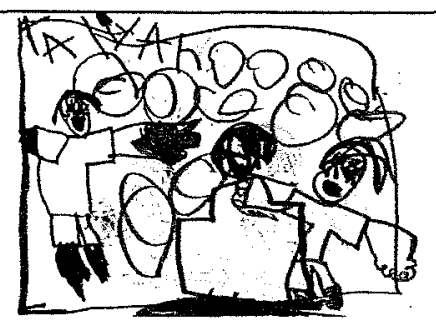

Figure 4.17. Talisha's writing. 09/30/05

"I'm drawing me and my mommy and my daddy and my brother. We running 'cause the spider trying to get us. My mommy is brown. My daddy and my mommy and me got purple hair. My mommy is brown but she still got purple hair. [The lines around the paper] A TV square so the spider can't run back into the house. So the spider can get back in the web."

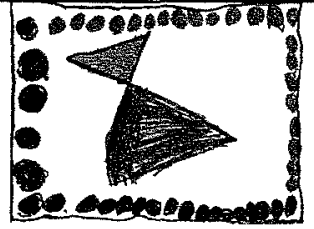

Figure 4.18. Josephina's writing. 09/30/05

"Raindrops."

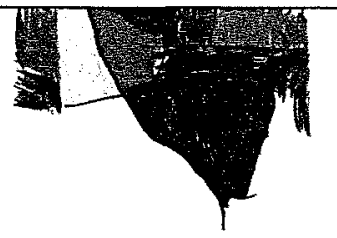

Figure 4.19. Cathie's writing. 09/30/05

"I'm drawing a light for the rainbows because it's going to rain. So it won't rain no more. The clouds are going to go up until the rain stops."

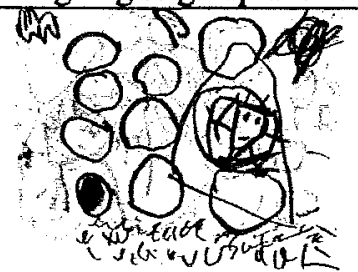

Figure 4.20. Lisa's writing. 09-30-05

Ronda: "Lisa, what are you writing today?"

Lisa: "I'm getting the idea from you. This is the little girl. Her mommy says she can't go outside so she's mad at her momma. She can't go outside "cause her daddy said her mom said she can't go outside."

Because Ronda's lessons were interactive, the children stayed engaged as she composed. They asked questions, offered suggestions, and made comments. Then, a few of them integrated what they learned from Ronda in their own writing. In some cases, the children watched carefully as Ronda crafted her writing and used similar strategies in 
their own. This was the case when Talisha witnessed Ronda referring back to previous writing about spiders to begin the lesson. This sparked an idea for Talisha and she implemented it in her own writing (Figure 4.17). Sometimes they simply repeated the symbols of her demonstration by re-creating them (Josephina's raindrops, Figure 4.18). Often, they infused elements of the teacher's text into their own unique stories and informational texts (Cathie's rainbows, Figure 4.19 and Lisa's story, Figure 4.20). The social nature of the teacher's demonstration influenced the writers in Ronda's classroom.

Before I show the influences of Ronda's demonstrations on the class, I will present information about the overall nature, which will include an analysis of the discourse of a "typical" writing demonstration. Following this analysis, I provide examples of the writing demonstrations on the young writers. The findings suggest that several children used the teacher's writing demonstrations in three observable ways: to develop ideas for writing, to enhance their incorporation of print, and to write using multiple genre structures.

The General Nature of the Teacher's Writing Demonstrations

In every observation of Ronda's classroom, she demonstrated a writing lesson in front of the children after a classroom experience. It served as the second component of her lesson and influenced the students' writing (Table 4.10). 


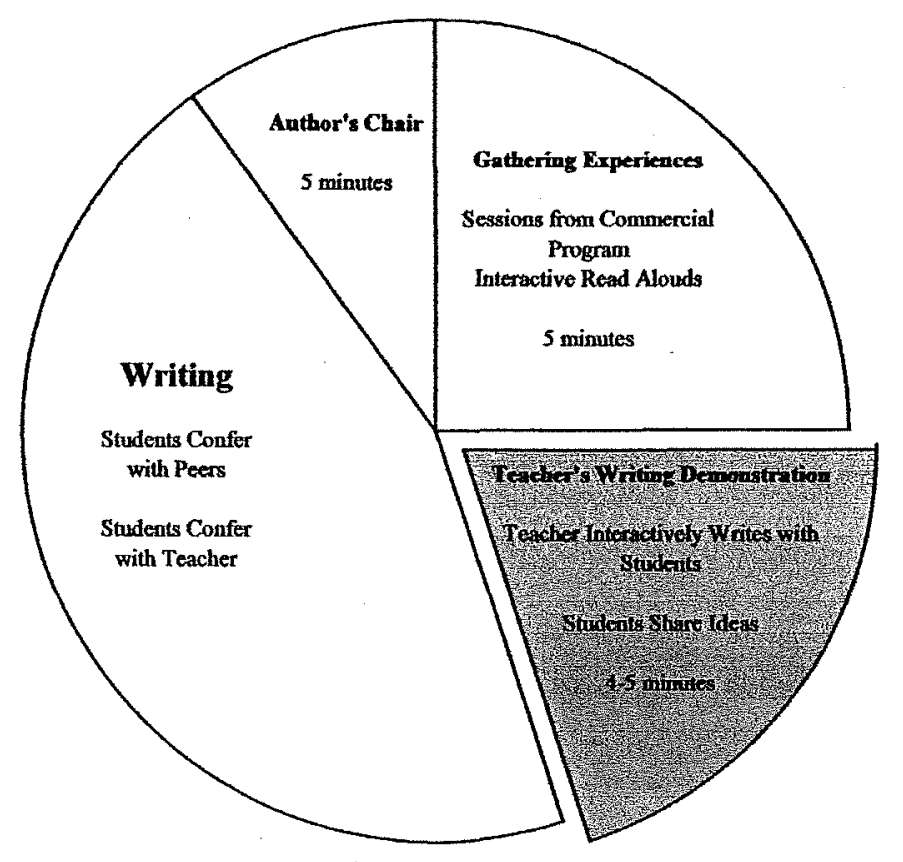

Table 4.10. The teacher's writing demonstration as a component of the Writer's Workshop in Ronda's pre-kindergarten class.

During this demonstration, Ronda consistently talked and conversed with the children as she wrote, and they gained numerous ideas for their own writing.

In the above vignette, as Ronda composed, she explained her reasoning for all the various choices she made in her writing. Table 4.11 dissects the lesson to show how she used talk throughout the demonstration in the opening vignette. In observations of Ronda's writing demonstration, this consistent pattern emerged. 


\begin{tabular}{|c|c|}
\hline $\begin{array}{l}\text { Teacher Revisits Previous } \\
\text { Work }\end{array}$ & $\begin{array}{l}\text { Ronda: Remember yesterday? I made an enormous spider. Then I put } \\
\text { a heart on it. I got that idea from Cathie. }\end{array}$ \\
\hline $\begin{array}{l}\text { Teacher Explains that } \\
\text { Others Can Influence the } \\
\text { Writing }\end{array}$ & $\begin{array}{l}\text { Ronda: When I am the writer, I get to choose whether I'm going to do } \\
\text { what other people tell me to do. Or, whether I get to do it the way I } \\
\text { want to do it. I can get ideas or I can just make up my own ideas. }\end{array}$ \\
\hline $\begin{array}{l}\text { Teacher Writes her } \\
\text { Name-First Inclusion of } \\
\text { Print }\end{array}$ & $\begin{array}{l}\text { Ronda: I'm going to put my name up here: } M s \text {. Ronda. I always want } \\
\text { to put my name on my paper. }\end{array}$ \\
\hline $\begin{array}{l}\text { Teacher Explains the } \\
\text { Genesis of Her Writing } \\
\text { Idea }\end{array}$ & $\begin{array}{l}\text { Ronda: I got an idea from Ms. Parmar today. } \\
\text { Jibir: Where you get that idea from? } \\
\text { Ronda: Well, I remember that she had a picture of a child who was } \\
\text { having a rainy day. [Ronda starts writing and talks as she does this.] } \\
\text { I'm going to make a rainy day picture. It's going to have rain coming } \\
\text { down all over. I'm going to put a window pane on here. It's going to } \\
\text { be a rectangle. I'm going to put a sad face here. This is a little girl and } \\
\text { she wants to go out to play. But it is raining outside. Her mom says, } \\
\text { "No, you can't go outside and play in the rain today. It's too cold. It's } \\
\text { too rainy." She is very sad in this picture. } \\
\text { Cathie: Oh, why is she sad? } \\
\text { Lisa: 'Cause it raining! }\end{array}$ \\
\hline $\begin{array}{l}\text { Teacher Demonstrates } \\
\text { Her Knowledge of the } \\
\text { Narrative Genre Structure }\end{array}$ & $\begin{array}{l}\text { Ronda: [continues] But then! In my story, the rain stops and her mom } \\
\text { let her put on her rain boots and her raincoat and let her go and jump in } \\
\text { the puddles. And then, she had a happy face when she was out in the } \\
\text { rain - after the rain. And she is wearing a rain poncho. She got to } \\
\text { jump and splish and splash. That made her so much happier. }\end{array}$ \\
\hline $\begin{array}{l}\text { Teacher Connects Letters } \\
\text { with Sounds in Writing- } \\
\text { Her Second Incorporation } \\
\text { of Print }\end{array}$ & $\begin{array}{l}\text { Ronda: Okay, that's my picture for today and I'm going to write the } \\
\text { word rain. } \\
\text { Ronda: [sounding out the individual letters in the words] /r/. } \\
\text { Talisha: R! } \\
\text { Ronda: R! Like Roderick and Ronda. } \\
\text { Ronda: /r/.../a/...../a/ } \\
\text { Lisa: A! [Ronda includes the } a \text { ] } \\
\text { Ronda: rain [Ronda inserts an } n \text { ] } \\
\text { Ronda: I also want to include the word } d a y . \text { Lisa, what does day start } \\
\text { with? } \\
\text { Lisa: } D \\
\text { Ronda: /a/ /a/ /a/ } \\
\text { Lisa: A } \\
\text { Ronda: Rain day. } \\
\text { Roderick: R starts with me. } \\
\text { Ronda: You do start with R. We share that together. }\end{array}$ \\
\hline $\begin{array}{l}\text { Teacher Encourages } \\
\text { Children to Announce } \\
\text { their own Writing Ideas }\end{array}$ & $\begin{array}{l}\text { Ronda: Okay, now put your thinking caps on. Think about what you } \\
\text { are going to write about today. }\end{array}$ \\
\hline
\end{tabular}


Ronda began the lessons by reviewing previous writing she had written.

Sometimes these reviews were conducted to show children that they could think about their previous writings for ideas or ways to add details in subsequent writings. Next, she referred back to the classroom experience as an impetus for current writing ideas. During these recollections, she explained that her ideas for writing were often sparked during the preceding classroom experience, after the read-aloud. Moments, thoughts, and feelings occurred to her in the middle of the experience that generated an idea for her demonstration writings. After she explained how her ideas formed, she began writingalways beginning with her name to designate ownership of the written composition.

Next, Ronda composed. During this composition phase of a demonstration, Ronda wrote using varied genres. Throughout, she incorporated the suggestions of the students, answered students' questions regarding her text, and engaged the students in further developments of her own text by adding details to her drawings. Towards the end of a demonstration, Ronda usually incorporated print to accompany her drawing. This print incorporation involved sounding out various words or sentences where the children were actively involved in matching letters to specific sounds.

A demonstration lesson concluded with students offering their plans for their own writing for the benefit of their peers. During each observed demonstration, Ronda explained her process as a writer as she composed her texts. These explanations provided students with insight into one writer's process for composing texts. It became apparent in the subsequent observations of student conversations at their tables as they wrote, and in their explanations of their final products, that the children internalized what they learned from Ronda and incorporated these understandings into their own writing. 
In an interview regarding her writing lessons, Ronda explained the different

components of them and the reasons for each element.

Before I put my name on my writing, I kind of want them to know where I get my idea from. I want them to know if I got the idea from a book, or a magazine, or just me talking to them about an experience before I actually start the writing so that they see where my ideas are coming from. I think that is the hardest thing for these guys - to understand where ideas are coming from and to verbalize it. They may know where their ideas are coming from but they are not able to verbalize it. So after my name is on my paper, then I go with my idea for the day. And after I have drawn the picture-I always think it is important to draw the picture firstthen I put some sort of print on the paper. I try to vary the print because I think that I have so many different levels. So, maybe one day I am just doingpumpkins start with $p$, so I just write $p$ 's on the paper. I think Talisha and a couple others are ready for sentences. So today, I wrote a sentence. I'm also trying to show them how to sound out words. I try to have them stretch out sounds and then I write down the sounds they say out loud. I am trying to get them to see how inventive spelling works and how we get the sounds.

[Interview, 10-18-05]

Ronda had a definitive process she used as she composed in front of her class of writers.

Each component served a specific purpose as Ronda introduced her students to notions about print.

Ronda went on to explain her purpose for talking aloud as she wrote:

Brian: I notice you are always talking about your thought process as you are writing. Why do you do that?

Ronda's Response: So that they can get into the habit of doing that themselves when they are writing. I also think it is important to take ideas from them, too, in the process. Sometimes I take their ideas and sometimes I don't so that they can understand that you don't ALWAYS have to listen to what somebody says about your writing. But it is also good for someone to make additions.

[Interview, 10-18-05]

The Three Major Elements of the Writing Demonstrations

In an analysis of the 34 writing demonstrations, Ronda incorporated these three elements: 1) she connected her writing to a gathering experience; 2) she incorporated 
print into her text; and 3) she provided a genre structure for the writing. She connected her writing to a gathering experience and provided a genre structure for her writing for every writing demonstration. She incorporated print into her text on 30 out of 34 occasions.

First, for every writing demonstration, the teacher made a connection with the preceding gathering experience. These connections involved her use of topics from her life, the read-aloud text, classroom conversations that occurred before writing, guidance counselor-led role plays, and outdoor events. The very purpose of the gathering experiences prior to the demonstration was to create a plethora of ideas for students to use as catalysts for their own writing. In the demonstration Ronda continuously showed how she used the gathering experience as a springboard for her writing with the hope that the students would recognize this as a possible strategy to use in their own writing. She never, however, told them to do likewise. They could always write about whatever they wanted.

Second, Ronda added print to her writing demonstrations $88 \%$ of the time. At the beginning of the observational period (at the start of the school year), she created drawings as her writing that were devoid of print. As the year progressed she began to incorporate letters to label specific symbols. This gradually increased to words and finally sentences, but she varied as a way to adjust to the various learning needs of her students. On each occasion Ronda incorporated print, she involved the students in helping her sound out the words. She accepted the general invented spelling concoctions of the students and transcribed the print on the page according to the students' understandings of the sound-symbol match. 
Third, Ronda used a specific genre structure to frame her writing. The genre structures varied during each observation with imaginary stories, personal recounts, and informational texts dominating her genre choices. Letters written to students and labeled writing were incorporated sporadically as structures, but not nearly as frequently as imaginary stories, personal recounts, and informational texts. Throughout the observational period, the pre-kindergarten students varied genre structures within their own compositions with some students experimenting with multiple genres.

In their own writing, the pre-kindergarten children did not incorporate print into their compositions at the beginning of the school year. As the year progressed, children began incorporating their notions of print into their writing by creating distinctly different forms on the paper to separate their print from drawing. Some students' print consisted of print-like forms that were linear in structure and maintained a traditional left-to-right progression. Some students started to use conventional letters by creating their names on their papers, thereby solidifying ownership of the page. Towards the completion of the observational period, I observed several students who purposefully matched specific letters to sounds in labels they created to describe their drawings. The teacher's inclusion of print into her own texts provided students with a demonstration of how print could be incorporated into their own.

Table 4.12 displays the frequency of the teacher's use of topics from the various gathering experiences, different genre structures, and types of print. Included in the table are the number of times the teacher used the aspects of each component in her writing and her percentage of frequency. 


\begin{tabular}{|c|c|c|}
\hline $\begin{array}{l}\text { Gathering Experience Provides } \\
\text { Idea for Text }\end{array}$ & $\begin{array}{c}\text { Number of Times Teacher Used } \\
\text { Experience as Catalyst for Her } \\
\text { Writing Idea }\end{array}$ & Percentage \\
\hline 1. Read Aloud & $22 / 34$ & $65 \%$ \\
\hline 2. Classroom Conversations & $7 / 34$ & $21 \%$ \\
\hline 3. Guidance Counselor Lesson & $3 / 34$ & $9 \%$ \\
\hline 4. Outdoor Events & $2 / 34$ & $5 \%$ \\
\hline \multicolumn{3}{|c|}{ Incorporation of Genre Structure } \\
\hline $\begin{array}{l}\text { Genres of the Teachers Writing } \\
\text { Demonstration }\end{array}$ & $\begin{array}{c}\text { Number of Times Teacher } \\
\text { Wrote Using Text Structures of } \\
\text { the Genre }\end{array}$ & Frequency Percentage \\
\hline 1. Imaginary stories & $13 / 34$ & $38 \%$ \\
\hline 2. Informational Texts & $11 / 34$ & $32 \%$ \\
\hline 3. Personal Recounts & $7 / 34$ & $21 \%$ \\
\hline 4. Pictures and Labels & $3 / 34$ & $9 \%$ \\
\hline 5. Letters* & $3 / 34$ & $9 \%$ \\
\hline \multicolumn{3}{|c|}{ Inclusion of Print in Writing } \\
\hline Types of Print & $\begin{array}{l}\text { Number of Times Teacher } \\
\text { Included Print in her Writing: }\end{array}$ & Frequency Percentage \\
\hline 1. Includes her name in writing & $30 / 34$ & $88 \%$ \\
\hline $\begin{array}{l}\text { 2. Matches letters with } \\
\text { corresponding sounds }\end{array}$ & $30 / 34$ & $88 \%$ \\
\hline $\begin{array}{l}\text { 3. Distinguishes between print } \\
\text { and drawing }\end{array}$ & $30 / 34$ & $88 \%$ \\
\hline $\begin{array}{l}\text { 4. Uses the Word Wall for } \\
\text { scaffolded support }\end{array}$ & $3 / 34$ & $9 \%$ \\
\hline
\end{tabular}

"Letters were written in addition to a regular writing demonstration

The next table (Table 4.13) displays each writing demonstration of the teacher, elements of the teacher's writing, and the influence of the teacher's writing demonstration on the final products of the students. 


\begin{tabular}{|c|c|c|c|}
\hline Date & Teacher's Writing & Elements of Teacher's Writing & $\begin{array}{c}\text { Influences of Teacher's } \\
\text { Demonstration on Student } \\
\text { Writing }\end{array}$ \\
\hline $8 / 29 / 05$ & & $\begin{array}{l}\text { Gathering Experience: } \\
\text { Classroom Conversation } \\
\text { Teacher talks with students about } \\
\text { hosting a party at her house. She } \\
\text { writes about the balloons she had } \\
\text { at the party. } \\
\text { Genre: Personal Recount } \\
\text { Types of Print } \\
\text { 1. Name } \\
\text { 2. Labels for drawing }\end{array}$ & $\begin{array}{l}\text { Idea from Gathering } \\
\text { Experience: None } \\
\\
\text { Personal Recount: } \\
\text { Talisha, Kendrick } \\
\text { Types of Print } \\
\text { 1. Name: None } \\
\text { 2. Letters to Drawing: } \\
\text { Malcolm, Talisha, Roderick }\end{array}$ \\
\hline $8 / 31 / 05$ & $\frac{b[a]}{\text { school bus }}$ & $\begin{array}{l}\text { Gathering Experience: } \\
\text { Classroom Conversation } \\
\text { Teacher and students talk about } \\
\text { the Open House from the night } \\
\text { before when parents arrived to } \\
\text { school on the school bus. } \\
\text { Genre: Personal Recount } \\
\text { Types of Print } \\
\text { 1. Writes the word: School } \\
\text { 2. Wus } \\
\text { Writes the word: stop }\end{array}$ & $\begin{array}{l}\text { Idea from Gathering } \\
\text { Experience: } \\
\text { 1. Bus: Pierson, Kallen } \\
\text { Personal Recount: None } \\
\text { Types of Print: } \\
\text { None }\end{array}$ \\
\hline $9 / 06 / 05$ & & $\begin{array}{l}\text { Gathering Experience: Read- } \\
\text { Aloud } \\
\text { Teacher and students interact } \\
\text { when reading a story. The teacher } \\
\text { writes about taking a walk to her } \\
\text { house. } \\
\text { Genre: Imaginary story } \\
\text { Types of Print: } \\
\text { None }\end{array}$ & $\begin{array}{l}\text { Personal Recounts: Frank, } \\
\text { Kallen, } \\
\text { Types of Print: } \\
\text { None }\end{array}$ \\
\hline
\end{tabular}




\begin{tabular}{|c|c|c|c|}
\hline $9 / 07 / 05$ & $\xi$ & $\begin{array}{l}\text { Gathering Experience: } \\
\text { Classroom Conversation } \\
\text { Teacher and students talk about } \\
\text { Cathie's birthday. Then Ronda } \\
\text { writes a birthday cake with } \\
\text { balloons and candles. } \\
\text { Genre: Informational text } \\
\text { Types of Print: } \\
\text { Name }\end{array}$ & $\begin{array}{l}\text { Idea from Gathering } \\
\text { Experience: } \\
\text { Balloons: Cathie, Chars } \\
\text { Birthday cake: Katalina, Kallen } \\
\text { Candles: Katalina } \\
\text { Informational Text: Katalina } \\
\text { Types of Print: } \\
\text { Names: Lisa, Josephina, Cathie, } \\
\text { Talisha, Ta-Loni, Malcolm }\end{array}$ \\
\hline $9 / 09 / 05$ & & $\begin{array}{l}\text { Gathering Experience: Guidance } \\
\text { Lesson } \\
\text { The guidance counselor talks with } \\
\text { the children about being happy. } \\
\text { Ronda and the children talked } \\
\text { about things that make them } \\
\text { happy. Ronda explained that her } \\
\text { children woke up happy so she } \\
\text { had a good night's sleep. } \\
\text { Genre: Personal Recount } \\
\text { Types of Print: } \\
\text { 1. Name } \\
\text { 2. The word, smile }\end{array}$ & $\begin{array}{l}\text { Idea from Gathering } \\
\text { Experience: } \\
\text { Happy feelings: Lisa, } \\
\text { Josephina, Kendrick, Ta-Loni, } \\
\text { Arianna } \\
\text { Faces: Lisa, Josephina, } \\
\text { Kendrick, Ta-Loni, Arianna } \\
\text { Smiling: Ta-Loni } \\
\text { Personal Recount: Katalina } \\
\text { Types of Print: } \\
\text { Names: Lisa, Josephina, Cathie, } \\
\text { Talisha, Ta-Loni, Malcolm }\end{array}$ \\
\hline $9 / 12 / 05$ & \begin{tabular}{|l|l}
1 & $x$ \\
& \\
\end{tabular} & $\begin{array}{l}\text { Gathering Experience: Outdoor } \\
\text { Experience } \\
\text { A balloon floated above the } \\
\text { school. The children went outside } \\
\text { to watch it. Ronda wrote an } \\
\text { imaginative story about how the } \\
\text { hot air kept the balloon afloat as } \\
\text { people waved to the children } \\
\text { below. } \\
\text { Genre: Imaginary story } \\
\text { Types of Print: } \\
\text { 1. Name } \\
\text { 2. The word, hot }\end{array}$ & $\begin{array}{l}\text { Idea from Gathering } \\
\text { Experience: } \\
\text { Hot Air Balloon: Talisha, Chars, } \\
\text { Travion } \\
\\
\text { Imaginary storles: Frank, Jibir, } \\
\text { Kallen, Talisha } \\
\text { Types of Print: } \\
\text { Names: Pierson, Jibir, Kallen, } \\
\text { Talisha } \\
\text { Adding Print to Drawing: } \\
\text { Pierson }\end{array}$ \\
\hline
\end{tabular}




\begin{tabular}{|c|c|c|c|}
\hline $9 / 14 / 05$ & $\underbrace{}_{\pi} A$ & $\begin{array}{l}\text { Gathering Experience: Read- } \\
\text { Aloud } \\
\text { Ronda read a story aloud about a } \\
\text { cat. In response to the story, she } \\
\text { wrote a personal account about } \\
\text { her own cat getting lost. During } \\
\text { this account she talks with the } \\
\text { students about how she left the } \\
\text { door open and that is how her cat } \\
\text { escaped. } \\
\text { Genre: Personal recount } \\
\text { Types of Print: } \\
\text { 1. Name } \\
\text { 2. The words, cat and love }\end{array}$ & $\begin{array}{l}\text { Idea from Gathering } \\
\text { Experience: } \\
\text { Door: Pierson, Cathie, Katalina } \\
\text { Personal recounts: Pierson } \\
\text { Types of Print: } \\
\text { Names: Lisa }\end{array}$ \\
\hline $9 / 16 / 05$ & Ms. & $\begin{array}{l}\text { Gathering Experience: Guidance } \\
\text { Lesson } \\
\text { During the guidance lesson, the } \\
\text { children and the guidance } \\
\text { counselor talked about sad } \\
\text { feelings. In response, Ronda } \\
\text { wrote an imaginative story about a } \\
\text { sad moon. } \\
\text { Genre: Imaginary story } \\
\text { Types of Print: Name }\end{array}$ & $\begin{array}{l}\text { Idea from Gathering } \\
\text { Experience: } \\
\text { Moon: Kallen } \\
\text { Face: Pierson, Chars } \\
\text { Sun: Jibir } \\
\text { Imaginary stories: Kallen, } \\
\text { Roderick, Lisa, Frank } \\
\text { Types of Print: } \\
\text { Names: Jibir, Talisha, Cathie }\end{array}$ \\
\hline $9 / 19 / 05$ & 3 & $\begin{array}{l}\text { Gathering Experience: Read- } \\
\text { Aloud } \\
\text { Ronda read the story, The Three } \\
\text { Billy-Goats Gruff. In response, } \\
\text { she wrote about a troll with green } \\
\text { hair, humongous eyes, and flared } \\
\text { nostrils. She writes the number } \\
\text { three to show how many billy- } \\
\text { goats came across his path. } \\
\text { Genre: Imaginative story } \\
\qquad \\
\text { Types of Print: } \\
\text { 1. Name } \\
\text { 2. Sounds out the word, troll } \\
\text { 3. The number: } 3\end{array}$ & $\begin{array}{l}\text { Idea from Gathering } \\
\text { Experience: } \\
\text { Mad face: Jibir, Kallen } \\
\text { Imaginary stories: Kallen, } \\
\text { Lisa, Frank } \\
\text { Types of Print: } \\
\text { Names: Cathie, Talisha, } \\
\text { Josephina, Malcolm, Lisa, Ta- } \\
\text { Loni, Kallen } \\
\text { Matching letters to sounds: } \\
\text { Talisha }\end{array}$ \\
\hline
\end{tabular}




\begin{tabular}{|c|c|c|c|}
\hline $9 / 21 / 05$ & Ms. Ronda & $\begin{array}{l}\text { Gathering Experience: } \\
\text { Classroom Conversation } \\
\text { Ronda and the students talk about } \\
\text { pumpkins. In response, Ronda } \\
\text { writes about a big, medium, and } \\
\text { small pumpkin based on the } \\
\text { suggestions of the students. } \\
\text { Genre: Imaginary story } \\
\text { Types of Print: } \\
\text { 1. Name } \\
\text { 2. The letter } p \text { to represent } \\
\text { pumpkin }\end{array}$ & $\begin{array}{l}\text { Idea from Gathering } \\
\text { Experience: } \\
\text { None } \\
\text { Imaginary stories: Kallen, } \\
\text { Lisa, Chars } \\
\text { Types of Print: } \\
\text { Names: Jibir }\end{array}$ \\
\hline $9 / 23 / 05$ & & $\begin{array}{l}\text { Gathering Experience: Read- } \\
\text { Aloud } \\
\text { Ronda and her students talk about } \\
\text { an informational book about } \\
\text { apples. In response, Ronda writes } \\
\text { an apple tree and explains to the } \\
\text { children how some apples fall to } \\
\text { the ground. } \\
\text { Genre: Informational text } \\
\text { Types of Print: } \\
\text { 1. Name } \\
\text { 2. The words, apple tree }\end{array}$ & $\begin{array}{l}\text { Idea from Gathering } \\
\text { Experience: } \\
\text { None } \\
\text { Informational texts: Ta-Loni, } \\
\text { Lisa } \\
\text { Types of Print: } \\
\text { Names: Chars, Jibir, Kallen, } \\
\text { Talisha, Frank }\end{array}$ \\
\hline $9 / 28 / 05$ & $\frac{8^{b g}}{1}$ & $\begin{array}{l}\text { Gathering Experience: Read- } \\
\text { Aloud } \\
\text { Ronda and her students talk about } \\
\text { an informational magazine about } \\
\text { spiders. Ronda creates a story } \\
\text { about a large, medium, and baby } \\
\text { spider. } \\
\text { Genre: Imaginary story } \\
\text { Types of Print: } \\
\text { 1. Name } \\
\text { 2. The letters bg for bug }\end{array}$ & $\begin{array}{l}\text { Idea from Gathering } \\
\text { Experience: } \\
\text { Spider: Lisa, Chars, Ta-Loni, } \\
\text { Roderick } \\
\text { Bugs: Lisa, Chars, Ta-Loni, } \\
\text { Roderick } \\
\text { Imaginary stories: Lisa, Ta- } \\
\text { Loni, Kallen } \\
\text { Types of Print: } \\
\text { Names: Cathie, Talisha, Jibir }\end{array}$ \\
\hline $9 / 30 / 05$ & & $\begin{array}{l}\text { Gathering Experience: Guidance } \\
\text { Lesson } \\
\text { The children participate in a } \\
\text { guidance lesson about rainy-day } \\
\text { feelings. In response, Ronda } \\
\text { writes an imaginative story about } \\
\text { a girl who is sad that she cannot } \\
\text { go outside to play because it is }\end{array}$ & $\begin{array}{l}\text { Idea from Gathering } \\
\text { Experience: } \\
\text { Raindrops: Josephina, Cathie } \\
\text { Little Girl: Lisa, Talisha }\end{array}$ \\
\hline
\end{tabular}




\begin{tabular}{|c|c|c|c|}
\hline & 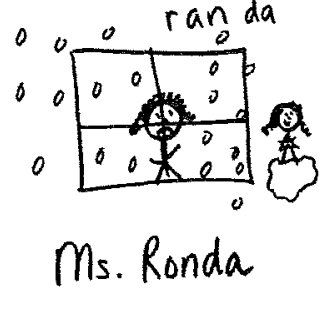 & $\begin{array}{l}\text { raining outside. } \\
\text { Genre: Imaginary story } \\
\text { Types of Print: } \\
\text { 1. Name } \\
\text { 2. The words, rain day }\end{array}$ & $\begin{array}{l}\text { Imaginary stories: Roderick, } \\
\text { Talisha, Lisa, Kallen, Jibir } \\
\text { Types of Print: } \\
\text { Names: Talisha }\end{array}$ \\
\hline $10 / 03 / 05$ & M. Ron & $\begin{array}{l}\text { Gathering Experience: Outdoor } \\
\text { Experience } \\
\text { Ronda and her students go } \\
\text { outside. When they gather back } \\
\text { into the classroom, Ronda creates } \\
\text { an imaginative story about a little } \\
\text { boy who goes outside to play with } \\
\text { his friends. } \\
\text { Genre: Imaginary story } \\
\text { Types of Print: } \\
\text { 1. Name } \\
\text { 2. The words, sune da to } \\
\text { represent sunny day. }\end{array}$ & $\begin{array}{l}\text { Imaginary story: Kallen, } \\
\text { Malcolm, Travion } \\
\text { Types of Print: } \\
\text { None }\end{array}$ \\
\hline $10 / 05 / 05$ & $\begin{array}{l}\text { Ms. Ronda } \\
\text { : }\end{array}$ & $\begin{array}{l}\text { Gathering Experience: } \\
\text { Classroom Conversation } \\
\text { Ronda and her students talk about } \\
\text { the weather outside. In response, } \\
\text { Ronda writes about a rainy day. } \\
\text { A boy is sad because he cannot go } \\
\text { outside to play. His mom tells the } \\
\text { child that he can play in the rain. } \\
\text { The child puts on his raincoat and } \\
\text { goes outside to play. } \\
\text { Genre: Imaginative story } \\
\text { Types of Print: } \\
\text { 1. Name } \\
\text { 2. The word, rain }\end{array}$ & $\begin{array}{l}\text { Imaginary stories: Kallen, } \\
\text { Pierson, Chars, Cathie } \\
\text { Types of Print: } \\
\text { Names: Jibir, Ta-Loni, Frank, } \\
\text { Talisha }\end{array}$ \\
\hline $10 / 07 / 05$ & IIIje pumpkin & $\begin{array}{l}\text { Gathering Experience: Read- } \\
\text { Aloud } \\
\text { Ronda and her students talk about } \\
\text { an informational magazine about } \\
\text { pumpkins. } \\
\text { Genre: Informational text } \\
\text { Types of Print: } \\
\text { 1. Name } \\
\text { 2. The sentence, I like pumpkins. }\end{array}$ & $\begin{array}{l}\text { Idea from Gathering } \\
\text { Experience: } \\
\text { Pumpkins: Pierson, Cathie, } \\
\text { Jibir, Arianna } \\
\text { Informational texts: Pierson, } \\
\text { Talisha, Malcolm, Cathie } \\
\text { Types of Print: } \\
\text { Names: Jibir }\end{array}$ \\
\hline
\end{tabular}




\begin{tabular}{|c|c|c|c|}
\hline $10 / 10 / 05$ & 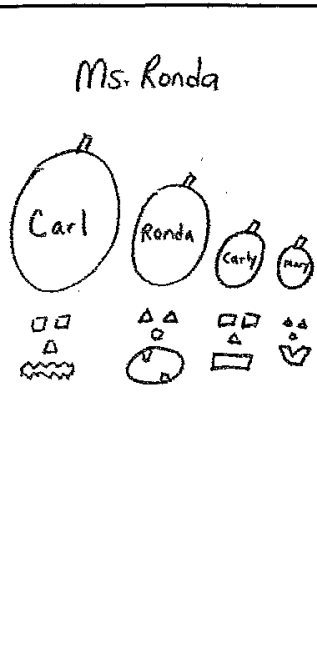 & $\begin{array}{l}\text { Gathering Experience: Read- } \\
\text { Aloud } \\
\text { After Ronda reads the book, the } \\
\text { students talk about carving } \\
\text { pumpkins. Ronda explains that } \\
\text { her family carved pumpkins last } \\
\text { year. She drew and labeled the } \\
\text { different Jack-O-Lanterns that } \\
\text { they created for Halloween } \\
\text { Genre: Draw and Label } \\
\text { Types of Print: } \\
\text { 1. Name } \\
\text { 2. The names of family members }\end{array}$ & $\begin{array}{l}\text { Idea from Gathering } \\
\text { Experience: } \\
\text { Family: Travion, Katalina, Ta- } \\
\text { Loni, Cathie, Talisha } \\
\text { Draw and Label: Pierson } \\
\text { Types of Print: } \\
\text { Names: Talisha, Frank, Pierson } \\
\text { Names of Family: Travion, } \\
\text { Pierson }\end{array}$ \\
\hline $10 / 11 / 05$ & $y^{A}$ & $\begin{array}{l}\text { Gathering Experience: Read- } \\
\text { Aloud } \\
\text { Ronda read an informational book } \\
\text { about apples growing on trees. In } \\
\text { response, Ronda writes about a } \\
\text { family visit to an apple orchard. } \\
\text { At the apple orchard, she picked } \\
\text { apples with her children. } \\
\text { Genre: Personal recount } \\
\text { Types of Print: } \\
\text { 1. Name } \\
\text { 2. The letter } A \text { to represent the } \\
\text { word apple. }\end{array}$ & $\begin{array}{l}\text { Idea from Gathering } \\
\text { Experience: } \\
\text { Apples: Jibir, Cathie, Chars } \\
\text { Personal recount: Arianna } \\
\text { Types of Print: } \\
\text { Names: Jibir } \\
\text { As on paper: Cathie }\end{array}$ \\
\hline $10 / 12 / 05$ & $\begin{array}{l}\text { Carly Mary } \\
\text { seds }\end{array}$ & $\begin{array}{l}\text { Gathering Experience: Read- } \\
\text { Aloud } \\
\text { After Ronda reads a book about } \\
\text { pumpkins, she pulls out two mini- } \\
\text { pumpkins from a bag. The } \\
\text { children look and touch the } \\
\text { pumpkins then describe the } \\
\text { feeling. In response, Ronda draws } \\
\text { two pumpkins on her paper and } \\
\text { writes the names of her children } \\
\text { underneath. She then tells the } \\
\text { class that there are seeds in the } \\
\text { pumpkins. } \\
\text { Genre: Draw and Label } \\
\text { Types of Print: } \\
\text { 1. Name } \\
\text { 2. The names of family members } \\
\text { 3. The word seds [seeds] }\end{array}$ & $\begin{array}{l}\text { Draw and Label: Pierson } \\
\text { Types of Print: } \\
\text { Names: Chars, Pierson, Jibir, } \\
\text { Talisha, Lisa, Cathie } \\
\text { Print: Pierson }\end{array}$ \\
\hline
\end{tabular}




\begin{tabular}{|c|c|c|c|}
\hline $10 / 17 / 05$ & ms. Ronda & $\begin{array}{l}\text { Gathering Experience: Read- } \\
\text { Aloud } \\
\text { After Ronda reads a book aloud to } \\
\text { the children, the students talk } \\
\text { about the Berenstein Bears. In } \\
\text { response, Ronda writes about a } \\
\text { bear who walks in the grass } \\
\text { carrying a basket of apples. } \\
\text { Genre: Imaginary story } \\
\text { Types of Print: } \\
\text { 1. Name } \\
\text { 2. The letters, apl for apple } \\
\text { 3. The letters, br for bear }\end{array}$ & $\begin{array}{l}\text { Idea from Gathering } \\
\text { Experience: } \\
\text { Apples: Talisha } \\
\text { Bear: Kendrick } \\
\text { Imaginary stories: Kallen, } \\
\text { Jibir, Kenderick, Lisa, Chars } \\
\text { Types of Print: } \\
\text { Names: Pierson, Roderick, } \\
\text { Jibir, Talisha, Arianna, Lisa } \\
\text { Print on Puper: Cathie, } \\
\text { Katalina }\end{array}$ \\
\hline $10 / 18 / 05$ & Ms. Ronda & $\begin{array}{l}\text { Gathering Experience: Read- } \\
\text { Aloud } \\
\text { After Ronda reads a book aloud } \\
\text { about spiders, she connects the } \\
\text { informational text to the story } \\
\text { Charlotte's Web. The students } \\
\text { and Ronda discuss how the spider } \\
\text { and the pig became friends in the } \\
\text { story. Ronda then writes an } \\
\text { imaginative story about the pig } \\
\text { and the spider. } \\
\text { Genre: Imaginary story } \\
\text { Types of Print: } \\
\text { 1. Name } \\
\text { 2. The sentence, I love pigs. }\end{array}$ & $\begin{array}{l}\text { Imaginary stories: Pierson, } \\
\text { Travion } \\
\text { Types of Print: } \\
\text { Names: Lisa, Travion, Ta-Loni, } \\
\text { Talisha, Jibir } \\
\text { Print on Paper: Cathie, } \\
\text { Katalina }\end{array}$ \\
\hline $10 / 19 / 05$ & & $\begin{array}{l}\text { Gathering Experience: Read- } \\
\text { Aloud } \\
\text { Ronda and the students talk about } \\
\text { animals and their mamas in } \\
\text { response to the read-aloud. For } \\
\text { writing, Ronda decides to draw a } \\
\text { picture of her mother and label the } \\
\text { drawing with her mother's name. } \\
\text { Like the read-aloud text, she then } \\
\text { creates rhyming words to } \\
\text { accompany her mother's name. } \\
\text { Genre: Draw and Label } \\
\text { Types of Print: } \\
\text { 1. Rhyming words }\end{array}$ & $\begin{array}{l}\text { Idea from Gathering } \\
\text { Experience: } \\
\text { Mother: Frank, Talisha, Ta- } \\
\text { Loni, Arianna } \\
\text { Draw and Label: None } \\
\text { Types of Print: } \\
\text { Print: Lisa, Talisha }\end{array}$ \\
\hline
\end{tabular}




\begin{tabular}{|c|c|c|c|}
\hline $10 / 27 / 05$ & $\begin{array}{l}\text { fsh Shre } \\
\infty \\
\text { La La La La La } \\
\text { Im coming affor you. }\end{array}$ & $\begin{array}{l}\text { Gathering Experience: } \\
\text { Classroom Conversation } \\
\text { Ronda and the students discuss } \\
\text { the topic of sharks eating fish. In } \\
\text { response, Ronda draws a shark's } \\
\text { mouth eating fish. She pretends } \\
\text { that the shark is talking by saying, } \\
\text { "La, la, la, la, la. I'm coming } \\
\text { after you." } \\
\text { Genre: Imaginary story } \\
\text { Types of Print: } \\
\text { 1. The words, fsh and shrc } \\
\text { 2. The sentences, La la la la la. } \\
\text { I'm coming after you. }\end{array}$ & $\begin{array}{l}\text { Idea from Gathering } \\
\text { Experience: } \\
\text { Shark: Travion, Pierson, } \\
\text { Roderick, Kallen, Lisa } \\
\text { Underwater scene: Kallen } \\
\\
\text { Imaginary stories: Pierson, } \\
\text { Travion } \\
\text { Types of Print: } \\
\text { None }\end{array}$ \\
\hline $10 / 31 / 05$ & & $\begin{array}{l}\text { Gathering Experience: Read- } \\
\text { Aloud } \\
\text { Ronda and her students talk about } \\
\text { an informational magazine about } \\
\text { pumpkins. In response, Ronda } \\
\text { writes about the life cycle of a } \\
\text { pumpkin. } \\
\text { Genre: Informational text } \\
\text { Types of Print: } \\
\text { Letters to Sounds: The sentence, } \\
\text { Mi pmpkn gros [My pumpkin } \\
\text { grow.] }\end{array}$ & $\begin{array}{l}\text { Idea from Gathering } \\
\text { Experience: } \\
\text { Pumpkins: Kallen, Lisa, } \\
\text { Josephina } \\
\text { Informational texts: Lisa, } \\
\text { Josephina } \\
\text { Types of Print: } \\
\text { Names: Katalina, Kallen, } \\
\text { Talisha, Lisa, Ta-Loni, Frank, } \\
\text { Cathie, Roderick, Arianna, } \\
\text { Pierson } \\
\text { Letters to sounds: Talisha }\end{array}$ \\
\hline $11 / 02 / 05$ & $v_{2}^{2}$ 由 & $\begin{array}{l}\text { Gathering Experience: } \\
\text { Classroom Conversation } \\
\text { Ronda hangs up a picture of a fall } \\
\text { scene. The students talk about } \\
\text { what they notice in the picture. } \\
\text { Ronda writes a personal account } \\
\text { describing the time a crow lived } \\
\text { by her house and woke her up } \\
\text { every morning. } \\
\text { Genre: Personal recount } \\
\text { Types of Print: } \\
\text { 1. Name } \\
\text { 2. The words, caw, caw, caw. }\end{array}$ & $\begin{array}{l}\text { Personal recounts: Frank, Lisa } \\
\text { Types of Print: } \\
\text { Names: Cathie, Frank, } \\
\text { Malcolm, Pierson, Ta-Loni, } \\
\text { Lisa, Arianna }\end{array}$ \\
\hline
\end{tabular}




\begin{tabular}{|c|c|c|c|}
\hline $11 / 03 / 05$ & $\begin{array}{l}\text { smores yonda } y \text { mmy } \\
\text { Smores } \\
\text { I love smores. }\end{array}$ & $\begin{array}{l}\text { Gathering Experience: Read- } \\
\text { Aloud } \\
\text { Ronda reads aloud an } \\
\text { informational text about autumn. } \\
\text { After reading the text, she talks } \\
\text { with her students about a family } \\
\text { camping trip. She writes about } \\
\text { making s'mores with her children } \\
\text { using marshmallows. } \\
\text { Genre: Personal recount } \\
\text { Types of Print: } \\
\text { 1. Name } \\
\text { 2. The words: } s^{\prime} \text { mores and ymmy } \\
\text { 3. The sentence: Ilove s'mores }\end{array}$ & $\begin{array}{l}\text { Personal recounts: Lisa, Ta- } \\
\text { Loni, Talisha, Frank } \\
\text { Types of Print: } \\
\text { Names: Roderick, Lisa, } \\
\text { Arianna, Talisha, Cathie, } \\
\text { Pierson, Kallen } \\
\text { Print: Chars, Kallen, Cathie, } \\
\text { Pierson }\end{array}$ \\
\hline $11 / 09 / 05$ & chpmk & $\begin{array}{l}\text { Gathering Experience: Read- } \\
\text { Aloud } \\
\text { Ronda and her students talk about } \\
\text { an informational magazine about } \\
\text { chipmunks. After their } \\
\text { discussion, Ronda draws a } \\
\text { chipmunk on her paper. She } \\
\text { informs the children that the } \\
\text { chipmunk stored nuts in his } \\
\text { mouth. } \\
\text { Genre: Informational text } \\
\text { Types of Print: } \\
\text { Matching Letters to Sounds: } \\
\text { chpmk for chipmunk }\end{array}$ & $\begin{array}{l}\text { Informational texts: Talisha, } \\
\text { Chars, Malcolm, Katalina } \\
\text { Types of Print: } \\
\text { Names: Katalina, Arianna, } \\
\text { Talisha, Lisa, Josephina, } \\
\text { Roderick, Chars, Cathie } \\
\text { Letters to sounds: Chars }\end{array}$ \\
\hline $11 / 10 / 05$ & 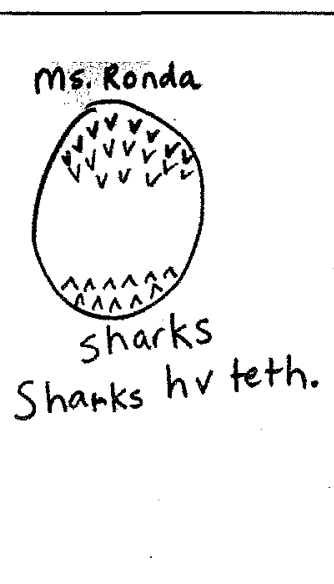 & $\begin{array}{l}\text { Gathering Experience: Read- } \\
\text { Aloud } \\
\text { Ronda and her students talk about } \\
\text { an informational book about } \\
\text { sharks. In response, Ronda writes } \\
\text { facts about sharks in her writing. } \\
\text { Genre: Informational text } \\
\\
\text { Types of Print: } \\
\text { 1. Name } \\
\text { 2. The word: sharks } \\
\text { 3. The sentence: Sharks } h v \text { teth } \\
\text { [Sharks have teeth] }\end{array}$ & $\begin{array}{l}\text { Informational texts: None } \\
\text { Types of Print: } \\
\text { Names: Lisa, Chars, Cathie, } \\
\text { Kallen } \\
\text { Letters to sounds: Frank, } \\
\text { Kallen }\end{array}$ \\
\hline
\end{tabular}




\begin{tabular}{|c|c|c|c|}
\hline $11 / 11 / 05$ & 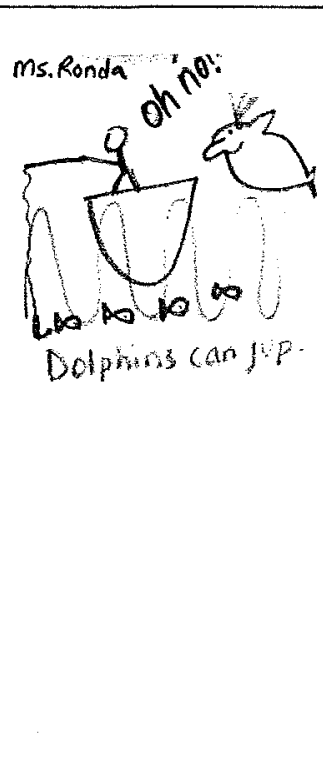 & $\begin{array}{l}\text { Gathering Experience: Read- } \\
\text { Aloud } \\
\text { Ronda reads an informational } \\
\text { book about dolphins. Ronda and } \\
\text { her children talk about the book } \\
\text { together. Then, Ronda writes an } \\
\text { imaginative story about a man } \\
\text { fishing from the boat. He realized } \\
\text { something was wrong when a } \\
\text { dolphin jumped into the boat with } \\
\text { him. } \\
\text { Genre: Imaginary story } \\
\text { Types of Print: } \\
\text { 1. The sentence, Oh no! } \\
\text { 2. The sentence, Dolphins can jup } \\
\text { [Dolphins can jump]. }\end{array}$ & $\begin{array}{l}\text { Imaginary stories: Kallen, } \\
\text { Chars, Pierson } \\
\text { Types of Print: } \\
\text { Name: Talisha, Kallen, } \\
\text { Josephina, Roderick, Katalina, } \\
\text { Cathie, Pierson, Lisa, Jibir }\end{array}$ \\
\hline $11 / 15 / 05$ & $\begin{array}{l}\mathrm{Brz} \\
\mathrm{Wr} \\
\mathrm{Br}\end{array}$ & $\begin{array}{l}\text { Gathering Experience: Read- } \\
\text { Aloud } \\
\text { Ronda read an informational book } \\
\text { about robins laying eggs. In } \\
\text { response, she wrote an } \\
\text { informational text by drawing a } \\
\text { tree and writing two facts about } \\
\text { birds. } \\
\text { Genre: Informational text } \\
\text { Types of Print: } \\
\text { 1. The sentence: Brz et wrms } \\
\text { [Birds eat worms.] } \\
\text { 3. The sentence: Brz fli [Birds } \\
\text { fly]. }\end{array}$ & $\begin{array}{l}\text { Idea from Gathering } \\
\text { Experience: } \\
\text { Eggs: Roderick } \\
\text { Informational texts: Kendrick, } \\
\text { Ta-Loni, Talisha, Lisa } \\
\text { Types of Print: } \\
\text { None }\end{array}$ \\
\hline $11 / 16 / 05$ & $\left(\begin{array}{ll}3 \\
0\end{array}\right.$ & $\begin{array}{l}\text { Gathering Experience: } \text { Read- } \\
\text { Aloud } \\
\text { Ronda read an informational book } \\
\text { about foods to eat for } \\
\text { Thanksgiving. In response, she } \\
\text { wrote an informational text about } \\
\text { foods that can be eaten at a } \\
\text { Thanksgiving feast. } \\
\text { Genre: Informational text } \\
\text { Types of Print: } \\
\text { 1. Words: frk [fork], nif [knife], } \\
\text { spn [spoon], km [com], pes } \\
\text { [peas], pie }\end{array}$ & $\begin{array}{l}\text { Idea from Gathering } \\
\text { Experience: } \\
\text { Foods: Talisha } \\
\text { Informational text: Pierson, } \\
\text { Talisha, Lisa, Cathie } \\
\text { Types of Print: } \\
\text { Matching letters to sounds: } \\
\text { Lisa }\end{array}$ \\
\hline
\end{tabular}




\begin{tabular}{|c|c|c|c|}
\hline $11 / 21 / 05$ & 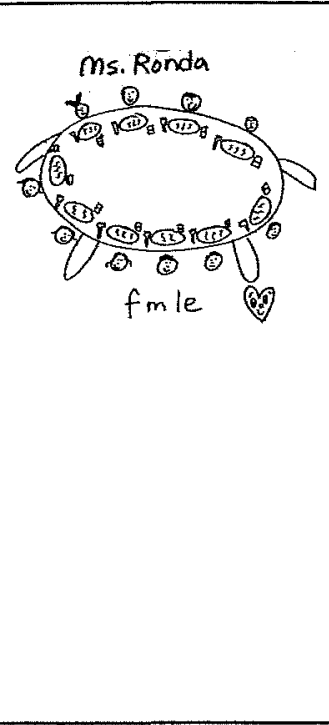 & $\begin{array}{l}\text { Gathering Experience: Read- } \\
\text { Aloud } \\
\text { Ronda read an informational book } \\
\text { about a Thanksgiving gathering. } \\
\text { The children and Ronda talked } \\
\text { about things that would be seen at } \\
\text { a Thanksgiving feast. Ronda } \\
\text { wrote an informational text when } \\
\text { she informed the children that a } \\
\text { family gathers around a table for } \\
\text { Thanksgiving. } \\
\text { Genre: Informational text } \\
\text { Types of Print: } \\
\text { Words: frk [fork], nif [knife], spn } \\
\text { [spoon], krn [com], pes [peas], pie }\end{array}$ & $\begin{array}{l}\text { Informational text: Pierson, } \\
\text { Talisha, Lisa, Cathie } \\
\text { Types of Print: } \\
\text { Matching letters to sounds: } \\
\text { Lisa }\end{array}$ \\
\hline $11 / 22 / 05$ & 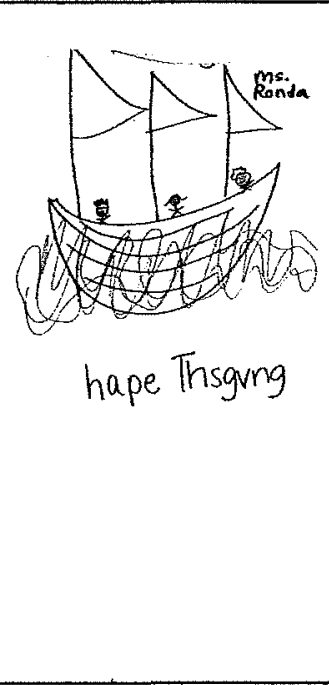 & $\begin{array}{l}\text { Gathering Experience: Read- } \\
\text { Aloud } \\
\text { Ronda read an informational book } \\
\text { about the Mayflower. The } \\
\text { children and Ronda talked about } \\
\text { the Mayflower coming to } \\
\text { America. Ronda wrote pilgrims } \\
\text { in a boat whose faces turned green } \\
\text { because they are sea-sick. } \\
\text { Genre: Informational text } \\
\text { Types of Print: } \\
\text { 1. Name } \\
\text { 2. Words: hape Thsgvng [Happy } \\
\text { Thanksgiving] }\end{array}$ & $\begin{array}{l}\text { Idea from Gathering } \\
\text { Experience: } \\
\text { Boat: Malcolm } \\
\text { Informational text: Talisha, } \\
\text { Lisa, Malcolm, Jibir, Roderick } \\
\text { Types of Print: } \\
\text { Names: Talisha, Lisa, Malcolm, } \\
\text { Jibir, Kallen, Cathie }\end{array}$ \\
\hline $11 / 28 / 05$ & $\frac{G \sqrt{\pi} \pi}{\text { Wetu }_{\pi}}$ & $\begin{array}{l}\text { Gathering Experience: Read } \\
\text { Aloud } \\
\text { Ronda read an informational book } \\
\text { about Native Americans. The } \\
\text { children and Ronda talked about a } \\
\text { wetu which is a Native American } \\
\text { tent. Ronda wrote an } \\
\text { informational text about how } \\
\text { Native Americans lived in wetus. } \\
\text { Genre: Informational text } \\
\text { Types of Print: } \\
\text { Words: frk [fork], nif [knife], spn } \\
\text { [spoon], km [corn], pes [peas], pie }\end{array}$ & $\begin{array}{l}\text { Idea from Gathering } \\
\text { Experience: } \\
\text { Bed: Talisha, Lisa, Ta-Loni } \\
\text { Informational text: Cathie } \\
\text { Types of Print: } \\
\text { Name: Cathie, Talisha, } \\
\text { Malcolm, Lisa, Roderick, Ta- } \\
\text { Loni }\end{array}$ \\
\hline
\end{tabular}


The students were influenced by the teacher's writing demonstration in three different ways. Most frequently, the students used the teacher's writing demonstration for initial ideas. This occurred when the students incorporated elements of Ronda's writing demonstration into their own texts when they included similar symbols, ideas, and themes. Next, the teacher's writing demonstration influenced children as they developed their understanding of written language. Students recognized the print the teacher added to her writing and added print to their own texts via name writing and matching letters with sounds. Finally, the teacher's writing demonstration influenced children's understandings of various genres. The teacher used varied genres in her demonstration texts, and, likewise, when the children wrote, they did not confine themselves to one particular genre. Rather, several students experimented with different genres as they composed their texts. Examples of the teacher's influence on the writing of the students will be fleshed out in the following sections.

\section{Children Use the Teacher's Writing Demonstration for Ideas in Their Own Writing}

After reading a story about a rooster finding her way home, Ronda decided to write a similar story using herself as the main character (Figure 4.21). In her story, she drew a house with a winding path leading to it. Along the way home, Ronda trotted past some flowers and a tree. When she finally made it home, she jumped over a newspaper in her path and walked into her house. 


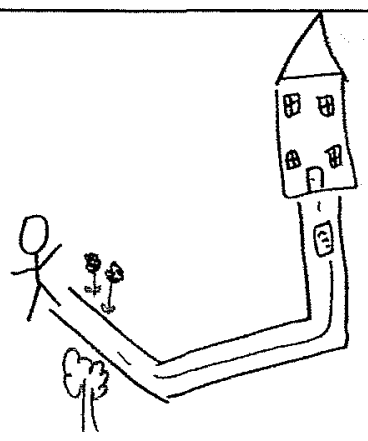

Figure 4.21. Ronda's writing demonstration. 9/06/05

The following conversation occurred during that demonstration:

Ronda: This book reminds me of a walk I took. I'm going to draw me walking. I love to walk. There I am! Down this path. Around the corner. Back up again. End up at my house. I walked around this tree. I walked on top of this newspaper here.

Roderick: It's a rerun!

Ronda: It's a rerun! It's like the book, isn't it?

Travion: I bet the chicken had the fox chasing him. I saw a fox at my grandma's house.

Ronda: And I jumped over the newspaper.

Chars: I went to grandma's house.

Kallen: I'm going to write my house and my whole family. And my house too.

[Transcript 9-06-05]

After the children wrote, they explained the meanings of their writing. Talisha's writing

(Figure 4.22) contained her name and a house.

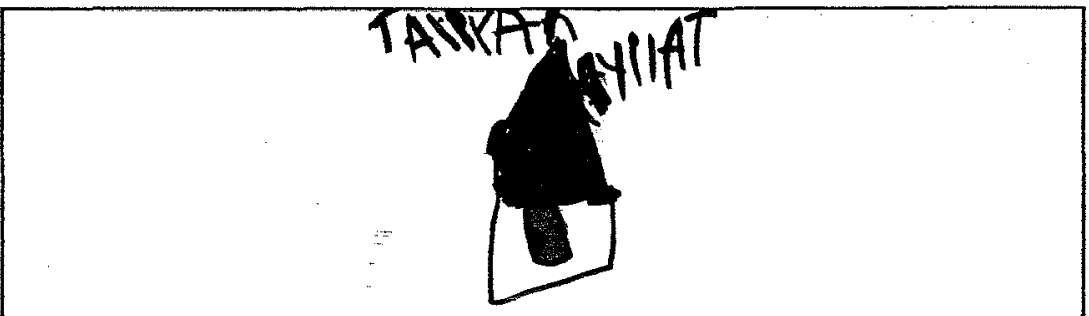

Figure 4.22. Talisha's writing. 9/06/05.

Talisha's explanation: "Me and my family and my house." 
Like the teacher, the home had a roof and a door; Talisha used the teacher's writing demonstration as a support for symbol-making in her text. She went further when she included her name and orally added her family to the text. In this way, Talisha used her teacher's initial writing idea, and then transformed it into her own product with meaning that is different than the teacher's.

Similarly, Pierson (Figure 4.23) incorporated several elements of the Ronda's demonstration into his own writing.

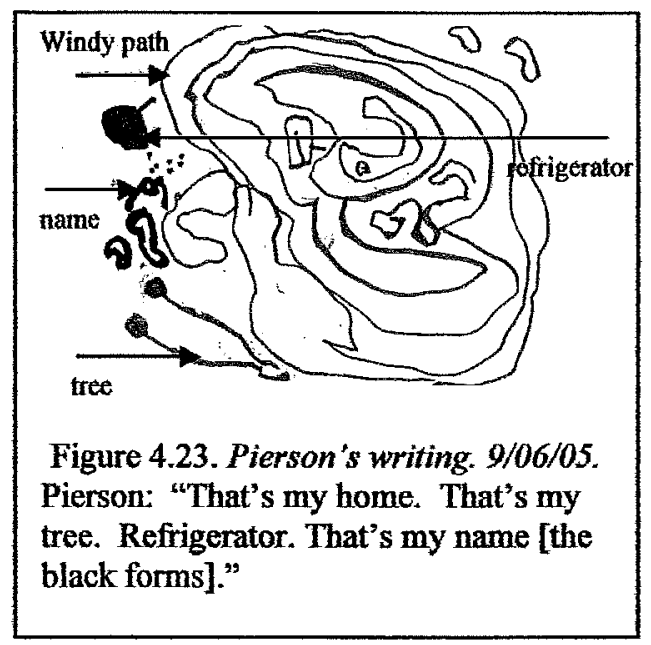

He created a long winding path and included a tree, thus incorporating several of the same symbols that are prevalent in the teacher's text. Then, the meaning of his text digresses to include his name and a refrigerator-two symbols not present in the teacher's writing. 
Kallen's writing contained the same winding path and grass around the house that is seen in the teacher's writing demonstration (Figure 4.24).

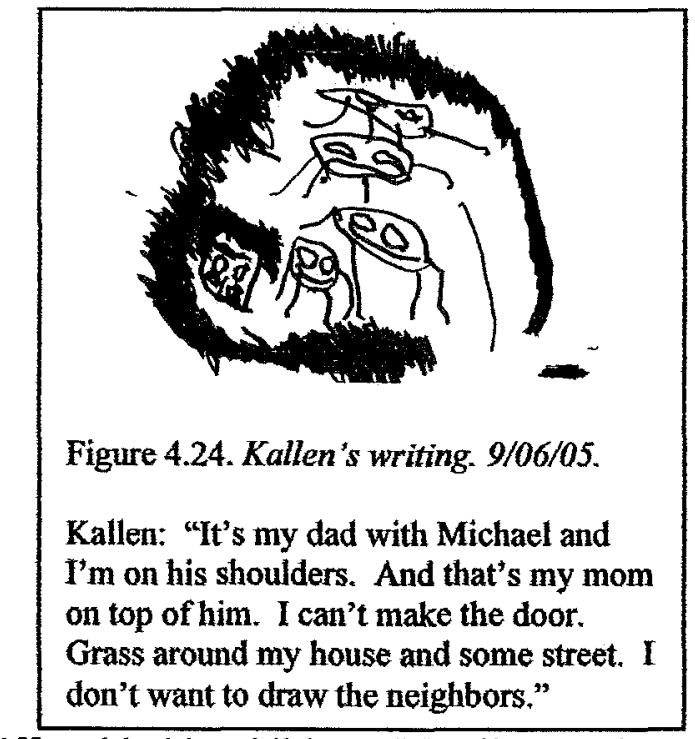

Kallen's writing differed in his addition of family members to his text. Then, without prompting, Kallen explained that he was not going to draw the neighbors into his writing. In this example, the teacher's writing demonstration was essential to Kallen's initial idea; her demonstration served Kallen's purpose of getting started in his writing. His own ideas and agenda transformed the teacher's symbols into his own unique text with meaning.

On another day, Kallen once again incorporated the teacher's writing demonstration into his own writing. Here Ronda wrote about a moon with a face (Figure 4.25). Then, she explained that the moon was crying because it was very sad. She did not give any reasons for the moon's sadness. She simply drew a moon, added facial features and tears, and explained to the students that the moon was sad. Kallen did something similar in his own writing (Figure 4.26). 


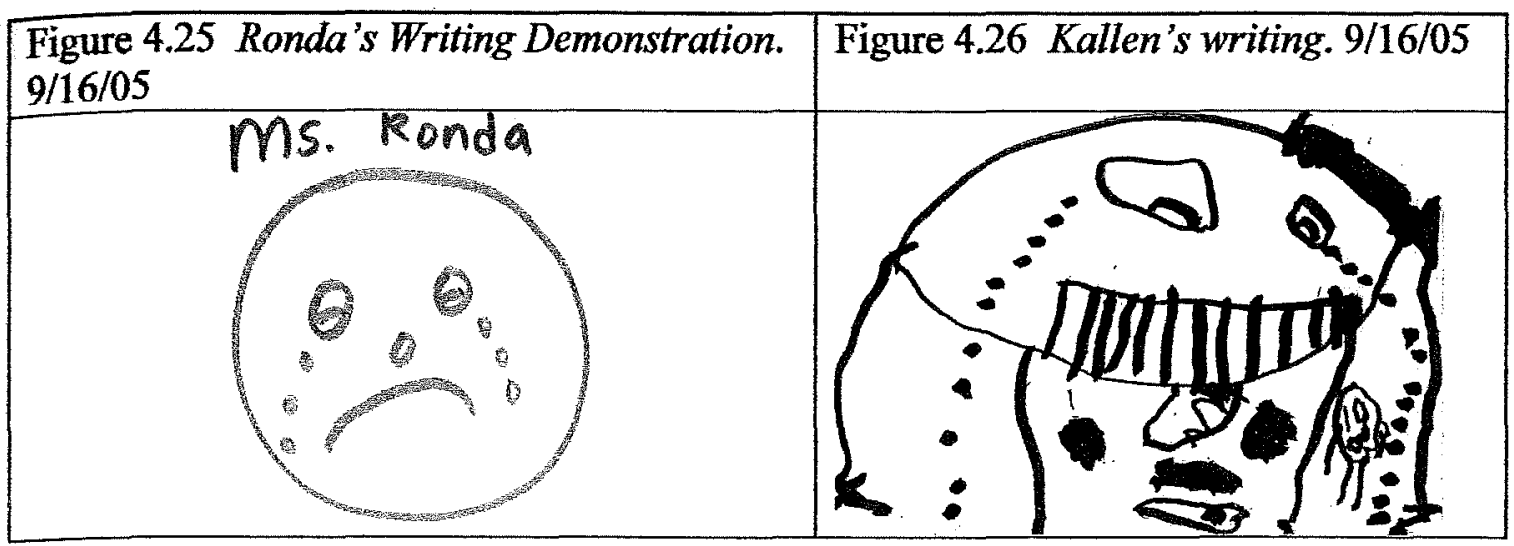

He explained, "That's a moon. And he's sad. Those are his tears." This reflected Ronda's writing. Then, Kallen continued his explanation of the meaning by diverging from the teacher's text. "He has arms and legs. And those are his teeth. And that is his sword and it is pointing that way. And these are the Sun's swords and that's one sword and this is a sword." The idea of the teacher's writing demonstration is present in Kallen's writing, but he took her symbols and transformed them to create his own. Ronda never provided an explanation for the moon's sadness. Kallen did. In Kallen's writing, the moon was in a battle with the Sun involving swords. The moon lost, contributing to his sadness.

Throughout the observational period, there were several instances of students incorporating specific ideas from the teacher's writing demonstrations. Children in the class were cognizant of the ideas, internalized them, talked about them with peers while in the process of writing, and created their own texts using similar ideas with unique twists.

When Ronda wrote pumpkins with the names of family members within them (Figure 27), Pierson did the same, differing in that his own name appears in every pumpkin rather than family names (Figure 4.28). 


Ms. Ronda

Talisha's writing (Figure 4.30) mirrored Ronda's when Ronda wrote about being awakened by crows (Figure 4.29). The two pieces of writing are almost identical in that they both contain the name of the writer, a home with doors and a window, and Zs coming from the window. Talisha's writing differs in that she continues to practice creating these symbols through repetition-repeating the symbol of a home, an additional $\mathrm{Z}$, a separate window, and additional print.

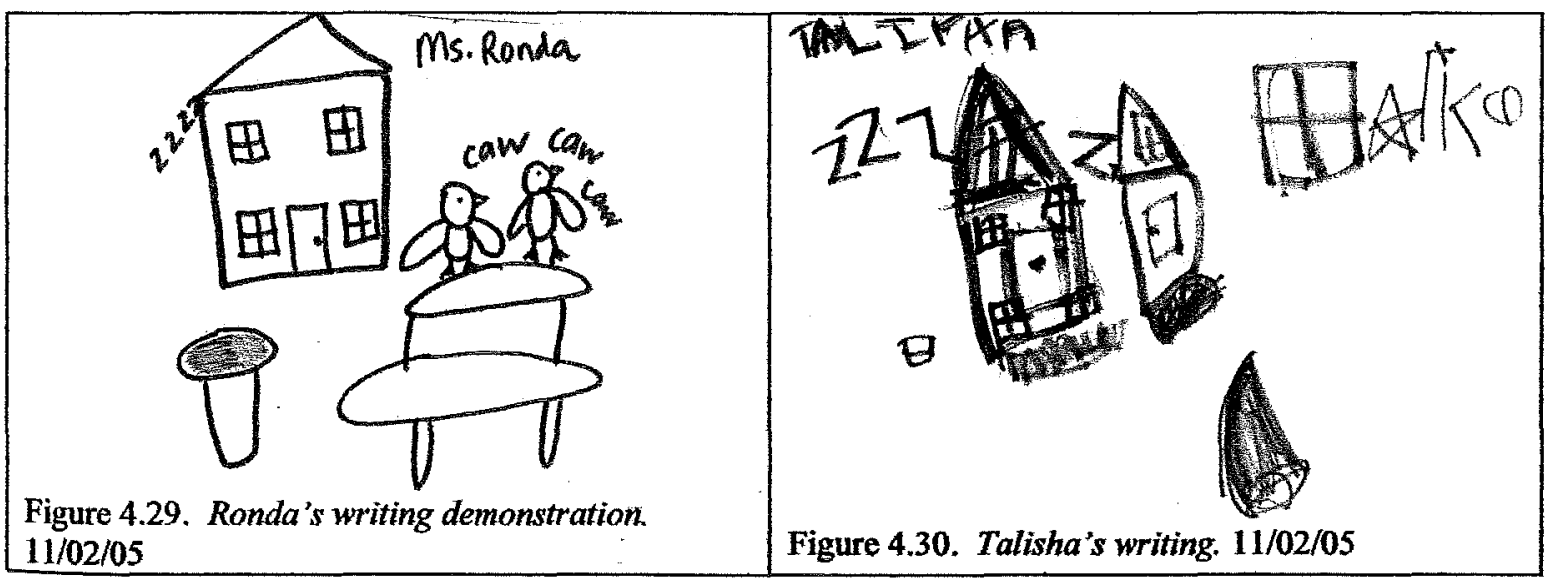

On the day when Ronda wrote about the Mayflower and its passage to America, Roderick created a text by drawing a boat and water (Figure 4.31). For Roderick, his writing differed in that people fell out of the boat and into the water (Figure 4.32). 


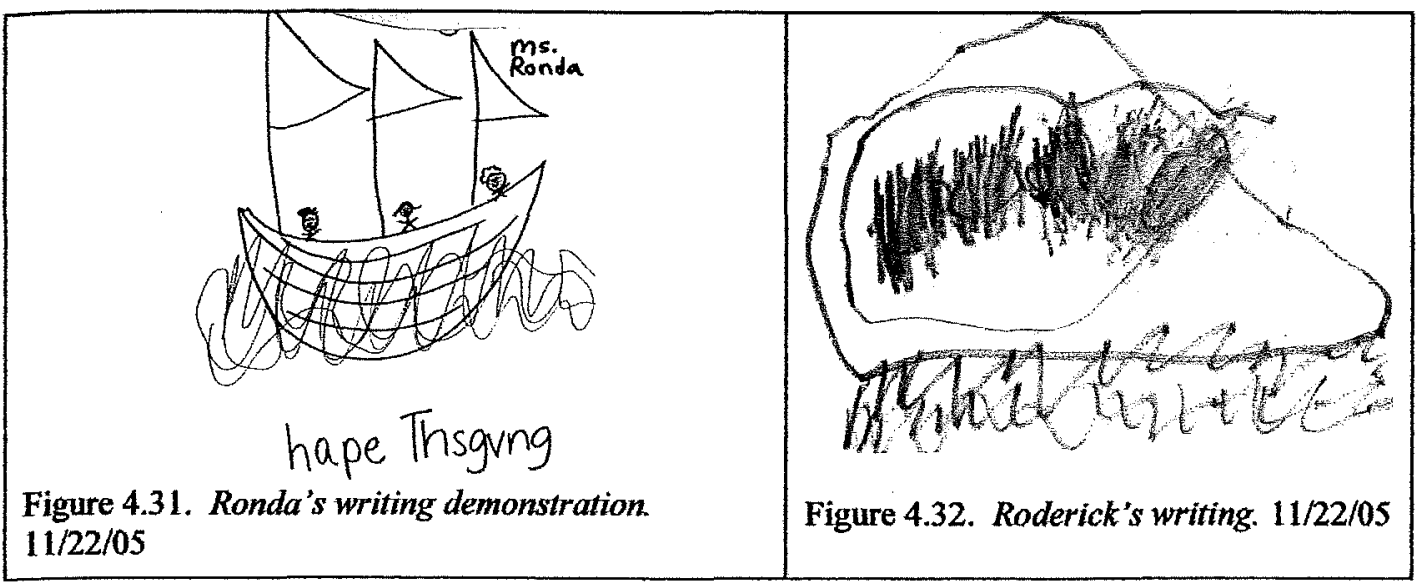

The teacher's writing demonstration, therefore, was a strong influence on the ideas and symbols the students used in their writing. The demonstration provided children with ideas for writing and a plethora of symbols for them to use to convey meanings in their own ways.

Table 4.14 displays the number of times a student incorporated a symbol from the teacher's writing demonstration into their own writing, and is arranged according to the child's frequency of use of the symbols. 


\begin{tabular}{|l|l|l|l|}
\hline $\begin{array}{l}\text { Table 4.14. Symbols of the Teacher's Writing Demonstration Incorporated by } \\
\text { Students in their Own Writing. }\end{array}$ \\
\hline Child & $\begin{array}{l}\text { Number of } \\
\text { Times a } \\
\text { Student } \\
\text { Incorporated a } \\
\text { Symbol from } \\
\text { the Writing } \\
\text { Demonstration } \\
\text { into their own } \\
\text { Writing }\end{array}$ & $\begin{array}{l}\text { Number of } \\
\text { Written } \\
\text { Documents } \\
\text { Collected } \\
\text { during Data } \\
\text { Collection }\end{array}$ & $\begin{array}{l}\text { Frequency (Out of their } \\
\text { total number of collected } \\
\text { products, the percentage } \\
\text { of student products that } \\
\text { incorporated a symbol } \\
\text { from the teacher's writing } \\
\text { demonstration into their } \\
\text { own writing) }\end{array}$ \\
\hline Talisha & 14 & 33 & $42 \%$ \\
\hline Pierson & 12 & 31 & $39 \%$ \\
\hline Chars & 12 & 31 & $39 \%$ \\
\hline Cathie & 11 & 33 & $33 \%$ \\
\hline Lisa & 9 & 32 & $28 \%$ \\
\hline Malcolm & 8 & 31 & $26 \%$ \\
\hline Ta-Loni & 6 & 24 & $25 \%$ \\
\hline Kallen & 8 & 33 & $24 \%$ \\
\hline Jibir & 7 & 32 & $22 \%$ \\
\hline Arianna & 6 & 28 & $21 \%$ \\
\hline Katalina & 6 & 32 & $19 \%$ \\
\hline Travion & 5 & 30 & $17 \%$ \\
\hline Kendrick & 4 & 24 & $17 \%$ \\
\hline Roderick & 5 & 31 & $16 \%$ \\
\hline Josephina & 4 & 32 & $13 \%$ \\
\hline Frank & 1 & 24 & $4 \%$ \\
\hline & & & \\
\hline
\end{tabular}

For some students the writing demonstration did not make a demonstrated impact in terms of symbol incorporation. Josephina, a Latina student who knew very little English, did not understand much of what was being said during the writing demonstration. On 4 out of 32 occasions she incorporated elements of the teacher's writing. Frank, Roderick, and Kendrick were unresponsive during most writing demonstrations. Frank looked around the classroom, at his classmates, or on the ground - rarely venturing his eyes upward toward the teacher. Kendrick and Roderick were often busy distracting others, rather than focusing their attention on the 
demonstration. These four students appeared to gain little from the teacher's writing demonstrations.

On the other hand, some students frequently used Ronda's writing demonstrations as support for their own writing. Talisha, Pierson, Chars, and Cathie offered Ronda suggestions for her writing and studied her process of creating particular symbols on the chart paper. When exposed to new symbols through the demonstration, these students tried to repeat the symbols in their own writing and used the writing of this "expert" as a guide for their own creations.

In general, the demonstration quenched an initial thirst for ideas. After the children were supplied with ideas from the demonstration, they continued to write beyond the symbols they witnessed; the energy gathered from the writing demonstration empowered the children to bring forth ideas; in this way, the teacher's writing demonstration was a critical component in students' understandings of the uses of ideas and symbols for written communication. The students learned ways of using symbols to show ideas, and used this knowledge to repeat, reconfigure, and reinvent the symbols.

\section{The Teacher's Writing Demonstration Led Children to Explore Uses of Print}

In Ronda's writing demonstrations, she gradually started to add print to her pictures. Repeated exposures to print in the teacher's writing demonstrations led the children to explore print in their own writing. Initially, this began with their names. However, as the children began to witness the letter-sound matching Ronda incorporated during her demonstrations, they began to use the same letter-sound correspondence process sporadically in their own writing. In the following sections, I will explore the 
connections between the teacher's writing demonstrations and the children's inclusion of their names and letter-sound print connections in their writing.

\section{Children include their names in their writing}

When Ronda began her writing demonstrations, she started by writing her name on the paper. She explained her purpose for this in an interview.

Well, I first put my name on the paper. I want them to know that they should have ownership of their writing and drawing. It is theirs and I want them to be proud of what they do.

[Interview 10-18-05]

Ronda's addition of her name on the writing served two purposes. First, she felt that writing was a personal endeavor for her children and adding their names to their writing differentiated the writing from those of their peers. Secondly, in informal interviews, she asserted that she added her name so that children would begin to acquire concepts of print. In the pre-kindergarten classroom, exposure to letters was an essential component of the curriculum. Ronda felt the best way to increase her students' knowledge of the alphabet was through repeated exposures to their names. Because of this, the students were constantly inundated with their names written around the classroom. Children saw their names on their chairs, the Word Wall, the cubbies, on bulletin boards, and charts. During writing, children often referred to the environmental print as a way to write letters and words into their own writing. This immersion allowed the children to instantly recognize their names and individual letters of their names when Ronda wrote. As Ronda matched letters and sounds to her own writing, children frequently announced, "That's my name" when they saw letters from their name connected with Ronda's print.

Table 4.15 shows the frequency with which children added their names to their writing. 


\begin{tabular}{|l|l|l|l|}
\hline \multicolumn{4}{|c|}{ Table 4.15. Frequency of Students' Name Addition to Text. } \\
\hline Child & $\begin{array}{l}\text { Number of } \\
\text { Collected } \\
\text { Writing } \\
\text { Documents: }\end{array}$ & $\begin{array}{l}\text { Number } \\
\text { of Times } \\
\text { a Child } \\
\text { Included } \\
\text { his/her } \\
\text { name: }\end{array}$ & $\begin{array}{l}\text { Percentage } \\
\text { of Written } \\
\text { Texts } \\
\text { Containing } \\
\text { their } \\
\text { Name }\end{array}$ \\
\hline Talisha & 33 & 25 & $76 \%$ \\
\hline Jibir & 32 & 18 & $56 \%$ \\
\hline Lisa & 32 & 16 & $50 \%$ \\
\hline Cathie & 33 & 15 & $45 \%$ \\
\hline Ta-Loni & 24 & 9 & $38 \%$ \\
\hline Roderick & 31 & 10 & $32 \%$ \\
\hline Kallen & 33 & 10 & $30 \%$ \\
\hline Frank & 24 & 7 & $29 \%$ \\
\hline Pierson & 31 & 9 & $29 \%$ \\
\hline Arianna & 28 & 7 & $25 \%$ \\
\hline Katalina & 32 & 7 & $22 \%$ \\
\hline Travion & 30 & 6 & $20 \%$ \\
\hline Chars & 31 & 5 & $16 \%$ \\
\hline Malcolm & 31 & 5 & $16 \%$ \\
\hline Kendrick & 24 & 2 & $8 \%$ \\
\hline Josephina & 32 & 2 & $6 \%$ \\
\hline
\end{tabular}

Those children who frequently added their names to the texts (Talisha, Jibir, Lisa, and Cathie) are the same children we will read about in the next section about letter-sound matching. The children (Josephina and Kendrick) who rarely incorporated their names into their writing were also reluctant to add any other print to their texts. Instead, they opted to only draw as their avenue of communication. Still others (Kallen and Malcolm) viewed print as an ancillary component of their writing. They occasionally added their names and even some letter-sound matching to their writing, but their focus was on the meaning they conveyed through their pictures. To appease the teacher, they occasionally wrote their names on top of their papers, but the stories and informational texts came alive through their explanations of their drawings. 
Children who frequently added their names to their texts did so for different reasons. Talisha explained her purpose for writing her name in an interview.

I do my name when I first start writing. I do that 'cause if I don't write my name, Ms. Ronda might put it in the wrong bookbag.

[Interview 11-21-05]

Talisha included her name because she wanted to make sure that her writing came back to her; printing her name served as a method of showing ownership. Table 4.16 displays Talisha's name progression throughout the observational period.

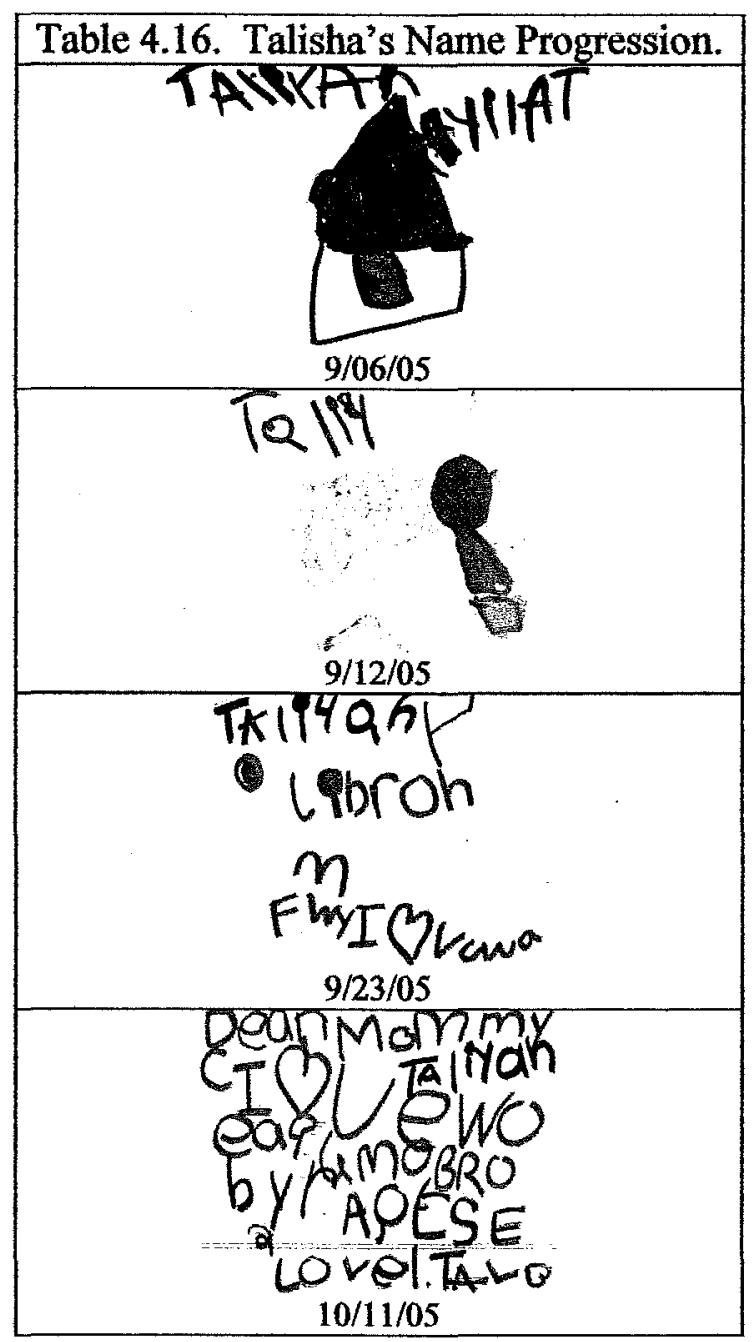




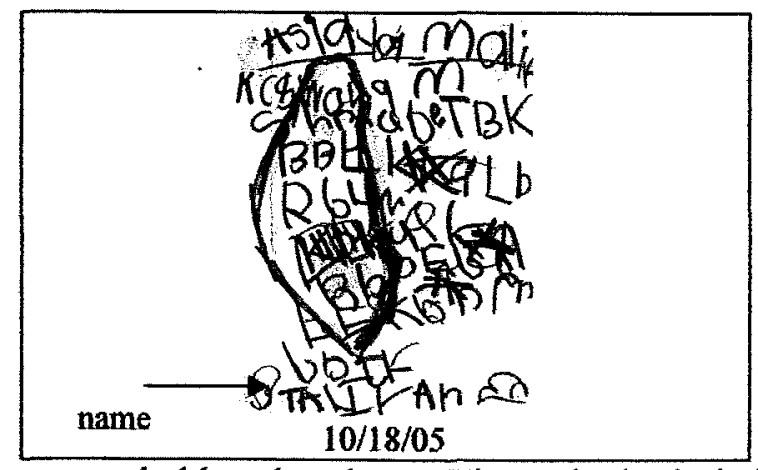

First, her name accompanied her drawings. Then, she included other print as she wrote on the page. She uses her name in a letter, then moves beyond her name and incorporates print into all forms of her writing.

Talisha's progression was rare in Ronda's classroom. Most children who included their names did so to accompany their drawings. The meaning was still conveyed through drawings with their names used primarily as an identification tool. As seen in the writing of Jibir, Lisa, and Cathie (Table 4.17), the name was an addition to the writing and not the purpose for writing.

\begin{tabular}{|l|l|l|}
\hline Table 4.17. Name Progression of Jibir, Lisa, and Cathie. \\
\hline Jibir & Lisa \\
\hline
\end{tabular}




\begin{tabular}{|l|l|}
\hline & \\
\hline
\end{tabular}

Besides ownership, name writing in Ronda's classroom served the purpose of introducing children to print. As children began to discover the letters of their own names, they also started to recognize the letters in the names of their peers. As evidenced in Jibir's writing on 11/16/05, he incorporated an A to represent Arianna's name. Other students began to do the same thing in their writing, as they paid close attention to their peers as they wrote.

The incorporation of others' names in their writing encouraged students to learn additional letters. As they interacted with one another while in the process of writing, they were exposed to various letters beyond their names. This entire process introduced children to the letters of the alphabet without the teacher explicitly focusing on a specific letter of the day. Thus, print awareness in this classroom was formed when students wrote, watched others write, and experimented with letters in their own writing. Their 
learning about alphabetic letters came within the context of social interactions with the teacher and peers.

Children match letters with corresponding sounds

As Ronda's writing demonstrations progressed throughout the year, she labeled her drawings with letters. In doing this, the children saw the relevance of print in writing as it related to the drawing they created on the page. On eight different occasions, children incorporated print in their writing that matched an element of their drawing. Table 4.18 shows how children accomplished this in their writing.

\begin{tabular}{|l|l|l|}
\hline Table 4.18. Students Match Letters and Sounds in their Writing. \\
Teacher's Writing with Print \\
Correspondence
\end{tabular}




\begin{tabular}{|c|c|c|}
\hline Rondanda & $\begin{array}{l}\text { Pierson's writing. } 9 / 28 / 05 \\
\text { Pins }\end{array}$ & $\begin{array}{l}\text { "C and T. I did cat. I just } \\
\text { said the word." }\end{array}$ \\
\hline Ronda's writing demonstration. 10/11/05 & $\begin{array}{l}\text { now } \\
\text { Cathie's writing. 10/11/05 }\end{array}$ & $\begin{array}{l}\text { "This is the apple and this is } \\
\text { the green apple. And this is } \\
\text { the rainbow. And this is an } \\
\text { A for apple." }\end{array}$ \\
\hline $\begin{array}{c}\text { Rs. Ronda } \\
\text { Shandarks hv teth. } \\
\text { Shanding demonstration. 11/10/05 }\end{array}$ & 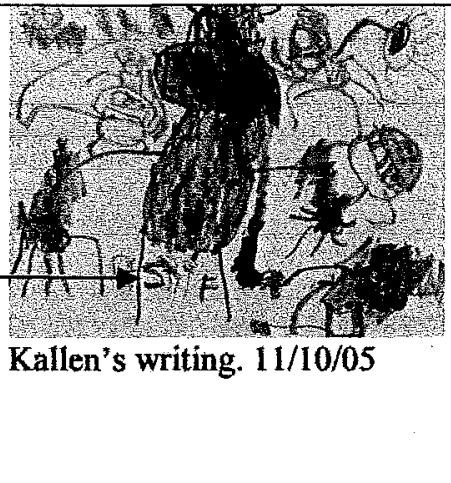 & $\begin{array}{l}\text { "I made a fire guy and a lot } \\
\text { of guys are trying to pull out } \\
\text { his brains so he can turn into } \\
\text { a small guy and not get fire } \\
\text { anymore. This guy has fire } \\
\text { pouring out of his brain. } \\
\text { This guy is pulling out his } \\
\text { brain. This guy is trying to } \\
\text { grab this guy's big giant } \\
\text { claw. And that's it. Oh, and } \\
\text { this down here says, 'Fire } \\
\text { show.' And that's it." }\end{array}$ \\
\hline$y$ & Frank's writing. $11 / 10 / 05$ & $\begin{array}{l}\text { "My bike. My food. } \\
\text { Waffles. These are } \\
\text { numbers. I wrote Bs. B } \\
\text { starts with bike." }\end{array}$ \\
\hline Ronda's writing demonstration. 11/09/05 & 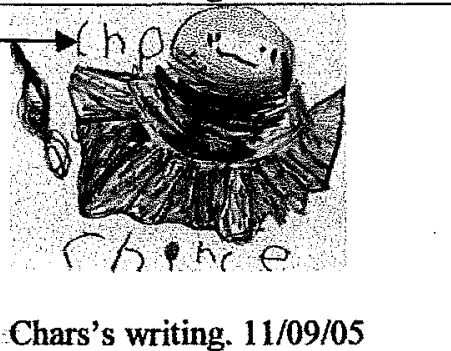 & $\begin{array}{l}\text { "A chipmunk. It's a } \\
\text { different chipmunk. He has } \\
\text { a green face. No, he have } \\
\text { a...I don't know how to put } \\
\text { it. He have two tails." }\end{array}$ \\
\hline
\end{tabular}

Pierson's $h$ for hot, Cathie's $A$ for apples, and Chars's $c h p$ for chipmunk were reflective of the same letters Ronda wrote in her own writing. Pierson's $h$ is truly a copy of Ronda's writing; it didn't fit into his text. Cathie's $A$ fits because she wrote about apples. The symbol and letter are similar to Ronda's demonstration, but Cathie appears to have a 
sense of purpose for including the $A$ next to her apple. Chars used Ronda's symbols and letters (along with the read-aloud text) but he did so in his own way. Other children stepped beyond Ronda's exact letters; they seemed to understand the concept of matching letters to sounds and did so in relation to their own pictures. Talisha printed a $b$ to accompany her butterfly. Pierson printed $C T$ for cat. Kallen printed $F S h$ for fire show. These three writers departed from the teacher's text and show a deeper understanding of matching letters to corresponding sounds.

It was the teacher's writing demonstration, however, that awakened these children to incorporate letter-sound connections in their writing. She involved them in the writing demonstration by asking for their assistance in matching letters to sounds in her own writing. The children saw print emerge in texts, and began to make similar connections in their own texts as they labeled different parts of their drawings with letters.

The Teacher's Writing Demonstrations Encouraged Children to Explore Various Genres In Ronda's writing demonstrations, the genres she used to frame her writing varied. In August and September she relied heavily on personal recounts and imaginary stories as structures for her texts. A shift happened in the months of October and November as she started to include more informational writing in her demonstrations. Without abandoning the other text genres, she started to incorporate more informationaltype of texts in her writing. This shift reflected the changes she made in the types of texts she read-aloud to her children. In the earlier months, the read-aloud texts reflected a recount and narrative structure, and towards the latter part of the observational period, the texts were more focused on conveying information. Immersed within the three dominant 
genres (personal recount, imaginary story, and informational text) were instances when Ronda drew and labeled texts and wrote letters to various students. The frequency of genre occurrences is displayed in Table 4.19.

\begin{tabular}{|c|c|c|c|c|c|}
\hline Table 4.19. The Genre Structures Used in the Teacher's Writing Demonstrations \\
\hline $\begin{array}{c}\text { Teacher's } \\
\text { Writing } \\
\text { Demonstration }\end{array}$ & August & September & October & November & Total \\
\hline $\begin{array}{c}\text { Personal } \\
\text { Recounts }\end{array}$ & 2 & 2 & 1 & 2 & 7 \\
\hline Imaginary stories & 0 & 7 & 5 & 1 & 13 \\
\hline $\begin{array}{c}\text { Informational } \\
\text { Text }\end{array}$ & 0 & 2 & 2 & 7 & 11 \\
\hline Letters & 0 & 0 & 3 & 0 & 3 \\
\hline Research Writing & 2 & 12 & 10 & 10 & 34 \\
\hline
\end{tabular}

As children were exposed to the various genres in the read-aloud text and the teacher's writing demonstration, they began to incorporate elements of the genres into their own writing. Personal recounts, imaginary stories, informational texts, letters, and other purposes for writing began to emerge in their written products and explanations. In the next four sections, I will show how several children incorporated the above genres into their writing.

\section{Personal Recounts}

Ronda wrote personal recounts on seven different occasions during the observational period. Each of these personal recounts involved an event that occurred with her family that often included her husband and two children. While it cannot be certain that the teacher's own personal recounts were the impetus for students' recounts, her tendency to write about her own family gave children the notion that writing about family events was valued. Table 4.20 displays the personal recounts of several students. 
Their knowledge of the genre is woven throughout the written text and elaborated upon in their oral explanations.

\begin{tabular}{|l|l|}
\hline Table 4.20. Students who Used Personal Recounts as a Genre \\
Structure. \\
\hline Student Writing & $\begin{array}{l}\text { Student Explanation } \\
\text { "This is a cab. So somebody can get a ride } \\
\text { home. Me and my mommy and my brother Ta- } \\
\text { Quan. We took a cab home last night." }\end{array}$ \\
\hline Talisha's writing. 9/06/05 & $\begin{array}{l}\text { "I did me and my mommy and my daddy and } \\
\text { my big sister and my little sister. We are } \\
\text { jumping in the water. That me and my daddy } \\
\text { name. But my daddy not home anymore. My } \\
\text { daddy told me that he working tonight because } \\
\text { my daddy want to get some money for me and } \\
\text { my sister and my baby sister and my mommy. } \\
\text { My daddy said that he going to work all night." }\end{array}$ \\
\hline
\end{tabular}


In each example, the children show their own knowledge of the genre in their writing. The reader is provided an orientation to a family member followed by an event or series of events that occurred in a sequence. The events that are recorded appear to reflect actual experiences that occurred in the lives of the students. As the children noticed this structure in the writing demonstration of the teacher, they experimented with elements of the genre in their own writing. In this way, the writing demonstration of the teacher was essential in their increasing knowledge of personal recount as a genre structure and of the importance of personal experiences to writers.

Imaginary stories

Ronda included 13 imaginary stories in her demonstration writings during the observational period. Her stories were character-driven with a problem that occurred at the beginning of the story and resolved at the end through a series of events. The child who incorporated stories most frequently in his writing was Kallen, an imaginative Caucasian boy, who wrote silently without much interaction with his peers. His stories were complex, often involving superheroes. A collection of his stories is displayed in Table 4.21.

\begin{tabular}{|l|l|}
\hline Table 4.21. Kallen's Stories. & Kallen's Explanation of the Stories \\
\hline Kallen's Written Stories & $\begin{array}{l}\text { That's Mike [Kallen's brother]. He has a black eye. } \\
\text { Me and Mike are fighting over a cookie. And I } \\
\text { have a black eye and a blue eye. Mike is happy } \\
\text { because he can pull my cookie away from me. } \\
\text { That's a small head jumping on the bed. But it } \\
\text { doesn't really happen. I don't even have a cookie } \\
\text { jar at home!" }\end{array}$ \\
\hline $9 / 14 / 05$
\end{tabular}




"That is a man. His mouth is messed up. That is a
ghost. He came to the man and bit off his mouth.
The ghost flew over to him and ripped off his
mouth."


Kallen's stories may be indicative of the shows he watches at home in front of the television where stories like these happen on a daily basis in cartoon programming geared towards young children. It could be that Kallen's narrative awareness comes more from these programs than the fantasy stories Ronda constructs in front of the class. However, Ronda's use of imaginary stories as a viable genre option, coupled with her own explanations of how to construct stories when writing, provided Kallen with encouragement to bring these texts to life on the page. Additionally, because Ronda created a classroom environment where all writing is valued and encouraged, Kallen found his own unique voice in constructing stories. As his knowledge of the story genre grew, his texts become more complex in their structure. Characters became more defined and detailed, problems were added, multiple events occurred which led to more definitive conclusions. Like the teacher's demonstration stories, Kallen learned that stories often have problems that are resolved at the end. The teacher's writing demonstration, and his own notions about story development, are reflected in his writing.

\section{Informational texts}

Ronda used informational texts throughout the observational period. She read seven informational texts as the read-aloud, and created informational texts 11 times as the genre structure for her writing demonstrations. For the purpose of this dissertation, informational text is defined as a report that "documents, organizes, and stores factual information on a topic" (Derewianka, 1990). Analysis of the data indicates that five children used informational text as a genre structure in a total of six texts they created. Their informational texts are displayed in Table 4.22. 


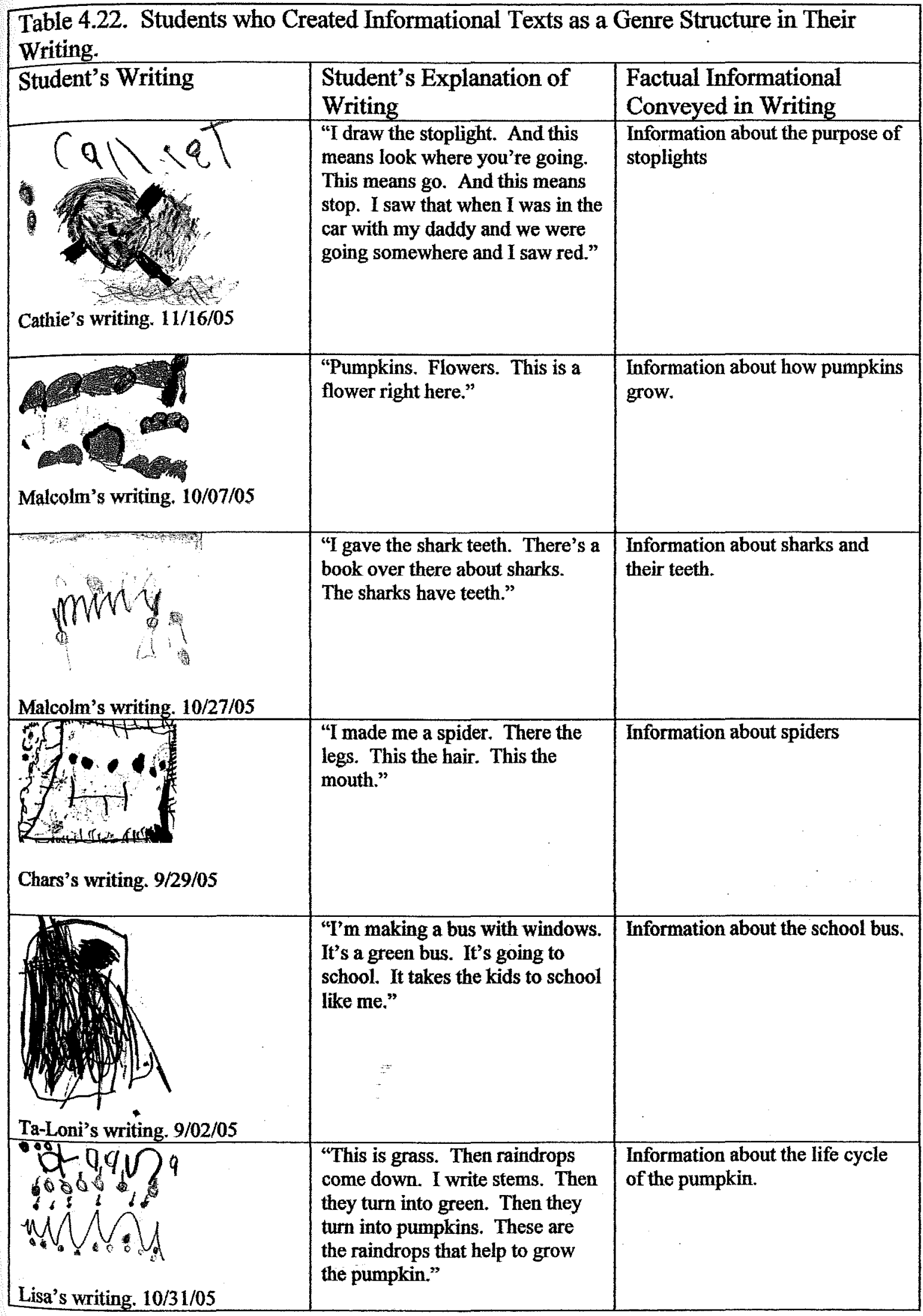


The texts about pumpkins created by Lisa and Malcolm, along with the spider text written by Chars, reflect the informational texts read by the teacher and her subsequent writing demonstrations. Along with teacher demonstrations and classroom books, the children drew on their own life experiences as they wrote. Cathie's knowledge about stoplights and their purposes is reflective of her experience driving around town with her father. Additionally, when Ta-Loni writes about the bus, she explains that children, like her, come to school daily by riding on a school bus. Children gain further knowledge about new concepts when they read information on their own. This is certainly the case when Malcolm writes about sharks and their teeth. The knowledge did not come directly from the teacher. Rather, it came from texts he read, on his own, during free choice time.

The teacher's influence on the children's genre selections extends beyond her uses of them in her demonstrations. By encouraging the children to bring knowledge from their life experiences and from other classroom texts, they are able to record what they know about particular topics. Moreover, by constructing informational texts in front of the children, the children are confronted with new ways of crafting factual information within a specific informational text structure.

\section{Letters}

In October, Ronda introduced a new genre of writing to the students: letter writing. On October 11, 2005, Ronda pulled Lisa's name out of box and informed the class that Lisa was the line leader of the day. Lisa was excited about this prospect and hopped up and down with joy. This was a typical reaction among students who were chosen. As the line leader, her name would be written on the chalkboard for the class to see, the letters of her name would be shouted by her peers, a word she selected would be 
written under her name on the Word Wall, and for the entire day she would lead her fellow classmates through the halls of the school. On this day, Lisa would reap another benefit of the line leader title; a letter would be written to her by the teacher in front of the entire class (Figure 4.33).

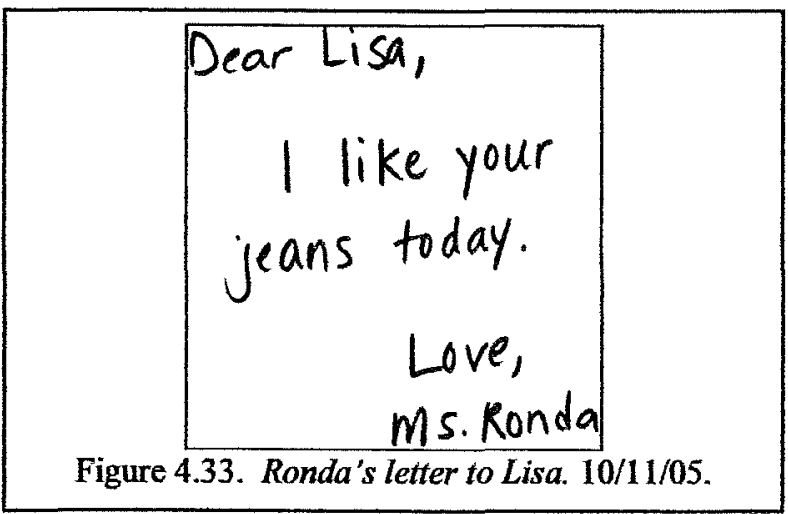

Ronda taped a blank piece of paper and started to talk.

Ronda: Today, I'm going to do something a little bit different. I'm going to write a letter to the line leader. Okay, how should I start my letter? Hmm...let's see. Okay, first I need to say, "Dear Lisa." [Begins writing and talking at the same time]: Dear Lisa.

Jibir: Look, she's writing a letter!

Roderick: That's BOO-TI-FUL!!!!

Ronda: Thank you. Wow, everybody. Look at Lisa's jeans today. She has a heart on her jeans. Those are fancy! Okay, let's see....Dear Lisa, I like your jeans todoy. Love, Ms. Ronda.

Class: [clapping]

Ronda: Okay, now I need to put this in an envelope. Now who is this letter to? Lisa: Me!

Ronda: Yep. If I don't write a name on it, I wouldn't remember who to give it to. So, I have to address it. I have to put Lisa's name on it. Then I need to put a stamp on it. Then, I become like the mailperson and find out where Lisa's cubbie is and I'll leave it for her to find it and read it. I'll say, "MAIL CALL!!!"

[Transcript 10-11-05]

Ronda placed the envelope in Lisa's cubbie for her to read later. The children went back to their tables and began writing. 
Talisha's interest in writing letters was already evident in a birthday card she created for her mother during the previous month (Figure 4.34). Talisha had explained it in an interview:

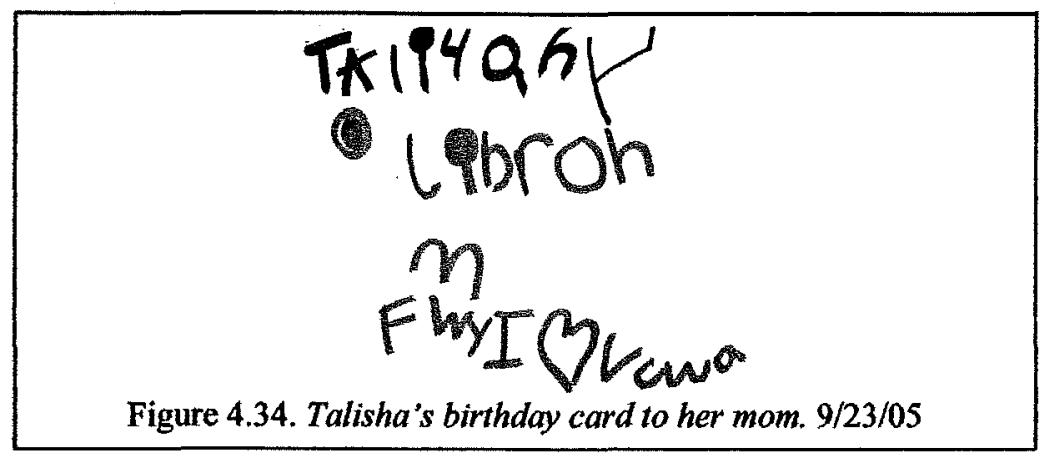

Talisha: I'm making my mommy a birthday card. I can spell my name. Want me to make a 4, 'cause I'm 4. I draw Jibir's name. My birthday card says, "I love you mom.' [Interview with Talisha 9-23-05]

When Talisha witnessed Ronda create the letter to Lisa, her interest in writing letters was again piqued. Immediately following Ronda's writing demonstration, Talisha ran back to the table and furiously wrote, leaving a gap of space at the top of her paper blank. After a few minutes, I brought a chair over to Talisha and started a writing conference by asking her to tell me about her writing:

Brian: Hi, Talisha. Tell me about your writing today.

Talisha: [desperate] Mr. Brian, please! Please write Dear Mommy on my paper. Brian: I can't do that. You know I don't write on your papers.

Talisha: [continues to beg relentlessly] Please! Just that one part. I'll write the rest.

Brian: But I want your writing to be your own writing. Not mine.

Talisha: [pleading] That is the only part I need. You don't have to write any more.

Brian: [feeling sorry and giving in] What if $I$ just write that part on a different piece of paper, then you can look at it and copy it if you want to.

Talisha: Great!

[Conversation between Talisha and researcher. 10/11/05]

Reluctantly, I wrote the greeting on a separate piece of paper and placed it in front of

Talisha. I felt uneasy doing this for fear of contaminating the data with my own 
influence, but her pleas were overwhelming, and I eventually succumbed to her desperate requests.

Talisha's head moved back and forth-from her paper to the piece of paper where I wrote Dear Mommy. She concentrated and took her time copying the writing. When the greeting was completed, she continued with her original print and finished. She motioned me to come back to her chair, and said:

"This is my letter to my mommy," (Figure 4.35). Then, sweeping her finger under the text, she read, "It says, Dear Mommy, I love you. I'm coming home next week. Love, Tal." This little girl had a very important message to convey.

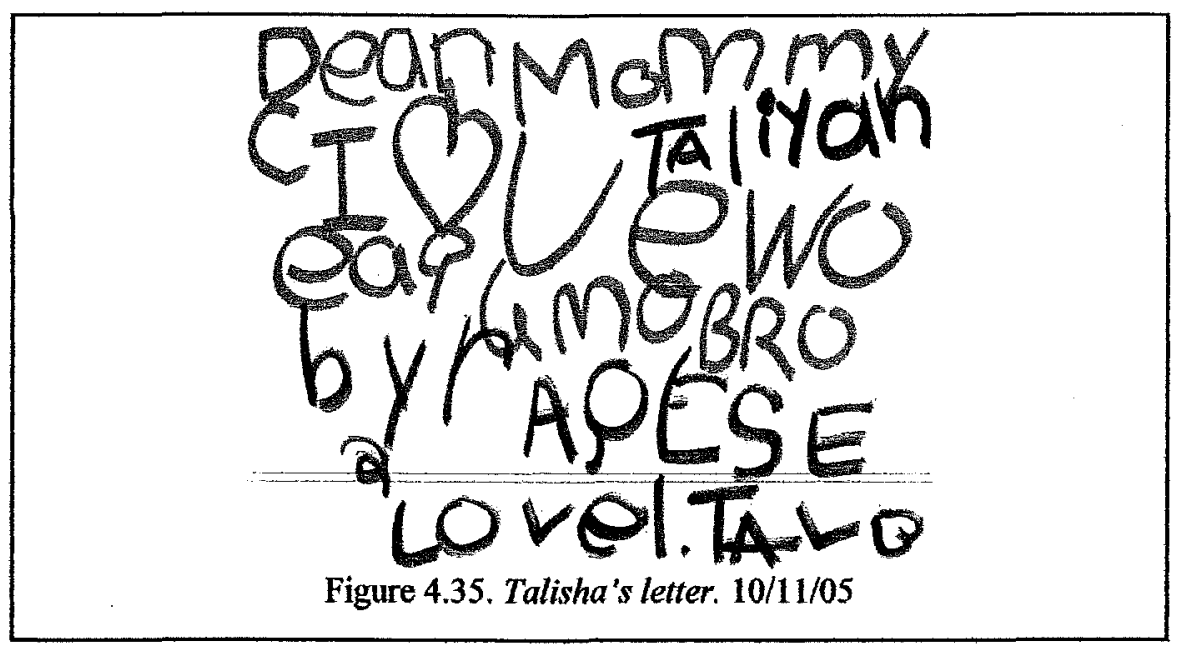

Ronda's letter to Lisa showed Talisha that letter writing follows a specific structure. In Ronda's demonstration, she highlighted the greeting, body, and ending found in most written letters. Talisha saw an entirely new way of structuring letters to her mother, and she used that knowledge to construct her own letter. In this way, the teacher's writing demonstration was a critical aspect of Talisha's new understanding of how to write letters. 


\section{Research Writing}

An unintended consequence of my presence in the classroom occurred when students started mimicking the way I took notes about their writing. Interestingly, my own influence in the classroom sparked a new genre of writing for students as they engaged in writing with their peers: research writing. On every observational day, I asked each child about their writing. Typically, I began my inquiry with a standard question, "Tell me about your writing today." As the children revealed the meanings of their writing, I would either write their responses on a notepad or type their responses onto my computer.

At the time I did not realize I was being watched. As I rotated from table to table, child to child, my mannerisms and my questions were being studied by two researchers: Talisha and Lisa. The observed became observers themselves.

I was first confronted with the genre of research writing when I entered Ronda's classroom after a day in which I was not present in her room. Ronda walked up to me, laughed, and showed me two pieces of writing created by Talisha and Lisa (Table 4.23).

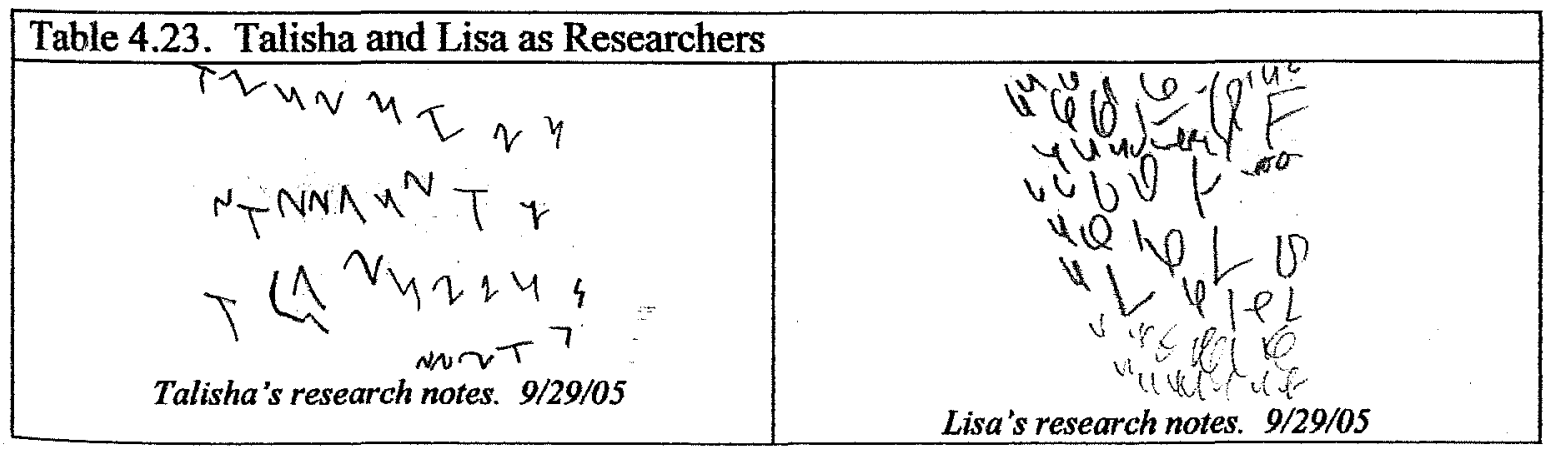

Ronda: [laughing] Look, we're being watched!

Brian: Huh? What do you mean?

Ronda: Well, since you were not here yesterday, Lisa and Talisha decided to help me with writing. So they went around and asked everyone about their writing. 
Brian: What did they say?

Ronda: They kept saying, "Tell me about your writing today." When their friends responded, they jotted down what they said. This is what these pieces of writing are. They are their notes from their discussions with the other children in the class.

Brian: Wow. That's pretty interesting.

[Conversation with teacher. 9/29/05]

For this genre of writing, children asked their peers about their writing and took notes. Their notes were devoid of all pictures and symbols. Instead, they were linear lines of letters and letter forms.

Research writing emerged in several texts written by Lisa and Talisha (Table 4.24). On each occasion, they sat among peers, marker in hand, and questioned. Some children refused to answer their inquiries. Others delighted in sharing their work with these two peers. When Lisa and Talisha employed this genre in their writing, their writing took on different characteristics. The print was linear, stretching from the left of the page to the right. Additionally, they began at the top of the page and worked their way down, indicating that the two girls had a concept about directionality in writing. Interestingly, there were no drawings attached to the print. The children seemed to understand that when this adult writes, he does so with letters and not with drawings.

\begin{tabular}{|l|l|}
\hline \multicolumn{2}{|l|}{ Table 4.24. Students who used research writing as a genre structure in their writing. } \\
\hline Student Writing & Student Explanation \\
\hline
\end{tabular}




\begin{tabular}{|l|l|}
\hline & $\begin{array}{l}\text { "I write my name. And I write } \\
\text { Arianna's snake. And I write house } \\
\text { "cause that's what Kendrick tell me. I } \\
\text { write Arianna's snake 'cause that's } \\
\text { what she told me." }\end{array}$ \\
\hline & $\begin{array}{l}\text { "I write Talisha. Then I write, "The } \\
\text { sky is falling, Lisa." And when Lisa } \\
\text { tell me about her writing, she told me } \\
\text { about the hat. I write that down." }\end{array}$ \\
\hline
\end{tabular}


Lisa's and Talisha's inclusion of research writing into their repertoire of genre knowledge is revealing. It shows that they watch adults as they write. They learned that adults question writers and ask them about the meaning of their work. This meaning is so important to the adult that the adult writes it down. The two girls understood this in the context of the classroom. As they played "researcher," they questioned peers, wrote down their responses, then moved on to other peers to elicit responses. Adults as writers demonstrate various genres of writing. The children, taught to watch Ronda, realize the importance of her writing and continue to watch her (and me) as we write.

\section{Summary}

The students in Ronda's classroom were writers who increased their knowledge about written language. Key to their heightened awareness was Ronda's writing demonstrations in front of the entire class when she provided essential, scaffolded instruction. Through the demonstration, she showed students where writers can obtain ideas for writing, how writers use a combination of print and drawing to convey their thoughts, and how writing can be structured using a variety of genres.

For Ronda, the writer, ideas came from classroom experiences that happened before writing. Sometimes the ideas came from her home life and occasional outdoor events she shared with her students. At other-times they came from other adults who came into the classroom. Read-alouds were especially influential. During her writing demonstrations, Ronda verbalized how she came to decisions about writing ideas. Because of these verbalizations, children were able to witness how events influenced their teacher - someone whom they looked to as an "expert writer." Students drew on 
outdoor experiences, Ronda's ideas, peer ideas, read alouds, home experiences, classroom conversations, and their own imaginations to acquire ideas for their own texts. In many ways, the teacher's writing demonstration and the teacher's talk throughout, was a major influence in the decisions they made.

Her inclusion of print in her writing was also an influential factor in children's developing notions of writing. Ronda consciously chose to write her name on almost every piece of writing she wrote in front of the children. This showed ownership of her writing and introduced children to the letters in her name. Then, throughout the months of my data collection, the teacher matched letters with sounds increasing this over that period of time. The students were involved in this process. She stretched out the words, spoke the sounds aloud, and the children told her the letters to write. It was an interactive, loud, and meaningful part of the production of the teacher's text. With increased repetition, children began to add print in their own writing. First, their names appeared in their texts. Then, some students started to write letters next to particular drawings to identify them with print. As the fall progressed, so did the letters students added to their texts. Letters beyond their names started to appear as children's awareness of print deepened.

Increasing knowledge of letters certainly can be the result of a myriad of other influences in the lives of the children. Environmental print surrounds them at home and at school, and the teacher's focus on print may make the children more conscious of the print around them. The children in this classroom are continuously reading books on their own. 
In this classroom, however, Ronda conducts daily writing in front of the students, actively engages students in sounding out words, and matches letters to the sounds they say. She shows children that writing goes beyond the drawings on a page.

The teacher's inclusion of varied genre structures to create her writing in front of the class was another way the children's writing was influenced. Children are surrounded by genres in their every day lives. Imaginary stories, personal recounts, informational texts, and letters surround children in their everyday lives and the teacher's writing reflected these. She informed the children that she was going to have characters in her stories, facts in her informational texts, greetings in her letters, and real-life events in her personal recounts. She showed how her own texts were formed by consistently talking as she wrote, and she encouraged children to try these structures in their own writing. Many children ignored these structures and continued to draw symbols without a story or facts attached. In the examples shown above, many students, however, did use structures to convey the meaning of their texts, and many of their own pieces were reflective of the same structures used by the teacher in her writing. In this way, the teacher's use of genre structure influenced her students as they used their knowledge of the structures in their own writing. 


\section{Third Finding}

The student interactions that occurred among the children while they were in the process of writing influenced them as writers.

\section{Vignette 4.3}

The weather is turning cooler as the fall air ushers out the hot days of summer. The air conditioner is off in Ronda's classroom and her windows are ajar, allowing a subtle breeze of air to occasionally creep into the classroom. This is apple-picking season and the children eagerly await their field trip to the local apple orchard. At the apple orchard they will run through rows of apple trees, choose and pick their own apples, drink apple cider, and look at the mountain views.

In preparation for the field trip, Ronda reads books about apples and apple picking. Using the classroom experience to conjure ideas for her own writing, she writes personal recounts and informational texts about apples and apple-picking during her writing demonstrations. The children listen to her stories and informational texts, ask questions, make comments, and share their excitement about the upcoming field trip.

After Ronda reads a magazine about apples, and writes an informational text about how apples grow and fall from trees, she asks the children about their own ideas for writing. Sensing that several children may write about the same topic because of the read-aloud text, writing demonstration, and the subsequent conversation about apples, Ronda asks the following question.

Ronda: What are you going to write about today? Malcolm, what are you going to write about?

Malcolm: An elephant.

Ronda: An elephant? Why are you going to write about an elephant?

Malcolm: 'Cause Travion writin' an elephant.

Ronda: Travion, are you going to write an elephant today? 
Travion: Yeah. I'm going to write a baby one.

Ronda: I have an idea. You know what I think...Travion and Malcolm, since you two want to write about elephants, maybe you two should sit together so you can maybe work together and share ideas? Malcolm and Travion, do you think that is a good idea?

Travion and Malcolm: [Nod their approval]

Ronda: Chars, what do you want to write about?

Chars: I'm making a dad elephant.

Ronda: Okay. Maybe you should sit at the table with them. Travion, Malcolm, and Chars.... why don't you three go to the table and start writing and I'll bring you markers.

When students write in Ronda's classroom, they write according to their own agendas. Sometimes they choose to be influenced by the teacher and her ideas for writing. Frequently, they choose a different path from the teacher and write about subjects of their own interest. And children who listen to the ideas of their peers often use them as an influence, much like they use the teacher's writing demonstration. On this day, apples do not interest Malcolm, Travion, and Chars. Elephants do. One boy (Travion) has an idea. The others follow.

At the conclusion of Ronda's writing demonstration, the children stand and walk over to the tables. In general, it is at this time that they encounter important decisions. Who were they going to sit next to during writing? Oftentimes, this is dictated by their friendship alliances. Children generally sit next to those they like. Sometimes, however, the choice is determined by who shares their writing interests and who could provide them with ideas and information. Today, this was the case for Malcolm, Travion, and Chars. Yes, they are friends. But they are also writers seeking to understand written language from each other in dialogic conversations.

The boys find a cozy corner at one of the tables and start to talk and write concurrently. 
Travion: I'm making a tail.

Malcolm: Arms

Travion: They have ears. They have big fat ears.

Malcolm: And they have eyes. [Malcolm leans over towards Travion and draws eyes on his elephant.]

Chars: Why you doin' that????

Malcolm: I'm helpin' Travion.

Travion to Malcolm: You not makin' it right. Elephants don't have no arms.

They can stand up. Red dot! Look at those fat ears! [Starts laughing]

Malcolm: Hey, Travion. Chars got his elephant some wings.

Travion: Elephants ain't have no wings. I'm makin' me a picture. All the elephants got on here. Even the dinosaur got here. Awwww!!! The elephant ate 'em all up.

Their talk continues and their writing shifts. They finish making their elephants and concentrate on creating crickets and grasshoppers in their writing.

Travion: I'm makin' a grasshopper.

Chars: I'm makin' a cricket now.

In general, after a period of student-initiated talk, the students quiet down and write individually. They have finished their discussion with each other and concentrate on their own texts. No longer do they concern themselves with their peers.

When the three boys finish their writing, they bring their papers to me and begin their explanation of them. Chars is first. He holds up his paper as he speaks (Figure 4.36).

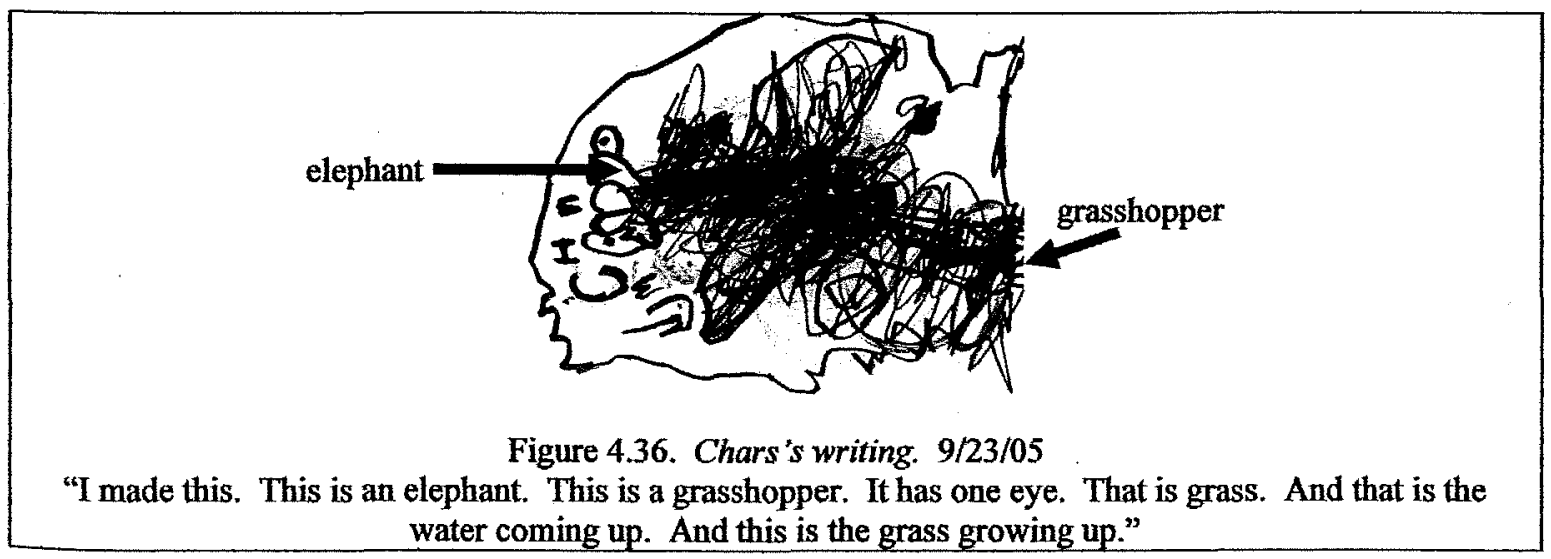


Travion is next, with a brief explanation of his writing (Figure 4.37). He is impatient and is ready to move over to the carpet to independently read. He talks quickly.

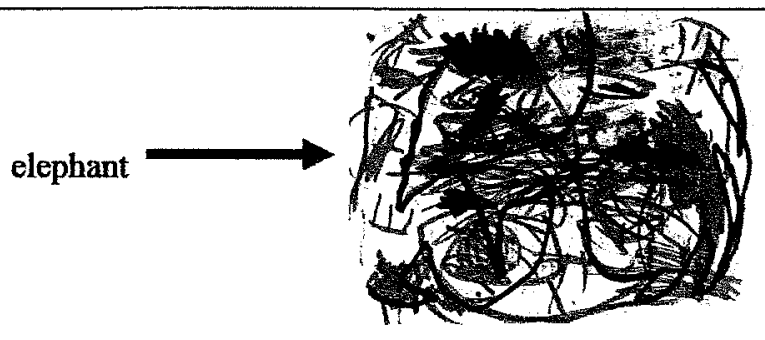

Figure 4.37. Travion's writing. 9/23/05 "This is an elephant."

Finally, Malcolm shares his writing with me (4.38). He proudly holds up his text and smiles as he starts explaining.

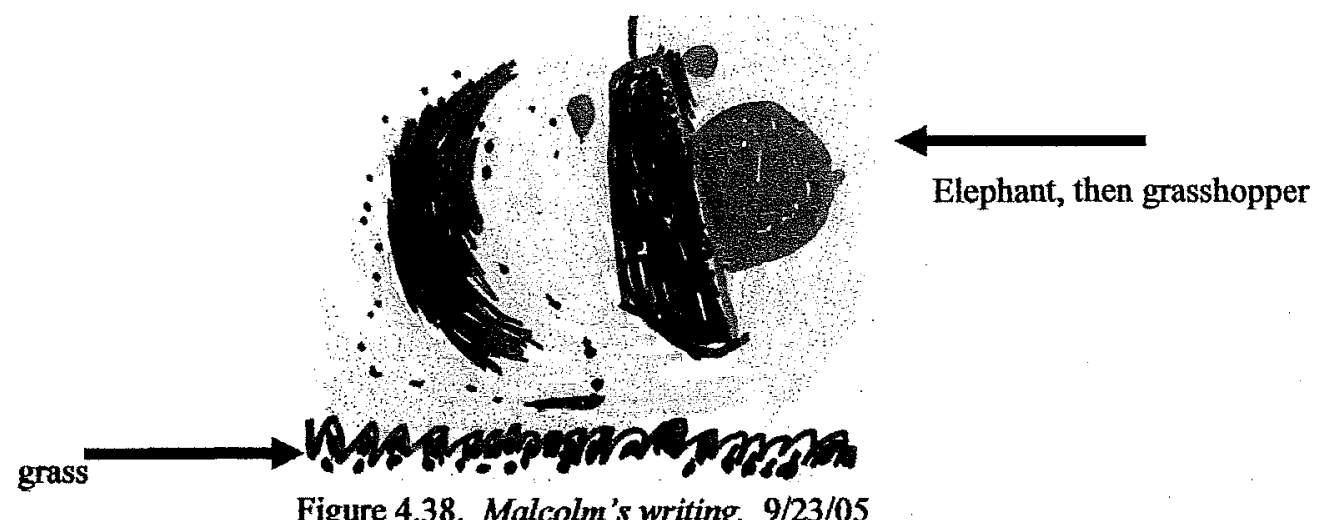

Figure 4.38. Malcolm's writing. 9/23/05

"I make a grasshopper and an elephant. I turned my elephant into a grasshopper. This is grass down here."

I make note of what I observe on that day in my field notes.

The talk at the tables turned to idea sharing. This began with the teacher's writing demonstration but extended to the talk that occurred among peers. Malcolm, Travion, and Chars talked about the elephants they were forming on their papers. They discussed the physical features of the elephant and conferred with each other about the various body parts. Each time someone suggested a body part, the other two boys would agree and add the parts to their 
own page. This occurred over the course of several minutes. Their talk was influencing what they chose to put on the paper.

Suddenly, Travion decided to switch his writing topic on the page. This may have been in response to his being upset at Malcolm for trying to fix his writing. Perhaps this led him to abandon the elephants and write about grasshoppers instead. He was animated in his expression as he wrote. He shouted things that were happening as he created the writing on his paper. Chars, sitting next to Travion and listening to his commentary, started to draw over his elephant and essentially covered the image of the elephant that he originally created. He exclaimed that he was writing about a cricket. His cricket was involved in a great deal of action (like Travion's grasshopper) and marks were written across the page in random, active movements.

These marks, which look like scribbles, really represent the actions of the elephant and grasshoppers on the pages of Travion and Chars. They are active components of their story-telling. While I believe some children playfully make these marks as they experiment with the markers and paper, Chars's and Travion's marks have actual action-meaning. With markers in their hands, Travion and Chars are using the movement of their hand and the marks of the paper to explain the meaning of the action of the elephant and the cricket/grasshopper. Their audience is each other.

The writings that these students created are alive, active, and represent a real-time existence. The children realize that the stories they are creating are just that-creations. However, the children use their markers and the paper to tell the story as it happens. When they are encouraged to socially interact when writing, this natural inclination seems to be a valuable aspect of the meaning they assign to their writing. In this way, their writings are a result of their social interactions. The meaning would be absent without the presence of the peer.

[Field Notes 9/23/05]

On a typical day in Ronda's classroom, the children engaged in an all-class experience, participated in her writing demonstration, and then went back to two long tables to write for 10-15 minutes (Table 4.25). They wrote together in small communities. Sometimes it was peaceful existence. They delightfully shared their ideas, passed different-colored markers to their friends, assisted each other in writing specific symbols or letters, and politely asked each other about the meanings of their writing. During other times, conflicts arose. Fighting over markers was almost a daily occurrence.

Occasionally, there was concern among the children about copying that created tension 
among students unwilling to share their work and thoughts with others. This was sometimes coupled with curt conversations among groups of boys about the status of their friendship with each other.

Overall, the peaceful interactions were overwhelmingly the norm as the children composed together. During my four months in the classroom, I never once heard a child say that they did not want to write, did not have an idea for writing, or did not want to write with a particular peer. Writing was predominately seen as an exciting classroom endeavor and the children genuinely looked forward to it everyday. As I scanned the room during my observational time, I saw tables where students smiled, concentrated on their work, conferred with friends, and shared their writing with classmates.

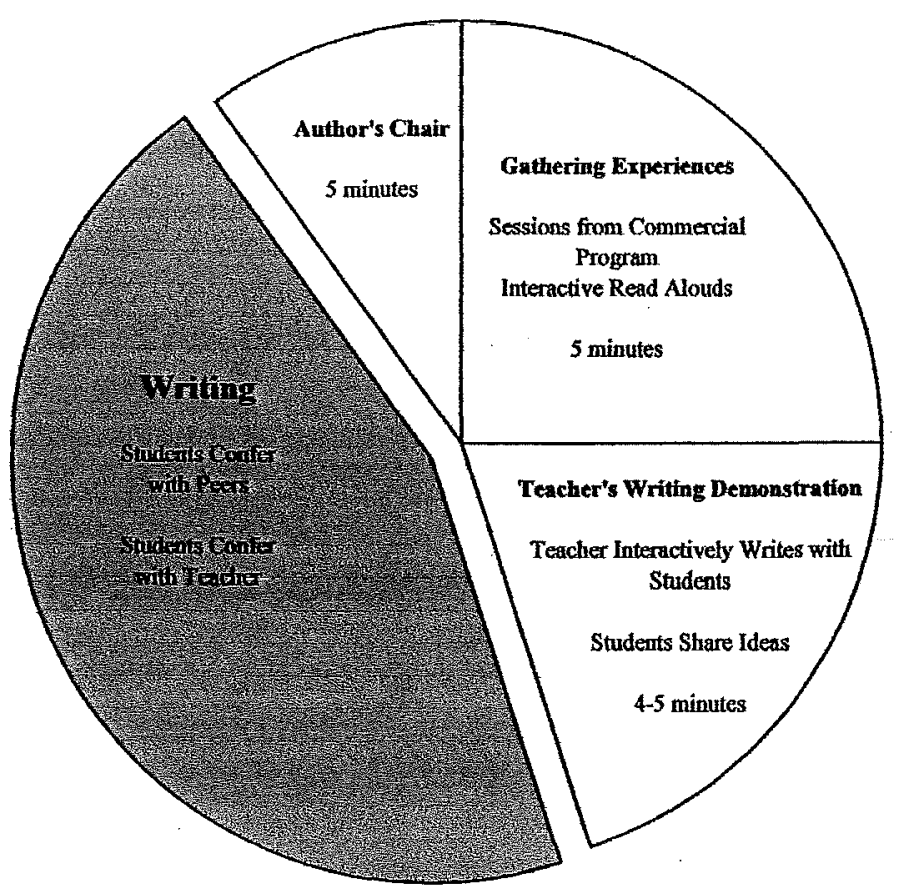

Table 4.25. Students confer while in the process of writing. 
Ronda discussed the importance of table conversations in an interview about the

topic. I asked what happened when students went to the tables and talked during writing

time. She responded.

Ronda: When they go to the tables, they are getting ideas from each other. They are excited when they go to the tables to write. A lot of them are starting to take print from the room and use it on their papers, too, as a way of expressing themselves. They also are really getting into writing their names and writing everyone else's names and the letters that everyone else's names start with. I think there is a lot of communication going on at those tables and I think we learn a lot about the children and their experiences. I also think they learn a lot about each other and their experiences. I think it is good that I stay out of those conversations. I am not sitting there drawing and writing with them. I have already done that in my demonstration. I just think this is their time. This is their time to choose. Are they going to be influenced by my writing, their friends, or are they going to come up with some ideas on their own? They know that it is their time to do what they want to do.

[Interview with Ronda. 10/18/05]

Ronda viewed this talk as child-driven. She purposefully detached herself from the conversations and allowed the natural flow of conversation to emerge from the children as they sat and wrote with their peers.

Ronda also viewed her role during this time as that of an observer. Rather than re-iterating the lessons of the writing demonstration as they children wrote, Ronda observed. She listened to the table conversations and learned from them. It was during these times that Ronda felt she could obtain valuable information from the students. Through conversations, Ronda heard about their interests, their experiences with popular culture, their home lives, and the status of the peer relationships within the classroom.

She expressed this point in the same interview.

Really and truly, the children need to be able to think out loud when they write. I demonstrate this when I write. I need to be able to hear their thinking. I also want their friends to be able to hear what they are saying about their writing too. That is why they talk when they write. Plus, if they didn't talk, their writing would just look like scribbles on their paper to me. I mean, I would be at a loss 
for what they are doing. It allows me to see their process. It allows me to really understand what they are saying.

I need to hear their thought process. I need to hear what is going on inside their head and that is the only way for them to do that-through their talk. And that goes with anything in the classroom. If they are not talking, then I don't know if they are understanding. Like Ta-Loni writing all those letters. It would just look like to me that she wrote a bunch of letters. And I would not have seen her excitement in it. I would not be able to see her pride. But I wouldn't have seen that she was trying to write Frank's name or the word zebra. And I wouldn't have been able to see that she understands that letters make up words. I would have missed all of that totally.

[Interview with Ronda. 10/18/05]

Ronda viewed this talk as an integral part of her students' ability to learn about written language from each other. Additionally, because she positioned herself to hear the talk that took place while students were engaged in the process of writing, Ronda learned essential insights about her students as writers.

Analysis of the data showed that interactions (both verbal and non-verbal) among students as they composed influenced the meaning they assigned to their writing. I will first show the general types of interactions that influenced the ideas the children brought to the page. Next, I show children talking about popular culture and how characters from these discussions appeared in their writing. After two months in the field, children began to mimic the style of questioning posed to them by their teacher and myself. Students questioning peers will be shown along with the writing that was created as a result. As students began to realize that the teacher would play the role of observer during this time of the Writer's Workshop, students, it appeared, began to rely on each other for scaffolded support. Students asked their peers how to create symbols in their writing and how to write the letters of their names. Finally, this section will end by showing examples of conflicts that arose as children composed together. These conflicts reveal 
the personal aspects of children writing as a community and the relationships that are negotiated when they compose together.

\section{Three General Types of Interactions Influenced these Young Writers}

When the children composed together, they shared their ideas with the others at the table as they wrote. These interactions occurred in different ways. Idea-sharing for some children occurred when they sat near each other, and talked and wrote back-and forth, influencing each other's evolving text. Other interactions occurred when one student mentioned an idea and several other children determined that it was a worthwhile pursuit, but the talk while they wrote was minimal. Finally, at times, no interactions occurred.

Some students' idea-sharing happened amidst much talk

Jibir and Frank sat side-by-side and talked to each other as they wrote. Jibir began the conversation as he composed (Figure 4.39).

Jibir: This is a big, big, big, horse.

Frank: [clenching his teeth and making a scared face] You make a horse? I'm scared of the horse.

Jibir: He's not mad at you. 'Cause he a good boy. See he won't get you. He can't get out. [Jibir draws a circle around his horse to relieve Frank of his fears.] See. He can't get out.

Frank: What?

Jibir: My big horse. He can't get out. I'm making a big circle so he can't get out. 


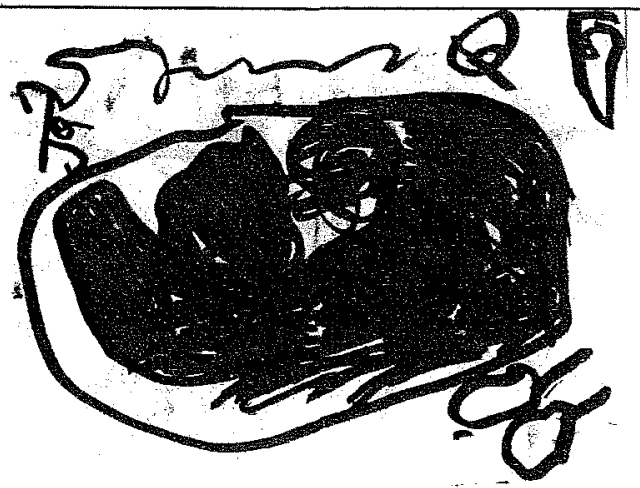

Figure 4.39. Jibir's writing. 9/12/05

Jibir began by writing about a horse. As Frank responded to his writing, and explained that he was scared of horses, Jibir made changes to his writing by drawing a circle around his horse. Then, he reassured Frank by telling him not to worry, the horses are safely in the circle. This protection was both physical and emotional. The writing Jibir created was ever-evolving because he was writing interactively with his friend. As his peer gave response to his writing, he made modifications. In this way, the audience played a critical role in Jibir's writing. He wrote and revised based on the reaction of his friend. Similar to the example in the vignette with the elephants created by Malcolm, Travion, and Chars, the children's writing interactions influenced the decisions they made while they were in the process of writing.

On another day, Ronda held up a picture of a fall scene. There was a tree with multi-colored leaves, leaf piles, a fence with resting crows, and a scarecrow. Several students expressed interest in the scarecrow and chose to use the scarecrow as an idea in their own writing. When they went back to their tables, Cathie, Chars, Malcolm, and Frank became engaged in a conversation. As they talked, they wrote. And the images that appeared on their pages reflected this interaction (Table 4.26). 
Cathie to Chars: This a monster.

Malcolm: I'm not scared.

Chars: This a scarecrow. Uh, uh. This is a scarecrow.

Malcolm: I'm making a scarecrow in a car.

Cathie: Scarecrows can't drive.

Frank: Yeah uh!

Malcolm: [Begins adding a car to his writing] This is the car.

Chars: [Draws a circular bubble around his scarecrow] Scarecrow is here. [He says this as he points to the scarecrow figure in his writing]

Frank: I'm making a car.

Malcolm: And this is my car.

Cathie: This is a monster.

Kallen: My mom and dad saw a scary monster. It had sharp claws.

Frederick to Malcolm: Help me make a car.

Frank: Help me make it.

Chars: I made a scarecrow.

Cathie: I'm not making a scarecrow.

[Transcript 11/02/05]

\begin{tabular}{|l|l|}
\hline Table 4.26. Student writing as a result of their table conversation. \\
\hline Student Writing & "I made a car for the scarecrow. Here is \\
\hline
\end{tabular}




\begin{tabular}{|l|l|}
\hline & \\
\hline Cathie's writing. 11/02/05 & \\
\hline This is my name." & \\
\hline Frank's writing. 11/02/05 & Frank: "This is a car." \\
\hline Frank: "My mommy is sitting next to me."
\end{tabular}

Cathie's writing did not change as a result of her interactions with Jibir and Chars. She told the two boys that she was going to write about monsters, and her composition is a reflection of this intention. Later, when I asked about the meaning of her writing, the idea remained constant.

The writing of Jibir, Chars, and Frank however, was influenced by the interaction that occurred as they wrote. All three boys discussed scarecrows and cars as they wrote. When Jibir wrote a car next to his scarecrow and declared, "This is a car for my scarecrow," Cathie challenged his writing by exclaiming, "Scarecrows can't drive." Jibir disagreed and continued to add details to his car.

Upon hearing about Malcolm's car, Frank's interest in creating a car of his own was piqued. Like his friend, Frank wanted to add a car to his writing and asked Malcolm for assistance. Malcolm ignored Frank's request and continued to write without offering help. Frank was determined to create a car in his writing. He looked back and forth between his paper and Malcolm's and added the car to his own writing. This slightly 
irritated Malcolm and his frustration was evident when I interviewed Frank about his writing. Frank announced that he created a car, and Malcolm quickly interjected, "He made it "cause I made it." Nevertheless, Frank included a car in his writing because he was an active participant in the conversation about scarecrows and cars. Other evidence that supports the interactive nature of the child's writing is displayed in Table 4.27. We see the writing of several students as they conferred with one another about cars.

\begin{tabular}{|l|l|}
\hline Table 4.27. Student writing as a result of their conversations \\
"A grandpa holding hands. They are going for a \\
walk. He has glasses and a beard. They are holding \\
hands. Yeah. He has eyes and a mouth. And arms. \\
And glasses and a beard. And they are holding \\
hands. My grandpa has a wand. A magic wand. I \\
have to make a magic wand. That's the kid. That's \\
the grandpa. Both of them are taking a walk and he \\
is holding his hand. And he has a magic wand with \\
it. The grandpa has a magic wand."
\end{tabular}




\begin{tabular}{|l|l|}
\hline & $\begin{array}{l}\text { Brian: "Ta-Loni, tell me about your writing today." } \\
\text { Talisha: "Tell him you did a police car." } \\
\text { Ta-Loni: "This a police car." }\end{array}$ \\
\hline Ta-Loni's writing. 8/31/05 & $\begin{array}{l}\text { Brian: "Travion, tell me about your writing today." } \\
\text { Travion: "I'm making a circle. You heard what I } \\
\text { said there [pointing at the table and referring to the } \\
\text { conversation that took place]. I makin' a building. } \\
\text { I made a house." }\end{array}$ \\
\hline Travion's writing. 8/31/05 &
\end{tabular}

During the writing demonstration, they saw Ronda create a text about the Open House at school the night before when the parents of the students arrived on the same buses their children took to school. After Ronda wrote about this experience, the children went back to their tables and composed. They talked as they wrote.

Travion: I'm going to draw a car.

Talisha: I'm makin' a car today.

Pierson: Ms. Ronda made a school bus car.

Travion: I'm makin' me a blue rainbow.

Kallen: I don't know how to make a school bus. I want Ms. Ronda to make a school bus.

Travion: I'm makin' myself a car.

Ta-Loni to Talisha: Can you make me a police car?

Travion: I'm makin' a house. I'm makin' a building.

Kallen to Ronda: Can you make a yellow school bus for me?

Ronda: I think you can do it. You make it the way you think it should be. This is your paper to write on.

Pierson: I made a school bus!

Kallen: [frustrated] I don't know how to do it!

Ronda: Ask Pierson how he did his. Don't ask him to do it for you. Just ask him to show you. 
Pierson: I make the big this...then I did this...I made a circle. Then I made another circle.

Kallen: I still don't know how to do it.

Ronda: Well, why don't you do it the way you think you are supposed to do it. We all do it different, don't we?

Talisha: I'm making a police. I want to be a police when I grow up.

Ta-Loni: I'm trying to make police car. And I can't make police car.

Talisha: Do you know how to draw windows?

Kallen: I just made a person instead.

Pierson to Kallen: What are you doing?

Kallen: I'm making a person instead because I can't make a bus. I'm making a grandpa and a boy. That's what I'm going to do instead.

[Transcript 8/31/05]

The writing of the children began, in effect, when they watched Ronda create a bus in her writing. Then they wanted to try to do the same in their own. As they wrote, Travion began their conversation by saying that he was going to create a car, instead of a bus. Talisha concurred and began writing a car of her own-a police car. Upon hearing this, Ta-Loni decided she wanted to write what Talisha was writing and they began to compose together. Meanwhile, Pierson mentioned to the table that Ronda created a bus in her writing. Along with Kallen, Pierson decided to re-create the same school bus that Ronda had composed minutes before. Pierson found success in this endeavor, but Kallen felt failure. Even after he consulted with Pierson about making the school bus, he ultimately changed his mind and composed something else-something which he knew how to write.

This writing event transpired on the second week of school and the first week the children started writing. During this time, the children were still unsure of Ronda's expectations during writing time. Some students were also uncertain about writing some were afraid to take risks. The field notes written about this day capture my thoughts about their writing. 
I notice several things happening in this classroom already. First, it seems to me that this is a time of uncertainty for the children. They are unsure of the expectations during writing. They are exploring the page for the first time. Kallen is uncertain how to create a school bus, and begs Ronda to show him how to do this. She refuses and encourages him to do it on his own. Similarly, TaLoni wants Ronda to draw a police officer on her paper. Ronda refuses. Rather, she encourages the children to look towards their friends for guidance. At this young age, Ronda is making sure children understand that she is not the arbiter of information. She encourages children to seek knowledge from other sources. During this peer time, she suggests that children look towards their peers for guidance. Ta-Loni took the risk and made the police officer. Kallen resisted and opted to draw something he knew he could create successfully. Rather than create the yellow bus, he created a yellow grandfather instead. His writing changed because he was unwilling to learn from Pierson and was too afraid to take the risk.

[Field Notes 8/31/05]

\section{Student Idea-Sharing that Happened Quietly}

Following her writing demonstration, Ronda asked the students their ideas for writing. After several of them shared their ideas, Lisa spoke.

Lisa: I'm going to make a sun because I like suns.

Talisha: Oh. Me too. I'm going to do a sun, too.

Ta-Loni: I'm going to do a green bus.

Malcolm: I'm going to make a blue bus.

Jibir: I'm going to do a sun. A yellow one. I got that idea from Lisa.

[Transcript 9/14/05]

After sharing their ideas, the students stood up on the alphabet carpet and quickly walked to the two tables. Lisa was first to a table as Talisha and Jibir followed closely after.

Malcolm decided to join the trio, evidently because he now intended to make a sun

(Table 4.28). They were silent as they composed. They already had their idea; it came

from Lisa. When they composed together, they did so by simply writing on their own papers, occasionally looking over at Lisa's composition. Lisa's idea provided an idea for several children. When they heard it, they chose to do the same thing in their own writing. 


\begin{tabular}{|l|l|}
\hline Table 4.28. Lisa's writing idea is incorporated by peers into their own writing \\
\hline
\end{tabular}

During a different occasion, Frank announced to the table that he had written a

car. The conversation is captured in this transcript:

Frank: Look! A car! A cool car!

Frank to Lisa: Look, a car.

Talisha: 'Cause she dropped the keys off, dummy.

Frank: This is my car. Vrooommm. Vroooooom! 
Frank's announcement and excitement about his car garnered the attention of his classmates at the table. Malcolm, who had been writing grass, clouds, and pumpkins began adding a car to his own writing. Travion, who was busy drawing a rainbow, shifted his idea to a car as well. It seemed as though Frank's declaration about the car he had written, inspired others to shift their ideas from general, somewhat unformed notions, to the more specific idea of a car (Table 4.29).

\begin{tabular}{|l|l|}
\hline Table 4.29. Frank's writing idea is incorporated into the writing of his peers. \\
\hline "This is my car. And some Ps."
\end{tabular}


Without Frank's exclamation about his car, the writing of Malcolm and Jibir may have been different. Perhaps they would have stopped at their original symbols. Or perhaps they would have written about something entirely different. Frank's idea, and his vocalization of it, influenced the decisions they made as writers.

On another occasion, Jibir began to forcefully make dots on his paper. Pressing the marker firmly on his paper repeatedly, he announced to his tablemates, "Look! I'm making dots!" Kendrick who watched Jibir create dots on his paper, began to do the same on his. Travion and Chars followed suit and violently attacked their pages with a barrage of dots (Table 4.30).

\begin{tabular}{|l|l|}
\hline Table 4.30. Jibir's writing idea is incorporated into the writing of his peers. \\
\hline "That a pig. And that a monster. The \\
monster is going to get the pig. He's going \\
to get all the pigs. Then I start putting on \\
some dots. Them dots are going to get the \\
pigs."
\end{tabular}




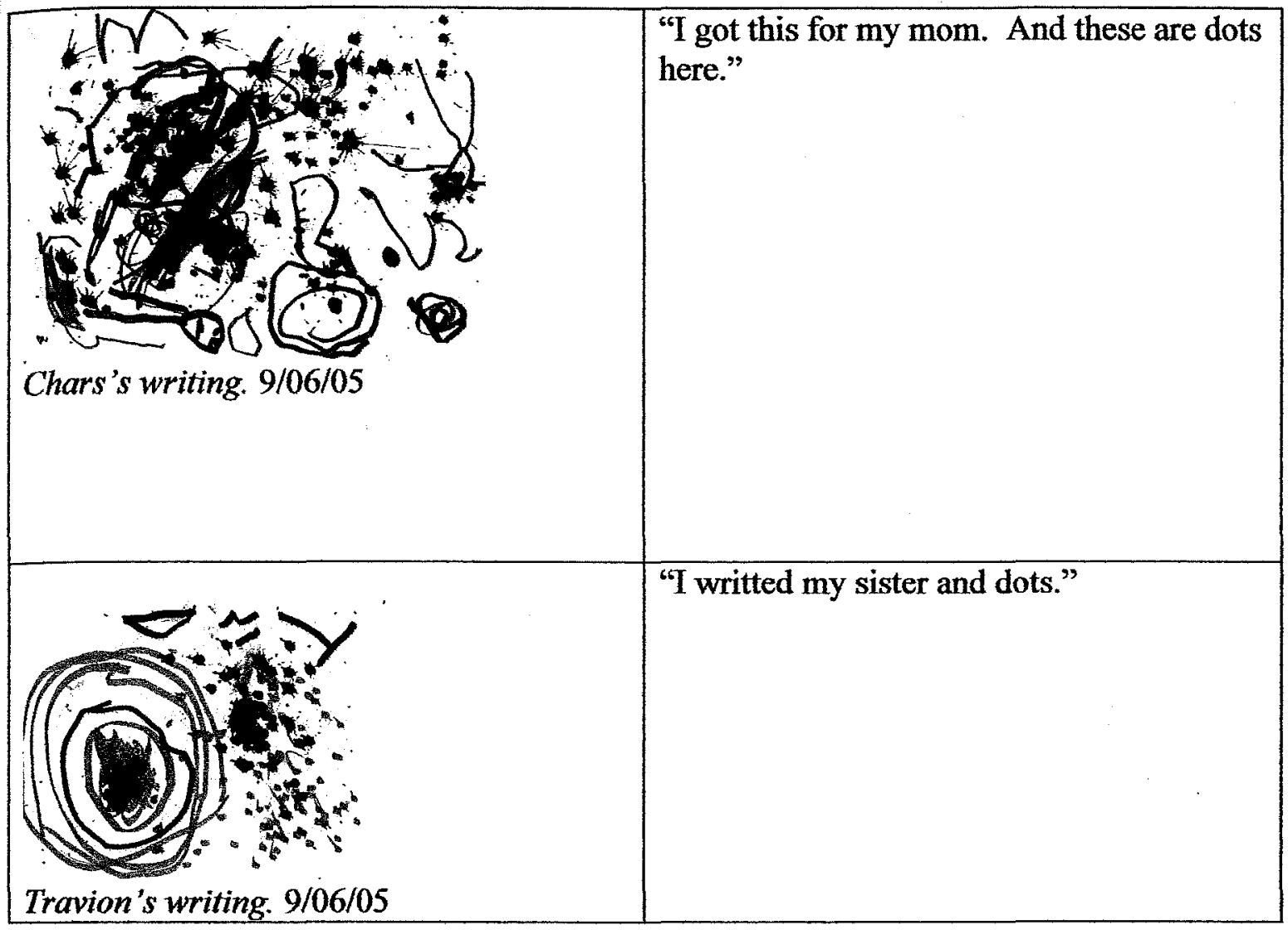

The idea for creating dots came from one student. His inclusion of dots in his writing and his apparent joy when composing among friends inspired his peers to make dots in their own writing. They delightfully slammed their markers on their papers to create a page of random dots. They're playful expressions were ceased when Ronda looked over at the table, realized that they were ruining the markers in this exercise, and demanded that they stop. The students did, but their inclusion of dots remained permanently on their pages. One students' idea is modified by others

Lisa sat in the seat directly in the middle of the table, surrounded by peers who were conferring with one another. Josephina and Katalina were speaking Spanish to one another, Pierson was asking Talisha to draw a heart on his paper, and Ta-Loni was 
talking about her new brother who finally arrived. Lisa ignored the conversation and started writing. Then, she nudged Katalina and told her to look at her writing.

Lisa: Look at this, Katalina.

Katalina: [Watches Lisa form a box around her writing. Then, she turns to Josephina and continues to speak Spanish to her. Their conversation leads Josephina and Katalina to both write boxes around their writing.]

Talisha and Ta-Loni: [Listening to Lisa, they look over at her writing, then create boxes in their own writing.]

Their writing, as a result of this interaction, is displayed in Table 4.31.

\begin{tabular}{|l|l|}
\hline Table 4.31. Lisa's writing idea is incorporated and modified by her peers. \\
\hline drain. And Ms. Spider are taking him legs \\
off and bugs. And he's takin' him. And \\
the Sun came up and blew him away. And \\
I put this box here. I need it. Because we \\
need to be able to keep our spiders in so \\
they don't bite."
\end{tabular}




\begin{tabular}{|l|l|}
\hline Ta-Loni's writing. $9 / 28 / 05$ & $\begin{array}{l}\text { "I made a spider. That the box 'cause they } \\
\text { cryin'. 'Cause they can't find their } \\
\text { momma." }\end{array}$ \\
\hline
\end{tabular}

When the children first gathered at the tables after the teacher's writing demonstration, they came with their own ideas. Josephina and Katalina were writing about water. Talisha was writing another letter to her mother. Lisa and Ta-Loni were writing about spiders, a response to the writing they saw demonstrated by Ronda and the text about spiders that she read aloud.

Then, Lisa wrote a box around her writing and called the children's attention to it. Suddenly, everyone included a box in their own writing. However, when asked, the box signified different things to the various children. For Josephina and Katalina, the meaning of the box was not clear. When asked about their writing, they simply said, "Water and box." These were typical short responses since communication was difficult due to my lack of Spanish knowledge. The box may be a container to hold the water. It may just be a symbol they included on the page. Either way, they created a box because they saw Lisa create one in her writing. For Lisa, the box meant something. She created the box around her characters to hold the spiders onto the page. The box was a significant part of the page because it protected the reader from being bitten by the characters. Talisha's box represented a television. She began by writing a letter to her mother. Then she modified her writing so that the letters were represented within a television show. Finally, Ta-Loni appears to have created the box as part of the action in her story, but the meaning is not entirely clear. Regardless, like all the boxes formed by 
the students, Lisa provided the idea. The other students witnessed her creation of the symbol and added it to their writing. Then, they modified the symbol to suit the meaning of their own writing.

A similar occurrence happened on another day when Talisha announced, after Ronda's demonstration, that she was going to write about a bus. The following discussion took place.

Ronda: Talisha, what are you going to write today?

Talisha: A bus.

Ronda: A bus? Instead of a police car?

Talisha: Yep.

Ronda: Alright! Ta-Loni, what are you going to write?

Ta-Loni: I'm going to do a green bus.

Ronda: Pierson, how about you?

Pierson: A blue bus.

The children went to the tables and wrote. Talisha, Ta-Loni, and Pierson choose to sit next to each other. They composed quietly, occasionally asking each other for a particular colored marker. Pierson grabbed a blue marker for his blue bus. Ta-Loni originally used a green marker, then asked Pierson to lend her his blue. Talisha stuck with orange as she wrote. Their products and explanations of them are displayed in Table 4.32 .

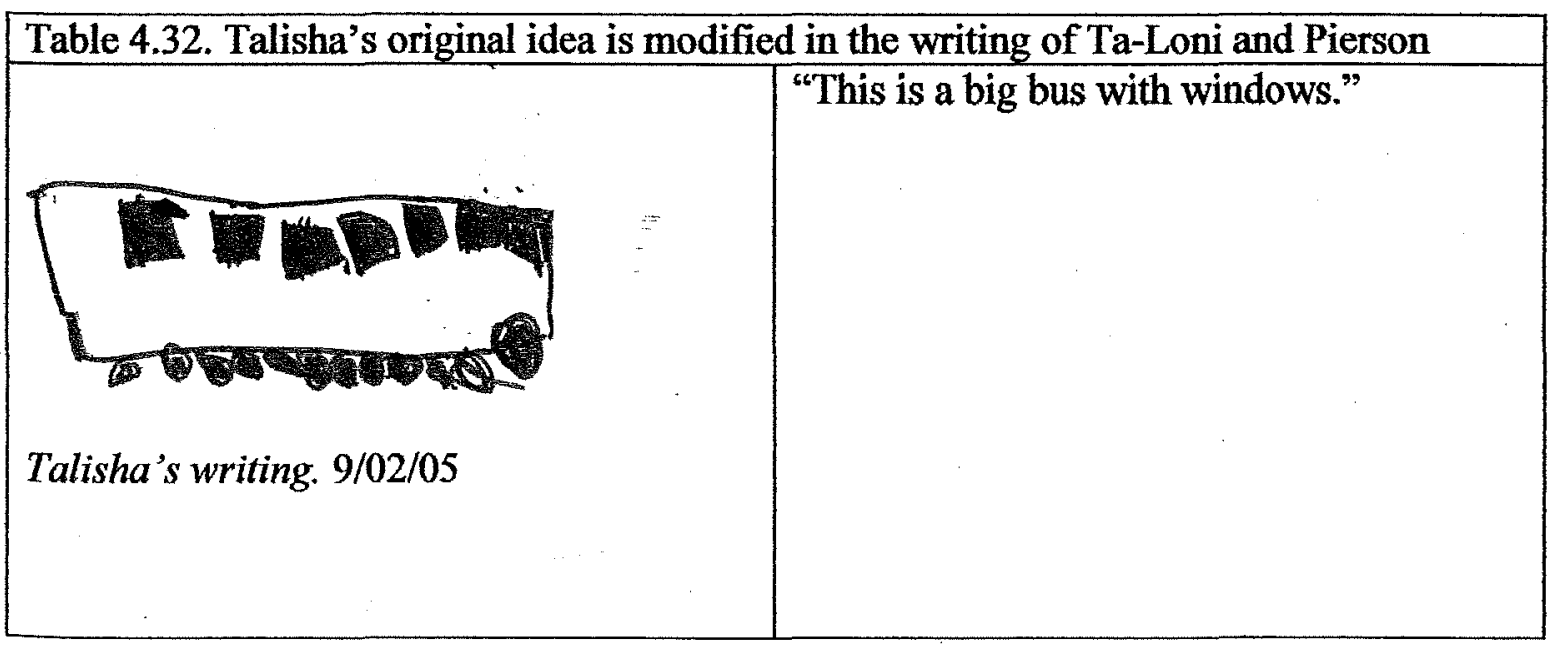




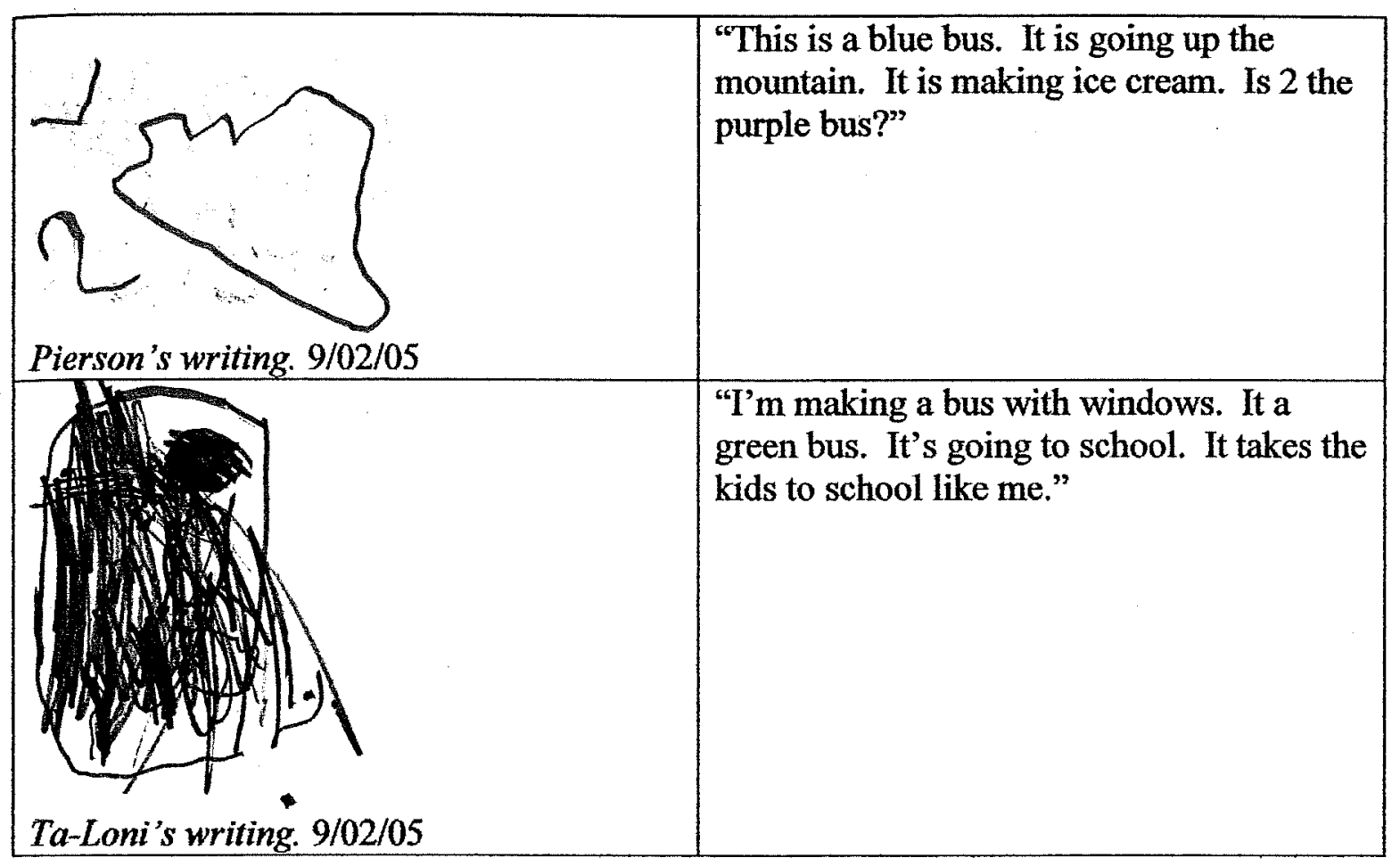

When sharing ideas, Talisha explained to the class that she was going to write about a bus. Upon hearing this, Pierson and Ta-Loni responded by saying that they were going to write about buses in their own writing. Their writing differed, however. They modified their writing from Talisha's by choosing different colors and adding different symbols. The students were influenced by Talisha, but they retained their originality in the colors they chose and the explanations they provided.

No interaction among children preserved their original ideas

During one of my observations, a table of students remained completely silent as they wrote. After Ronda's writing demonstration, Chars, Pierson, Kendrick, and Arianna walked back to their tables and wrote in silence. This was not demanded of them by the teacher; it was simply the mood of these students on this day. This was unusual. This one table of writers was silent and this provided insight into what children do when there is no peer interaction during writing (Table 4.33). 


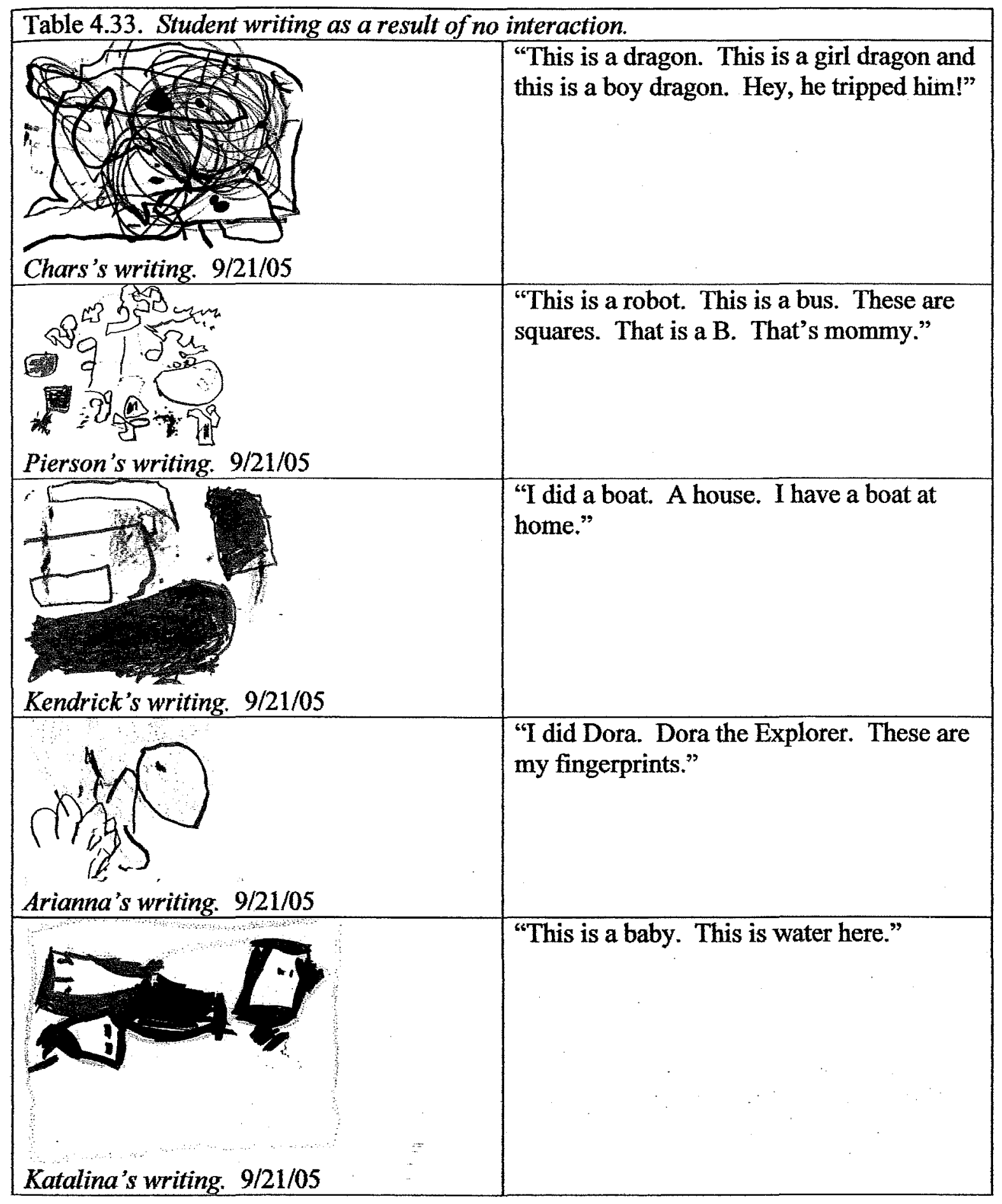

The writing of the children represents different ideas, themes, and influences.

Chars created a story about dragons, Pierson wrote a series of symbols, and Kendrick composed a boat he had at home. Arianna wrote Dora the Explorer on her paper along 
with a handprint. Katalina created a baby and water, two symbols she made frequently in her writing.

When the students wrote silently, they created their own symbols and drew upon their own interests in writing; their writing differed greatly. When the children did not interact they created written products that were quite different from each other.

\section{Students' Interactions about Popular Culture Influenced Their Writing}

The emergence of discussions concerning popular culture was evidenced in the writing of the children and their subsequent explanations. For the purpose of this dissertation, popular culture is defined as images, sounds, symbols, and the like that are media-produced and appeal to different audiences (Alvermann \& Xu, 2003). Television shows, movies, cartoons, and videogames are included in this media-produced list. Media-produced images surrounded the children in their everyday environment and conversations. Children came to school carrying Spiderman lunch boxes, wearing Pokemon shirts, and talking about Chicken Little during breakfast conversations with peers. When children were in the process of writing, many of these popular culture elements weaved into the conversations that took place with their peers.

One day as the children engaged in Ronda's writing demonstration, they started to talk about Sponge Bob, Square Pants, a popular children's cartoon. Then, when Ronda completed her writing, and the students shared their ideas for writing, this conversation took place:

Cathie: I'm going to draw a hamburger. I can make a crabby patty from Sponge Bob.

Ronda: Cathie, you know what. I happened to watch Sponge Bob last night. Jibir: Ms. Ronda, my daddy always brings Sponge $B o b$ movies home.

Kallen: Yeah. Squid worm ate them all!

[Field Notes 9/19/05] 
After the conversation at the carpet, the children walk to the tables, choosing their own seating arrangement. Roderick and Frank follow Cathie to one table, sit next to her, and continue the conversation about Sponge Bob. Cathie discusses the crabby patties that Sponge Bob makes as Frank acts out an episode of the show in his writing (Table 4.34).

Cathie: Look. I got a hamburger and a hot dog. And I make a house and a crabby sandwich.

Roderick: Sponge Bob, Square Pants. I make eyes. Now fingers. Ghosts have fingers.

Frank: This is Sponge Bob. He says, "Save me!"

Talisha: He copying Sponge Bob putting his hand on the stove.

Frank: Save me! OwwwEEEEEE!!! [Frank touches his paper and takes his hand away quickly like it was hot to him.]

[Field Notes 9/19/05]

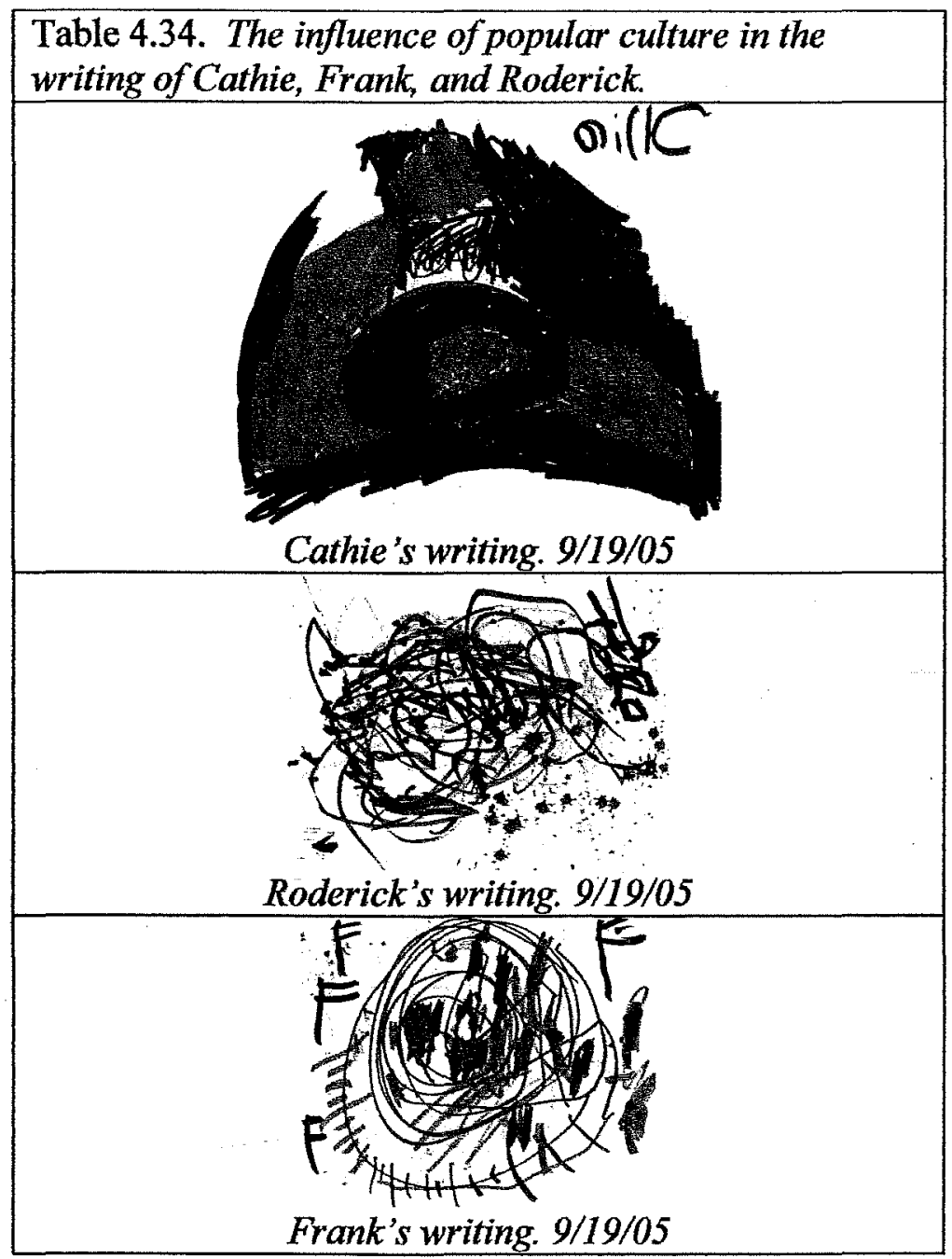


In the writing of these three students, Sponge Bob was a central character. For Frank, the plot of the cartoon program was critical in telling his story. Meanings existed within the the scribbles on their pages. Sponge Bob was the popular culture force behind the images they created.

One another occasion, Lisa sat down for breakfast at a table full of peers. She began to eat her powdered donut and drank orange juice from a box. In between bites and sips, she shouted, "The sky is falling! The sky is falling!" Her friends laughed.

One after another, the children began repeating the same phrase. Each time it was said, the group of students laughed at themselves. This cadence continued for several minutes, each time producing loud rounds of laughter. In the midst of their laughter, I asked Lisa about this phrase.

Brian: What are you guys talking about?

Lisa: "The sky is falling. The sky is falling."

Brian: What does that mean?

Lisa: I don't know. I just saw it on a movie.

Brian: What movie?

Lisa: Chicken Little. I saw it last night with my family.

[Field Notes 11/21/05]

Later, I asked Lisa about her writing idea. Immediately she replied, "Oh, I'm writing about Chicken Little today.”

The students went back to the tables and began composing. Talisha and Travion joined Lisa at the table. They talked as they wrote.

Travion: I'm makin' a house.

Lisa: Chicken Little.

Talisha: The sky is falling. The sky is falling. [The three students laugh.]

Talisha to Lisa: Tell me about your writing today.

Lisa: I'm writing Chicken Little.

Talisha: [To Travion] Tell me about your writing today. The sky is falling?

Travion: Is the sky falling down? Yes it is! Ha ha!

[Field Notes 11/21/05] 
Lisa's writing displays the influence of popular culture had on her decision to include elements of Chicken Little in her writing (Figure 4.40). She included both the character from the movie and other essential plot lines.

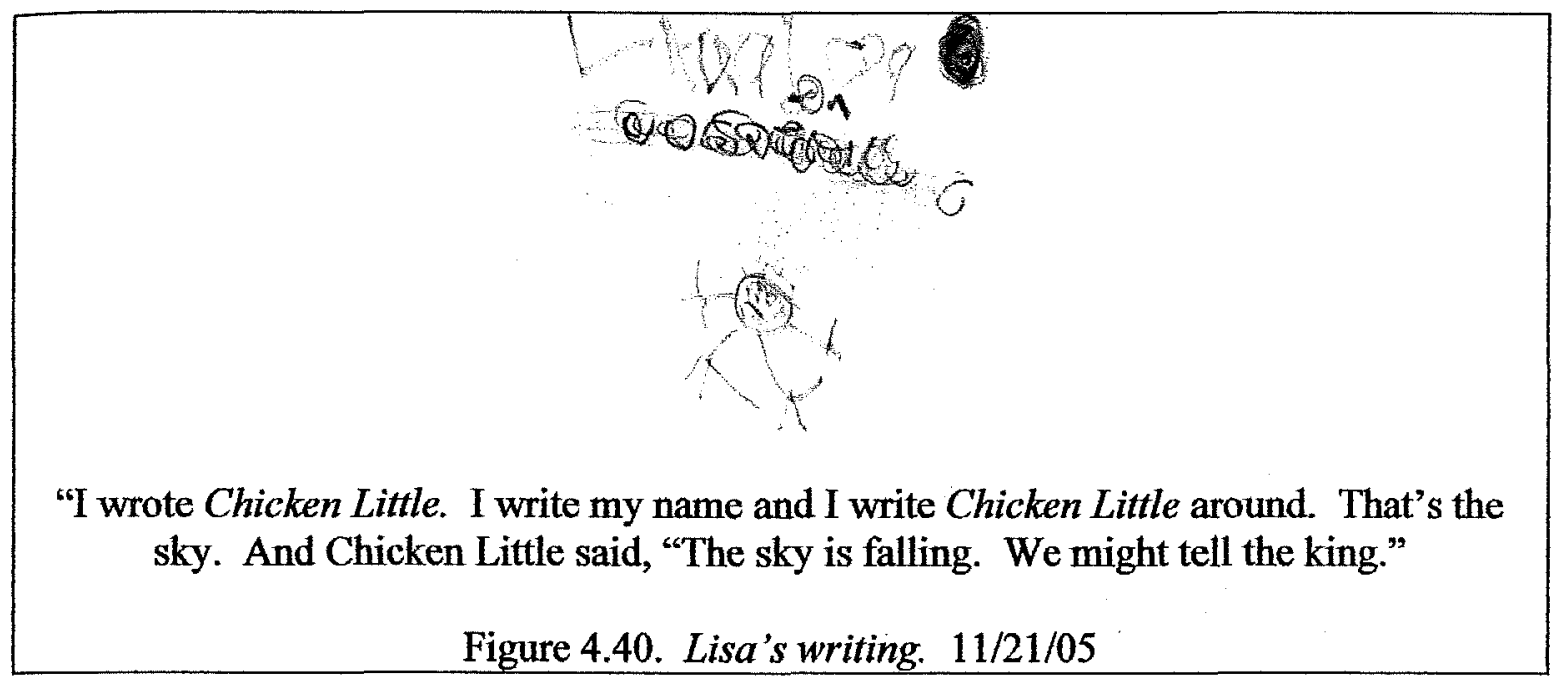

The following table displays several popular culture elements and evidence of the media in the writing of the students (Table 4.35). On five different observed occasions, children wrote about a particular popular culture topic that I heard them talk about. On the 22 other occasions they mentioned popular culture features in their explanations of their writing. I either did not observe their conversations or they did not take place. In many of these cases, I was present, and the children incorporated elements of popular culture media without the influence of peer interaction. 
Table 4.35. Popular Culture and its Influence on the Writing of Pre-kindergarten Students as a Result of Student Interaction.

\begin{tabular}{|c|c|c|c|c|}
\hline Date & $\begin{array}{c}\text { Popular Culture } \\
\text { Entity }\end{array}$ & Source of the entity & $\begin{array}{l}\text { The student who } \\
\text { used elements of } \\
\text { the entity in their } \\
\text { writing }\end{array}$ & $\begin{array}{c}\text { Students used } \\
\text { elements of the } \\
\text { media based on } \\
\text { interactions with } \\
\text { peers }\end{array}$ \\
\hline $8 / 29 / 05$ & Kirby & $\begin{array}{l}\text { Videogame } \\
\text { character }\end{array}$ & Pierson & $=$ \\
\hline $8 / 31 / 05$ & Robots & Movie & Lisa & Yes \\
\hline $9 / 02 / 05$ & Robots & Movie & Roderick, Lisa & Yes \\
\hline $9 / 06 / 05$ & $\begin{array}{c}\text { Beauty and the } \\
\text { Beast }\end{array}$ & Movie & Cathie & - \\
\hline $9 / 07 / 05$ & Batman Begins & Movie & Jibir & - \\
\hline $9 / 12 / 05$ & $\begin{array}{l}\text { Frosty the } \\
\text { Snowman }\end{array}$ & Television Show & Kallen & - \\
\hline $9 / 16 / 05$ & $\begin{array}{l}\text { Sponge Bob, } \\
\text { Square Pants }\end{array}$ & Television Cartoon & Cathie & - \\
\hline $9 / 16 / 05$ & Hello Kitty & Stickers and Toys & Arianna & - \\
\hline $9 / 19 / 05$ & $\begin{array}{l}\text { Sponge Bob, } \\
\text { Square Pants }\end{array}$ & Television Cartoon & $\begin{array}{c}\text { Cathie, } \\
\text { Malcolm, } \\
\text { Roderick, Frank }\end{array}$ & Yes \\
\hline $9 / 21 / 05$ & Robots & Movie & Pierson & - \\
\hline $9 / 21 / 05$ & Dora the Explorer & Television Cartoon & Ariama & - \\
\hline $9 / 21 / 05$ & Power Rangers & Television Show & Roderick & - \\
\hline $9 / 30 / 05$ & Robots & Movie & Chars & - \\
\hline $10 / 03 / 05$ & $\begin{array}{c}\text { Proud Family } \\
\text { Movie }\end{array}$ & Movie & Jibir & - \\
\hline $10 / 03 / 05$ & Dinosaur Movie & Movie & Roderick & - \\
\hline $10 / 05 / 05$ & Static Shock & Television Cartoon & Kallen & - \\
\hline $10 / 10 / 05$ & Dinosaur Movie & Movie & Roderick & - \\
\hline $10 / 11 / 05$ & Alphabits & Television Show & Cathie & - \\
\hline $10 / 12 / 05$ & Monsters, Inc. & Movie & Malcolm, Cathie & Yes \\
\hline $10 / 19 / 05$ & Kim Possible & Television Cartoon & Jibir & - \\
\hline $10 / 27 / 05$ & Robots & Movie & Roderick & $=$ \\
\hline $11 / 03 / 05$ & The Fantastic Four & Movie & Kallen & - \\
\hline $11 / 15 / 05$ & Chicken Little & Movie & Kallen & - \\
\hline $11 / 16 / 05$ & Spiderman & Movie & Jibir & - \\
\hline $11 / 16 / 05$ & Sponge Bob & Television Cartoon & Pierson & - \\
\hline $11 / 21 / 05$ & Chicken Little & Movie & Lisa, Talisha & Yes \\
\hline $11 / 28 / 05$ & Kirby & Videogame & Pierson & $=$ \\
\hline
\end{tabular}

Popular culture provided characters and plotlines of stories for the children as they sought ideas for their writing. It also provided students with shared interests and commonalities as they participated with their peers in discussions concerning television shows, movies, videogames, and cartoons as they engaged in writing. 
Student Interactions as Teacher/Researcher Influenced Their Writing

After two months of school, children began to mimic the questioning of the teacher and myself. As the children sat at tables together, they questioned each other about the content of their writing. This happened on five observed occasions. On each occasion, one child took the role of teacher/researcher and started to ask other children about the meaning of the writing they created. As peers responded to the inquiries, the "teacher/researcher" took notes, thus creating their own genre of writing.

On four of the five occasions, Lisa and Talisha inquired about the writing of their peers. In tandem, they conferred with their peers together as they asked questions about the meaning of their writing. Each time they assumed the role of teacher/researcher, they composed text that was note-like. The discussion and subsequent writing composed on November 15, 2005 is illustrated in this transcript and subsequent table.

Talisha: Tell me about your writing today.

Talisha: Kallen, tell me about your writing today.

Kallen: No.

Lisa: Kallen, Chars, tell me about your writing today.

Travion: This is a snake.

Lisa: [Writes his response on her paper]

Arianna: A big, big, big, big snake.

Talisha to Lisa: Let's ask everyone.

Lisa: Good idea. Kendrick, tell me about your writing today.

Kendrick: Um...a house. [Lisa writes his response on her paper.]

Talisha: Okay, Travion. Tell me about your writing today.

Travion: No.

Lisa to Talisha: You have to write your name on your paper, Talisha.

Talisha: [Disagreeing] Nuh uh. Malcolm, tell me about your writing today.

Malcolm: No.

Talisha: Arianna, tell me about your writing today.

Arianna: I'm writing a lake.

Talisha: [Writes on her paper]

Talisha: Kendrick, tell me about your writing today.

Kendrick: [annoyed] I said a house!

Talisha: [Writes his response on her paper.] 


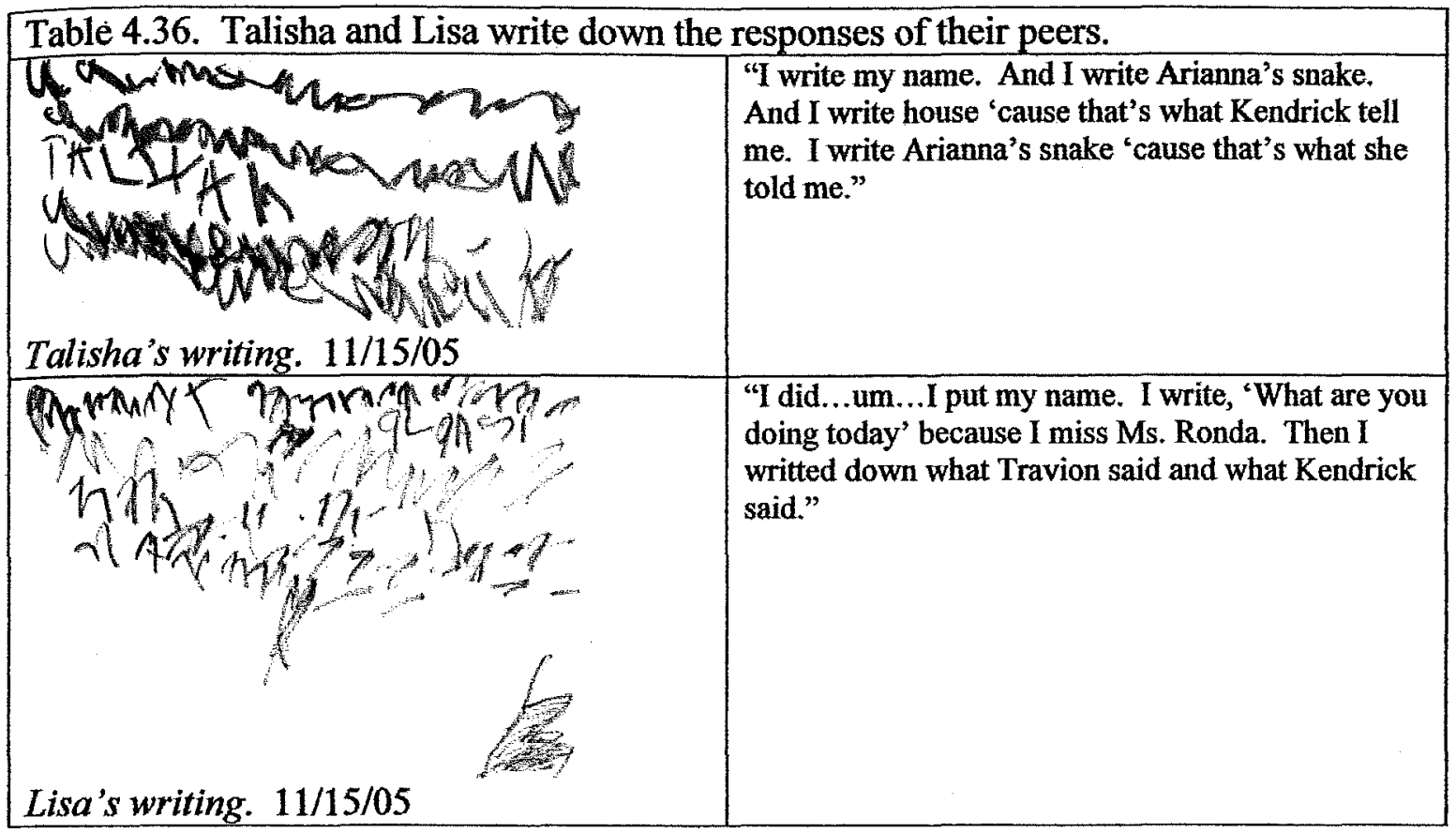

On one occasion, Roderick inquired about the writing of his peers and wrote down their responses. As Roderick sat with Cathie, Katalina, Kallen, Pierson, Travion, and Frank, he addressed each student and asking them to explain the meaning of their writing.

Roderick to Frank: What you doing today?

Frank: Dots.

Roderick: Travion, tell me about your writing today.

Travion: No.

Jibir: Oh, Roderick, you tell me about your writing today.

Roderick: No. Pierson, tell me about your writing today.

Pierson: Hat.

Roderick: Hat. And what else.

Pierson: B

Cathie: That's not a B. This is a B.

Roderick: Cathie, tell me about your writing today.

Cathie: Um...a baby.

Pierson: This is a $\mathrm{B}$.

Cathie: No, this is a B, Pierson.

Roderick: Um.....Kallen, tell me about your writing today.

Kallen: I'm not going to tell you about my writing.

Roderick: I'm not going to be mean to you. 


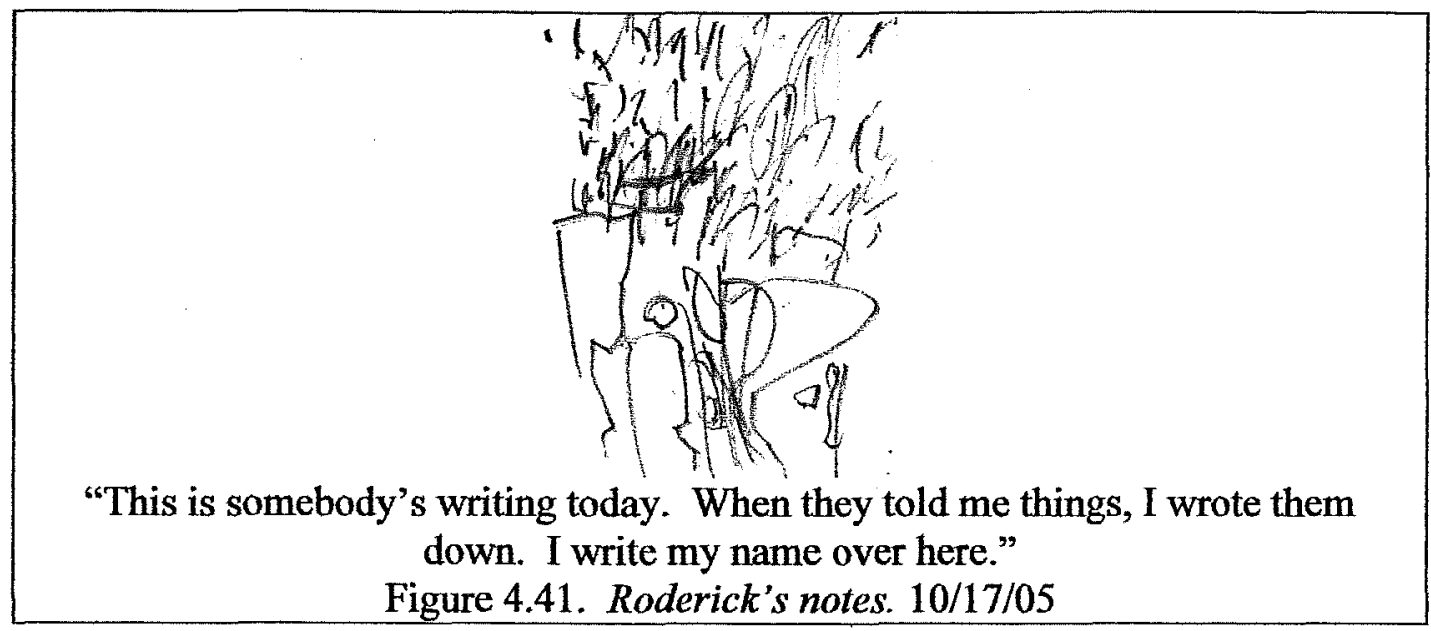

Like Talisha and Lisa, Roderick asked his peers questions about their writing. As they answered his inquiries, he wrote down notes based upon their responses. Frank, Pierson, and Cathie willingly described their writing to Roderick. For reasons of their own, Travion and Kallen refused to answer. Even after Roderick reassured Kallen that he would regard his feelings, Kallen still did not respond to Roderick's inquiries.

This form of inquiry among the students seemed to reveal power struggles in the classroom. Lisa, Talisha, and Roderick assumed the role of teacher/researcher when they asked their peers about their writing. Some students willingly played along and answered their questions seriously. When this happened, Lisa, Talisha, and Roderick recorded their responses in their notes. Other students refused to answer. In this way, they appeared to be telling the questioner that they were a peer, not an authoritative figure.

This power struggle is further illustrated in a conversation that took place at a table with Lisa. Ronda briefly walked out of the classroom as the children were writing because of a phone call in the office. In her absence, Lisa took control of her table. As they wrote, the following conversation occurred. 
Lisa: I'm going to ask you guys about your writing. Cathie, tell me about your writing today.

Cathie: A chicken.

Lisa: A chicken? I thought you were writing a book.

Cathie: I changed my mind.

Lisa: [addressing her peers] Um...I want it quiet, okay. For Ms. Ronda.

Cathie: [Pointing to her writing] This is the initials I start with.

Lisa: Cathie, be quiet so Ms. Ronda will be proud, okay? Let's be quiet.

Chars: [angrily] So what!

Lisa: [demandingly] SH!!!!! Ms. Ronda is going to proud of us when she comes back.

Chars: Lisa, look over here.

Lisa: [whispering] Ms. Ronda is going to be so proud of us.

Chars: Sh!!!

Lisa: [correctly Chars] Oh, I can talk. Frank, be good so you can go outside. You need to act like a grown-up right now.

Cathie: I can talk.

[Transcript 11/10/05]

Lisa began the conversation by asking Cathie about her writing. The conversation changed, however, when she decided to take a more authoritative tone with her classmates, silencing them as they were writing. The other students were annoyed by her castigation and rebelled. After telling Chars to be quiet, he questioned her. "So what" he said, meaning (I infer), we always talk when writing. Why do I have to be quiet now?

Cathie, who at the beginning, shared her writing insights with Lisa, grew increasingly irritated with her. Lisa demanded that everyone be quiet, and Cathie disagreed, "I can talk."

Instead of a table of writers who talked as they composed, Lisa wanted silence. Knowing that this was not the way writers worked in their classroom, Cathie and Chars resisted her dictatorial tone as they continued to talk while composing.

The tendency of children talking and asking questions about the writing of their peers became more common in Ronda's classroom. In one sense, the children were roleplaying - acting out the parts of the teacher and researcher in the classroom. In other 
ways, children were actually curious about the ideas and symbols their peers were placing on the page. As children asked peers about their writing, they took notes based on their responses, and the questioning influenced the children's compositions.

\section{Students Help Their Peers with Their Writing}

On five observed occasions, when the students wrote with their peers, one student helped another student to create a particular symbol. This typically occurred when a student wanted to make a specific picture, turned to a peer, and asked for assistance. The discussions that occurred and the resulting products are displayed in Table 4.37.

\begin{tabular}{l}
\hline Table 4.37. Students ask for assistance in symbol-making. \\
\hline Discussion \\
Kugust 31, 2005 \\
Rallen: I don't know how to make a school bus. \\
for you. Jsk Pierson how he did his. Don't ask him to do it \\
Kallen to Pierson: How did you do yours? \\
Pierson: I made the big this...then I did this...I made a \\
circle. Then I made another circle. \\
Kallen: I still don't know how to do it. \\
Pierson and instead wrote \\
people. \\
October 3, 2005 \\
Tisa to Talisha: Show me how to make a heart. \\
own paper and explains her process as she does this.] Then \\
go like this. Then go like that. \\
Lisa: Likee that? \\
Talisha: Yes. Now, go down. Look! I showed her! \\
Lisa: Let's do it again! \\
Talisha: Okay. Make that. Then go down. \\
Lisa: Does that look pretty?
\end{tabular}


October 3, 2005

Kallen: I don't know how to make triangles.

Ronda: Why don't you ask someone.

Talisha: I'll show you how to do it. You make this thing here. Then you make a line here. Then you color it in. See, a triangle.

Kallen: [Does the same thing in his writing.]

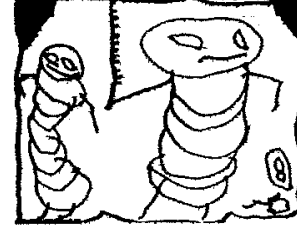

Kallen's writing

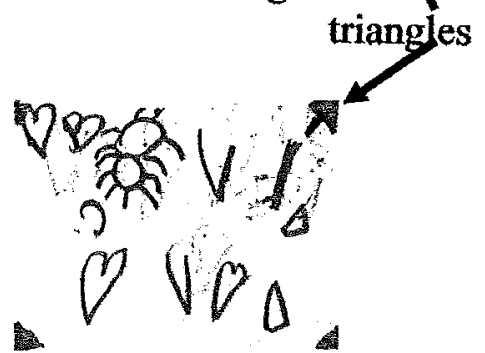

Talisha's writing

October 7, 2005

Talisha: Oh, I like those rainbows. Can you show me. Lisa: I learned it from my old school. You use different colors and you just make lines like this. [Lisa writes as Talisha watches.]
November 15, 2005

Arianna: Chars, can you show me how you made that snake. Chars: You just put your marker line and draw a squiggly line. Like this.

Arianna: Thank you.

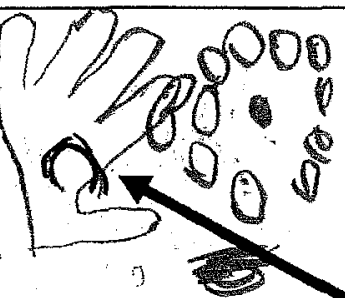

Lisa's writing.

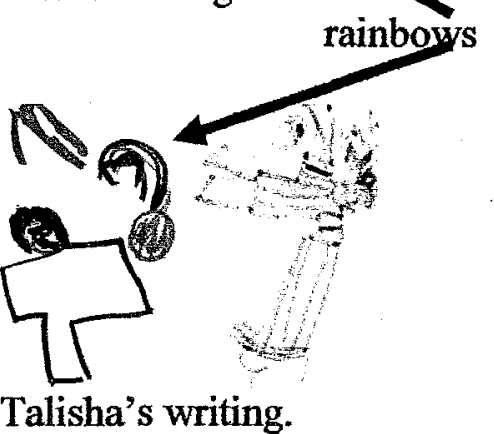

Talisha's writing.

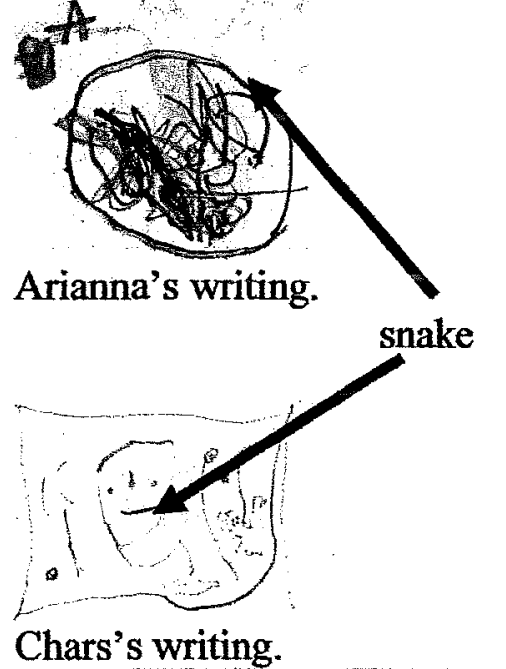


In each of these cases, one student asked another for assistance in creating a symbol. The "expert" explained his/her process to their peer. The peer either accepted the scaffolding, or didn't' understand, as was the case with Kallen and Pierson.

Students went beyond the creation of symbols to ask their peers for assistance in writing letters on their page. They positioned themselves near particular peers and watched as those children created their names on their pages. Then, the writer who wanted help asked for assistance in writing specific letters of the other child's name. On five observed occasions, a student vocalized their desire to write the name of his/her peer. The talk and resulting products are displayed in Table 4.38.

\begin{tabular}{|l|l|l|}
\hline Table 4.38. Students ask for assistance in name writing. \\
\hline Discussion & Writing Products \\
\hline October 18, 2005 \\
Talisha: Malcolm, how do you \\
write your name? \\
Malcolm: I got an M in my name. \\
And I got these letters. [Malcolm \\
writes his name. Talisha watches \\
and copies the letters onto her own \\
paper.] \\
Talisha: Arianna, tell me how you \\
write your name. \\
Asiayanna: I got A in my name. \\
[Arianna writes an A. Talisha \\
copies it. Then, she looks on the \\
back of Arianna's chair and writes \\
other letters that she sees in her \\
name.]
\end{tabular}




\begin{tabular}{|c|c|}
\hline $\begin{array}{l}\text { November } 15,2005 \\
\text { Cathie: Malcolm, how you write } \\
\text { your name? } \\
\text { Malcolm: It has an M. Then it has } \\
\text { these other letters. } \\
\text { Cathie: How do you make that M? } \\
\text { Malcolm: You make lines go like } \\
\text { this. [Malcolm writes an M in the } \\
\text { air to show Cathie. She writes the } \\
\text { M on her page.] }\end{array}$ & Cathie's writing \\
\hline $\begin{array}{l}\text { November } 15,2005 \\
\text { Pierson: Jibir, I'm going to write } \\
\text { your name. } \\
\text { Jibir: Okay. } \\
\text { Pierson: Show me how I do it. } \\
\text { Jibir: I got these letters in my } \\
\text { name. Now you do it. } \\
\text { Pierson: This is easy. }\end{array}$ & Jibir's writing. Jibir's name \\
\hline $\begin{array}{l}\text { November } 16,2005 \\
\text { Arianna: Jibir, you make my } \\
\text { name? } \\
\text { Jibir: Yeah. I'm going to do your } \\
\text { name. } \\
\text { Arianna: I have an A in it. This is } \\
\text { how it looks. } \\
\text { Jibir: Look, here's my A! }\end{array}$ & Arianna's name \\
\hline
\end{tabular}


Children adding the names of their peers to their writing occurred throughout the classroom and beyond my recordings of their conversations. Like the symbol-making examples, children asked their peers about creating letters; the knowledge they gained from these interactions appeared to aid their growing awareness of letters and, ultimately, their increasing knowledge of the purposes for written language.

\section{Students' Non-Verbal Interactions Influenced their Writing}

Beyond the spoken conversations that took place among peers as they wrote, children also used non-verbal cues to assess the writing of their peers. Their observations of their peers' writing led students to incorporate symbols, letters, and names onto their own pages. These non-verbal interactions occurred throughout the writing time and are captured in Table 4.39.

Table 4.39. Non-verbal interactions of students and incorporation of symbols, letters, and names into the writing.

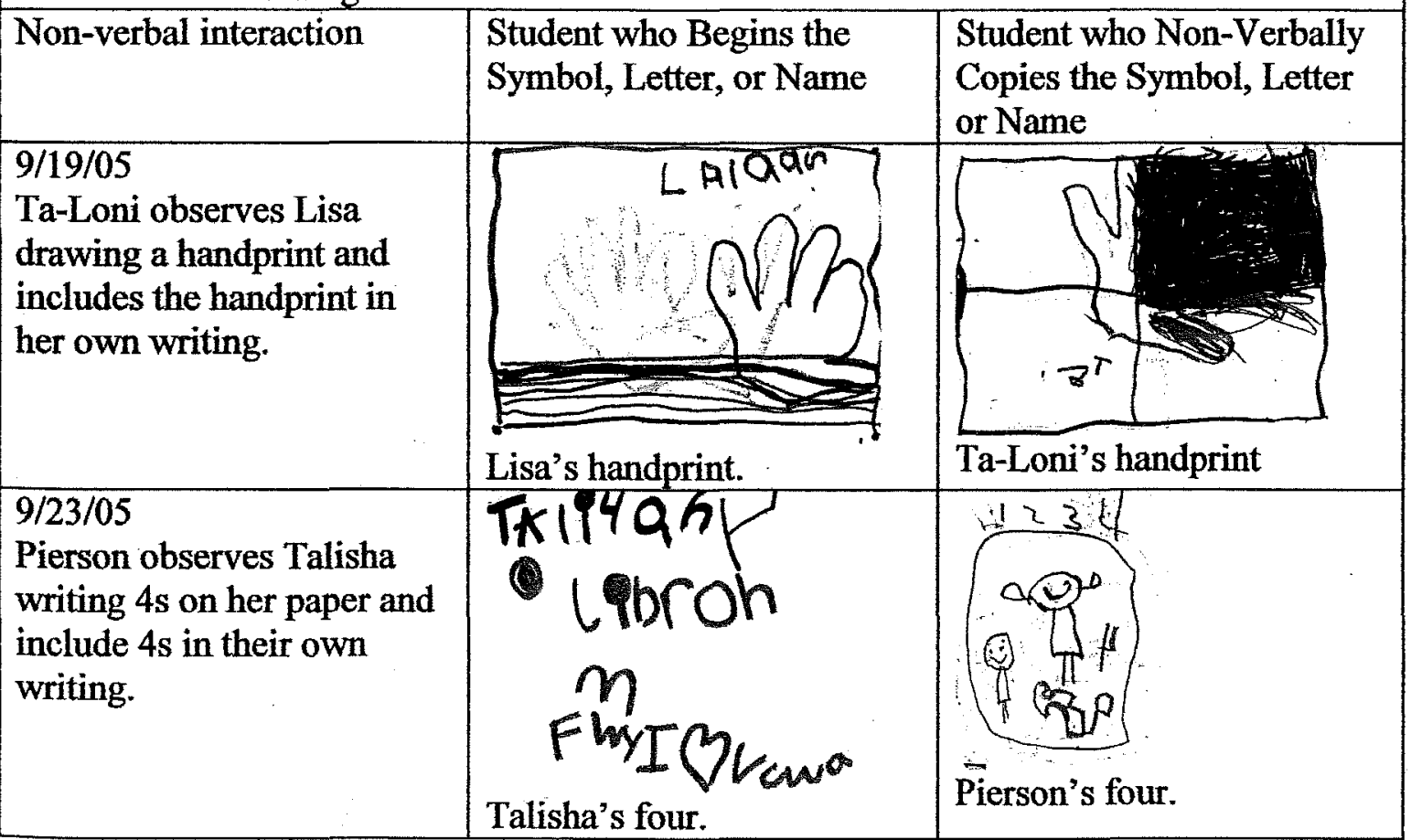




10/11/05
Roderick observes Lisa
drawing rainbows on her
paper and includes
rainbows in his writing.

In this way, peer scaffolding of written language extended beyond verbal communication.

As students observed their peers create symbols, letters, and names while in the process

of writing, they incorporated these forms into their own products. Because children 
wrote together, they were able to access the knowledge of peers as a means of understanding written language.

\section{Student Talk Not Related to Written Products}

As writers, the students learned by observing others. Often, children attempted to make pictures and print that was similar to those of other students in the class. Generally, this was tolerated by peers. As students engaged in writing together, the interplay of the conversations and the willingness of peers to help others was exhibited in collegial exchanges. On rare occasions, however, some children took issue with peers looking on their papers and became annoyed. These conflicts always arose among the boys in the classroom who sometimes used this cooperative writing time as a means of negotiating peer relationships.

In one exchange, Chars, Travion, and Malcolm sat at the same table. Travion informed the table that he was writing about monsters. Chars, finding the idea equally appealing, decided to create the same thing in his writing. The following verbal exchanged happened as a result.

Travion: Oh...he [Chars] makin' a monster. Don't copy me! I said I was going to make a monster.

Chars: I can do what I want to do!

Travion: [yelling] DON'T COPY ME!!!

Chars: I do what I want.

Malcolm: [to Chars] I'm movin'. You not comin' over to my house!

[Transcript 10/05/05]

Travion was irritated with Chars for writing about the same idea. Chars, aware that he was entitled to borrowing ideas in this classroom, informed Travion that he could write about whatever he pleased. Chars's flippant remark inflamed Travion who screamed at 
him. Malcolm, siding with Travion, declared his allegiance to Travion, further alienating Chars as they engaged in writing.

Issues of friendship arose on another occasion when the children self-selected their seat arrangement for writing and naturally separated themselves into single-sex groups. This happened on only one observed occasion and the conversation that took place shows how the students were more interested in negotiating relationships with one another than composing.

Roderick to Travion: You my friend?

Travion: Yeah.

Roderick: [pointing to Jibir, Malcolm, and Chars] And not his friend or his friend, or his friend?

Travion: [ignores Roderick]

Malcolm: Travion, is you my friend?

Travion: No.

Malcolm: [angrily] I'm not your friend. [Malcolm begins to look worried]

Roderick: [A frown emerges on his face.]

Malcolm: Why? Why you sad? Roderick, what wrong with you?

Roderick: [hurtfully] I'm not your friend.

Jibir: Hey, Travion. Roderick says he live with you.

Travion: No, he live on the floor.

Jibir: I was lying on my bed looking at the TV and he knocked me on the floor.

Chars: I punch my brother in the face and he fell.

Malcolm: A little boy said he wore a skirt to school.

Travion: EWWWW!!!! He had a skirt?

Malcolm: Travion, he was wearing a pocketbook to school, too.

Travion, Chars, and Jibir: EWWWW!!!!!

[Transcript 9/30/05]

This separation of same-sex groups elicited an explosion of talk among the boys, but little writing. Immediately, the boys sat at their table and began talking. The majority of the talk revolved around friendship issues. Before the writing demonstration, Roderick and Malcolm had exchanged confrontational words on the carpet that 
transferred to the table during writing. At first, the boys talked about their writing ideas and the smells of the markers. Quickly, however, the talk turned towards friendship.

Roderick began the discussion by asking Travion if they were friends. Malcolm, feeling vulnerable, asked different peers if they were still his friend. When Malcolm nicely asked Travion if he was Malcolm's friend, Travion was ruthless with his reply. "No," he answered in a sharp tone. Looking hurt and defensive, Malcolm looked over at Travion and announced, "I'm not your friend." Malcolm's eyes grew big as he became nervous. He furrowed his brow and looked down on his paper. He was not writing. It appeared that he was thinking about something. Then, in a quiet tone, he looked over at Roderick and asked him, "Why you sad? Roderick, what's wrong with you?" Roderick immediately responded, "I'm not your friend." Suddenly, writing did not seem important to Malcolm any longer. He became much more concerned with his friendships and position among his peers.

Eventually, the talk turned towards a boy who came to school one day wearing a skirt. They thought this was funny and inappropriate, they began making references to his femininity, and were disgusted by actions of bringing a pocketbook to school. The boys laughed at the boy who acted like a girl at school. This discussion seemed to bond the boys back together. After they laughed, they continued to write. The talk dissipated as the boys resumed composing.

On another day, another group of boys (Travion, Frank, Jibir, and Kallen) sat at the same table as a group of girls (Talisha, Josephina, and Cathie). The girls quietly composed together as the boys talked. All writing ceased momentarily when Travion announced to the table that his brother was in jail. The following conversation occurred. 
Travion: My brother in jail

Frank: Well, my brother in jail too.

Malcolm: I was in jail when I was a little boy. Jibir, you brother in jail?

Jibir: No

Malcolm: A jail is in D.C. There's a jail in New York. They are everywhere. [Transcript 9/19/05]

The mood during the conversation was unusually subdued. The children conducted this conversation in whispers and all writing stopped. The talk about jail was not present in their writing or subsequent explanations of their texts.

In the above conversations, talk at the writing tables was not limited to the writing they created on the page. Conversations that occurred as children engaged in writing explored friendship relationships and revelations about their families that they chose not to make concrete in their writing.

\section{Summary}

As students engaged in the writing process, peers were influential in the decisions they made in their writing. Idea-sharing was prevalent in the classroom and it occurred during the read-aloud experience, during the teacher demonstration, and during initial discussions at the tables as students wrote. Upon hearing ideas from peers, many students incorporated similar ideas into their own writing, both in the symbols they produced and letters they wrote. Similarly, discussions about popular culture were a common occurrence in the classroom. The children discussed movies, television programs and cartoons, and included elements of the popular culture in their written products. Their exposure to popular culture media began at home, and the transfer of it 
into the classroom through conversations influenced writing decisions the children made when they incorporated characters and story lines from popular culture into their writing.

As students observed the writing of the teacher and myself, their awareness of writing purposes was furthered. Ronda and I asked students questions about their writing and wrote down their responses in our notes; children began to mimic us. They asked peers about their writing and recorded their responses in their own texts.

Children went beyond the teacher to ask peers for scaffolded assistance in their writing. On other occasions, they non-verbally learned, as they watched their classmates create symbols, letters, and names. The interactions that occurred assisted students in creating new forms that they could add to their growing written language awareness. In most cases, the children welcomed peer interaction and delighted in showing others how to form particular ideas, symbols, letters, and names in their writing. On rare occasions, some students were less forthcoming and were annoyed by students who tried to copy their writing.

Not all the talk that occurred at the tables centered on their written products. Occasionally, student talk while writing revolved around discussions about friendship and family. During these discussions, the talk was more important than the writing and they ceased composing to engage fully in the conversations. When writing commenced, the conversations were not present in their final products and explanations.

Student interaction, while engaged in the process of writing, was a critical component of the children's developing awareness of written language. As seen in the samples shown above, peers influenced the writing decisions of the pre-kindergarten children. Because the teacher encouraged children to interact with one another as they 
composed, and the classroom environment was structured so that these interactions could occur as children were engaged in the writing process, students' notions about writing and written language were enhanced. 


\section{CHAPTER FIVE:}

\section{DISCUSSION OF FINDINGS}

In this study, I sought to understand the writing processes and products of prekindergarten writers by examining the social interactions that occurred in a classroom where they engaged in daily writing. Previous research examined the orthographic and spelling development of children as they formulate their initial notions of print (Clay, 1975; Gentry, 1982; Henderson \& Beers, 1980; Read, 1971). Additional research ventured beyond the page to consider the processes children use as they engage in writing acts (Calkins, 1994; Graves, 2003; Hansen, 2001; Harste, Woodward, \& Burke, 1984), and some research of child writing examined the social contexts in which children compose (Dyson, 1993; Gundlach, McLane, Scott, \& McNamee, 1985; Jones, 2002; Kantor, Miller, \& Fernie, 1992). In examining the why of writing rather than the how, several researchers have asserted that the meanings of children's written compositions are found beyond their drawings and orthographic attempts; in order to understand their efforts we must consider the socio-cultural influences that occur within their classroom (Dyson, 1989, 1993; Gallas, 1994; Genishi, Stires, \& Yung-Chan, 2001; Goncu \& Weber, 2000; Kendrick \& Mckay, 2004).

Almost all the aforementioned studies address writers in kindergarten and elementary school. As a result, there remained a gap in the research that examined the social influences that occur in pre-kindergarten classrooms as young children engage in 
writing. Due to this research gap, I investigated those influences in one classroom of prekindergarten students. In an attempt to understand the meanings these children assigned to their writing, I addressed the following research questions:

1. What are the settings in which social interactions occur in one prekindergarten classroom during writing instruction?

2. In what ways, if any, do these social interactions influence the children's writing processes?

3. In what ways, if any, are these social influences manifested in the written products of the pre-kindergarten children?

Research data were collected over an extended period of time in the field. As I observed, I recorded field notes and conducted interviews with the children and teacher. I collected examples of the children's writing to accompany all observations and interviews. Analysis of the data resulted in the emergence of three findings that show in which classroom settings the most influential interactions occurred: during the read-aloud experiences, during the teacher's writing demonstration, and when the students were at the tables engaged in the process of writing. Further analysis showed how the social interactions in these settings influenced the children's writing processes and products.

\section{Discussion of Findings}

Pre-kindergarten students bring only a few years of life experience to their pages as they write. In their initial years, the home and the community are the major contributors to their knowledge of the world (Dorsey-Gaines \& Taylor, 1988; Heath, 1983). At the young age of four, the children in my research ventured beyond home or 
child care settings into a new environment-the pre-kindergarten classroom. In this realm they were surrounded by peers who were equally new to the learning environment. As individuals, they entered the classroom with their own notions of language and writing (Morrow, 2001; Purcell-Gates, 1996). Collectively, they developed new notions about written language as they engaged in interactions with their teacher and peers. Learning, therefore, became a function of the culture, context, and activity in which it was situated (Lave \& Wenger, 1991). The students in this pre-kindergarten classroom were embedded within a "community of practice." Their texts displayed the collective influences of the classroom.

I found that:

1) Several influential interactions occurred at the beginning of each day as the children gathered around their teacher. These events, which led into the children's engagement in their daily writing, included rote recitation of a scripted language program, engagement with children's literature, and conversations that were initiated by the teacher and students. Findings suggest that the interactions that occurred during these gathering experiences either stunted the children's writing ideas (as was the case with the scripted language program) or provided them with ideas for their writing (as was seen with the read-aloud texts). In addition to gaining ideas from the read-aloud experiences, the children used the children's literature for support as they created symbols and letters, and developed a growing awareness of genre structure.

2) The interactions that occurred during the teacher's writing demonstration also influenced the children's writing. As she composed in front of her students, the occasion was interactive; the students became co-creators of her texts. These interactions included 
the teacher showing the children how to obtain ideas for their writing, how to incorporate symbols into it, how to add their names and print to their texts, and how to write within specific genre structures. These interactions were manifested in the writing of the children as they, like the teacher, used classroom experiences as the impetus for their texts, included symbols that were similar to those of the teacher, and wrote in genre structures that bore semblance to hers.

3) Students' verbal and non-verbal interactions, as they engaged in writing, comprise the third finding. These interactions were influential to the children as writers. As they composed, they collaboratively talked about ideas, engaged in conversations about popular culture, questioned peers about their writing, assisted peers in creating symbols and non-verbally used peers as resources when they created symbols, letters, and wrote their names.

First Finding: Interactions during the Read-Aloud Influenced Children's Writing Graves (2003) asserted that children need choice in topic selection when they engage in writing. His data showed that children who were able to make their own decisions when writing were more likely to show significant growth, feel ownership of their writing, and take pride in their work. In the classroom I studied, ideas came to the children as they transacted with the children's literature that Ronda (the teacher) read to them. Rosenblatt's transactional theory (1978) attests to this inter-play between readers and texts; as the students engaged with the read-aloud texts, they ascribed their own experiences to them in aesthetic and efferent responses. Because the read-alouds provided additional life experiences, the children were able to use their expanded knowledge in the texts they produced. 
The read-alouds also provided the pre-kindergarten children with exposure to how written language functions within texts. Research has suggested that children who have a growing awareness of print can begin to differentiate between the language used in speech and the language used in writing (Ferreiro \& Teberosky, 1983; Sulzby, 1985). When the pre-kindergarten children I studied told me about their writing, they used language that sounded more like written than spoken language.

As found by Dahl and Farnan (1998), the children in my study expressed their writing ideas through art/media, letters, and/or words. Newkirk (1989) showed how the meaning of child writing was often conveyed through the drawings they created on the page. In addition, as asserted in the research of Dyson (1993), Gallas (1994), Genishi, Stires, and Yung-Chan (2001), the children used methods beyond the paper to convey the meanings of their writing, such as movement and talk.

As exposure to various genres occurred in the read alouds texts, children began to incorporate elements of them into their own compositions. When the children told me, in interviews, what their writing meant, they spoke in genre structures that bore similarity to a particular genre. Similar to the findings of Purcell-Gates (1988) and Duke and Kays (1998), when the students wrote stories, their explanations reflected a narrative structure with an inclusion of characters, problems, events, and solutions. Similarly, when they wrote using an informational text structure, they used facts to explain their meaning.

As noted by Adams (2001) and Clay (1989), the texts also contributed to the students' increased notions of print. As the teacher read aloud, she swept her finger under words that accompanied the pictures. Students began to notice the print on the pages and started to experiment with adding print to their own writing. 
Second Finding: Interactions during the Teacher's Writing Demonstration Influenced

\section{the Young Writers}

The second setting in which social interactions occurred that influenced the children was that of the teacher's writing demonstrations. Here, the children were exposed to how writers create meaning when writing texts. As Ronda composed in front of the class, she told them where her ideas came from, incorporated symbols and print into her writing, and situated her writing within specific genre structures. Thus, engagement in these demonstrations provided the children with additional ideas for writing, examples of symbols to include, differences between drawing and print, and enhanced awareness of genre structures.

Rief (1994) noted the importance of teachers being writers. In order to understand the processes that writers go through when composing, the teacher must actively write to understand her own notions of writing, and to show her students these notions. Atwell's research (1998) focused on the teacher as she composed in front of her children and vocalized her intentions as a writer. Through these verbalizations of thought, their students witnessed how their teacher, as an "expert," engaged in writing. Ronda was a writer. She composed in front of her children and she noted her process aloud as she wrote. She verbalized her thoughts for writing ideas and asked for help from the students. Because of this, the children witnessed her struggles and successes and conducted themselves similarly as they wrote interactively with their peers. They explained their processes. Atwell's research differed in that it was conducted with middle school children. However, results from this study mirrored hers. Whether the 
children were four or fourteen, the teacher provided a powerful model for children who were continuously learning new notions about writing.

Calkins (1994) recognized in her research that teachers who created opportunities for children to write using a variety of contexts and purposes helped them understand the communicative intention of written language. Children's notions of communicative intention in their writing were prevalent in Ronda's classroom. The children wrote letters home, stories to entertain their peers, and informational texts to inform their audience about something they knew. Like the twelfth graders in the study conducted by Flower and Hayes (1984), the pre-kindergarten children considered their audience as they composed. Within the social nature of the classroom, the children asked each other questions about their writing, entertained others through stories, informed others through informational text, and communicated with others by writing letters home.

In a classroom studied by Wiseman (2003), kindergarten children were engaged in writing demonstrations with the teacher and often incorporated the teacher's ideas into their own writing. I found similar results with the pre-kindergarten children. Ronda tended to use classroom experiences as the impetus for her writing ideas, and, similarly, the students also used these experiences for ideas. The teacher explained in her demonstrations that she often received ideas from others as she composed and included their ideas in her writing. Likewise, students listened to the ideas of peers and chose to sit next them on several occasions to co-construct texts together. The data in this study supports the same results as seen in the Wiseman study.

Sometimes, however, the children did not use any of Ronda's ideas. They were entirely free to make their own choices, and even though they did glean ideas from 
Ronda, they always set their own writing agendas. Ronda encouraged them to do so, and in so doing her students did not resist writing. These findings differed from the findings of Corsaro and Nelson (2003) that showed power struggles between the teacher and students as the teacher restricted first grade writing by setting her own agenda for their writing ideas. This was not found in Ronda's pre-kindergarten classroom because she never set limits on the writing the children composed.

Read (1971), Bissex (1980), and Schickedanz (1990) all noted the development of spelling acquisition in their studies pertaining to young writers. In each study, children used their knowledge of letter sounds and formations to create print on the page. They inventively spelled words by matching the sounds to letters that they knew. In Ronda's classroom, children began to match letters and sounds to particular symbols in their writing. Much of this awareness came from Ronda's practice of asking students to help her apply words to the drawings she created in her own writing demonstrations. During each occasion, she slowly sounded out words and invited students to interactively make the letter-sound connections. Several children brought this knowledge to their own writing as they labeled their drawings with specific letters.

Third Finding: Peer Interactions during the Process of Writing Influenced the Children as Writers

Peers exist within the situated learning environment of the writer and they have great influence on the decisions children make when writing and the meaning they assign to the page where they talk about it later. In Ronda's classroom, student-student interactions that focused on writing ideas, symbol-creation, print production, and popular culture were decidedly influential in the meaning children created within their texts. 
Kantor, Miller, and Fernie (1992) observed pre-school children engaged in interactions during play times that also involved literacy acts. Within these play occasions, children co-constructed signs during block building and collectively wrote print together on the superheroes they painted at an art center. In Ronda's classroom, children engaged in similar acts, but they were done within a specific time designated for writing. In some cases, the writing the children composed was interactive in that the actions of the characters and the symbols that were created on the page were done as students vocalized the meanings of their writing and received responses from their peers. In this way, other students were actively involved in the concept development of the writing. Eyes were added to elephants, fences were built around horses, boxes were used to contain spiders, letters were affixed next to symbols, and names were added to writing. This occurred because, as the writers composed, they received oral feedback from peers and visual scaffolding to show them how to make the forms.

Children who wrote in the pre-kindergarten classroom often sought peers who were more knowledgeable about writing particular symbols, letters, or names. This was witnessed as children who did not know how to create particular symbols, letters, or names consciously chose to sit next to peers who did. As they sat with peers, they asked questions and made observations of the more competent writer, then used their observations to create similar symbols, letters, and names in their own writing. The findings extend the research of Neuman and Roskos (1997) and Nixon and Topping (2001) who found that when peers interact with one another during classroom events, the peer interaction can actually strengthen their abilities to use oral language, develop their vocabulary knowledge, and improve their attitudes about writing. Whereas Neuman and 
Roskos (1997) saw improvements in oral language and vocabulary development, the findings of this study found that when children composed together, their written language improved as they increased their awareness of ideas, symbols, letters, and name production in their writing. Unlike the study conducted by Nixon and Topping (2001), in which two children were paired by the teacher during writing events, the children in this study paired themselves naturally. Because writing instruction was done within an interactive environment, children knew the strengths and writing habits of their peers. When they were ready to try new things in their writing, and needed assistance, they knew exactly who to seek for guidance as they wrote and did so on their own.

As noted in studies by Jones (2002), Matthew and Kesner (2003), Craig-Unkefer and Kaiser (2003), and Paley (2004), peers play an important role in the social development of children within pre-kindergarten settings. The findings of my study support these claims and those made by Jones (2002), that students who compose with friends during writing showed appropriate instances of collaboration. On most observable days, there was little conflict among peers as they composed because they made their own choices in seating arrangement. Often, these choices were made based on the students' tendency to sit with friends. These choices resulted in little conflict.

The assertions made by Matthew and Kesner (2003) who found that students with a lack of knowledge were ostracized from a group who composed together, was not corroborated in my study. I found no observable cases in which students were ostracized because of their lack of writing knowledge. However, there was one incident in which a groups of boys engaged in conversations about the status of their friendships during writing. During this conversation, writing ceased. Within this conversation, one child 
was rejected by a small group of male peers. The child was ostracized not because of his knowledge of written language, but because of his status among the group of boys.

In all observations but one, children sat at integrated tables of boys and girls. These seating arrangements were made entirely by the children who freely chose who to sit next to during writing. The findings differ from those of Martin and Fabes (2001) and Maccoby and Jacklin (1987) who claim that children prefer to interact with same-sex peers at proportionally higher levels than different-sex peers. In the specific class I studied, both boys and girls interacted collaboratively within the designated writing time. In the one case in which the children naturally segregated themselves into single-sex groups, the girls quietly composed together as the boys spent more time negotiating their

friendship status among peers than they did writing. Analysis of the data revealed no real separation occurring as boys and girls composed in the classroom.

\section{Implications for Practice and Policy}

In an effort to close achievement gaps in education, the notion of universal prekindergarten systems has gained popularity in several states due to results of a study conducted by the National Research Council (2000) that found that at-risk children who attend quality child care programs are less likely to be retained in later years (Smith, 2004). The gain in popularity of pre-kindergarten programs has resulted in a 4-year scientific evaluation of preschool curricula funded by the Department of Education's Institute of Education Sciences. The study, titled Preschool Curriculum Evaluation Research (PCER), is an effort to determine outcomes that specific curricula produce in 
the learning of children. Print concepts and writing is part of the curricula being studied in this research study.

It is inevitable that pre-kindergarten writing and the methods of instruction that are employed to assist children in understanding written language will receive increased scrutiny in the coming years. As a result, teachers and policy makers will seek research that explores writing instruction in pre-kindergarten classrooms.

My study in particular can have important implications for teachers and policy makers involved in early childhood classrooms. The results show that children make meaning when they write. When children create scribbles, drawings, symbols, and letters on the page, they assign meaning to them as they write and, later, when they explain their final products. Additionally, the meaning that is formed is sometimes based on a collection of influences that occur in the classroom. For teachers and policy makers, the notion that children create meaningful forms on the page has important ramifications. The forms pre-kindergarten children create should be honored as true, meaning-filled messages used for communication.

The final written product provides an incomplete picture of the entire meaning. Children must be observed as they write, their gathering experiences must be considered, and the teacher's writing demonstration must be studied. When this is done, the teacher can ascertain additional meanings that may not be interpretable from the page. For teachers, it is not enough to look at the final written products of student writing and make judgments about their understandings of written language. For policy makers, it is not enough to mandate assessments that make assertions based on the final written product. To do so would result in incomplete knowledge of the writer. 
Gathering experiences that are conducted before children engage in writing provide students with support when determining ideas for writing. When presented with a scripted language program that required rote recitation rather than rich language usage, the children's writings were stifled. It provided them with no ideas for writing. Readaloud experiences provided children with ample opportunities to explore similar topics further in their own texts. For policy makers, these results give further evidence that scripted programs may possibly be harmful instructional practice in early childhood classrooms.

On the other hand, the children gleaned general information and specific written language awareness when a read-aloud was used as a gathering experience. This knowledge is important for teachers who conduct read-alouds with their classes. As the data showed, when the teacher highlighted elements of written language within the readaloud texts, children gained increased knowledge about print and genre structure. As a result, text selection is important; teachers need to choose books to read from various genres. Also important is the teacher's role in making explicit the differences between the print and drawing as they read the pages of the chosen text.

For pre-kindergarten teachers, their role in helping students develop increased awareness of written language using demonstration lessons is critical. As seen in the data presented here, the teacher's willingness to compose in front of her children provided children with essential understandings about how written language works and how writers make decisions in their writing. The children became increasingly aware of symbol creation, letter formation, and letter-sound correspondences when they actively engaged in co-constructing texts with Ronda. Additionally, the children's involvement 
in co-construction of texts with the teacher became a skill that was extended beyond the teacher's demonstration as children composed.

For policy makers, these data reflect the power of teachers to increase the written language knowledge of their young students using authentic experiences. The teacher's writing demonstration served as a catalyst to meet the individual written language needs of her students. The writing demonstration was an interactive tool that allowed the teacher to guide children towards increased understandings of how written language works. The scripted program hindered this scaffolding because it did not consider what the children already knew, nor did it allow for the independent needs of the children. As a result, policy makers should use extreme caution when mandating specific curricula programs. Scripted programs that require teachers to read from scripts, as their children give robotic recitations, deny teachers the ability to respond adequately to the written language needs of individual children in the classroom resulting in stunted written language growth.

Classroom environments that are structured so that pre-kindergarten children are given opportunities to socially interact with one another during writing are essential. The data show how the interactions students had with peers were influential in their growing awareness of written language. For teachers, awareness that peers influence children's written language growth is important. By knowing this, teachers should develop classroom environments where children confer with one another, share ideas, write together, and share their writing with peers. In structuring these classrooms, teachers should be cognizant that these classrooms will not be quiet. Student interaction creates noise in the classroom as students talk to one another while writing. Additionally, 
teachers should consider structuring the learning environment so that children are empowered to make their own choices in seat arrangement. When children were given the opportunity to do this as they composed, other classmates were influential in helping students accomplish particular written language tasks.

\section{Suggestions for Future Study}

Several studies of early writing acquisition have focused on the written products of young children as they move from oral to an understanding of written language (Bissex, 1980, Clay, 1975; Henderson \& Bears, 1980; Read, 1971; Schickedanz, 1990). Through examination of their written products, these studies have shown how children gradually develop their awareness of written language. Other studies have focused on the processes children use to create their written products (Calkins, 1983; Graves, 1983/2003; Harste, Woodward, \& Burke, 1984). These studies highlight how children implement their awareness of written language as their write. Other studies focus on how the home and community are influential contributors for children acquiring written language (Heath, 1983; Dorsey-Gaines, 1988).

Additional knowledge about written language acquisition can be obtained when preschool children are studied holistically within the classroom environment. More studies are needed to determine how the pres-kindergarten classroom environment directly influences the writing acquisition of young children. By studying the instructional techniques of the teacher and the writing processes and products of the children, we may learn more about how they conceptualize new information and bring it onto the page. By recording and transcribing the voices of children as they interact with 
others, the social interplay among them can yield additional insights into their writing purposes. By asking students questions researchers can begin to more completely understand the multiple meanings encoded within the work of preschool children. In light of the observations conducted in Ronda's classroom, I wonder if her style of teaching and the types of writing produced by the children occur elsewhere. It would be helpful to our profession to see other teachers like Ronda currently employing similar methods. What are the social interactions that occur in those classrooms? In what ways, if any, are those social interactions influential to the children as they compose? In what ways, if any, do those social interactions manifest in the writing of the children?

These questions merit further exploration. Research to answer these questions should not be limited to early childhood classrooms. A necessary study would be to explore these questions within the context of multiple grade levels from early childhood settings to environments of higher education.

\section{Summary}

In conclusion, complete understandings of children's meaning-making cannot be fully ascertained by adults who study samples of students' writing, nor by asking students about their writing. Adults who seek to understand children's unconventional forms are restricted unless they observe and listen to the children as they write. Children have their own intentions when they create writing and their explanations of these intentions may be radically different than the meanings teachers and researchers bring to their writing. In studying child writing, a delicate balance between assumptions and truths exists somewhere in the intentions of the writer. 
In this study, I sought to capture the social influences that exist in one learning environment. In describing these social influences, I showed how the children wove these interactions into their writing. It was my intention to understand, as clearly as possible, the meaning of these young children's writing as they engaged in these social interactions within their learning environment. The data show that there are connections, but the entirety of the connections cannot be comprehensively realized. As adults, we can comprehend some aspects of child writing. However, only the writers know the entire truth of their work. 


\section{AFTERWORD}

I began this dissertation with a Chinese proverb: "One written word is worth a thousand pieces of gold." I chose it because I believe it is a testament to the power of writing to change perspectives. My decision to include this proverb may seem odd, since the writing of the children is not solely contained within the forms they place on a page.

So, I ask: How does this Chinese proverb apply to me and my understanding of young writers? In my early days as an early education educator I sometimes saw meaningless marks when I looked at pre-kindergarten children's writing. I hate to admit this, but I believed that the forms or scribbles on the page were too simple and too immature to possibly carry meaning.

Now I realize that I didn't pay enough attention to those things that influenced these children when they created texts. I didn't watch and listen to what happened in their classrooms. I ignored the experiences that took place before they wrote. I dismissed the power of the teacher to gently scaffold children towards an understanding of how written language works. My ears fell silent when conversations among the children took place. My eyes were closed when they looked to peers to assist them in their writing.

Given what I have learned about the power of children's early writing, I wonder if I could tweak, or amend the proverb. Would the language of the proverb become cumbersome if it were re-stated to say, "One written word, drawing, symbol, letter, 
conversation, and explanation of these is worth a thousand pieces of gold?" Perhaps this is how we should view child writing. Always the meanings of their texts go beyond the images placed on the page.

Our perspective of pre-kindergarten writing needs to be changed. As evidenced in the interactions and writing samples shown in this dissertation, children have more sophisticated understandings of how written language works than we originally thought. To acknowledge their knowledge of written language, perhaps it would behoove us to consider the multiple influences that occur throughout the classroom. Perhaps we need to venture beyond the printed page. Only then will we be able to accept their writing as precious pieces of gold. 


\section{REFERNENCES}

Adams, M. (2001). Beginning to read: Thinking and learning about print (14th ed.). Cambridge, MA: The MIT Press.

Atwell, N. (1998). In the middle. Portsmouth, NH: Heinemann.

Baker, A., Kessler-Sklar, S., Piotrkowski, C., \& Parker, F. (1999). Kindergarten and firstgrade teachers' reported knowledge of parents' involvement in their children's education. The Elementary School Journal, 99(4), 367-380.

Baker, L., Serpell, R., \& Sonnenschein, S. (1995). Opportunities for literacy learning in the homes of urban preschoolers. In L. Morrow (Ed.), Family literacy: Connections in schools and communities (pp. 236-252). Newark, DE: International Reading Association.

Bakhtin, M. (1981). The dialogic imagination: Four essays. Austin, TX: University of Texas Press.

Bandura, A. (1977). Social learning theory. New York: General Learning Press.

Barnett, W. S. (2002). Early childhood education. In A. Molnar (Ed.), School reform proposals: The research evidence (pp. 1-26). Greenwich, CT: Information Age Publishing, Inc.

Bissex, G. (1980). Gnys at wrk. Cambridge, MA: Harvard University Press. 
Black, B., \& Logan, A. (1995). Links between communication patterns in mother-child, father-child, and child-peer interactions and children's social status. Child Development, 66(1), 255-271.

Bloodgood, J. (1999). What's in a name? Children's name writing and literacy acquisition. Reading Research Quarterly, 34(3), 342-367.

Bond, G., \& Dykstra, R. (1967). The cooperative research program for in first-grade reading instruction. Reading Research Quarterly, 2, 5-142.

Bredekamp, S. (1987). Developmentally appropriate practice in programs serving children birth through age 8 . Washington, DC: NAEYC.

Bredekamp, S., \& Copple, C. (1997). Developmentally appropriate practice in early childhood programs, revised edition. Washington, DC: NAEYC.

Bronfenbrenner, U. (1979). The ecology of human development: Experiments by nature and design. Cambridge, MA: Harvard University Press.

Bronfenbrenner, U. (1989). Ecological systems theory. In R. Vasta (Ed.), Annals of child development. Greenwich, CT: JAI Press.

Bruner, J. (1986). Actual minds, possible worlds. Cambridge, MA: Harvard University Press.

Bussey, K., \& Bandura, A. (1999). Social cognitive theory of gender development and differentiation. Psychological Review, 106(4), 676-713.

Calkins, L. (1983). Lessons from a child. Portsmouth, NH: Heinemann.

Calkins, L. (1994). The art of teaching writing. Portsmouth, NH: Heinemann.

Campbell, R. (1998). Facilitating preschool literacy. Newark: International Reading Association. 
Cayer, R., \& Sacks, R. (1979). Oral and written discourse of basic writers: Similarities and differences. Research in the Teaching of English, 13(2), 121-128.

Cazden, C. (1992). Whole language plus: Essays on literacy in the United States and New Zealand. New York: Teachers College Press.

Chafe, W., \& Tannen. (1987). The relation between written and spoken language. Annual Review of Anthropology, 16(383-407).

Chall, J. (1967). Learning to read: The great debate. New York: McGraw-Hill.

Chomsky, N. (1986). Knowledge of language. New York: Praeger.

Clay, M. (1975). What did I write? Beginning writing behaviour. Auckland, NZ: Heinemann.

Clay, M. (1989). Concepts about print: In English and other languages. The Reading Teacher, 42(4), 268-277.

Coolahan, K., Fantuzzo, J., Mendez, J., \& McDermott, P. (2000). Preschool peer interactions and readiness to learn: Relationships between classroom peer play and learning behaviors and conduct. Journal of Educational Psychology, 92(3), 458-465.

Craig-Unkefer, L., \& Kaiser, A. (2003). Increasing peer-directed social-communication skills of children enrolled in head start. Journal of Early Intervention, 25(4), 229247.

Dahl, K., \& Farnan, N. (1998). Children's writing: Perspectives from research: International Reading Association, Inc. and National Reading Conference. 
Danielewicz, J., \& Chafe, W. (1985). How "normal" speaking leads to "erroneous" punctuating. In S. Freedman (Ed.), The acquisition of written language: Response and revision (pp. 213-225). Norwood, NJ: Ablex.

Derewianka, B. (1990). Exploring how texts work. Australia: Primary English Teaching Association.

Dickinson, D., \& Tabors, P. (1991). Early literacy: Linkages between home, school and litearcy achievement at age five. Journal of Research in Childhood Education, $6(1), 30-44$.

Donovan, C. (2001). Children's development and control of written story and informational genres: Insights from one elementary school. Research in the Teaching of English, 35, 394-447.

Donovan, C., \& Smolkin, L. (2002). Children's genre knowledge: An examination of K-5 students' performance on multiple tasks providing differing levels of scaffolding. Reading Research Quarterly, 37(4), 428-465.

Dorsey-Gaines, C., \& Taylor, D. (1988). Growing up literate: Learning from inner-city families. Portsmouth, NH: Heinemann.

Dyson, A. (1989). Multiple worlds of child writers: Friends learning to write. New York: Teachers College Press.

Dyson, A. (1990). Symbol makers, symbol weavers: How children link play, pictures, and print. Young Children, 45(2), 50-57.

Dyson, A. (1993). Social worlds of children learning to write in an urban primary school. New York: Teachers College Press. 
Dyson, A. (1997). Writing superheroes: Contemporary childhood, popular culture, and classroom literacy. New York: Teachers College Press.

Dyson, A. (2002). Writing and children's symbolic repertoires: Development unhinged. In S. Neuman \& D. Dickinson (Eds.), Handbook of early literacy research (pp. 126-141). New York: The Guilford Press.

Egan, K. (1987). Literacy and the oral foundations of education. Harvard Educational Review, 57, 445-472.

Ehri, L., \& Sweet, J. (1991). Fingerpoint-reading of memorized text: What enables beginners to process the print? Reading Research Quarterly, 26, 442-462.

Emig, J. (1971). The composing process of twelfth graders. Urbana, IL: National Council of Teachers of English.

Erickson, F. (1986). Qualitative methods in research on teaching. In M. Wittrock (Ed.), Handbook of research on teaching ( 3 rd ed.). New York: McMillan.

Fabes, R. A. (1999). Regulation, emotionality, and preschoolers' socially competent peer interactions. Child Development, 70(2), 432-442.

Fabes, R. A., Martin, C., Hanish, L., Anders, M., \& Madden-Derdich, D. (2003). Early school competence: The roles of sex-segregated play and effortful control. Developmental Psychology, 39(5), 848-858.

Ferreiro, E., \& Teberosky, A. (1983), Literacy before schooling. Portsmouth, NH: Heinemann Educational Books.

Fletcher, R., \& Portalupi, J. (2000). Writing workshop: The essential guide. Portsmouth, NH: Heinemann. 
Flower, L., \& Hayes, J. (1984). Images, plans, and prose: The representation of meaning in writing. Written Communication, 1(1), 120-160.

Gallas, K. (1994). The languages of learning: How children talk, write, dance, draw, and sing their understanding of the world. New York: Teachers College Press.

Gee, J. (2002). A sociocultural perspective on early literacy development. In S. Neuman \& D. Dickinson (Eds.), Handbook of early literacy research. New York: The Guilford Press.

Geertz, C. (1973). The interpretation of cultures. New York: Basic Books.

Genishi, C., Stires, S., \& Yung-Chan, D. (2001). Writing in an integrated curriculum: Prekindergarten English language learners as symbol makers. The Elementary School Journal, 101(4), 399-416.

Gentry, R. (1982). An analysis of developmental spelling in Gnys at Wrk. The Reading Teacher, 36, 192-200.

Goldenberg, C. (2002). Making schools work for low-income families in the twenty-first century. In S. Neuman \& D. Dickinson (Eds.), Handbook of Early Literacy Research (pp. 211 231). New York: The Guilford Press.

Goncu, A., \& Weber, E. (2000). Preschoolers' classroom activities and interactions with peers and teachers. Early Education and Development, 11(1), 93-107.

Goodman, Y. (1986). Children coming to know literacy, In W. H. Teale \& E. Sulzby (Eds.), Emergent literacy: Writing and reading (pp. 1-14). Norwood, NJ: Ablex. Graves, D. (1982). Research update: How do writers develop? Language Arts, 59, 173179. 
Graves, D. (2003). Writing: Teachers and children at work. Portsmouth, NH:

Heinemann.

Graves, D., \& Hansen, J. (1983). The author's chair. Language Arts, 60, 176-183.

Gundlach, R., McLane, J., Scott, F., \& McNamee, G. (1985). The social foundations of early writing development. In M. Farr (Ed.), Advances in writing research (pp. 158). Norwood, NJ: Ablex.

Gunn, B., Simmons, D., \& Kameenui, E. (1998). Emergent literacy: Research bases. In D. Simmons \& E. Kameenui (Eds.), What research tells us about children with diverse learning needs. Mahwah, NJ: Lawrence Erlbaum Associates.

Hansen, J. (1998). Young writers: The people and purposes that influence their literacy. In J. Osborn \& F. Lehr (Eds.), Literacy for all (pp. 205-236). New York: The Guilford Press.

Hansen, J. (2001). When writers read. Portsmouth, NH: Heinemann Press.

Harste, J., Woodward, V., \& Burke, C. (1984). Language stories and literacy lessons.

Cambridge, MA: Cambridge University Press.

Heath, S. (1983). Ways with words: Language, life and work in communities and classrooms. Cambridge, MA: Cambridge University Press.

Henderson, A., \& Berla, N. (1994). The family is critical to student achievement: A new generation of evidence. Washington, DC: National Center for Citizens in Education.

Henderson, E. (1981). Learning to read and spell: A child's knowledge of words. DeKalb: Northern Illinois University Press.

Henderson, E. (1990). Teaching spelling (2nd ed.). Boston: Houghton Miflin. 
Henderson, E., \& Beers, J. (1980). Developmental and cognitive aspects of learning to spell. Newark, DE: International Reading Association.

Henderson, E., \& Templeton, S. (1986). A developmental perspective of formal spelling instruction through alphabet, pattern, and meaning. Elementary School Journal, $86,305-316$.

Horowitz, R., \& Samuels, S. (1987). Comprehending oral and written language: Critical contrasts for literacy and schooling. In R. Horowitz \& S. Samuels (Eds.), Comprehending oral and written language (pp. 1-52). San Diego, CA: Academic.

Jones, I. (2002). Social relationships, peer collaboration, and children's oral language. Educational Psychology, 22(1), 63-73.

Jones, I., \& Pellegrini, A. (1996). The effects of social relationships, writing media, and microgenetic development on first-grade student's written narratives. American Educational Research Journal, 33, 691-718.

Kamps, D. M. (1995). Peer-inclusive social skills groups for young children with behavioral risks. Preventing School Failure, 39(4), 10-15.

Kantor, R., Miller, S., \& Fernie, D. (1992). Diverse paths to literacy in a preschool classroom: A sociocultural perspective. Reading Research Quarterly, 27(3), 184201.

Kemple, K. M., David, G. M., \& Hysmith, C. (1997). Teachers' interventions in preschool and kindergarten children's peer interactions. Journal of Research in Childhood Education, 12(1), 34-47. 
Kendrick, M., \& Mckay, R. (2004). Drawings as an alternative way of understanding young children's construction of literacy. Journal of Early Childhood Literacy, $4(1), 109-128$.

Krefting, L. (1999). Rigor in qualitative research: The assessment of trustworthiness. In A. Milinki (Ed.), Cases in qualitative research. Los Angeles, CA: Pyrczak Publishing.

Kress, G. (1997). Before writing: Rethinking the paths to literacy. London: Routledge.

Lave, J., \& Wenger, E. (1991). Situated learning: Legitimate peripheral participation. Cambridge: University of Cambridge Press.

Leaper, C. (1994). Exploring the consequences of gender segregation on social relationships. In C. Leaper (Ed.), Childhood gender segregation: Causes and consequences (pp. 67-86). San Francisco: Jossey-Bass.

Lincoln, Y. S., \& Guba, E. G. (1985). Naturalistic inquiry. Beverly Hills, CA: Sage. Lindfors, J. (1999). Children's inquiry: Using language to make sense of the world. New York: Teachers College Press.

Lindsey, E. (2002). Preschool children's friendships and peer acceptance: Links to social competence. Child Study Journal, 32(3), 145-156.

Maccoby, E. (2002). Gender and group process: A developmental perspective. Current Directions in Psychological Science, 11, 54-58.

Maccoby, E., \& Jacklin, C. (1987). Gender segregation in childhood. In H. Reese (Ed.), Advances in child development and behavior (Vol. 20, pp. 239-287). Orlando, FL: Academic Press. 
Marshall, C., \& Rossman, G. (1999). Designing qualitative research (3rd ed.). Thousand Oaks, CA: Sage.

Martin, C., \& Fabes, R. A. (2001). The stability and consequences of young children's same-sex peer interactions. Developmental Psychology, 37(3), 431-446.

Mason, J., \& Allen, J. (1986). A review of emergent literacy with implications for research and practice in reading. Review of Research in Education, 13, 3-47.

Mathews, M., \& Kesner, J. (2003). Children learning with peers: The confluence of peer status and literacy competence within small-group literacy events. Reading Research Quarterly, 38(2), 208-234.

McCarthey, S. J. (1994). Authors, text, and talk: The internalization of dialog from social-interaction during writing. Reading Research Quarterly, 29(3), 201-231.

McCormick, L., Noonan, M., \& Heck, R. (1998). Variables affecting engagement in inclusive classrooms. Journal of Early Intervention, 21, 160-176.

Miles, M., \& Huberman, A. (1984). Qualitative data analysis: A sourcebook of new methods. Beverly Hills, CA: Sage.

Morris, D. (1981). Concept of word: A developmental phenomenon in the beginning reading and writing process. Language Arts, 58, 659-668.

Morrow, L. (2001). Literacy development in the early years: Helping children read and write (4th ed.). Needham Heights, MA: Allyn \& Bacon.

Neuman, S., \& Roskos, K. (1997). Literacy knowledge in practice: Contexts of participation for young writers and readers. Reading Research Quarterly, 32(1), $10-32$. 
Nystrand, M. (1989). A social-interactive model of writing. Written Communication, 6(1), 66-85.

Paley, V. (2004). A child's work: The importance of fantansy play. Chicago: The University of Chicago Press.

Patton, M. (2002). Qualitative research and evaluation methods. Thousand Oaks, CA: Sage.

Pellegrini, A. (2002). Some theoretical and methodolgical considerations in studying literacy in social context. In S. Neuman \& D. Dickinson (Eds.), Handbook of Early Literacy Research (pp. 54-65). New York: The Guilford Press.

Pellegrini, A., \& Galda, L. (1991). Longitudinal relations among preschoolers' symbolic play, metalinguistic verbs, and emergent literacy. In J. Christie (Ed.), Play and early literacy development (pp. 47-68). Albany, NY: State University of New York Press.

Piaget, J. (1959). The language and thought of the child ( $3^{\text {rd }}$ ed.; M. Gabain, Trans.). London: Routledge \& Kegan Paul.

Powlista, K., Serbin, L., \& Moller, L. (1993). The stability of individual differences in gender-typing: Implications for understanding sex segregation. Sex roles, 29, $723-$ 737.

Purcell-Gates, V. (1988). Lexical and syntactic knowledge of written narrative held by well-read-to kindergarteners and second graders. Research in the Teaching of English, 22(128-160). 
Purcell-Gates, V. (1996). Stories, coupons, and the TV guide: Relationships between home literacy experiences and emergent literacy knowledge. Reading Research Quarterly, 31, 406-428.

Ray, K. W., \& Cleaveland, L. (2004). About the authors: Writing workshop with our youngest writers. Portsmouth, NH: Heinemann.

Raz, I., \& Bryant, P. (1990). Social background, phonological awareness and children's reading. British Journal of Developmental Psychology, 8, 209-225.

Read, C. (1971). Pre-school children's knowledge of English phonology. Harvard Educational Review, 41, 1-34.

Read, C. (1975). Children's categorization of speech sounds in English. Urbana, IL: National Council of Teachers of English.

Richgels, D. J. (2002). Informational texts in kindergarten. Reading Teacher, 55(6), 586595.

Rief, L. (1994). Writing for life: Teacher and students. In M. Barbieri \& L. Rief (Eds.), Workshop by and for teachers (pp. 84-101). Portsmouth, NH: Heinemann Press. Rogoff, B., \& Lave, J. (1984). Everyday cognition: Its development in social context. Cambridge, MA: Harvard University Press.

Rosenblatt, L. (1978). The reader, the text, the poem: The transactional theory of the literary work. Carbondale: Southern Illinois University Press.

Schickedanz, J. (1990). Adam's righting revolutions: One child's literacy development from infancy through grade one. Portsmouth, NH: Heinemann.

Schickedanz, J. (1999). Much more than the ABCs. Washington, D.C.: NAEYC. 
Serbin, L., Moller, L., Gulko, J., Powlishta, K., \& Colburne, K. (1994). The emergence of sex segregation in toddler playgroups. In C. Leaper (Ed.), The development of gender and relationships (pp. 7-18). San Francisco: Jossey-Bass.

Smith, R. (2004). A call for universal preschool. Educational Leadership, 62(3), 38-39. Sperling, M. (1996). Revisiting the writing-speaking connection: Challenges for research on writing and writing instruction. Review of Educational Research, 66(1), 53-86.

Spradley, J. (1979). The ethnographic interview. New York: Holt, Rinehart, \& Winston.

Stanovich, K. (1986). Matthew effects in reading: Some consequences of individual differences in the acquisition of literacy. Reading Research Quarterly, 21, 360407.

Steward, E. (1995). Beginning writers in the zone of proximal development. Mahwah: Lawrence Erlbaum Associates.

Sulzby, E. (1985). Kindergarteners as writers and readers. In M. Farr (Ed.), Advances in writing research, Vol. 1: Children's early writing. Norwood, NJ: Ablex.

Temple, C., Nathan, R., Temple, F., \& Burris, N. (1993). The beginnings of writing. Needham Heights, MA: Allyn and Bacon.

Vernon-Feagans, L., Hammer, C., Miccio, A., \& Manlove, E. (2002). Early language and litearcy skills in low-income African American and Hispanic children. In S. Neuman \& D. Dickinson (Eds.), Handbook of early literacy. New York: The Guilford Press.

Vygotsky, L. (1978). Mind in society. Cambridge, MA: Harvard University Press.

Wagner, R., \& Torgesen, J. (1987). The natural of phonological processing and its causal role in the acquisition of reading skills. Psychological Bulletin, 101, 192-212. 
Whitehurst, G., \& Lonigan, C. (1998). Child development and emergent literacy. Child Development, 68, 848-872.

Wiseman, A. (2003). Collaboration, initiation, and rejection: The social construction of stories in a kindergarten class. The Reading Teacher, 56(8), 802-809. 


\section{APPENDIX A}

\section{Human Subjects Research Protocol Submitted for Review to the Institutional Review Board for the Social and Behavioral Sciences University of Virginia}

\section{GENERAL INFORMATION}

1. Project Title: Prekindergarten and Writing

2. Type of submission (check one):

New Protocol

$\mathrm{X}$ Resubmission of previously rejected protocol Fourth year full protocol submission of approved protocol due to expire Reopening expired protocol

If you checked Resubmission, Fourth year submission or Reopening, provide the IRBSBS protocol number: Project \#2004-0319-00

3. Principal Investigator and Sub-Investigator(s): Repeat information as needed for each Sub-Investigator and provide original signatures for each.

Name: Brian T. Kissel

Title: Graduate Student

School, Department or Center: CISE (Curriculum, Instruction, and Special

Education), Curry School of Education

Division (if applicable): Elementary Education

Mailing Address (only if messenger mail address is not available): 115 Pepper

Place, Charlottesville, VA 22902

Telephone: 434.293 .1613

UVA e-mail address (no aliases, please): btk7m@virginia.edu

Your computing $I D$ is used for tracking on-line human subjects training.

Preferred e-mail address for correspondence (if applicable): btk $7 \mathrm{~m} @$ virginia.edu

Are you (Please underline or circle all that apply.):

Faculty Graduate Student $\quad$ Undergraduate Student Staff

This research is for (Please underline or circle all that apply):

Class project Master's thesis Doctoral dissertation Faculty research

4. Please list all other researchers associated with this project.

None

5. Faculty Advisor (Must be completed for all student and staff research proposals.):

Name: Jane Hansen 
School, Department or Center: Department of Curriculum, Instruction, and Special Education; Curry School of Education

Messenger mail address: 126 Ruffner Hall, Curry School of Education

Telephone: (434) 924-0810

UVA e-mail address (no aliases, please): jh5re@virginia.edu

Your computing ID is used for tracking on-line training.

Signature of Faculty Advisor:

\section{DESCRIPTION OF THE RESEARCH STUDY}

6. Brief Description of the Research. Write an original, brief, non-technical description of the project addressed to lay members of the SBS Review Board. Do not copy the abstract from your grant proposal.

a) Your research hypothesis or question;

Overreaching Question: What do prekindergarten students do when they write?

Subset Questions: 1.) In what ways do prekindergarten writers change over time?

2.) From where do prekindergarten children receive ideas for writing? 3.) What are the social influences that occur in a classroom that affect child writer?

b) A narrative that explains the major constructs of your study;

There is a surprising lack of research revealing what prekindergarten students do when they write. From creating forms on the paper to setting purposes for their writing, there exists a need for deeper inquiry. This research is intended to fulfill four goals: 1) The principal investigator is interested in extending the research in the field of prekindergarten writing. By seeking answers to the overreaching question (What do prekindergarten students do when they write), the principal investigator hopes to extend the research base for practitioners of writing. 2) Some researchers (Bissex, 1980; Schickedanz,1990) have conducted studies involving the writing progression and habits of their own children within their home environment. The principal investigator hopes to extend previous research by examining the writing progression and habits of several children in a prekindergarten classroom setting. 3) Many researchers (Graves, 1983; Calkins, 1994; Hansen, 1998), agree that there are several factors that influence the ideas children use when writing. This research project seeks to highlight what influences affect the writing ideas of prekindergarten children

c) The methodology;

In January of 2005, a local prekindergarten teacher will be asked to participate in this study by written request (see Appendix A) and via use of an Informed Consent Agreement (see Appendix B). Parents of the prekindergarten students will be asked to participate in this study by written request (see Appendix C) and via use of Informed Consent Agreement (see Appendix D). Data will be collected over a six month period from January 2005 to May 2006. 
To examine what prekindergarten students do when they write, a descriptive case study approach will be used. Two important aspects of this research will be the participant-observer records that will be collected within the classroom and multiple case studies of children. Data will be collected by means of observation, student writing responses, teacher-response journal entries, teacher (Appendix E) and student (Appendix F) interviews, field notes, student read alouds, children's writing samples, and photocopies of the children's writing. During phase two of the data collection, three children will be selected in a case study investigation to provide an in-depth examination of their writing progression.

Students from the teachers' class will be invited to participate, with a targeted enrollment of 16 prekindergarten students.

d) From where/whom the data will be collected: The data will be collected from sixteen prekindergarten students from a single classroom in a local elementary school. All data collection will occur in the classroom. Data will be collected from both the teacher and children in the classroom.

e) How the data will advance your research hypothesis or question.

An in-depth study of what prekindergarten students do when they write can provide continued research in the field of early childhood education. A descriptive case study approach will provide answers to the questions posed in section a) by revealing what prekindergarten students do as they write throughout a school semester.

7. What will the participants do in the study? Describe all steps the participants will follow. What do the data consist of? (Please submit 4 copies of all instruments, surveys, interview questions or outlines, observation checklists, etc.)

Over the course of six months, the participants in the study will operate in their natural classroom setting. The teacher will conduct writing lessons as she normally does and the students will continue to write as a result of the lessons. The role of the principal investigator is to study what the teacher and children are already doing in the classroom.

Field notes will be taken by the principal investigator describing the interactions that occur in the classroom. The teacher will be asked to write a weekly journal entry offering reflections and observations that she notices about the children as they write. The weekly journal entry should take no longer than fifteen minutes. Classroom observations and field notes will provide the principal investigator with rich description of the transactions occurring in the classroom. Student writing samples will help the principal investigator expose the writing outcomes of the students. Three interviews of the teacher will provide insights into how the teacher approaches writing from a practitioner point of view. During each observation session, the researcher will ask each student to describe his/her writing. Responses by the students are typically brief (between two to three minutes each). 
Baseline data will be collected. This data will consist of observations, field notes, photocopies of student writing work, interviews, and journal entries. In-depth case studies of three individual children will consist of observations, field notes, photocopies of student writing work, interviews, and journal entries.

8. Location where study will be conducted (Please be specific.):

The study will be conducted in a prekindergarten classroom at Greenbrier Elementary School in Charlottesville, Virginia.

9. Anticipated start and completion dates for collecting and analyzing data: Data will be collected from January 3, 2005 through June 7, 2005

\section{Funding source: Personal}

11. Describe what will be done with the data and resulting analysis and who will have access to this information. The principal investigator and the faculty advisor will have access to the data and resulting analyses. Each student will be provided a pseudonym. There will be no association between the students' names and pseudonyms except for a list linking pseudonyms to personal real names. Both the data and the list linking the pseudonyms with the real names will be kept in a locked file cabinet in the home of the principal investigator when not in use. The principal investigator will share the general findings of the study with the prekindergarten teacher to inform the teacher what prekindergarten do when they write. The principal investigator intends to include the results of the study in a manuscript for publication in a reading or language arts journal.

12. What benefits can reasonably be expected from the study? Information from the study will benefit both the classroom teacher and reading/writing researchers. The study is significant because it will provide supporting research about the writing progression of prekindergarten children. There are no direct benefits to the children, parents, or school.

\section{RECRUITMENT AND SELECTION OF PARTICIPANTS}

\section{Participants:}

Prekindergarten Participants

Number to be studied in upcoming protocol year or sample size for archival data sets: 16 students

Ages: All students are between the ages of four and five

Gender: Both male and female students.

Teacher Participant: 1 teacher

14. a) What are the criteria you will use for selecting participants?

i. All prekindergarten students whose parents agree to participate in the study.

ii. All prekindergarten students must meet the following criteria: (1) their teacher agreed to participate in the study (Appendix B) and (2) students returned parent consent form (Appendix D) 
b) How will the participants be contacted?

i. The teacher of the prekindergarten classroom has already verbally stated to the Principal Investigator that she would be interested in participating in a research study involving writing. She has informed the Principal Investigator that she has participated in writing research studies in the past and would appreciate to continue research in her classroom throughout the Spring semester. I have attached consent forms (Appendix A and B) so that the teacher's agreement will be represented in print.

ii. The parents/guardians of the prekindergarten students will be contacted by letter (Appendix C) and consent form (Appendix D) notifying them of the opportunity to voluntarily participate in the study. If any parents do not agree to participate in the study, the primary investigator will not include the child in the study.

c) State the relationship between Principal Investigator, Faculty Advisor (if applicable) and Participants.

i. The principal investigator is a $3^{\text {rd }}$ year doctoral candidate at the Curry School of Education, in the Elementary Education program. The primary investigator is already serving as a researcher in the classroom during the Fall 2004 semester as part of an IRB research project established by Professor Jane Hansen. The primary investigator plans to use the same methodology already established by Professor Hansen but wishes to include a couple modifications for the Spring 2005 semester. These modifications include an addition of a teacher journal and brief 2-3 minute interviews with children. The teacher-participant has participated in writing research studies for the past three years and has expressed interest to the Principal Investigator that she would like for her classroom to continue to be used as a site for continuing research studies concerning writing. The teacher-participant has asked if I would continue conducting observations in her classroom throughout the Spring 2005 semester. Professor Hansen serves as the program advisor for the principal investigator. It was recommended to the principal investigator by his two advisors (Professor Jane Hansen and Professor Laura Smolkin) that he submit an individual protocol for IRB approval for the Spring 2005 semester so that he could use the findings for individual papers submitted to various educational journals. As a result, the Spring 2005 protocol is generally the same protocol already established in the classroom with slight modifications. The principal investigator and the faculty advisor hold no supervisory role in relation to the teacher or the students. The faculty advisor has no previous experience with the studentparticipants. The data collection that I propose would minorly disrupt the learning environment of the students for about five to six minutes a week when I ask them to describe their writing. Since the student-participants are four years old, the questioning lasts no longer than one to two minutes per observation. 
15. Describe in detail how you will obtain consent from participants and/or parents. Attach a copy of all Informed Consent/Assent Agreement(s). Please include all the headings included on the sample agreement. (For ethnographic research please see "Alternative Consent and Risk Reduction Procedures For Ethnographic Work in IRBSBS Protocols" on the forms page of the IRB-SBS website.)

i. The prekindergarten teacher will be asked to participant in the study (Appendix A) and will be provided with a consent form (see Appendix B). The prekindergarten teacher has already informed the Principal Investigator that she would like to continue in a writing research study for the Spring 2005 semester. The consent forms drafted confirm this verbal exchange between the teacher and Principal Investigator. For each prekindergarten student from Greenbrier Elementary School who is in the participating teacher's classroom, a letter (Appendix C) notifying the prekindergarten students' parents of the study accompanied by a consent form (Appendix D) will be sent to that student's home. Only prekindergarten students whose consent forms are returned will be eligible for the study.

16. How will you protect the confidentiality of your participants? (Check one.)

Data is archival (already collected) AND researcher will receive data stripped of identifying information. Identifying information includes name, postal address, telephone numbers, e-mail address, social security number, medical record number, etc.

If an archival data set is being used, please provide a list of all fields that will be included in the data set

OR provide the original instrument from which the data was obtained.

Data to be collected does not contain identifying information, or cannot be linked to identifying information by use of codes or by other means (data are anonymous).

X Data to be collected contains identifying information or can be linked to identifying information by use of codes or by other means (data are confidential or confidentiality is not assured in the study) and the list linking codes to personal identifiers will be kept secure.

Other (please describe).

\section{RISKS, HAZARDS AND DECEPTION}

17. Are any aspects of the study kept secret from the participants? _ $\mathrm{X}$ No _ _ Yes (Describe.) 
18. Is any deception used in the study? $\mathrm{X}$ No Y Yes (If yes, describe the deception involved and the debrief procedures. Attach a post-experiment debriefing statement and consent form offering participants the option of having data destroyed.)

19. Will participants be debriefed? $X$ N No _ Yes (Attach a copy of your Debriefing Statement. If the answer to protocol question $\overline{\# 18}$ is yes, then the investigator must debrief the participant.)

20. Will participants be recorded on audiotape? N_ No $\quad X \quad$ Yes

Note: Only the teacher's interviews will be recorded on audiotape.

Will participants be photographed or recorded on videotape? ____No___ Yes

If yes in either case, will participants be recorded or photographed without their knowledge?

_X_No _ _ Yes (If yes, include a post-experiment release form offering the participants the option of

having their tape erased.)

21. What are the possible physical, psychological, professional or personal risks and/or hazards for the participants?

There are no physical, psychological, professional or personal risks and/or hazards for the participants.

22. What will you do to protect participants from these risks or hazards?

N/A

Please submit the following materials:

Fourteen (14) typed copies of the following:

Protocol form (1 copy with original signatures and 13 copies)

Request for Exemption Form (Submit ONLY if your proposal qualifies for exemption status.)

Consent form(s)

Debriefing form (if applicable)

Video and audio recording permission form (if applicable)

Protocol Status Form (for fourth year review of continuing protocols ONLY) 


\section{Introductory Letter for Teacher Informed Consent}

\section{August 2005 \\ Dear Teacher,}

As you have stated in previous conversations, I wish to continue conducting research concerning writing in your classroom for the Fall 2005 semester. As you may already know, I am a third year doctoral student in Elementary Education at the University of Virginia and I am interested in observing how prekindergarten students develop as writers. For research, I am examining the writing progression of prekindergarten students.

I would like for you to be a participant in the research I conduct at your school. I would like to come into your classroom for three days a week over the course of six months and observe you teach writing to your students. I am planning to observe your teaching and write field notes as you teach writing to your students. I also plan on asking you interview questions regarding your teaching on three different occasions during the semester. Throughout the semester, I would like for you to write your thoughts and observations once a week in your journal. I expect your journal reflections would take no more than fifteen minutes a week. Each day I spend in your classroom, I plan to spend an hour and a half observing your teaching and taking field notes.

Please read the attached informed consent agreement and consider participating in this research on prekindergarten writing. Please do not hesitate to call me at (434) 293-9613 or Professor Hansen at (434) 924-0810 if you have any questions regarding this research.

Thank you for your consideration.

Sincerely,

Brian T. Kissel 


\section{Teacher Informed Consent Agreement}

\section{Page 1 of 2}

\section{Project Title: Prekindergarten and Writing \\ Please read this consent agreement carefully before you decide to participate in the study.}

Purpose of the research study:

The purpose of the study is to examine the writing of prekindergarten children.

\section{What you will do in the study:}

From August 2005-December 2005 you will continue to conduct writing lessons in your natural classroom setting. You will be asked to reflect on your teaching once a week by recording your thoughts and observations in a journal. Three times throughout the year and a half, you will be asked your thoughts about writing through an interview. The interviews will be audio-recorded.

\section{Time required:}

You will spend the amount of time you typically spend teaching writing to prekindergarten children. Three times you will be asked interview questions by the researcher to provide him with a deeper understanding of your methods and observations. Each interview should last about thirty minutes. Since there will be three interviews, I expect you to spend one hour and a half over the course of one year. Additionally, you will be asked to record your thoughts and observations in a journal once a week for approximately fifteen minutes. Throughout the duration of one year, you will spend approximately ten hours recording in a journal. The principal researcher will observe your classroom three times a week over a period of a year. He expects to spend an hour and a half for each observation. The observations will last three hours a week. Over a period of one semester, I expect to observe in your classroom for 80 hours.

\section{Risks:}

There are no anticipated risks.

Benefits: There are no direct benefits to you for participating in this research study.

Confidentiality: The information that you give in the study will be handled confidentially. Your personal name and school will be assigned a pseudonym. The list connecting your name and school will be kept in a locked file. When the study is completed and the data have been analyzed, this list will be destroyed. Your name will not be used in any report. You will be recorded on audiotape as a part of your interviews. The audiotape will only be used as a tool to help the researcher understand your thoughts about writing. The audiotape will not be played for others to hear. 
Your participation in the study is completely voluntary.

Right to withdraw from the study:

You have the right to withdraw from the study at any time without penalty and the data and audio tapes will be destroyed.

How to withdraw from the study:

If you want to withdraw from the study, tell the researcher in person or in writing. There is no penalty for withdrawing.

\section{Payment:}

You will receive no payment for participating in the study.

If you have questions about the study, contact:

Brian Kissel

115 Pepper Place

Charlottesville, VA 22902

Telephone: (434) 293-9613

Faculty Advisor: Jane Hansen, Ph.D.

Telephone: (434) 924-0810 jh5re@virginia.edu

If you have questions about your rights in the study, contact:

Luke Kelly, Chairman, Institutional Review Board for the Social and Behavioral

Sciences, 400 Ray C. Hunt Drive, Suite 360, Room 4, P.O. Box 800392, Charlottesville, VA 22908-0392.

Telephone: (434) 243-2915

\section{Agreement:}

I agree to participate in the research study described above.

Signature:

Date:

You will receive a copy of this form for your records. 
Introductory Parent Letter

Dear Parents and Guardians of

I am writing to tell you about a research study that I will be conducting in your child's classroom this year. I am researching what prekindergarten children do when they write. Between August 2005 and December 2005, I will observe your child's teacher teaching writing to your child. I will also observe what your child does as he/she writes.

In the study, your child will continue to learn in his/her natural classroom environment. Your child's teacher will continue to teach writing to your child as already does in the classroom. I will play a passive role in the classroom and will observe and take notes of the teacher teaching as she teaches. I will also make observations of your child as he/she writes in the classroom and take notes about what he/she is writing. Occasionally, I may ask your child a question about his/her writing. I may speak to your child 2-3 minutes a day or 6-8 minutes a week. During this study I will save examples of your child's work, photocopy them in many cases, and regularly take notes on what they say and do as writers and learners.

My overall goal is to share the work of your child with other educators so they may understand what prekindergarten children do when they write. I plan to use samples of your child's writing and oral comments of your child when I teach classes for teachers, give presentations for teachers at conferences, and write about the children's work in publications for teachers. I will not use your child's name in any situation. Your child will have a pseudonym and when I speak about the writing of your child, I will not use his/her name. Your child will be recorded on audiotape as he/she participates in the classroom. The audiotape will only be used as a tool to help me understand your child's meaning of their writing. The audiotape will only be used to help me write my research notes and will be destroyed immediately after each day I visit the classroom. They will not be played for others to hear. Your child's information, however, will not be anonymous because I will photocopy some of your child's writing. Also, due to the nature of the study, in some cases children may be identified if others recognize their writing styles. If you choose not to permit me to share information about your child, there will be no consequences for your child in the classroom.

I have attached a consent form for you to sign. If you change your mind later and want to withdraw your permission for me to share information about your child, please contact me or Jane Hansen (my faculty advisor) and I'll accommodate your wishes.

If you have any questions, please call me. Thank you for your consideration.

Sincerely,

Brian T. Kissel

Doctoral student-researcher

Phone: (434) 293-9613
Jane Hansen

Faculty Advisor

(434) 924-0810 


\section{Page 1 of 2}

\section{Informed Parent Consent Agreement}

\section{Project Title: Prekindergarten and Writing}

Please read this consent agreement carefully before you decide to participate in the study.

\section{Purpose of the research study:}

The purpose of the study is to examine the writing of prekindergarten children.

\section{What your child will do in the study:}

From August 2005-December 2005 your child will continue to write in his/her natural classroom setting. Your child may be asked to dictate what he/she wrote during their classroom writing time. Your child's writing may be photocopied. Your child will be recorded on audiotape as he/she participants in the classroom. The audiotape will only be used as a tool to help the researcher understand the meaning of your child's writing and will be destroyed at the end of each day I am in the classroom. The audiotape will not be played for others to hear.

\section{Time required:}

Your child will continue to write according to the time established by the classroom teacher. I will ask your child questions about his/her writing that will probably take about five minutes a week. Throughout the course of five months, I may talk to your child a total of 75 minutes.

\section{Risks:}

There are no anticipated risks.

Benefits: There are no direct benefits to your child for participating in this research study. The study may help us better understand what prekindergarten children do when they write.

Confidentiality: The information that your child gives in this study will be handled confidentially. Your child's name and school name will be assigned a pseudonym. The list connecting your name and school will be kept in a locked file. When the study is completed and the data have been analyzed, this list will be destroyed. Your child's name will not be used in any report. Because of the nature of the research, it is possible that your child may be identified through their writing samples. Your child's writing may be shared or published. The researcher will make every effort to make sure that the only name attached to their writing if it used in publication is the pseudonym given.

Voluntary participation:

Your child's participation in the study is completely voluntary.

Right to withdraw from the study:

You have the right to withdraw your child from the study at any time without penalty. 
How to withdraw from the study:

If you want to withdraw your child from the study, please inform the researcher or the classroom teacher. There is no penalty for withdrawing. If you decide to withdraw, your data collected from your child will be destroyed.

\section{Payment:}

You will receive no payment for participating in the study.

If you have questions about the study, contact:

Brian Kissel

115 Pepper Place

Charlottesville, VA 22902

Telephone: (434) 293-9613

btk7m@virginia.edu
Faculty Advisor: Jane Hansen, Ph.D.

126 Ruffner Hall

Charlottesville, VA 22903

Telephone: (434) 924-0810

jh5re@virginia.edu

If you have questions about your rights in the study, contact:

Luke Kelly, Chairman, Institutional Review Board for the Social and Behavioral

Sciences , 400 Ray C. Hunt Drive, Suite 360, Room 4, P.O. Box 800392, Charlottesville, VA 22908-0392.

Telephone: (434) 243-2915

Your name (print)

Your name (signature)

Date:

Child's Name:

You will receive a copy of this form for your records. 